\title{
Band 2 Kapitel 3: $\quad$ Der Einfluss des Klimawandels auf die Biosphäre und Ökosystemleistungen
}

\section{Volume 2 Chapter 3: Climate Change Impact on the Biosphere and Ecosystem Services}

\author{
Koordinierende Leiltautoren \\ Manfred J. Lexer, Wolfgang Rabitsch, Georg Grabherr
}

\section{Leitautorlnnen}

Martin Dokulil, Stefan Dullinger, Josef Eitzinger, Michael Englisch, Franz Essl, Günter Gollmann, Michael Gottfried, Wolfram Graf, Gernot Hoch, Robert Jandl, Andreas Kahrer, Martin Kainz, Thomas Kirisits, Sigrid Netherer, Harald Pauli, Eugen Rott, Christa Schleper, Astrid Schmidt-Kloiber, Stefan Schmutz, Axel Schopf, Rupert Seidl, Wolfgang Vogl, Hans Winkler, Harald Zechmeister

\author{
Beiträge von \\ Johannes Gepp, Beatrice Grummer, Andreas Schindlbacher
}

Für den Begutachtungsprozess

Carsten Loose

Inhalt

ZUSAMMENFASSUNG

SUMMARY

\section{KERNAUSSAGEN}

\subsection{Einleitung}

3.1.1 Allgemeines

3.1.2 Untersuchungsmethoden

\section{2}

3.2.1 Mikroben (Archaea, Bakterien, Blaualgen)

3.2.2 Algen

3.2.3 Pilze und pilzähnliche Organismen

3.2.4 Moose

3.2.5 Blütenpflanzen und Farne

3.2 .6

3.2 .7

3.2 .8

3.2 .9

3.2.10 Fauna

3.3 Gesellschaften und Ökosysteme

3.3.1

3.3.2

3.3.3

3.3 .4
Waldbaumarten

Einjährige landwirtschaftliche Nutzpflanzen

Landwirtschaftliche Dauerkulturen

Schadorganismen an Nutzpflanzen

Allgemeines

Moore

Alpine und nivale Pflanzengesellschaften

Wälder
468

469

470

471

471

473

474

474

475

480

484

486

490

495

501

504

504

522

522

522

522

524
3.3.5 Grünland 526

3.3.6 Gewässer 530

3.4 Ökosystemleistungen 532

3.4.1 Definition und Abgrenzung 532

3.4.2 Moore 533

3.4.3 Wälder 533

3.4.4 Grünland, Weiden und Wiesen 536

3.4.5 Ackerflächen 537

3.4.6 Aquakulturen 537

3.5 Forschungsbedarf 538

3.6 Literaturverzeichnis 538 


\section{ZUSAMMENFASSUNG}

Dieses Kapitel behandelt die bereits beobachteten und potentiell möglichen Auswirkungen eines Klimawandels auf Organismen und Arten, Biozönosen und Ökosysteme in Österreich.

Klimawandelfolgen (,impacts“) resultieren aus der jeweiligen artspezifischen Reaktion von Organismen auf die Klimaumwelt und den Wechselwirkungen mit anderen Arten bzw. dem jeweiligen Biotop. Für viele Artengruppen liegt sehr wenig Wissen für eine Klimafolgenabschätzung auf regionaler und lokaler Ebene vor. Studien zu Klimawandelfolgen für die Biosphäre in Österreich beschränken sich im Allgemeinen auf einige wenige Ökosysteme (u. a. Fließgewässer, Wälder, Ackerflächen) bzw. Sektoren (Forstwirtschaft, Landwirtschaft). Für den überwiegenden Teil der Biosphäre baut die Wissensbasis auf internationale Literatur bzw. auf erste Studien mit Pilotcharakter mit spezifischem Österreichbezug auf. Entsprechend groß ist die Unsicherheit, die aus teilweise unvollständigem Systemverständnis und fehlendem Bezug der dargestellten Klimawandelfolgen zu konkreten Klimawandelszenarios resultiert. Vor allem das Fehlen von Studien, die eine größere Anzahl von Klimawandelszenarios in Bezug auf ihre Auswirkungen systematisch analysieren, erschwert konkrete Aussagen zu möglichen bedeutsamen Schwellenwerten klimatischer Veränderungen.

Die meisten Pflanzenarten reagieren sensitiv in Bezug auf wärmere Temperaturen und Sommertrockenheit. Für viele andere Artengruppen, u. a. auch die Fauna, ist wenig Wissen zu deren Sensitivität in Bezug auf Temperatur- und Niederschlagsveränderungen vorhanden. Die komplexen ökosystemaren Interaktionen generieren Systemverhalten, dass äußerst schwer über längere Zeiträume abschätzbar ist. Generell ist jedoch von einer nicht-linearen Zunahme der Auswirkungen mit der Stärke des Klimawandels auszugehen. Zusammenfassend lassen sich u. a. folgende Klimawandelfolgen beispielhaft darstellen.

Agrarökosysteme und damit die landwirtschaftliche Produktion (Nutzpflanzen und Nutztiere) sind direkt und indirekt vom Klimawandel betroffen, da sich die standortbezogenen natürlichen Produktionsfaktoren stark verändern. Im topografisch stark gegliederten Österreich ergibt sich damit eine massive räumliche Verschiebung agrarklimatologischer Produktionszonen mit Konsequenzen für die standortübliche landwirtschaftliche Landnutzung und die Produktionstechnik. In kühleren, niederschlagsreicheren Gebieten, beispielsweise im nördlichen Alpenvorland, steigert wärmeres Klima weitgehend das durchschnittliche Ertragspotenzial von agrarischen Nutzpflanzen. In niederschlagsärmeren Gebieten nörd- lich der Donau sowie im Osten und Südosten Österreichs werden zunehmende Trockenheit und Hitze das durchschnittliche Ertragspotenzial, vor allem unbewässerter Sommerkulturen, langfristig verringern und die Ausfallsrisiken erhöhen. Das klimatische Anbaupotenzial wärmeliebender Nutzpflanzen, wie z. B. Körnermais oder Wein, weitet sich deutlich aus. Durch - zum Teil neu auftretende - wärmeliebende Insekten, Krankheiten und Unkräuter nimmt das Schadpotential im Ackerbau zu. Zunehmende Hitzeperioden können bei Nutztieren (Rinder, Schweine, Geflügel) die Leistung verringern, das Krankheitsrisiko erhöhen und bis zum Hitzetod führen.

In den österreichischen Waldökosystemen wird die Produktivität in Berglagen und in Regionen mit ausreichendem Niederschlag aufgrund der Klimaerwärmung zunehmen. In östlichen und nordöstlichen Tieflagen und in inneralpinen Beckenlagen nimmt sie hingegen aufgrund zunehmender Trockenperioden ab. Für die zukünftige Ökosystemdynamik wird ein intensiver werdendes Störungsregime aus abiotischen und biotischen Störungsfaktoren entscheidend werden. Insbesondere gilt dies für das Auftreten wärmeabhängiger Insekten wie z. B. dem Fichtenborkenkäfer. Zusätzlich ist mit neuartigen Schäden durch eingeschleppte oder aus südlicheren Regionen einwandernde Schadorganismen zu rechnen. Abiotische Störungsfaktoren wie etwa Stürme, Spät- und Frühfröste und Nass-Schneeereignisse oder Waldbrände könnten ebenfalls höhere Schäden als bisher verursachen. Diese Störungen können zudem Auslöser für Massenvermehrungen und Epidemien von bedeutenden forstlichen Schadorganismen wie z. B. von Fichtenborkenkäfern sein. Störungen führen zu geringeren Erlösen in der Holzproduktion. Auch die Schutzfunktion der Wälder etwa vor Steinschlag, Muren und Lawinen sowie die Kohlenstoffspeicherung können beeinträchtigt werden. Langfristig ist davon auszugehen, dass ab Temperaturerhöhungen über etwa $1{ }^{\circ} \mathrm{C}$ Laubbaumarten im Vergleich zu Nadelbaumarten konkurrenzkräftiger werden und in Seehöhen über $1000 \mathrm{~m}$ ihren Anteil am Waldaufbau potentiell deutlich erhöhen könnten. Wie rasch und umfassend dies geschehen wird, ist von der Waldbewirtschaftung und der Größenordnung der klimatischen Veränderungen abhängig.

Moore und altholzreiche Wälder können sich nur langsam an den Klimawandel anpassen und sind deswegen stark gefährdet. Über die Wechselwirkungen mit anderen Faktoren des Globalen Wandels, wie Landnutzungsänderungen oder die Einbringung invasiver Arten, ist wenig bekannt. Die Anpassungskapazitäten der Arten und Lebensräume sind nicht ausreichend erforscht.

In alpinen Lagen können kälteangepasste Pflanzen in größere Höhen vordringen und dort eine Vermehrung der Ar- 
tenvielfalt bewirken. In inselartigen Mikro-Nischen können kälteangepasste Arten trotz der Erwärmung überdauern, was mittelfristig zu einer Erhöhung der Artendiversität führen kann. Zunehmende Fragmentierung von Populationen kann jedoch zu lokalem Aussterben führen. Aus dem Hochgebirge stammende Arten in den niedrigeren Randlagen der Alpen sind davon besonders betroffen. Auch Tierarten sind stark betroffen. In der Tierwelt sind Änderungen im Jahresverlauf, wie die Verlängerung von Aktivitätsperioden, erhöhte Generationenfolge oder Vorverlegung der Ankunft von Zugvögeln sowie Arealverschiebungen nach Norden bzw. in höhere Lagen für einzelne Arten bereits dokumentiert. Der Klimawandel wird manche Tierarten, vor allem Generalisten, weiter begünstigen und andere, vor allem Spezialisten, gefährden. Die Erwärmung der Fließgewässer führt zu einer theoretischen Verschiebung der Fischhabitate um bis zu 30 km flussaufwärts. Quantitative Abschätzungen von regionalen faunistischen Veränderungen fehlen weitgehend.

\section{SUMMARY}

This Chapter presents the observed and potential future impacts of climate change on organisms, species, communities and ecosystems in Austria.

Climate change impacts result from the species specific response of organisms to climate stimuli and the interactions with other species and the biotope, respectively. For many species, knowledge on their sensitivity towards climatic changes and potential impacts is scarce. Available studies on climate change impacts on the biosphere in Austria are limited to a few ecosystems (e.g., river ecosystems, forests, agricultural land) and sectors, respectively (e.g., forestry, agriculture). For major parts of the biosphere, the knowledge is based on international studies or a few local and regional pilot studies, at best. Therefore, the uncertainty due to the limited knowledge about system behaviour, and frequently missing explicit references to specific climate change scenarios, is huge and makes concrete statements about likely impacts and possible „tipping points“ difficult. Most plant species respond sensitively to increasing temperatures and summer droughts. For many other species groups, including fauna, the impact of changes in precipitation and humidity in warmer climates is not well known. Complex interdependencies with feedbacks generate emerging system behaviours which are difficult to predict. It is to be expected that the severity of impacts is not linearly related to the severity of climate change. To summarize: Given the uncertainties discussed above, the following climate change impacts on biosphere and ecosystem services have been identified.
Agricultural systems and thus crop and livestock production are either directly or indirectly affected by climate change. For the complex topography of Austria, this translates into a substantial change in agricultural production zones with implications for agricultural land-use and production systems. In the cool and moist regions in the northern foothills of the Alps, a warmer climate will increase the crop yield potential, while in the drier regions north of the river Danube and in the southeastern parts of Austria, reduced precipitation and increasing number of heat days will negatively impact crop production. The spatial range for crops like corn and grapes will increase in a warmer climate; however, due to - partly emerging - insects, pathogens and weed plants, the risk of crop damage will increase. More frequent heatwaves may decrease dairy farming, pig fattening, poultry and cattle farming, increase risk of deseases and may even directly increase stress-related mortality.

In Austrian forests, biomass production will increase in mountains and regions with sufficient precipitation, while production will decrease at low-elevation sites in the east, north-east and in dry inner-alpine basins. Future forest dynamics will be largely driven by intensifying disturbance regimes, particularly due to poikilotherm insects such as spruce bark beetles. New invasive pest species and abiotic risk factors such as storms, early and late frost, snow breakage events and forest fires will further increase the damage from disturbances and may exhibit a positive feedback on bark beetle populations and trigger outbreaks of forest insects and severe epidemics of forest diseases. Disturbances lead to lower contribution margins in forestry, and negatively impact protection functionalities against gravitative natural hazards as well as the sink capacity of forests regarding in-situ carbon sequestration. In the long run, a temperature increase of more than $1^{\circ} \mathrm{C}$ may result in markedly increased competitivity of broadleaved tree species over conifers. This may lead to higher shares of broadleaved species in forests at altitudes above 1000 m.a.s.l. How fast this development happens will depend on forest management policies and the magnitude and pace of climate change.

Bogs and old growth forests can only adjust very slowly to a changing climate and are thus at high risk. Data on interdependencies with other factors of global change such as land-use change or the introduction of non-native species are scarce. In addition, the current knowledge on the adaptation capacity of species and ecosystems is insufficient. In alpine habitats, cold-adapted plants may move upwards and locally increase species diversity. Increasing landscape fragmentation may lead to the local extinction of some species. Animal species may adjust their activity profile to a warmer climate (e.g. migrating birds) or experience range shifts to the north or to 
higher altitudes. Some generalist animal species will benefit from climate change while habitat specialists may be threatened. Warming of running waters may shift fish communities farther upstream.

\section{KERNAUSSAGEN}

In vielen Fällen sind österreichspezifische Studien zu Klimawandelfolgen wenig konkret in Bezug auf analysierte Klimawandelszenarios. Dies macht spezifische Aussagen zur Bandbreite möglicher Klimawandelauswirkungen und das Abschätzen von möglichen bedeutsamen Schwellenwerten für klimatische Veränderungen bzw. der Unsicherheit von Klimawandelfolgen schwierig.

- Die Auswirkungen des Klimawandels auf die Landwirtschaft sind regional unterschiedlich

In kühleren, niederschlagsreicheren Gebieten, beispielsweise im Nördlichen Alpenvorland, steigert wärmeres Klima weitgehend das durchschnittliche Ertragspotenzial von Nutzpflanzen. In niederschlagsärmeren Gebieten nördlich der Donau sowie im Osten und Südosten Österreichs werden zunehmende Trockenheit und Hitze das durchschnittliche Ertragspotenzial, vor allem unbewässerter Sommerkulturen, langfristig verringern und die Ausfallsrisiken erhöhen. Das klimatische Anbaupotenzial wärmeliebender Nutzpflanzen, wie z. B. Körnermais oder Wein, weitet sich deutlich aus. Das Schadpotenzial in der Landwirtschaft durch - zum Teil neu auftretende - wärmeliebende Insekten nimmt zu. Durch den Klimawandel verändert sich auch das Auftreten von Krankheiten und Unkräutern. Trockenschäden im Grünland können die Verunkrautung mit Wurzelunkräutern fördern (hohe Übereinstimmung, starke Beweislage).

- Wärmeres und trockeneres Klima wird die Biomasseproduktivität der österreichischen Wälder stark beeinflussen

Die Produktivität nimmt in Berglagen und in Regionen mit ausreichendem Niederschlag aufgrund der Klimaerwärmung zu. In östlichen und nordöstlichen Tieflagen und in inneralpinen Beckenlagen nimmt sie hingegen aufgrund zunehmender Trockenperioden ab (hohe Übereinstimmung, starke Beweislage).

- Die Störungen in Waldökosystemen nehmen unter allen diskutierten Klimaszenarien an Intensität und Häufigkeit $\mathrm{zu}$

Insbesondere gilt dies für das Auftreten von Insekten wie z. B. Fichtenborkenkäfer. Zusätzlich ist mit neuartigen Schäden durch eingeschleppte oder aus südlicheren Regionen einwandernde Schadorganismen zu rechnen. Abiotische Störungsfaktoren wie etwa Stürme, Spät- und Frühfröste und NassSchneeereignisse oder Waldbrände könnten ebenfalls höhere Schäden als bisher verursachen. Diese Störungen können zudem Auslöser für Massenvermehrungen und Epidemien von bedeutenden forstlichen Schadorganismen wie Fichtenborkenkäfer sein. Störungen führen zu geringeren Erlösen in der Holzproduktion. Auch die Schutzfunktion der Wälder etwa vor Steinschlag, Muren und Lawinen sowie die Kohlenstoffspeicherung leiden (hohe Übereinstimmung, starke Beweislage).

- Besonders vom Klimawandel betroffen sind Ökosysteme mit langer Entwicklungsdauer sowie Lebensräume der Alpen oberhalb der Waldgrenze

Moore und altholzreiche Wälder können sich nur langsam an den Klimawandel anpassen und sind deswegen besonders gefährdet (hohe Übereinstimmung, starke Beweislage). Über die Wechselwirkungen mit anderen Faktoren des Globalen Wandels, wie Landnutzungsänderungen oder die Einbringung invasiver Arten, ist wenig bekannt. Die Anpassungskapazitäten der Arten und Lebensräume sind nicht ausreichend erforscht (mittlere Übereinstimmung, moderate Beweislage).

- In alpinen Lagen können kälteangepasste Pflanzen in größere Höhen vordringen und dort eine Vermehrung der Artenvielfalt bewirken

In inselartigen Mikro-Nischen können kälteangepasste Arten trotz der Erwärmung überdauern (hohe Übereinstimmung, starke Beweislage). Zunehmende Fragmentierung von Populationen kann zu lokalem Aussterben führen. Aus dem Hochgebirge stammende Arten in den niedrigeren Randlagen der Alpen sind davon besonders betroffen (hohe Übereinstimmung, mittlere Beweislage).

- Auch Tierarten sind von klimatischen Veränderungen stark betroffen

In der Tierwelt sind Änderungen im Jahresverlauf, wie die Verlängerung von Aktivitätsperioden, erhöhte Generationenfolge oder Vorverlegung der Ankunft von Zugvögeln sowie Arealverschiebungen nach Norden bzw. in höhere Lagen für einzelne Arten bereits dokumentiert (hohe Übereinstimmung, starke Beweislage). Der Klimawandel wird manche Tierarten, vor allem Generalisten, weiter begünstigen und andere, vor allem Spezialisten, gefährden (mittlere Übereinstimmung, mittlere Beweislage). Die Erwärmung der Fließgewässer führt zu einer theoretischen Verschiebung der Fischhabitate um bis zu 
$30 \mathrm{~km}$ flussaufwärts. Für Bachforelle und Äsche werden geeignete Lebensräume geringer (hohe Übereinstimmung, starke Beweislage).

- Auch Nutztiere leiden unter dem Klimawandel

Zunehmende Hitzeperioden können bei Nutztieren die Leistung verringern, das Krankheitsrisiko erhöhen und bis zum Hitzetod führen (hohe Übereinstimmung, starke Beweislage).

\subsection{Einleitung \\ 3.1 Introduction}

\subsubsection{Allgemeines}

Dieses Kapitel behandelt die potentiellen Auswirkungen eines möglichen Klimawandels (siehe Band 1, Kapitel 4) auf Organismen, deren Biozönosen und in Erweiterung um Biotopaspekte die Auswirkungen auf Ökosysteme. In Anlehnung an das Millenium Ecosystem Assessment (MEA, 2005) wird als Ökosystem als ein dynamischer Komplex von Pflanzen, Tieren, Mikroorganismen und ihrer unbelebten Umwelt verstanden $(, \ldots$ an ecosystem can be practically defined as a dynamic complex of plant, animal and micro-organism communities, and the non-living environment, interacting as a functional unit"). Damit wird ein weiter Bogen gespannt von stark anthropogen geprägten künstlichen Systemen (Ackerland, Grünland), bis zu naturnahen (Wälder, Wiesen) und natürlichen Ökosystemen (alpine Lebensräume, Moore).

Klimawandelfolgen ("impacts") resultieren aus der jeweiligen artspezifischen Reaktion von Organismen auf die Klimaumwelt und den Wechselwirkungen mit anderen Arten bzw. dem jeweiligen Biotop. Dieses Kapitel versucht, für die wichtigsten taxonomischen Artengruppen, aufbauend auf einer kurzen einleitenden Darstellung der ökosystemaren Relevanz, ihre Sensitivität in Bezug auf Klimafaktoren und, wenn möglich, die potentiellen Auswirkungen eines Klimawandels wie in Band 1, Kapitel 4 im Rahmen von Klimaänderungsszenarien für Österreich beschrieben, für österreichische Verhältnisse darzustellen (Abschnitt 3.2). Die sich aufgrund von Wechselwirkungen mit anderen Arten im ökosystemaren Kontext ergebenden Konsequenzen werden für wichtige Biozönosen bzw. Ökosysteme behandelt (Abschnitt 3.3). Schließlich wird versucht, für ausgewählte Ökosystemtypen (Wälder, agrarische Ökosysteme, Moore, Gewässer) die potentiellen Auswirkungen für die Erbringung von Ökosystemleistungen qualitativ abzuschätzen (d.h. Vulnerabilität; Abschnitt 3.4).
Möglichkeiten zur Anpassung an einen Klimawandel sowie die Abschätzung der Effekte von Anpassungsmaßnahmen werden in Band 3, Kapitel 2 behandelt.

Unter der Sensitivität wird die Reaktion eines Systems (d.h. Art, Ökosystem) auf die Einwirkung von bestimmten Klimafaktoren verstanden. Lokal-regionale Klimawandelbedingungen bzw. Klimawandelszenarios bestimmen mit den Eigenschaften des betrachteten Systems die Exponiertheit („exposure") und ergibt unter Einbeziehung der Sensitivität die potentiellen Klimawandelauswirkungen (,impacts“) für ein betrachtetes System. Der Begriff der Vulnerabilität beschreibt zum einen, in welchem Umfang ein exponiertes sozial-ökologisches System gegenüber Störungen oder Stress empfänglich ist und zum anderen die eingeschränkten Möglichkeiten, mit diesen Herausforderungen umzugehen bzw. diese zu bewältigen. Wird nach O’Brien et al. (2004) Vulnerabilität im gegenständlichen Kontext als „starting point“ betrachtet (d.h. die Klimawandelauswirkungen unter der Annahme, dass noch keine Anpassungsmaßnahmen mitberücksichtigt wurden), charakterisiert der Begriff Vulnerabilität im Kontext des gegenständlichen Kapitels die (qualitative) Bewertung der potentiellen Klimawandelauswirkungen. Band 2, Kapitel 1 enthält weitere Hinweise zu den verwendeten Begriffen und Konzepten.

Literatur mit Österreichbezug konzentriert sich vor allem auf Wälder und alpine Pflanzengesellschaften, einige Fischarten und Flußökosysteme sowie allgemein die Sektoren Landwirtschaft und Forstwirtschaft. Es wurde jedoch der Ansatz verfolgt, sich nicht auf wenige, besser beforschte Ökosysteme bzw. Arten zu beschränken. Dies führte jedoch teilweise zu relativ inhomogenen Subkapiteln mit stark unterschiedlicher Wissensbasis. Als ebenfalls einschränkend für ein Assessment von Klimawandelfolgen in der Biosphäre hat sich der Umstand erwiesen, dass in vielen der für diesen Bericht ausgewerteten Quellen mit Österreichbezug unklar bleibt, auf welche klimatischen Veränderungen sich die beschriebenen Auswirkungen beziehen.

Für die Beurteilung von beobachteten Klimawandelfolgen sowie zur Abschätzung möglicher zukünftiger Auswirkungen eines Klimawandels ist von Bedeutung, dass dieses Konzept die „Neuformierung“ von Ökosystemen mit einschließt. Es kann nicht einfach davon ausgegangen werden, dass heute bestehende Artenvergesellschaftungen (,communities“) unter veränderten Klimabedingungen gemeinsam eine neue Nische im ökologischen Raum einnehmen werden, sondern dass es zu neuen, heute nicht existierenden Artenkombinationen kommen kann (z. B. Austin und Smith, 1990). Verändern sich Ökosysteme unter dem Einfluss eines Klimawandels in Bezug 


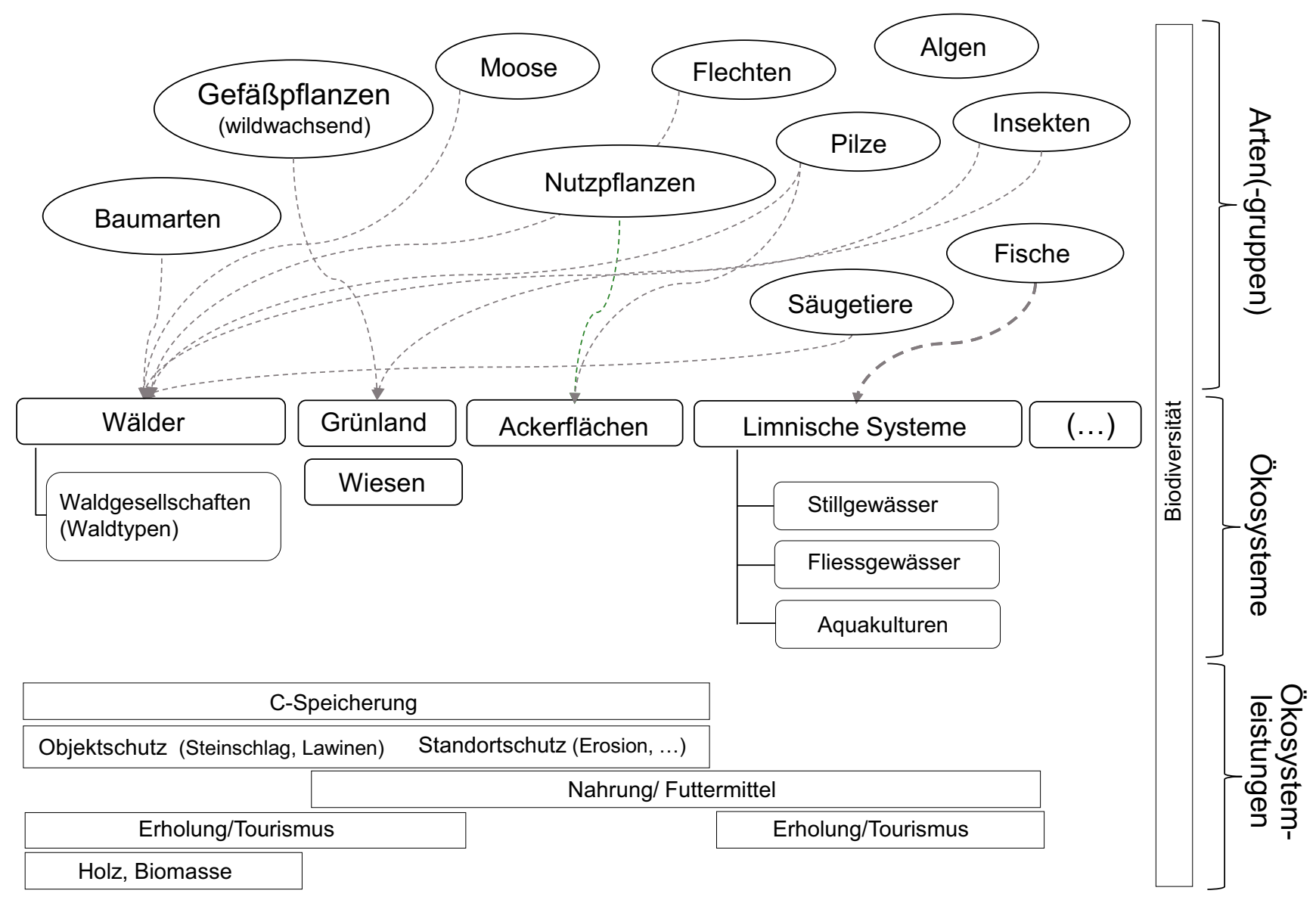

Abbildung 3.1 Konzept für das Kapitel Biosphäre (schematische Darstellung). Aufbauend auf einer Zusammenschau des Wissens zu Klimawandelfolgen für Arten bzw. Artengruppen werden Auswirkungen für Ökosysteme und ausgewählte Ökosystemleistungen in Österreich analysiert. Biodiversität wird als Voraussetzung für die Erbringung von Ökosystemleistungen betrachtet

Figure 3.1 Schematic representation of the conceptual frame for the Biosphere chapter. Based on a synthesis of species specific climate change impacts implications for ecosystems and related selected ecosystem services in Austria are discussed. Biodiversity is considered as prerequisite for the provisioning of ecosystem services

auf ihre Artenzusammensetzung bzw. Struktur (Raumstruktur, Biomasseverteilung) und Funktionsweise, hat das Auswirkungen auf die Ökosystemleistungen (,ecosystem services“im Sinne des Millenium Assessment; MEA, 2005).

Diesem Konzept folgend gliedert sich das vorliegende Kapitel wie folgt: Für Arten (bzw. Artengruppen) wird vorhandenes Wissen zur Reaktion auf Klimafaktoren dargestellt. Darauf aufbauend werden, sofern Informationen aus der Literatur vorliegen, die für Österreich zu erwartenden Auswirkungen („impacts") in Bezug auf konkrete Klimawandelszenarien (vgl. Band 1, Kapitel 4) bzw. mögliche zukünftige Klimabedingungen auf Artenebene und auf Ebene von Ökosystemen (bzw. Biozönosen) abgeschätzt. Dabei wird auf die Kapitel zu Biotopaspekten (z. B. Hydrosphäre, Pedosphäre) in Band 2 verwiesen. Es wird versucht, die Überschneidung mit diesen Kapiteln so gering als möglich zu halten und im gegenständlichen Kapitel Arten und die sich durch Interaktionen zwischen
Arten und Habitaten ergebenden Eigenschaften von Ökosystemen darzustellen.

Klimawandelauswirkungen können sich auf die Produktivität, auf Veränderungen des geografischen Vorkommens, auf das Verhalten, auf die Vergesellschaftung mit anderen Arten oder das Erlöschen von Vorkommen beziehen. Bei der Betrachtung der möglichen Implikationen für Ökosystemleistungen im Sinne des Millenium Assessment (MEA, 2005) fokussiert das vorliegende Kapitel auf bereitstellende Ökosystemleistungen (,provisioning services“). Allgemein sind Analysen für österreichische Verhältnisse, die sich des Konzepts von Ökosystemleistungen bedienen, selten. Biodiversität bzw. deren Erhaltung wird als Voraussetzung für die Erbringung von Ökosystemleistungen betrachtet. Abbildung 3.1 zeigt schematisch das verfolgte Konzept. 


\subsubsection{Untersuchungsmethoden}

\section{Beobachtung und Experiment}

Für die Identifizierung von (potentiellen) Klimawandelfolgen für die Biosphäre stehen als Methoden die Beobachtung, das Experiment sowie Modellbildung und Simulation zur Verfügung. Durch diese unterschiedlichen methodischen Zugänge ist wahlweise eine isolierte Betrachtung der Wirkungsweise einzelner Umweltfaktoren oder aber eine Analyse von Interaktionseffekten möglich. Mit bestehenden Monitoringsystemen, wie etwa permanenten Wald- oder Landschaftsinventuren, ist es kaum möglich, die Effekte von vielfach interagierenden Umweltfaktoren zu isolieren. Dies würde erfordern, dass erstens die Veränderungen eines beobachteten Systems wahrgenommen werden und zweitens zur Erklärung solcher Veränderungen ihre verursachenden Faktoren in vergleichbarer räumlich-zeitlicher Auflösung bekannt sein müssten. Als Beispiel seien hier die möglichen Auswirkungen des Klimawandels und der atmosphärische Stickstoffeintrag in terrestrischen Ökosystemen genannt. Klimaparameter lassen sich mit einiger Genauigkeit ausgehend von einem hinreichend dichten Messstationennetz in den geografischen Raum interpolieren. Der Eintrag von Stickstoff (N) in Ökosysteme lässt sich jedoch geografisch erst in vielfach gröberer Auflösung differenzieren (d.h. innerhalb einer Region wird unterstellt, dass die $\mathrm{N}$-Einträge gleich hoch sind). Es ist hier kaum möglich, mit Beobachtung (z. B. Inventuren) aussagekräftige Ergebnisse zu erhalten. Mit Experimenten hingegen können die Wirkungen von Faktorenkombinationen gezielt überprüft werden. Der experimentelle Ansatz ist jedoch in Bezug auf die Zeit- und vor allem die Raumdimension der zu untersuchenden Ökoysteme stark eingeschränkt (z. B. Wälder).

\section{Modellbildung und Simulation}

Etwa seit den 1970er-Jahren werden Modellbildung und Simulation erfolgreich zur Systemanalyse angewendet. Neben der Durchführung virtueller Experimente ermöglichen Szenario-Simulationen auch die Abschätzung von Auswirkungen möglicher zukünftiger Klimabedingungen. Prinzipiell ist zu unterscheiden, ob es sich um Modelle für einzelne Arten oder für Gesellschaften („communities“) bzw. Ökosysteme handelt oder auch ob statische oder dynamische Modellansätze zum Einsatz kommen.
- Statische Nischen-Modelle

Minimalvoraussetzung für das Überleben einer Art an einem gegebenen Standort (Biotop) ist, dass die dort vorherrschenden Bedingungen innerhalb der artspezifischen physiologischen Amplitude liegen („fundamental niche“). Außerhalb dieses Bereichs ist eine Art nicht lebensfähig. Die Abgrenzung dieser physiologischen Nische berücksichtigt keine Interaktion mit anderen Arten (wie z. B. die Konkurrenz um Licht, Wasser, Nährstoffe). Die physiologischen Nischen von Arten sind über die tatsächlichen beobachteten Vorkommensbereiche schwierig zu bestimmen, da die meisten Arten natürlicherweise meist nicht bis an ihre physiologischen Toleranzgrenzen vorkommen. Die realisierte ökologische Nische ergibt sich durch die Konkurrenzwirkung von besser angepassten und konkurrenzkräftigeren Arten, wodurch viele Arten mehr oder weniger weit von ihren eigenen physiologischen Grenzen verdrängt werden. Zudem ist die realisierte Nische meist vielfach durch anthropogen bedingte Landnutzungseffekte überprägt.

Das Konzept der Nische wird vielfach in korrelativen Modellansätzen verwendet, um das Vorkommen einer Art oder die Vergesellschaftung von Arten in Abhängigkeit von Umweltfaktoren mathematisch-statistisch zu beschreiben (Guisan und Zimmermann, 2000; Guisan und Thuiller, 2005). Enthalten solche korrelativen Modelle auch Klimavariablen können die gefundenen Zusammenhänge zur Abschätzung der potentiellen Auswirkungen von klimatischen Veränderungen auf die Artenverbreitung verwendet werden. Während derartige Ansätze erste Einsichten in die Sensitivität von Arten bzw. Gesellschaften auf sich verändernde Klimabedingungen ermöglichen, müssen ihre methodischen Probleme berücksichtigt werden. Nischenmodelle sind statisch, d. h. es kann damit nicht abgeschätzt werden, wie lange es dauern würde, bis eine Art ein erwartetes künftiges Areal auch tatsächlich besiedeln könnte, bzw. wie lange es dauern würde, bis eine Art aus einem derzeitigen Habitat verdrängt wäre. Zusätzlich sind Nischenmodelle nicht imstande, die Veränderung von zwischenartlichen Konkurrenzverhältnissen zu berücksichtigen, was ihre Anwendung zur Abschätzung von Klimawandelfolgen äußerst unsicher macht.

- Dynamische Ökosystemmodelle

Dynamische Ökosystemmodelle, die Konkurrenz zwischen Arten in Abhängigkeit der Umweltbedingungen dynamisch über die Zeit beschreiben, können sehr gut zur Analyse von Klimawandelfolgen für Ökosysteme verwendet werden (z. B. Lexer und Hönninger, 2001; bzw. Seidl et al., 2011a für Waldökosysteme in Österreich). In Szenarioanalysen („Was wäre, wenn [...]?“) werden Auswirkungen von klimatischen Verän- 
derungen in der Regel transient simuliert, d.h. Änderungen in der Artenzusammensetzung sind nicht nur von Umweltbedingungen sondern auch von der Ausgangssituation und von dynamischen Prozessen über die Zeit abhängig (z. B. durch zwischenartliche Konkurrenz verursachte Veränderung der Baumartenzusammensetzung in Wäldern).

- Hybridansätze

Während Nischen- und dynamische Ökosystemmodelle eine längere Tradition haben und für die Simulation von Klimawandelfolgen mehr oder weniger direkt verwendbar sind, wurde das räumlich explizite Abschätzen von klimabedingten Wanderungsbewegungen lange Zeit eher vernachlässigt. Erst in den letzten Jahren hat sich, teilweise unter Rückgriff auf Ansätze der Invasionsbiologie (Hastings et al., 2005; Nathan et al., 2011), die Forschung in diesem Bereich mit der Entwicklung sogenannter Hybrid-Modelle (Thuiller et al., 2008) intensiviert. Hybrid-Modelle integrieren demographische Prozesse und Ausbreitungsfunktionen in Nischenmodellen (z. B. Engler et al., 2009; Dullinger et al., 2012). Ausbreitungsfunktionen in dynamischen Ökosystemmodellen (Meier et al., 2012; Lehsten et al., in Revision) erlauben die transiente Simulation der Arealdynamik von Arten unter sich ändernden klimatischen Bedingungen. Mit Ausnahme der Baumarten in Waldökosystemen fokussieren diese Modelle aber bislang auf Wanderungsbewegungen einzelner Arten und sind nicht in der Lage, simultane Migrationsbewegungen kompetitiv, trophisch oder mutualistisch interagierender Artengruppen zu simulieren.

\section{- Kombinierte Methoden}

Durch kombinierte Verfahren können Nachteile der einzelnen Methoden ausgeglichen werden. So ist etwa die Kombination von Großrauminventuren und Simulationsmodellen ein erfolgversprechender diagnostischer Ansatz (z. B. Hasenauer et al., 1999). Hier ist auch die Erweiterung bestehender Inventursysteme ein wichtiger Beitrag. Letztendlich sind im Wesentlichen alle derzeitigen großräumigen Monitoringverfahren nicht mit dem Ziel entwickelt worden, Klimawandeleffekte zu identifizieren. Ein Beispiel für ein gezielt auf diesen Zweck zugeschnittenes Verfahren stellt hingegen GLORIA dar (Gottfried et al., 2012), das Effekte des Klimawandels auf die Artenzusammensetzung in Hochgebirgshabitaten untersucht. Letztendlich sind zur Bestätigung sowohl Experiment als auch Simulation auf standardisierte Beobachtung (Monitoring) angewiesen.

\subsection{Arten \\ 3.2 Species}

\subsubsection{Mikroben (Archaea, Bakterien, Blavalgen)}

\section{Abgrenzung und Charakterisierung}

Bakterien und Archaea sind weit verbreitet und wichtige Komponenten jedes terrestrischen oder aquatischen Ökosystems (z. B. Delong und Pace, 2001). Erst seit molekulare Techniken verwendet werden, anstatt die Organismen durch Kultivierung zu charakterisieren, ist die große Biodiversität von Bakterien und Archaea erkannt worden (Delong und Pace, 2001; Fierer et al., 2012). Sie besiedeln auch extreme Biotope, wie Salzseen und heiße Quellen, extrem nährstoffarme Habitate, wie etwa den Erdmantel und kommen in großer Zahl in und am menschlichen Körper sowie bei Tieren vor. Aufgrund ihrer großen metabolischen Diversität übernehmen viele verschiedene Gruppen von Bakterien und Archaea Schlüsselfunktionen in den globalen biogeochemischen Kreisläufen.

\section{Klimawandelrelevante funktionale Rolle im öko- systemaren Kontext}

Mikrobielle Gemeinschaften sind ein Schlüsselelement in vielen Ökosystemen, da sie an der Umsetzung anorganischen und organischen Materials in allen Nährstoffketten direkt und indirekt beteiligt sind. Ein Beispiel für die direkte funktionale Bedeutung von Bakterien und Archaea im Ökosystem ist ihre Bereitstellung von Stickstoffverbindungen für Pflanzen (sowohl Stickstofffixierung als auch Nitratbildung aus mineralisiertem Ammonium). Weiters sind Bakterien zusammen mit Pilzen die treibenden Kräfte beim Abbau organischen Materials im Boden (Peterson und Luxton, 1982), wobei hier bestimmte Organismengruppen zum Teil auf den Abbau bestimmter Pflanzenteile spezialisiert sind (Berg und McClaugherty, 2008) und sie tragen durch heterotrophe Atmung auch zum Netto-Kohlenstoffumsatz bei.

Bakterien und Archaea spielen eine direkte wichtige Rolle sowohl bei der Produktion als auch beim Abbau von Treibhausgasen (THG). Sie dominieren die natürliche und die anthropogen induzierte Produktion von Kohlendioxid, Methan und Lachgas. Photosynthetische Cyanobakterien und viele andere Bakterien, bzw. Archaea fixieren Kohlendioxid zum Aufbau eigener Materie aus der Atmosphäre (autotroph), während insbesondere Bodenbakterien beim Abbau von organischen 
Kohlenstoffverbindungen $\mathrm{CO}_{2}$ erzeugen (heterotroph). Bei der Oxidation von, aus abgestorbenem organischen Material mineralisiertem, Ammoniak zu Nitrat (durch bakterielle und archaeale Organismen) und bei der anschließenden Denitrifikation, bei welcher der Stickstoff zurück in die Atmosphäre überführt wird, entsteht Lachgas $\left(\mathrm{N}_{2} \mathrm{O}\right)$ als Nebenprodukt (bei der Denitrifikation bis zu $50 \mathrm{~kg}$ je Tonne umgesetztem Stickstoff). Methanogene Archaea sind für die Bildung von etwa $75 \%$ des Methans in der Atmosphäre verantwortlich, das hauptsächlich in Feuchtgebieten, im Verdauungssystem von Termiten und Wiederkäuern und in den Meeren produziert wird (Garcia et al., 2000). Methan wird aber auch von verschiedenen spezialisierten Archaea und Bakteriengruppen als Energiequelle genutzt, d. h. aktiv sowohl in anaeroben (unter Sauerstoffausschluss, z. B. in Meeressedimenten) als auch in aeroben Habitaten (Böden) abgebaut. Die Vermehrung und Aktivitäten von Denitrifikanten und methanbildenden (methanogenen) Archaea sind in den letzten Jahrzehnten durch intensivierte Landwirtschaft (Stickstoffdüngung, Tierhaltung) in Böden stark angestiegen (siehe Band 2, Kapitel 5 für detaillierte Ausführungen dazu).

\section{Sensitivität in Bezug auf Klimavariable}

Direkte Effekte auf Mikroorganismen sind z. B. durch Änderungen der Temperatur und Bodenfeuchte zu erwarten. Diese können entweder eine Veränderung in der Aktivität der bestehenden Mikrobiota oder/und eine Veränderung der Struktur der mikrobiellen Gemeinschaften verursachen. So kann Erwärmung direkt zu einer Erhöhung der mikrobiellen Aktivitäten führen und z. B. Bodenatmung und damit $\mathrm{CO}_{2}$-Produktionsraten erhöhen. Diese Reaktion auf Erwärmung wurde z. B. in Bodenerwärmungsexperimenten in den Nord-Tiroler Kalkalpen bestätigt (Schindlbacher et al. 2011). Erhöhte $\mathrm{CO}_{2}$-Konzentrationen wirken sich auf die Bodenmikrobiota eher indirekt über verändertes Pflanzenwachstum und -metabolismus (He et al., 2012) und die damit verbundenen Veränderungen im Boden (wie Bodenfeuchtigkeit und C:NVerhältnis) aus.

Wenn ein Klimafaktor eine strukturelle Veränderung der mikrobiellen Gemeinschaft verursacht, so hat dies Auswirkungen auf Prozessraten und Kontrollmechanismen, da die neuen Mikroorganismen andere Physiologien aufweisen (Shimel und Gulledge, 1998). Im Extremfall könnte ein spezieller Prozess (z. B. Methanogenese) durch den Verlust einer bestimmten Organismengruppe wegfallen oder ein zuvor wenig relevanter Prozess durch Ausbreitung einer neuen funktionellen Gruppe hinzukommen (Smith et al., 2004). Im weitgehend naturbe- lassenen „Urwald“ Rothwald in den niederösterreichischen Kalkalpen wurden schnelle Veränderungen nitrifizierender und denitrifizierender Bodenpopulationen als Reaktion auf Änderungen im Bodenwassergehalt und der Temperatur gemessen (Szukics et al., 2010). Andererseits können verschiedene funktionell redundante Gruppen, wie z. B. Ammoniakoxidierende Bakterien und Archaea, konträre Reaktionen auf sich ändernde Umweltbedingungen zeigen, wie dies für zwei österreichische Waldböden in einem Experiment mit variiertem Stickstoff- und Wassergehalt gezeigt wurde (Szukics et al., 2012; siehe auch Band 2, Kapitel 5) oder auch für Phytoplankton, das erhöhten Temperaturen ausgesetzt wurde.

Es lässt sich nicht vorhersehen, welches der beiden Reaktionsmuster unter welchen Klimaveränderungen am häufigsten auftreten wird. Jedoch lässt sich aus bisherigen ökophysiologischen Studien ableiten, dass sich die mikrobiellen Gemeinschaften strukturell umso stärker verändern, je stärker und langanhaltender die eintretende Umweltänderung ist, wobei insbesondere Änderungen des pH-Werts, der Temperaturund der Sauerstoffverfügbarkeit wichtige Faktoren darstellen.

\section{Klimawandelfolgen in Österreich}

Die Effekte des Klimawandels auf Mikroorganismen sind aufgrund ihrer großen Zahl und teilweise extrem unterschiedlicher Stoffwechselprozesse und funktioneller Komplexität sowie der Interaktionen mikrobieller Gemeinschaften äußerst schwer abschätzbar. So bleibt unklar, ob und unter welchen Bedingungen eine Veränderung des Klimas eine positive oder negative Feedbackwirkung, z. B. auf THG-Emissionen haben wird (siehe dazu auch Band 2, Kapitel 5 zur Pedosphäre).

Mikrobielle Krankheitserreger werden auf Klimaveränderungen reagieren. So bergen künftige Temperaturerhöhungen die Gefahr ihrer verstärkten Ausbreitung, wie dies z. B. für den cholerähnlichen Erreger Vibrio vulnificus in der Ostsee gezeigt wurde (Baker-Austin et al., 2012).

\subsubsection{Algen}

\section{Abgrenzung und Charakterisierung}

Algen sind eine entwicklungsgeschichtlich diverse, sehr artenund individuenreiche Gruppe niederer Pflanzen, die über einen Zeitraum von über $2 \mathrm{Mrd}$. Jahre der Erdgeschichte die dominierenden Pflanzen waren und die Entstehung der Erdatmosphäre gesteuert haben. Auch heute produzieren sie im Meer und in Binnengewässern noch ca. 50 \% des Sauerstoffs der Atmosphäre (Falkowski, 2012). Sie sind zum überwiegen- 
Tabelle 3.1 Sensitivität von Phytoplankton auf ausgewählte Klimavariablen

Table 3.1 Sensitivity of phytoplankton to selected climate drivers

\begin{tabular}{|c|c|c|c|}
\hline Klimafaktor & Wirkungsmechanismus & Algenarten/funktionale Gruppen & Literatur \\
\hline \multirow[t]{3}{*}{ Höhere Temperatur } & \multirow[t]{2}{*}{$\begin{array}{l}\text { Besseres Wachstum durch } \\
\text { höhere Netto-Photosynthese, da } \\
\text { Temperatur-Optima noch nicht } \\
\text { erreicht sind }\end{array}$} & $\begin{array}{l}\text { Eurytherme Phytoplankter (insbes. Grün- } \\
\text { algen, bzw. Cyanobakterien) werden bei } \\
\text { Temperaturen über } 18^{\circ} \mathrm{C} \text { gefördert; poten- } \\
\text { tiell negative Auswirkung auf Kieselalgen- } \\
\text { wachstum }\end{array}$ & $\begin{array}{l}\text { Kosten et al. (2011); Schab- } \\
\text { hüttl et al. (2010) }\end{array}$ \\
\hline & & $\begin{array}{l}\text { Einwanderung wärmeliebender Cyanobak- } \\
\text { terien (Cylindrospermopsis) wird gefördert }\end{array}$ & $\begin{array}{l}\text { Dokulil und Mayer (1996); } \\
\text { Nöges et al. (2010) }\end{array}$ \\
\hline & $\begin{array}{l}\text { Verringertes Wachstum/Konkur- } \\
\text { renzfähigkeit kalt-stenothermer } \\
\text { Arten }\end{array}$ & $\begin{array}{l}\text { Auswirkungen in kalten Gebirgsseen noch } \\
\text { wenig erforscht (Beispiel kalt-stenother- } \\
\text { me = psychrophile Dinoflagellaten) }\end{array}$ & $\begin{array}{l}\text { Flaim et al. (2010); } \\
\text { Obertegger et al. (2011) }\end{array}$ \\
\hline Verkürzte Eisbedeckung & $\begin{array}{l}\text { Frühjahrsdurchmischung intensi- } \\
\text { viert und verlängert; langzeitliche } \\
\text { Erwärmung des Hypolimnions } \\
\text { in tiefen Seen und Erhöhung der } \\
\text { thermischen Stabilität; Steuerung } \\
\text { durch Winter "North Atlantic } \\
\text { Oscillation" }\end{array}$ & $\begin{array}{l}\text { Thermische Änderungen beeinflussen Dauer } \\
\text { und Zusammensetzung des Frühiahrspeaks } \\
\text { (Diatomeen, Cryptophyceen) und fördern } \\
\text { spätsommerliche Tiefen-Maxima von schwe- } \\
\text { benden toxischen Cyanobakterien (Plank- } \\
\text { tothrix rubescens) }\end{array}$ & $\begin{array}{l}\text { Bleckner et al. (2007); Dokulil } \\
\text { et al. (2006); Dokulil und } \\
\text { Teubner (2010, 2012); Dokulil } \\
\text { et al. (2010); Koinig et al. } \\
\text { (2002); Nöges et al. (2010) }\end{array}$ \\
\hline $\begin{array}{l}\text { Verlängerte Vegetati- } \\
\text { onsperiode }\end{array}$ & $\begin{array}{l}\text { Veränderung der räumlich-zeit- } \\
\text { lichen Nischen funktionaler Phy- } \\
\text { toplanktongruppen; komplexe } \\
\text { Interaktion zwischen Nahrungs- } \\
\text { qualität von Algen und Grazern } \\
\text { (herbivore Freßfeinde) gestört }\end{array}$ & $\begin{array}{l}\text { Synchronisierung von Phytoplankton und } \\
\text { Zooplanktonpeaks kann gestört werden; } \\
\text { langzeitliche Änderung der Phytoplankton- } \\
\text { zusammensetzung und Förderung von } \\
\text { langsam wachsenden opportunistischen } \\
\text { Cyanobakterien }\end{array}$ & $\begin{array}{l}\text { Thies at al. (2011); Tolotti } \\
\text { et al. (2012); Winder und } \\
\text { Schindler (2004); Winder und } \\
\text { Sommer (2012) }\end{array}$ \\
\hline $\begin{array}{l}\text { Verringerter Nieder- } \\
\text { schlag im Sommer }\end{array}$ & $\begin{array}{l}\text { Verringerung des DOC; höhere } \\
\text { Lichtdurchlässigkeit führt zu ver- } \\
\text { stärkter UV-Wirkung / -Schäden } \\
\text { in Hochgebirgsseen }\end{array}$ & $\begin{array}{l}\text { Insbesondere im Hochgebirgsphytoplankton } \\
\text { und Nahrungsnetzen deutliche Auswirkun- } \\
\text { gen auf das Artenspektrum }\end{array}$ & $\begin{array}{l}\text { Koinig et al. (1998); Psenner } \\
\text { (2002); Sommaruga et al. } \\
\text { (1999) }\end{array}$ \\
\hline $\begin{array}{l}\text { Erhöhter Niederschlag } \\
\text { (insbes. Starkregener- } \\
\text { eignisse im Sommer) }\end{array}$ & $\begin{array}{l}\text { Erhöhter Nährstoffeintrag (P, N) } \\
\text { aus dem Einzugsgebiet bewirkt } \\
\text { Überdüngung (Eutrophierung), } \\
\text { Starkregen erhöhen die Trübung }\end{array}$ & $\begin{array}{l}\text { Verschiebung der Artendominanz zu eutro- } \\
\text { phen Taxa und maskierte Reoligotrophie- } \\
\text { rung; u.a. zentrische Diatomeen werden } \\
\text { gefördert }\end{array}$ & $\begin{array}{l}\text { Dokulil und Teubner (2005); } \\
\text { Dokulil et al. (2010); Koinig } \\
\text { et al. (1998); Nöges et al. } \\
\text { (2010); Tolotti et al. (2012) }\end{array}$ \\
\hline $\begin{array}{l}\text { Erhöhte diffuse Stoffein- } \\
\text { träge aus Niederschlag }\end{array}$ & $\begin{array}{l}\text { Stickstoff-Düngungseffekte auf } \\
\text { Phytoplankton im Hochgebirge }\end{array}$ & $\begin{array}{l}\text { Zeitlich verschobene Langzeiteffekte sind } \\
\text { wahrscheinlich }\end{array}$ & $\begin{array}{l}\text { Batterbee et al. (2002); } \\
\text { Elser (2011); Holtgrieve et al. } \\
(2011)\end{array}$ \\
\hline $\begin{array}{l}\text { Erhöhter } \mathrm{CO}_{2} \text {-Gehalt in } \\
\text { der Atmosphäre }\end{array}$ & $\begin{array}{l}\text { Verbessertes Wachstum durch } \\
\mathrm{CO}_{2} \text {-Düngungseffekt, pH-Verrin- } \\
\text { gerung }\end{array}$ & $\begin{array}{l}\text { Verringerte Diatomeendominanz; erhöhte } \\
\text { Grünalgen-/Desmidiaceenanteile }\left(\mathrm{CO}_{2^{-}}\right. \\
\text {Verwerter), kombinierter Effekt mit UV in } \\
\text { Hochgebirgsseen }\end{array}$ & $\begin{array}{l}\text { Adrian et al. (2009); Batterbee } \\
\text { et al. (2002); Beardall und } \\
\text { Raven (2004); Beardall und } \\
\text { Stojkovic (2006); Psenner } \\
\text { (2002) }\end{array}$ \\
\hline
\end{tabular}

den Teil photoautotroph, d.h. sie betreiben Photosynthese, wobei sie Kohlenstoff aus $\mathrm{CO}_{2}$ direkt oder intermediär (als gelöstes dissoziiertes Bikarbonat - $\mathrm{HCO}_{3}$ ) aufnehmen und Sauerstoff freisetzen. Weltweit schätzt man ihre Artenzahl auf über 100 000, wovon derzeit ca. 3000 Arten für Gewässer in Österreich nachgewiesen sind. Ihre Größe reicht im Plankton von wenigen Tausendstel zu wenigen Millimeter mit einer hohen Dichte (über $10^{6}$ Individuen pro Liter) bzw. im Aufwuchs von wenigen Tausendstel Millimeter zu mehreren Zentimeter Größe (über $10^{6}$ Individuen pro $\mathrm{cm}^{2}$ ). Algen umfassen überwiegend eukaryontische Organismen (d.h. Zellen haben ei- nen Zellkern) unterschiedlicher Pigmentierung (Farbgebung), sind aber meist mit oxygenen Photosynthese betreibenden Cyanobakterien (Blaualgen) assoziiert (in vielen Lebensräumen, insbesondere im Boden, auf Felsen, Baumstämmen und in Gewässern) und werden gemeinsam als Algengemeinschaften bezeichnet. Algengemeinschaften sind wesentlich für den Sauerstoffhaushalt und die Aufrechterhaltung der gewässertypischen Nahrungsnetze, spielen u. a. zusammen mit Pilzen eine wesentliche Rolle in Flechten und sind für die Bodenbildung relevant. 
Tabelle 3.2 Sensitivität von Phytobenthos (Algenaufwuchs) in Fließgewässern in Bezug auf Klimavariablen

Table 3.2 Sensitivity of phytobenthos in rivers to selected climate drivers

\begin{tabular}{|c|c|c|c|}
\hline Klimafaktor & Wirkungsmechanismus & Algenarten/funktionale Gruppen & Literatur \\
\hline \multirow[t]{2}{*}{ Höhere Temperatur } & $\begin{array}{l}\text { Besseres Wachstum durch } \\
\text { höhere Netto-Photosynthese, da } \\
\text { Temperatur-Optima noch nicht } \\
\text { erreicht }\end{array}$ & $\begin{array}{l}\text { Eurytherme Taxa (Grünalgen; Cyanobakte- } \\
\text { rien; Rotalgen) werden gefördert; Algen- } \\
\text { massenentwicklungen in unbeschatteten } \\
\text { Gerinnen zu erwarten }\end{array}$ & $\begin{array}{l}\text { Ellwood und Whitton (2007); } \\
\text { Meyer et al. (1999); Schab- } \\
\text { hüttl et al. (2013) }\end{array}$ \\
\hline & $\begin{array}{l}\text { Verringertes Wachstum kalt- } \\
\text { stenothermer Arten }\end{array}$ & $\begin{array}{l}\text { Beispiel Hydrurus-Nische, aber auch andere } \\
\text { saisonale oligotrophe Arten }\end{array}$ & $\begin{array}{l}\text { Klaveness und Lindstroem } \\
\text { (2011); Rott et al. (2000, } \\
\text { 2006); Uehlinger et al. (2011) }\end{array}$ \\
\hline Verkürzte Frostperiode & $\begin{array}{l}\text { Fehlende/Verkürzte Eis-/Schnee- } \\
\text { bedeckung }\end{array}$ & $\begin{array}{l}\text { Verlängerung von zeitlich-räumlichen Peaks } \\
\text { insbesondere in Gletscherbächen in Früh- } \\
\text { jahr und Herbst }\end{array}$ & $\begin{array}{l}\text { McGregor et al. (1995); Rott } \\
\text { et al. (2006) }\end{array}$ \\
\hline $\begin{array}{l}\text { Auftauen von Perma- } \\
\text { frost }\end{array}$ & $\begin{array}{l}\text { Auswaschung von Schwerme- } \\
\text { tallen }\end{array}$ & Auswirkungen auf Algenaufwuchs & $\begin{array}{l}\text { Thies et al. (2007); Koinig et } \\
\text { al. (in Vorb.) }\end{array}$ \\
\hline $\begin{array}{l}\text { Rückschmelzen der } \\
\text { Gletscher }\end{array}$ & $\begin{array}{l}\text { Abschmelzen der Gletscher; } \\
\text { Verringerung der Gletscherbach- } \\
\text { zonen (Kryal }<4^{\circ} \mathrm{C} \text { ) }\end{array}$ & $\begin{array}{l}\text { Rückgang der Gletscherbach-Algengemein- } \\
\text { schaften (z.B. kryale Diatomeen }\end{array}$ & $\begin{array}{l}\text { Jakobsen et al. (2012); Rott et } \\
\text { al. (2010) }\end{array}$ \\
\hline $\begin{array}{l}\text { Verlängerung der Vege- } \\
\text { tationsperiode }\end{array}$ & $\begin{array}{l}\text { Störung der Interaktionen } \\
\text { zwischen Algennischen und her- } \\
\text { bivoren Insektenlarven („Grazer") }\end{array}$ & $\begin{array}{l}\text { Makroalgen gefördert und Aufwuchs in } \\
\text { Zusammensetzung verändert; Eutrophierung } \\
\text { (Überdüngung) }\end{array}$ & $\begin{array}{l}\text { Perkinsen et al. (2010); Ueh- } \\
\text { linger (2000) }\end{array}$ \\
\hline $\begin{array}{l}\text { Verringerter Nieder- } \\
\text { schlag }\end{array}$ & $\begin{array}{l}\text { Verringerte Erneuerung und Um- } \\
\text { lagerung der Bettsedimente }\end{array}$ & $\begin{array}{l}\text { Verringerung der Diversitäts-/Mikrohabitat- } \\
\text { vielfalt (insbes. epilithische Formen in Berg- } \\
\text { bächen); Makroalgenmassenentwicklungen } \\
\text { bei gleichzeitiger Temperaturerhöhung; } \\
\text { Neophyten werden begünstigt }\end{array}$ & $\begin{array}{l}\text { Coste und Ector (2000); } \\
\text { Ellwood und Whitton (2007); } \\
\text { Falasco und Bona (2013) }\end{array}$ \\
\hline Erhöhter Niederschlag & $\begin{array}{l}\text { Erhöhte Nährstoffauswaschung } \\
\text { aus Feuchtgebieten - Anreichung } \\
\text { DOC und organischer Phosphate } \\
\text { im Frühiahr und Herbst; erhöhter } \\
\text { Ferntransport von Nitraten }\end{array}$ & $\begin{array}{l}\text { Massenentwicklung Phosphatasenbildender } \\
\text { Taxa, Nitratanreichung bewirkt Verringerung } \\
\text { von Stickstoff-Fixierern; verringerte biogene } \\
\text { Kalkfällung durch pH-Verschiebung }\end{array}$ & $\begin{array}{l}\text { Ellwood und Whitton (2007); } \\
\text { Rott et al. (2012); Whitton und } \\
\text { Neal (2011) }\end{array}$ \\
\hline $\begin{array}{l}\text { Starkregenereignisse } \\
\text { im Sommer werden } \\
\text { häufiger }\end{array}$ & $\begin{array}{l}\text { Erhöhte Umlagerung der Bettse- } \\
\text { dimente, erhöhte anorganische } \\
\text { Frachten }\end{array}$ & $\begin{array}{l}\text { Abrieb der Bettsedimente bewirkt geringeres } \\
\text { Algenwachstum, Selektion zu abrieb-resili- } \\
\text { enten Arten }\end{array}$ & Uehlinger (2000) \\
\hline
\end{tabular}

Klimawandelrelevante funktionale Rolle im ökosystemaren Kontext

Gewässeralgen stellen eine wesentliche Nahrungsgrundlage für kleintierische Organismen in Gewässern (insbesondere Zooplankton bzw. Zoobenthos) dar, die wiederum eine wesentliche Nahrungsgrundlage für Fische sind. Da die steuernden Bedingungen für Algen aus dem Phytoplankton (freies Wasser) und Algenaufwuchs (Gewässergrund) teils unterschiedlich sind, sollten die beiden Lebensgemeinschaften differenziert betrachtet werden (Meyer et al., 1999; Perkins et al., 2010; Tabelle 3.1 bzw. 3.2).

Für Niederungs-(=Tiefland-)Seen liegen sehr genaue Datenreihen und Modelle zu jahreszeitlichen Nischen und Abfolgen des Phytoplanktons vor (Adrian et al., 2009), die ganz wesentlich durch Temperatur und Mischungstiefe gesteuert werden. Algen im Hochgebirge sind zwar oft nur in geringen
Mengen bzw. nur während kurzer Zeitperioden in größeren Mengen (Rott et al., 2006) vorhanden, stellen dennoch eine wesentliche Nahrungsgrundlage bzw. Lebensraum für benthische Zoozönosen dar. Algen im Hochgebirge reagieren empfindlich auf qualitative Veränderungen des Niederschlages (Ferntransport von Nährstoffen und Feinstaub; Stickstoffanreicherung) und sind gleichzeitig überwiegend oligotroph (benötigen nährstoffarme Bedingungen) und daher z. B. durch vermehrte Bildung von intra- bzw. extrazellulären Phosphatasen als Verwerter von organischen Phosphaten (Rott et al., 2000; Whitton und Neal, 2011) charakterisiert.

\section{Sensitivität in Bezug auf Klimavariable}

Aquatische Algenarten sind vergleichsweise gut erforscht und reagieren sowohl rasch als auch spezifisch auf Umweltänderungen. Daher sind Algengemeinschaften aus Gewässern für die 
Tabelle 3.3 Beispiele von prognostizierten und bereits belegten Auswirkungen des Klimawandels auf pathogene Pilze an Waldbäumen (Desprez-Loustau et al., 2006; Engesser et al., 2008; La Porta et al., 2008; Lindner et al., 2008; Kliejunas et al., 2009; Jung et al., 2009; Sturrok et al., 2012). Quelle: Kirisits (2010), erweitert und verändert. Direkte oder indirekte Wirkung auf Krankheitserreger: $(+)=$ positive Wirkung auf Pilze (höhere Krankheitsintensität), $(-)=$ negative Wirkung auf Pilze (niedrigere Krankheitsintensität); KE = Krankheitserreger Table 3.3 Examples of predicted and observed impacts of climate change on pathogenic fungi on forest trees (Source: Kirisits, 2010, extended and modified). $(+)$ = positive impact on fungi (higher disease intensity on trees), $(-)=$ negative impact on fungi (lower disease intensity on trees); $\mathrm{KE}=$ pathogenic organism

\begin{tabular}{|c|c|c|}
\hline Klimaparameter & Wirkung (+/-) & Auswirkungen mit Beispielen \\
\hline \multirow{8}{*}{$\begin{array}{l}\text { Klimawandel } \\
\text { (generell) }\end{array}$} & + & Auftreten neuer KE durch Einschleppung und Arealausweitung \\
\hline & - & Arealveränderungen von KE \\
\hline & - & $\begin{array}{l}\text { Direkter Einfluss auf Lebenszyklen von KE (Anzahl an Lebenszyklen/Jahr, Zyklendauer, Wachstums- } \\
\text { und Überlebensraten, Phänologie, Sporulation, Infektionsbedingungen) }\end{array}$ \\
\hline & + & Veränderung des Areals und der Widerstandsfähigkeit von Wirtsbäumen gegenüber KE \\
\hline & + & Entstehung von Eintrittspforten für KE an ihren Wirtspflanzen (Wunden) \\
\hline & + & Einfluss auf Antagonisten (Gegenspieler) von KE \\
\hline & + & Einfluss auf Zwischenwirte und Alternativwirte von KE \\
\hline & + & Einfluss auf Insekten als Überträger von KE \\
\hline \multirow[t]{13}{*}{$\begin{array}{l}\text { Höhere Tempe- } \\
\text { raturen }\end{array}$} & + & $\begin{array}{l}\text { Größere Wahrscheinlichkeit der Einschleppung/Etablierung gebietsfremder KE, v. a. auch aus wärme- } \\
\text { ren Klimazonen }\end{array}$ \\
\hline & + & $\begin{array}{l}\text { Horizontale und vertikale Arealausweitungen oder -verschiebungen heimischer (Heterobasidion abie- } \\
\text { tinum), eingeschleppter (Phytophthora cinnamomi und andere Phytophthora-Arten, Mycosphaerella } \\
\text { dearnessii, Mycosphaerella pini, Giberella circinata) und südeuropäischer KE (Biscogniauxia mediterra- } \\
\text { nea, Diplodia pinea) }\end{array}$ \\
\hline & - & Horizontale und vertikale Arealverkleinerungen, v.a. von kälteliebenden KE (Gremmeniella abietina) \\
\hline & - & $\begin{array}{l}\text { Geringere Befallshäufigkeit und -intensität durch kälteliebende Pilze und damit vermindertes Risiko } \\
\text { von intensiven Epidemien (Gremmeniella abietina) }\end{array}$ \\
\hline & + & Höhere Überlebensrate im Winter (Phyophthora cinnamomi) \\
\hline & + & $\begin{array}{l}\text { Direkter Einfluss auf Lebenszyklen von KE (Anzahl an Lebenszyklen/Jahr, Zyklendauer, Wachstums- } \\
\text { und Überlebensraten, Phänologie, Sporulation, Infektionsbedingungen), z. B. Steigerung der Sporulati- } \\
\text { on und Infektionshäufigkeit von Heterobasidion spp., erhöhte Rate der Freisetzung von Ascosporen bei } \\
\text { Cryphonectria parasitica }\end{array}$ \\
\hline & + & $\begin{array}{l}\text { Verlängerung und Erhöhung der sporotrophen und parasitischen Aktivität bei höheren Temperaturen } \\
\text { (v.a. außerhalb der Vegetationszeit), dadurch höhere Befallsintensitäten (viele KE; Armillaria spp., My- } \\
\text { cosphaerella pini, Phytophthora cinnamomi und andere Phytophthora-Arten, Gremmeniella abietina) }\end{array}$ \\
\hline & + & $\begin{array}{l}\text { Höhere Befallsintensität der Holländischen Ulmenwelke (Erreger: Ophiostoma novo-ulmi) bei höheren } \\
\text { Temperaturen (in künstlichen Inokulationsversuchen) }\end{array}$ \\
\hline & + & $\begin{array}{l}\text { Höhere Befallsintensität an flussbegleitenden Erlen durch Phytophthora alni bei höheren Wassertem- } \\
\text { peraturen }\end{array}$ \\
\hline & + & $\begin{array}{l}\text { Arealausweitung, schnellere Entwicklung und mehr Generationen / Jahr der Überträger (Scolytus- } \\
\text { Arten, Ulmensplintkäfer) des Ulmenwelke-Erregers Ophiostoma novo-ulmi }\end{array}$ \\
\hline & + & $\begin{array}{l}\text { Schnellere Entwicklung und mehr Generationen / Jahr von rindenbrütenden Borkenkäfern (v.a. } \\
\text { Buchdrucker [lps typographus] an Fichte); dadurch indirekte Förderung assoziierter, von den Käfern } \\
\text { übertragenen pathogenen Bläuepilzen (Ophiostoma spp., Grosmannia spp., Ceratocystis spp.) }\end{array}$ \\
\hline & - & $\begin{array}{l}\text { Förderung der Aktivität und Konkurrenzkraft des Riesen-Rindenpilzes (Phlebiopsis gigantea), eines Ant- } \\
\text { agonisten von Heterobasidion spp.; dadurch möglicherweise Steigerung der Effizienz der biologischen } \\
\text { Kontrolle des Wurzelschwamms (Behandlung der Baumstöcke nach der Fällung mit einer Sporensus- } \\
\text { pension von Phlebiopsis gigantea) }\end{array}$ \\
\hline & - & Effektivere Übertragung des Hypovirulenz-Virus bei Cryphonectria parasitica \\
\hline
\end{tabular}




\begin{tabular}{|c|c|c|}
\hline Klimaparameter & Wirkung (+/-) & Auswirkungen mit Beispielen \\
\hline \multirow[t]{4}{*}{$\begin{array}{l}\text { Höhere Nieder- } \\
\text { schläge }\end{array}$} & + & $\begin{array}{l}\text { Förderung der Sporulation, günstige Infektionsbedingungen, mehrere Lebenszyklen pro Jahr bei KE } \\
\text { mit sekundären Krankheitszyklen (viele KE, u.a. Nadelpilze [z.B. Mycosphaerella pini, Lophodermium } \\
\text { seditiosum, Mycosphaerella laricina, Hypodermella laricis, Meria laricis und viele andere], Blattpilze } \\
\text { [Apiognomonia errabunda] Triebsterbenspilze [Gremmeniella abietina, Hymenoscyphus fraxineus] und } \\
\text { Phytophthora-Arten ) }\end{array}$ \\
\hline & + & Größere Wahrscheinlichkeit der Einschleppung / Etablierung gebietsfremder KE \\
\hline & + & $\begin{array}{l}\text { Arealausweitungen oder -verschiebungen heimischer, gebietsfremder KE (Mycosphaerella pini) und } \\
\text { südeuropäischer Arten }\end{array}$ \\
\hline & - & Erhöhung der Widerstandsfähigkeit von Wirtsbäumen gegenüber KE \\
\hline $\begin{array}{l}\text { Geringere Nie- } \\
\text { derschläge }\end{array}$ & - & Hemmung der Sporulation, ungünstige Infektionsbedingungen (viele KE) \\
\hline \multirow[t]{4}{*}{$\begin{array}{l}\text { Trocken- und } \\
\text { Hitzeperioden }\end{array}$} & + & $\begin{array}{l}\text { Schwächung der Wirtsbäume, erhöhte Anfälligkeit gegenüber KE bzw. raschere Ausbreitung von KE } \\
\text { in Geweben bereits infizierter Bäume (viele KE, Armillaria spp., Heterobasidion spp., Diplodia pinea, } \\
\text { Cryptostroma corticale, Phytophthora spp., Phacidium coniferarum) }\end{array}$ \\
\hline & + & $\begin{array}{l}\text { Prädisponierung lebender Bäume für den Befall durch rindenbrütende Borkenkäfer (v. a. Buchdrucker } \\
\text { [lps typographus] an Fichte); dadurch indirekte Förderung assoziiierter, von den Käfern übertragenen } \\
\text { pathogenen Bläuepilzen (Ophiostoma spp., Grosmannia spp., Ceratocystis spp.) }\end{array}$ \\
\hline & + & $\begin{array}{l}\text { Bei latenten KE Auslöser des Wechsels von endophytischem zu pathogenem Verhalten (z. B. Diplo- } \\
\text { dia pinea, Cryptostroma corticale, Cenangium ferruginosum, Apiognomonia quercina, Biscogniauxia } \\
\text { nummularia) }\end{array}$ \\
\hline & + & $\begin{array}{l}\text { Häufig Auslöser von Komplexkrankheiten unter Beteiligung pathogener Pilze (z. B. Eichensterben: } \\
\text { Armillaria spp., Phytophthora spp., Erysiphe alphitoides) }\end{array}$ \\
\hline \multirow{3}{*}{$\begin{array}{l}\text { Kürzere Schnee- } \\
\text { bedeckung } \\
\text { und geringere } \\
\text { Schneehöhen }\end{array}$} & + & $\begin{array}{l}\text { Erhöhte Infektionsrate von Stöcken durch H. annosum aufgrund verkürzter Zeiträume der Bedeckung } \\
\text { der Stöcke mit Schnee }\end{array}$ \\
\hline & - & $\begin{array}{l}\text { Schnee als entscheidender epidemiologischer Faktor bei einigen Krankheitserregern in Hochlagen } \\
\text { (Schneeschimmel-Pilze [Herpotrichia juniperi, Neopeckia coulteri, Phacidum infestans] sowie Gremme- } \\
\text { niella abietina an Pinus cembra), Befallshäufigkeit und -intensität werden bei kürzerer Schneebede- } \\
\text { ckung und geringeren Schneehöhen in Zukunft sinken }\end{array}$ \\
\hline & - & $\begin{array}{l}\text { Geringere Häufigkeit und Intensität des Befalls von Fichten durch den Fichtennadelrost (Chrysomyxa } \\
\text { ledi var. rhododendri) mittels indirekter Wirkung auf die Dikaryontenwirte (Rhododendon spp.); diese } \\
\text { sind frostempfindlich und werden bei kürzeren Zeiträumen der Schneebedeckung im Gebirge ver- } \\
\text { mehrt durch Frost geschädigt, wodurch auch der Rostpilz (überwinternde Teleutolager auf den Blättern } \\
\text { der Alpenrosen!) geschädigt und der Infektionsdruck verringert wird }\end{array}$ \\
\hline \multirow[t]{3}{*}{$\begin{array}{l}\text { Häufigere und } \\
\text { intensivere } \\
\text { Sturm- und } \\
\text { Schneebruch- } \\
\text { ereignisse }\end{array}$} & + & $\begin{array}{l}\text { Windwurfkalamitäten sind Schlüsselfaktoren für die Entwicklung von Borkenkäferepidemien (v. a. } \\
\text { Buchdrucker [lps typographus] an Fichte); auch Schneebruchereignisse können für deren Populati- } \\
\text { onsdynamik von großer Bedeutung sein; dadurch indirekte Förderung assoziierter, von den Käfern } \\
\text { übertragenen pathogenen Bläuepilzen (Ophiostoma spp., Grosmannia spp., Ceratocystis spp.) }\end{array}$ \\
\hline & + & $\begin{array}{l}\text { Schaffung von Eintrittspforten (Wunden) für KE (Wurzel- [Heterobasidion spp.] und Stammfäuleerreger } \\
\text { [z. B. Stereum sanguinolentum]) }\end{array}$ \\
\hline & + & $\begin{array}{l}\text { Schwächung der Wirtsbäume, dadurch erhöhte Anfälligkeit gegenüber KE bzw. raschere Ausbreitung } \\
\text { von KE in Geweben bereits infizierter Bäume (Heterobasidion spp., Armillaria spp.) }\end{array}$ \\
\hline \multirow[t]{3}{*}{$\begin{array}{l}\text { Häufigere und } \\
\text { intensivere Ha- } \\
\text { gelereignisse }\end{array}$} & + & $\begin{array}{l}\text { Schaffung von Eintrittspforten (Wunden) für KE (Erreger von Rindenerkrankungen und Baumkrebsen } \\
\text { [Diplodia pinea, Neonectria ditissima, andere Neonectria- und Nectria-Arten], Stammfäule-Erreger } \\
\text { [z. B. Stereum sanguinolentum]) }\end{array}$ \\
\hline & + & $\begin{array}{l}\text { Schwächung der Wirtsbäume, dadurch erhöhte Anfälligkeit gegenüber KE bzw. raschere Ausbreitung } \\
\text { von KE in Geweben bereits infizierter Bäume (Heterobasidion spp., Armillaria spp.) }\end{array}$ \\
\hline & + & $\begin{array}{l}\text { Prädisponierung lebender Bäume für den Befall durch sekundäre rinden- und holzbrütende Insekten } \\
\text { (v. a. Borkenkäfer, Bockkäfer, Holzwespen); dadurch indirekte Förderung assoziierter, von den Insekten } \\
\text { übertragenen pathogenen Pilzen (Holzfäule-Erreger [Amylostereum areolatum, Amylostereum chailletii] } \\
\text { und Bläuepilze [Ophiostoma spp., Grosmannia spp., Ceratocystis spp.]) }\end{array}$ \\
\hline \multirow{2}{*}{$\begin{array}{l}\text { Überschwem- } \\
\text { mungen }\end{array}$} & + & Förderung der Sporulation, günstige Infektionsbedingungen (Phytophthora alni, Phytophthora spp.) \\
\hline & + & $\begin{array}{l}\text { Schwächung der Wirtsbäume, erhöhte Anfälligkeit gegenüber KE (Phytophthora alni, Phytophthora } \\
\text { spp., Armillaria spp.) }\end{array}$ \\
\hline
\end{tabular}


Bewertung von Auswirkungen des Klimawandels prinzipiell gut geeignet.

Die Sensitivität des Phytoplanktons in Bezug auf Temperaturerwärmung ist besonders gut abschätzbar (Nöges et al., 2010), obwohl andere steuernde Faktoren, insbesondere hydrologische Faktoren zeitweise von größerer Bedeutung sind (siehe Dokulil und Teubner, 2005; Thies et al. 2011; Band 2, Kapitel 2). Detaillierte Sensitivitäten für Plankton- und Aufwuchsalgen in Bezug auf ausgewählte Klimavariablen sind in Tabellen 3.1 und 3.2 überblicksweise dargestellt.

\section{Klimawandelfolgen in Österreich}

Klimaszenarien mit fortschreitender Temperaturerhöhung, steigenden maximalen Sommertemperaturen und verlängerten sommerlichen Trockenperioden (vgl. Band 1) können Veränderungen im Phytoplankton bewirken, die zum Teil bereits zu beobachten sind. In großen tiefen Voralpen- und Alpenseen ist bei langfristiger klimatischer Erwärmung und vor allem mit höheren sommerlichen Temperaturmaximalwerten die neuerliche Dominanz von toxinbildenden Cyanobakterien (wie vor der Abwassersanierung der Seen, siehe Dokulil und Teubner, 2012; Ostermayer et al., 2012) zu erwarten. Zunehmende Cyanobakterien-Massenentwicklungen sind besonders auch für die Spätsommer- und Frühherbstsituation in flachen Bereichen größerer Seen bzw. in kleineren Seen sehr wahrscheinlich (Beispiele dazu: u. a. Dokulil und Mayer, 1996; Fresner et al., 1998).

Im Hochgebirge nimmt zwar der Artenreichtum an Phytoplankton mit der Höhenlage ab (Stomp et al., 2011), gleichzeitig nimmt aber der Anteil spezifisch angepasster Arten in Plankton und Aufwuchs zu: insbesondere kalt-stenotherme Arten, die bisher noch wenig untersucht wurden, dominieren (Flaim et al., 2010; Klaveness und Lindstroem, 2011; Obertegger et al., 2011). Es ist zu erwarten, dass diese Arten mit zunehmender Wassererwärmung stark zurückgedrängt werden. Die Veränderungen durch Klimaerwärmung in Hochgebirgsseen sind vielfach mit komplexen Prozessen verbunden. So bewirkt verringerter Sommerniederschlag z. B. die Verringerung des DOC (dissolved organic carbon compounds) und eine Zunahme der UV Strahlung (Psenner, 2002; Sommaruga et al., 1999).

Da Langzeitdatensätze für das Hochgebirgs-Phytoplankton selten und die Auswirkungen oft von mehreren Faktoren gesteuert sind (Battarbee et al., 2002; Beardall und Stojkovic, 2006; Koinig et al., 1998; Psenner, 2002; SommarugaWögrath et al., 1997; Sommaruga et al. 1999) ist der Einbezug von paläoökologischen Untersuchungen für die Erstellung von Prognosen von Auswirkungen verschiedener Klimaszenarien auf Algengemeinschaften als Stellvertreter für die Lebewelt unabdingbar (Battarbee, 2002). Jüngste paläolimnologische Untersuchungen der Diatomeen-Gesellschaften in alpinen Seen in den Niederen Tauern weisen darauf hin, dass die Einwanderung einzelner opportunistischer Arten bereits heute durch Klimaerwärmung begünstig wird, während die Reaktionen der heimischen Arten oft habitatspezifisch unterschiedlich ausfallen (Catalan et al., 2013; Weckström et al., in Vorb.).

Für Fließgewässer-Aufwuchsalgen in Niederungen sind neben Artverschiebungen durch Temperaturzunahme (Verdrängung von Kaltwasserformen) und $\mathrm{CO}_{2}$ Anreicherung insbesondere hydrologische Veränderungen für den Nährstoffumsatz und die Steuerung von Nahrungsnetzen von Bedeutung (Uehlinger 2000, Tabelle 3.2). Dabei sollten insbesondere auch vermehrt Effekte der periodischen Austrocknung, wie diese für zentral- und südalpine Bereiche Österreichs prognostiziert werden, eine Rolle spielen. Da ökophysiologische Untersuchungen zu speziellen Nischen des Algenaufwuchses erst neueren Datums sind (Ellwood und Whitton 2007; Klaveness und Lindstroem, 2011; Rott et al., 2006; Rott et al., 2010, 2012; Uehlinger et al., 2011), liegen nur wenige Unterlagen für die Abschätzung von Klimawandelfolgen auf den Algenaufwuchs vor, wenn auch zum Teil ähnliche Veränderungen (z. B. Zunahme von Jochalgen) wie in arktischen Gebieten zu erwarten sind. Auf Grund der Spezifität der Lebewelt in schwach gepufferten Grundwasseraustritten und Quellen im Gebirge (Rott et al., 2010, Rott, unpubl. Daten) sowie die Zurückdrängung von Permafrostgebieten (u.a. von Blockgletschern) sind gravierende Auswirkungen auf die Artenzusammensetzung des Algenaufwuchses zu erwarten. Für Fließgewässer der Niederungen ist für Österreich vermehrte Einwanderung von opportunistischen Kieselalgen-Arten in Folge von Klimaerwärmung zu beobachten, wie das schon vielfach aus anderen Teilen Europas berichtet wurde (u. a. Coste und Ector, 2000).

\subsubsection{Pilze und pilzähnliche Organismen}

\section{Abgrenzung und Charakterisierung}

Pilze und pilzähnliche Organismen umfassen eine Reihe nicht näher miteinander verwandter, Gruppen eukaryontischer (das sind Lebewesen, deren Zellen einen Zellkern besitzen), kohlenstoffheterotropher (d. h. auf organische Kohlenstoffverbindungen, die von anderen Lebewesen oder von totem Substrat bezogen werden, angewiesene) Lebewesen (Dörfelt und Ruske, 2008; Krisai-Greilhuber und Kraus, 2013). Im engeren Sinne betrachtet man heute ausschließlich die Echten Pilze (Fungi), die einen einheitlichen Verwandtschaftskreis darstel- 
len und ca. 100000 beschriebene Arten umfassen, als Pilze. Der Großteil der Echten Pilze gehört zu den Abteilungen der Ascomycota (Schlauchpilze, inklusive der meisten anamorphen Pilze, von denen man kein geschlechtliches Stadium kennt; ca. 64000 Arten weltweit) und Basidiomycota (Ständerpilze; ca. 31000 Arten weltweit; vgl. Raven et al., 2000; Dörfelt und Ruske, 2008; Krisai-Greilhuber und Kraus, 2013). Von den verschiedenen Gruppen pilzähnlicher Organismen sind vor allem die Oomyceten (Eipilze, ca. 1000 Arten weltweit), von denen zahlreiche Arten Krankheiten an Pflanzen und Bäumen und einige auch an Tieren verursachen, für den vorliegenden Band von Relevanz (Tabelle 3.3; z. B. Phytophthora spp.; Raven et al., 2000; Dörfelt und Ruske, 2008; Butin, 2011). Nach einer Abfrage vom 8. Mai 2013 umfasst der Datenbestand der „Datenbank der Pilze Österreichs“ (Dämon und KrisaiGreilhuber, 2012; Österreichische Mykologische Gesellschaft [ÖMG], 2013) derzeit 8000 Pilztaxa (praktisch ausschließlich Großpilze, deren Fruchtkörper mit freiem Auge erkennbar sind), wobei Basidiomyceten mit rund $65 \%$ am häufigsten und Ascomyceten mit $27 \%$ auch noch relativ häufig vertreten sind.

\section{Funktionale Rolle im ökosystemaren Kontext}

Nach ihrer Ernährungsweise und Rolle im Ökosystem lassen sich drei Gruppen von Pilzen unterscheiden: Saprobionten, Parasiten und Symbionten (Raven et al., 2000; Dörfelt und Ruske, 2008; Senn-Irlet et al., 2012).

- Saprobionten (Zersetzer, Destruenten) bauen abgestorbenes, organisches Material ab und sind daher von großer ökologischer Bedeutung (Dörfelt und Ruske, 2008). Sie führen „Abfälle“, beispielsweise Totholz, Pflanzenreste und Tierkadaver, in den natürlichen Stoffkreislauf zurück und bilden damit wichtige Glieder in den Nahrungsketten. Pilze können praktisch alle von Lebewesen gebildeten Substanzen abbauen und halten damit die Stoffkreisläufe auf der Erde in Bewegung. Manche Substrate, beispielsweise Holz, werden praktisch ausschließlich von bestimmten, spezialisierten Pilzarten - vorwiegend Basidiomyceten - abgebaut (Butin, 2011). Pilze sind daher gemeinsam mit Bakterien die wichtigsten natürlichen Kohlenstoff-Quellen der Biosphäre und wichtige klimarelevante Systemelemente (Kauserud et al., 2012).

- Parasiten unter den Pilzen ernähren sich von der organischen Substanz lebender Organismen (Raven et al., 2000; Dörfelt und Ruske, 2008). Viele parasitische Pilze sind Krankheitserreger an Pflanzen und Tieren, die ihre Wirtsorganismen schädigen, oft sogar töten und dadurch enor- me sozioökonomische Verluste verursachen. An Pflanzen und Bäumen sind sie die bedeutendste Gruppe von $\mathrm{Pa}$ thogenen, sowohl hinsichtlich der Anzahl an Erregern als auch der Summe an Schädigungen und Verlusten, die sie verursachen (Butin, 2011). Sie sind daher ein wichtiger Teil der Störungsregime in natürlichen wie vom Menschen beeinflussten Ökosystemen und beeinflussen deren Dynamik. Durch die Schädigung ihrer Wirtspflanzen, die im Extremfall zu deren Absterben führen kann, beeinflussen sie indirekt den Kohlenstoffkreislauf der Erde.

- Eine besondere Gruppe von Parasiten sind endophytische Pilze, die zumindest eine Zeit lang Organe von Pflanzen besiedeln ohne Krankheitssymptome zu verursachen. Manche Krankheitserreger können längere Zeit, oft jahrelang, endophytisch in Pflanzengeweben ihrer Wirtspflanzen überdauern, ehe sie, zumeist ausgelöst durch extreme Witterungsereignisse, pathogenes Verhalten zeigen und ihre Wirte schädigen (Butin, 2011). Solche Erreger werden auch als latente Pathogene bezeichnet. Symbionten gehen mit anderen Organismen eine Lebensgemeinschaft ein, aus der beide Partner Nutzen ziehen (= mutualistische Symbiose). Die bekanntesten Symbiosen mit Pilz. B. teiligung sind die Flechten und die Mykorrhiza, die Vergesellschaftung von Pflanzenwurzeln mit Pilzen (Raven et al., 2000; Dörfelt und Ruske, 2008; Egli und Brunner, 2011; Senn-Irlet et al., 2012). Über $80 \%$ aller bekannten Gefäßpflanzen, darunter die überwiegende Mehrzahl der Gehölze, sind mit Mykorrhizapilzen assoziiert. Mykorrhizapilze sind in terrestrischen Ökosystemen von hervorragender Bedeutung für die Effizienz der Wasserund Nährstoffaufnahme von Pflanzen, beeinflussen ihr Wachstum und ihre Produktivität und damit auch ihre Rolle als Kohlenstoffspeicher (Egli, 2011; Egli und Brunner, 2011; Büntgen et al., 2012; Senn-Irlet et al., 2012).

\section{Sensitivität in Bezug auf Klimavariable}

So wie bei anderen Organismengruppen ist das Wissen über die Klimasensitivität von Pilzen fragmentarisch. Neben der Witterung werden Pilze durch andere Umwelteinflüsse wie Luftverschmutzung und Nährstoffeinträge sowie durch Habitatzerstörung (z. B. dem Fehlen von Alt- und Totholz in Waldökosystemen) stark beeinflusst. In Waldökosystemen wirken sich erhöhte Stickstoffeinträge etwa negativ auf Mykorrhizapilze aus, während die Anzahl an Pilzarten und die Menge an Fruchtkörpern nach einer Durchforstung stark ansteigen können (Egli, 2011; Senn-Irlet et al., 2012). Ein methodisches Problem bei der Analyse der Sensitivität von Pilzen in 
Bezug auf klimatische Faktoren besteht darin, dass ihre Aktivität und ihr Wachstum zumeist nur indirekt abgeschätzt werden können. Das Vorkommen, die Häufigkeit, Aktivität und Phänologie von Großpilzen werden überwiegend aufgrund des Erscheinens und der Anzahl von Fruchtkörpern beurteilt (Büntgen et al., 2012; Kauserud et al., 2012), wenn man von pathogenen Arten, insbesondere Mikropilzen absieht, deren Auftreten in erster Linie aufgrund von Krankheitssymptomen und der Diagnose der Schädigungsursache dokumentiert werden kann (Kirisits, 2010; Butin, 2011).

Alle Pilze werden durch Witterungsfaktoren - vor allem Niederschläge und Temperatur - beeinflusst, entweder direkt oder indirekt. Obligate Parasiten (z. B. Rostpilze und Echte Mehltaupilze) und obligate Mykorrhizapilze, vor allem solche, die nur zusammen mit einer Wirtspflanze vorkommen, sind in ihren Lebenszyklen streng an ihre Wirte gebunden (Egli, 2011; Büntgen et al., 2012; Senn-Irlet et al., 2012). Klimabedingte Verschiebungen des Areals und der Häufigkeit ihrer Wirtspflanzen werden daher parallele Areal- und Häufigkeitsverschiebungen der assoziierten Pilze nach sich ziehen.

Klimatische Faktoren beeinflussen Pilzarten auch direkt, z. B. wirken sich Niederschlag und Temperatur maßgeblich auf die Bildung von Pilzfruchtkörpern aus. Während ausreichend hohe Niederschläge während der Pilzsaison eine Voraussetzung für die Fruchtkörperbildung sind, werden der Zeitpunkt und der Zeitraum des Auftretens von Pilzfruchtkörpern von der Temperatur gesteuert (Büntgen et al., 2012; Senn-Irlet et al., 2012). Bei der Analyse von saprotrophen und mykorrhizabildenen Pilzarten mit kurzlebigen Fruchtkörpern (Ordnungen Agaricales, Boletales, Cantharellales und Russulales) in Großbritannien und Nordirland, Norwegen, Österreich und der Schweiz wurde festgestellt, dass sich der Zeitraum der Fruchtkörperbildung bei vielen Pilzen von 1970 bis 2007 verlängert und innerhalb des Jahreskreislaufs (die Pilzsaison ist definiert von März bis Februar des Folgejahres) auf später verschoben hat (Kauserud et al., 2012). In einem Pilzreservat in der Schweiz wurde die Verschiebung der Pilzsaison im Zeitraum von 1975 bis 2006 auf insgesamt rund 12 Tage geschätzt (Senn-Irlet et al., 2012). Die Veränderung und Ausdehnung der Pilzsaison wird auf den Temperaturanstieg seit 1970 und der damit verbundenen Verlängerung der Wachstumsperiode der Pilzmycelien zurückgeführt. Darüber hinaus wird der verlängerte Zeitraum der Fruchtkörperbildung im Herbst und Winter durch den in allen vier Ländern beobachteten Trend des späteren Auftretens von Frost erklärt (Kauserud et al., 2012). In Süd-England wird ferner seit den 1970er Jahren beobachtet, dass manche Pilzarten während zweier Perioden im Jahr fruktifizieren, anstatt wie früher nur einmal jährlich
(Gange et al., 2007), ähnliche Entwicklungen sind in Mitteleuropa bisher aber nicht dokumentiert.

In den letzten Jahren wurden wärmeliebende, seltene Pilzarten mit südeuropäischem Verbreitungsschwerpunkt, beispielsweise der Kaiserling (Amanita caesarea), vermehrt in Österreich gefunden (ÖMG, 2013). Viele Gebirgsarten, die an kühlere Klimabedingungen angepasst sind, scheinen dagegen seltener zu werden (I. Krisai-Greilhuber, persönliche Mitteilung). Diese pilzfloristischen Befunde können als bereits jetzt beobachtbare Auswirkungen einer Temperaturerhöhung interpretiert werden.

Pflanzenpathogene Pilze werden ebenfalls in vielfältiger Weise, direkt und indirekt, durch Witterungsfaktoren beeinflusst. Umweltfaktoren modifizieren den Grad der Anfälligkeit von Wirtsbäumen gegenüber Pathogenen und die Fähigkeit von Pathogenen ihre Wirte zu besiedeln und Krankheiten bei ihnen hervorzurufen. Dazu kommen häufig noch biotische Umweltfaktoren, beispielsweise Insekten als Überträger von Krankheitserregern oder Antagonisten, die Krankheitserreger hemmen und ebenfalls dem Einfluss von Klimaparametern unterliegen. Die Bedeutung von Klimafaktoren variiert stark, bei manchen Krankheiten, beispielsweise vielen Nadel-, Blatt-, Trieb-, Rinden- und Wurzelerkrankungen sind sie Schlüsselfaktoren bei der Entstehung einer Epidemie, bei anderen sind sie von geringerer Bedeutung (Desprez-Loustau et al., 2006; Kliejunas et al., 2009; Butin, 2011).

\section{Klimawandelfolgen in Österreich}

Da die Verbreitung und Häufigkeit von Pilzen maßgeblich von Klimafaktoren und jene von parasitischen Arten und Mykorrhizapilzen von ihren Wirtsbaumarten beeinflusst werden, sind lokale und regionale Veränderungen in der Pilzflora hinsichtlich des Auftretens und der Häufigkeit von Arten sowohl unter wärmer-feuchteren als auch unter wärmer-trockeneren Klimawandelszenarien wahrscheinlich. Es ist insgesamt mit einer Zunahme von wärmeliebenden und einem Rückgang von kälteliebenden Arten zu rechnen. Klimatisch bedingte Verschiebungen der Aktivität und des Wachstums von saprotrophen und mykorrhizabildenden Pilzen könnten große Änderungen der Kohlenstoff- und Mineralnährstoff-Kreisläufe sowie anderer Ökosystemprozesse nach sich ziehen, vor allen bei einem warm-feuchtem Klimwandelszenario (Büntgen et al., 2012; Kauserud et al., 2012). Diese Änderungen könnten noch größer sein, wenn auch holzzerstörende Pilze einbezogen werden. Aufgrund der gesteigerten Photosyntheseleistung ihrer Wirtspflanzen könnten Mykorrhizapilze vermehrt mit Kohlenstoffverbindungen versorgt werden, was bei Arten, die 


\section{Box 3.1: Eingeschleppte pathogene Pilze an Waldbäumen und Klimawandel Box 3.1: Introduced pathogenic fungi on forest trees and climate change}

Die potentiell hohe Anfälligkeit von Pflanzen und Bäumen auf gebietsfremde pathogene Pilze wird auf die fehlende Koevolution (d.h. die wechselseitige Anpassung zweier Arten über evolutionäre Zeiträume) mit den gebietsfremden Erregern zurückgeführt. Insgesamt ist zu erwarten, dass die Bedeutung eingeschleppter Krankheitserreger an Wald- und Zierbäumen in Zeiten des Klimawandels weiter zunehmen wird. Jüngstes Beispiel ist das seit 2005 in Österreich bekannte Triebsterben der Esche (Bild A), das von dem aus Asien eingeschleppten Schlauchpilz Hymenoscyphus fraxineus hervorgerufen wird. Hymenoscyphus fraxineus ist hitzeempfindlich, und die Krankheit wird durch hohe Niederschläge während der Sporulationszeit des Pilzes im Sommer gefördert. Bei einer Temperaturerhöhung und geringeren Niederschlägen während der Vegetationszeit wäre zu erwarten, dass der Infektionsdruck des Erregers zukünftig auf warm-trockenen Standorten zurückgeht. Bei wärmerer und feuchterer Witterung und insbesondere bei einer Erhöhung der Niederschläge während der Vegetationsperiode ist dagegen mit einer anhaltend hohen Krankheitsintensität zu rechnen, selbst unter der Annahme des häufigeren Auftretens von extremen Hitzeperioden im Sommer.

Auch Ophiostoma novo-ulmi ist ein aus Asien eingeschleppter aggressiver Krankheitserreger, der die Holländische Ulmenwelke (Bild B), eine tödliche Welkekrankheit, an Ulmenarten verursacht. Der Pilz wird durch Ulmensplintkäfer (Scolytus spp.) übertragen. Es ist zu erwarten, dass sich eine Temperaturerhöhung durch Arealausweitungen, schnellere Entwicklungszeiten und mehr Generationen pro Jahr positiv auf die Populationen der Käfer auswirkt. Dadurch sind eine effektivere Übertragung des Krankheitserregers durch die Käfer und vermehrt Infektion von Ulmen mit Ophiostoma novo-ulmi wahrscheinlich. Kleinflächige Vorkommen der Bergulme, die bisher kaum oder gar nicht durch die Ulmenwelke gefährdet sind, könnten in Zukunft verstärkt betroffen sein, wenn effektive Überträger, beispielsweise der Große Ulmensplintkäfer (Scolytus scolytus) in diese Gebiete einwandern.
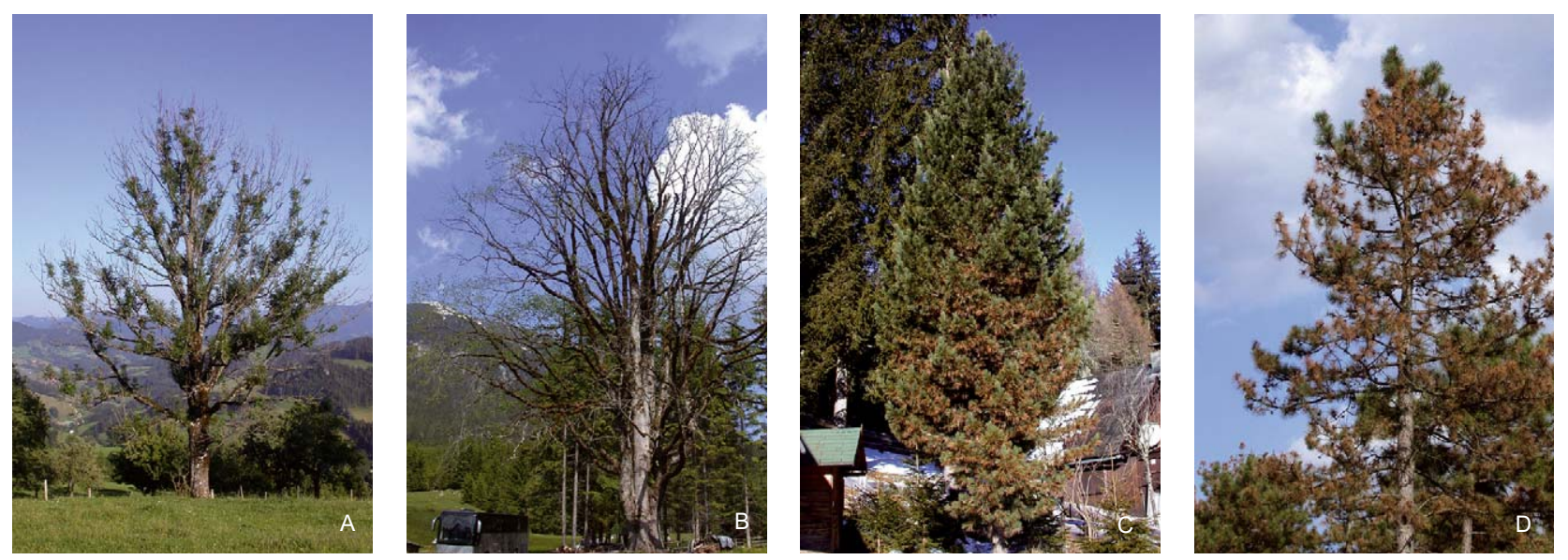

Box 3.1 Abbildung 1A-D Beispiele von wichtigen Krankheiten an Waldbäumen, die von eingeschleppten oder möglicherweise eingeschleppten pathogenen Pilzen in Österreich verursacht werden (Namen der Erreger in Klammern): A Eschentriebsterben (Hymenoscyphus fraxineus), B Holländische Ulmenwelke (Ophiostoma novo-ulmi), C Dothistroma-Nadelbräune (Dothistroma septosporum) an Zirbe, D Diplodia-Kieferntriebsterben (Diplodia pinea) an Schwarzkiefer: Aus Kirisits (2010); Kirisits und Cech (2012)

Box 3.1 Figure 1A-D Examples for important deseases in forest tree species in Austria caused by introduced pathogenic fungi (desease organism in parentheses). A ash dieback (Hymenoscyphus fraxineus), B elm desease (Ophiostoma novo-ulmi), C Dothistroma-needle rust (Dothistroma septosporum) on Pinus cembra, D Diplodia-pine shoot dieback (Diplodia pinea) on Pinus nigra. From Kirisits (2010); Kirisits and Cech (2012)

Andere eingeschleppte Krankheitserreger an Waldbäumen werden in noch stärkerem Ausmaß von Witterungsfaktoren beeinflusst. Starker Befall durch die Dothistroma-Nadelbräune (Erreger: Dothistroma septosporum; z. B. an Zirben in Österreich [Bild C]), kann durch Perioden mit hohen Niederschlägen während der Vegetationszeit und durch eine Temperaturerhöhung in den letzten Jahrzehnten erklärt werden (Woods et al., 2005). Auslösender Faktor des Diplodia-Triebsterbens an 
der Schwarzkiefer (Erreger: Diplodia pinea; Bild D) in Ostösterreich waren lang andauernde, seit 1990 wiederholt auftretende Trocken- und Hitzeperioden, welche Wirtsbäume schwächen und bewirken, dass sich der endophytisch bereits vorhandene Krankheitserreger in verschiedenen Pflanzengeweben ausbreiten und diese schädigen kann. Trockenstress der Wirtsbäume ist auch ein Schlüsselfaktor für verstärkt auftretende Schäden durch Phytophthora-Arten, beispielsweise an Rotbuche im und nach dem trockenen Jahr 2003.

zum Abbau von organischen Substanzen befähigt sind, eine Erhöhung der Zersetzungsraten und eine damit verbundene gesteigerte Freisetzung von $\mathrm{CO}_{2}$ bewirken könnte (Kauserud et al., 2012). Ausschließlich saprotroph lebende Pilze können durch eine Steigerung und eine Verlängerung ihrer Aktivität ebenfalls vermehrt organisches Material abbauen und dadurch mehr $\mathrm{CO}_{2}$ freisetzen (Kauserud et al., 2012). Die kürzlich klar dokumentierten Veränderungen der Aktivität und Produktivität von Pilzen sollten zukünftig bei der Abschätzung von Kohlenstoff-Bilanzen und anderer Ökosystemprozesse berücksichtigt werden (Büntgen et al., 2012; Kauserud et al., 2012). Die Initiierung von Experimenten zur Abschätzung solcher Effekte wäre wünschenswert.

Am Beispiel von Waldbäumen wird ersichtlich, dass forstpathologische Probleme oft überraschend auftreten, vor allem wenn Krankheitserreger eingeschleppt werden oder wenn bisher als nicht pathogen bekannte Arten aufgrund von geänderten Umweltbedingungen Krankheiten verursachen (siehe Box 3.1). Genaue Abschätzungen, welche Erreger von einer Temperaturerhöhung und anderen Klimawandelphänomenen profitieren werden, sind daher schwierig. Tabelle 3.3 listet Beispiele von prognostizierten und bereits belegten Auswirkungen des Klimawandels auf pathogene Pilze mit Fokus auf Waldbäume auf. Bei einem wärmeren und feuchteren Klima sind vor allem direkte positive Auswirkungen auf pathogene Pilze über verbesserte Sporulations- und Infektionsbedingungen zu erwarten. Bei einem wärmeren und trockeneren Klima wäre dagegen, zumindest zwischenzeitlich, mit vermehrtem Stress und mit einer Abnahme der Widerstandsfähigkeit der Wirtsbaumpopulationen gegenüber biotischen Schädigungsfaktoren zu rechnen, wovon vor allem Schwächeparasiten und latente Pathogene profitieren würden. Trocken- und Hitzeperioden haben einen ähnlichen Effekt. Ihre Häufigkeit, Intensität und Dauer in einem sich wandelnden Klima sind aber schwer abschätzbar (vgl. Band 1, Kapitel 4). Das Gleiche gilt für andere Extremereignisse (Sturm- und Schneebruch, Hagel und Überschwemmungen). Da Niederschläge zukünftig vermehrt als Regen und weniger häufig als Schnee auftreten werden, sind negative Auswirkungen auf pathogene Pilze, die direkt oder indirekt auf Schnee angewiesen sind, wahrscheinlich. Indirekte Auswirkungen des Klimawandels auf Krankheitserreger über die Einwirkung auf Antagonisten sind sehr schwer abschätzbar, da ökologische Zusammenhänge und Wechselwirkungen nur beispielhaft bekannt sind. Überträger von pathogenen Pilzen, bei denen es sich zumeist um Insekten handelt, dürften aber bei beiden Szenarien, wärmer-feuchter und wärmer-trockener, gefördert werden.

Insgesamt ist davon auszugehen, dass pathogene Organismen ein höheres Migrations- und Anpassungspotential an eine sich rasch ändernde Umwelt besitzen als ihre langlebigen Wirtsbaumarten. Auch Pilzkrankheiten an Tieren werden durch den Klimawandel gefördert (siehe Box 3.7). In Abschnitt 3.2.9 werden Pilzkrankheiten in der Landwirtschaft nochmals kurz aufgegriffen.

\subsubsection{Moose}

\section{Abgrenzung und Charakterisierung}

Moose stehen stammesgeschichtlich zwischen den Algen und den Gefäßpflanzen, es handelt sich dabei aber um keine einheitliche Verwandtschaftsgruppe. Sie werden in drei Gruppen gegliedert (Vanderpoorten und Geoffinet, 2009): Die Hornmoose (Anthoceratophyta), welche zu den allerersten Landpflanzen zählten, die Lebermoose (Marchantiophyta) und die Laubmoose (Bryophyta). Der Lebenszyklus umfasst zwei Generationen, den haploiden Gametophyten - die eigentliche, grüne Moospflanze - und den diploiden Sporophyten. Bei den Moosen erreicht demnach die haploide Phase die größte Differenzierung im gesamten Pflanzenreich. Als Relikt ihrer Abstammung sind sie in ihrer Fortpflanzung an Wasser gebunden. Die Gruppe der Moose ist in Österreich mit ca. 1070 Arten in allen Ökosystemen und Höhenstufen vertreten (Köckinger et al., 2012a). 
Klimawandelrelevante funktionale Rolle im ökosystemaren Kontext

Moose zeigen aufgrund ihrer wechselfeuchten Lebensweise eine Vielzahl an physiologischen Eigenschaften die einzigartig im Pflanzenreich sind. Diese Spezialisierungen machen sie aber auch höchst anfällig gegenüber Veränderungen, z. B. im Luftchemismus, dem atmosphärischen Nährstoffeintrag oder dem Temperatur- und Feuchtigkeitsregime.

Moose sind in Bezug auf die Funktionalität und Zusammensetzung ein wichtiger Bestandteil vieler Ökosysteme. In manchen klimarelevanten Ökosystemen (z. B. Moore) nehmen sie eine dominierende Rolle ein und machen bis zu $90 \%$ der Biomasse des Systems aus. Entsprechend groß ist ihre Stellung als $\mathrm{CO}_{2}$ Speicher. Weitere Beispiele für ihre Bedeutung sind die Regulierung der Luftfeuchtigkeit in bodennahen Bereichen (Tuba, 2011), die Einflussnahme auf das Keimverhalten vieler Pflanzen (Bates, 2009) oder ihre Rolle als Pionierpflanzen und Bodenbildner in frühen Sukzessionsstadien. Moose regulieren über ihre Fähigkeit atmosphärisch deponierte Partikel (z. B. Nährstoffe) aufzunehmen den Mineralstoffhaushalt vieler Ökosysteme (Vanderpoorten und Geoffinet, 2009).

\section{Sensitivität in Bezug auf Klimavariable}

Klimawandel beeinflusst Moose auf direktem und indirektem Weg: Direkt, weil Moose nur einen geringen Toleranzbereich in Bezug auf ausgewählte Umweltfaktoren haben. Dies betrifft in Österreich vor allem Moose niedriger Lagen. Wie Grafschafter (2007) in Wachstumsversuchen gezeigt hat, ist die Absterbensrate selbst von wärmeadaptierten Arten des pannonischen Raumes bei erhöhten Temperaturen groß.

Eine deutlich größere Beeinflussung geht von indirekten Folgen aus. Die meisten Moose haben ein deutlich geringeres Temperaturoptimum (um ca. $15^{\circ} \mathrm{C}$ ) als die Gefäßpflanzen. Das Optimum von Hochgebirgsarten liegt um $5^{\circ} \mathrm{C}$, manche Spezialisten vermögen sogar unter $0^{\circ} \mathrm{C}$ positive Assimilationsleistungen zu erbringen (z. B. unter einer Schneedecke). Moose haben aufgrund dieser Eigenschaften in Extremlebensräumen wie im Hochgebirge, in Mooren oder Trockenrasen einen großen Anteil an der Biomasse (Bates et al., 1998). Moose sind in Bezug auf ihren $\mathrm{CO}_{2}$ Haushalt C3-Pflanzen, können aber nur bedingt das erhöhte $\mathrm{CO}_{2}$-Angebot in bodennahen Schichten nutzen (Sveinbjörnsson und Oechel, 1992). Temperatursteigerungen führen zu Wachstumseinbußen bei an Kälte angepassten Arten (Tuba et al., 2011, Jägerbrand et al., 2011). Gleichermaßen begünstigen atmosphärische Stickstoffeinträge viele Gefäßpflanzen (z. B. Gräser). Die meisten Moose, welche den zusätzlichen Dünge-Eintrag nicht nutzen können, werden durch Konkurrenz allmählich aus ihren Nischen verdrängt (Jägerbrand et al., 2011). Auch innerhalb der Moose gibt es Unterschiede in der Verwertung des zusätzlichen N-Angebots und somit Gewinner, bzw. Verlierer. Konkurrenz durch Gefäßpflanzen ist in (hoch)alpinen Systemen ein das Vorkommen von Moosen bestimmender Ökosystemprozess. Das veränderte Regime der Schneeschmelze und einer dadurch bedingten längeren Vegetationsperiode für Gefäßpflanzen bewirken zusätzlichen Konkurrenzdruck.

\section{Klimawandelfolgen in Österreich}

Die indirekte Beeinflussung der Diversität von Moosen durch Stickstoffdepositionen, welche aufgrund veränderter Niederschlagsregime in weiten Teilen Österreichs zu erwarten sind (siehe Band 2, Kapitel 4) ist in anthropogenen (Wiesen), als auch natürlichen Ökosystemen (Moore, Trockenrasen) bereits seit Jahren zu beobachten und punktuell untersucht (z. B. Zechmeister et al., 2003, 2007a; Koranda et al., 2007). In diesen Studien wurde ein deutlicher Rückgang der Moosarten mit steigender Stickstoffdeposition nachgewiesen. Zechmeister et al. (2007a) zeigten am Beispiel epiphytischer Moose auf der Integrated Monitoring-Fläche Zöbelboden jedoch auch unterschiedliche Konkurrenzverhältnisse innerhalb der Gruppe der Moose. Sie wiesen in dieser Langzeitstudie die Verdrängung seltener, stenöker Arten (z. B. Zygodon dentatus) durch starkwüchsige Moose (z. B. Hypnum cupressiforme var. cupressiforme) aufgrund hoher atmosphärischer Stickstoff-Einträge nach.

Konkurrenz durch Gefäßpflanzen aufgrund steigender Temperatur und veränderter Schneedeckendynamik mit kürzeren Schneedeckenperioden in alpinen und nivalen Lagen betrifft besonders Moose der Schneetälchengesellschaften. Untersuchungen hierfür gibt es von Hohenwallner et al. (2011) vom Schrankogel in Tirol, welche den Zusammenhang zwischen Schneedeckendauer und Zusammensetzung der Schneetälchenmoose zeigten und auf das Verschwinden einzelner Arten (z. B. Anthelia julacea) hinwiesen.

Auch das Verschwinden von Tayloria rudolphiana oder Brotherella lorentziana aus Niederösterreich, als auch das Höhersteigen der Arten Saelania glaucescens oder Zygodon gracilis (Kalk-Jochzahnmoos) könnte mit der Klimaerwärmung in Zusammenhang stehen (Zechmeister et al., 2013). Weiters sind in den letzten Jahren eine Reihe von Moosarten in Österreich gefunden worden, welche bislang primär aus dem mediterranen Raum bekannt waren (z. B. Barbula consanguinea, in: Köckinger et al., 2012b; Ryhnchostegium megapolitanum, in: Zechmeister et al., 2007b). Als Ursache für Einwanderung 
und Ausbreitung kann in beiden Fällen aktuelle Klimaerwärmung angenommen werden. Zunehmende Erwärmung und steigende Niederschläge haben auch in Westösterreich bereits zu vermehrtem Auftreten von Arten geführt, welche bislang nur aus atlantischen Gebieten bekannt waren (z. B. Calypogeia arguta, in: Schröck et al., 2013).

In Österreich gibt es bislang nur punktuelle Untersuchungen zum Thema Klimawandel und Moose. Die dabei gegebenen Befunde und eine Vielzahl internationaler Studien lassen aber auf einen engen Zusammenhang zwischen Arealveränderungen und Dominanz von Moosen und dem Klimawandel schließen.

\subsubsection{Blütenpflanzen und Farne}

\section{Allgemeine Charakterisierung}

Die Artenzahl der Farn- und Blütenpflanzen (Gefäßpflanzen oder höhere Pflanzen) in Österreich ist mit 3308 beständigen, wildwachsenden Arten und Unterarten (ohne Apomikten, d.h. Sippen ohne sexuelle Reproduktion; Niklfeld et al., 2008) im Vergleich zur Fläche des Landes sehr hoch und liegt über jener von Deutschland. In den collinen und montanen Landschaften Österreichs ist mit weit über tausend wild wachsenden Arten ein sehr heterogenes und vielfältiges Spektrum an funktionalen Typen anzutreffen. Dieses reicht von den zahlreichen Gräserartigen, die oft auf Feuchtstandorte spezialisiert sind, über Ephemere (kurzlebige) bis zu Klonpopulationen (genetisch idente, asexuell entstandene Nachkommen) ausbildenden Arten mit ewigem Leben. Innerhalb Österreichs liegen die artenreichsten Gebiete in den wärmebegünstigten Regionen (Englisch et al., 2005; Niklfeld et al., 2008). Der hohe Artenreichtum ist insbesondere auf die biogeographische Lage Österreichs am Kreuzungspunkt verschiedener Florengebiete, konkret der pannonischen, nordisch-borealen, atlantischen, submediterranen und mediterranen Floren zurückzuführen.

Mit zunehmender Seehöhe nimmt die Pflanzendiversität bis an die Kältegrenze des Pflanzenlebens ab (Moser et al., 2005). An und über der Waldgrenze bereichern neben arktisch-alpischen Elementen auch Endemiten und Subendemiten die Ausstattung Österreichs. Insgesamt sind es 103 endemische Arten und Unterarten, deren Verbreitungsareal ausschließlich oder überwiegend auf Österreich beschränkt ist (Essl et al., 2009), wobei eine deutliche Konzentrierung in den östlichsten Teilen der Alpen, die während der letzten Eiszeit nicht vergletschert waren, zu verzeichnen ist.

$\mathrm{Zu}$ den wichtigsten Arten, die auch wesentlich die ökosystemaren Serviceleistungen bestimmen, gehören zweifellos die
Bäume, wobei der Großteil der Baumarten von Natur aus selten ist. Waldbildende Baumarten werden in Abschnitt 3.2.6 behandelt. Sträucher, die natürliche Gebüsche bilden sind vor allem an Randflächen des Waldes oder in Auen anzutreffen. Hier reicht das Spektrum von der Stechpalme (Ilex aquifolium) im regenreichen Westen bis zur Zwergmandel (Prunus tenella) im pannonischen Osten und zu Zwergsträuchern, die vor allem subalpin-alpin große Flächen einnehmen können.

Eine fundierte Darstellung der Lebensumstände unter Klimawandelbedingungen und die möglichen Reaktionen für die Gesamtheit der in Österreich vorkommenden Gefäßpflanzenarten erscheint gegenwärtig unmöglich. Im Folgenden werden anhand einiger besser bekannter Beispiele Reaktionsmuster in Bezug auf Klimafaktoren dargestellt. Forstlich relevante Baumarten und landwirtschaftlich genutzte Kulturpflanzen, über die bessere Kenntnisse vorliegen, werden in eigenen Unterkapiteln behandelt.

\section{Klimawandelrelevante funktionale Rolle im öko- systemaren Kontext}

Farn- und Blütenpflanzen dominieren die Vegetation der meisten natürlichen bis semi-natürlichen terrestrischen Ökosysteme und besiedeln alle Höhenstufen Österreichs vom planar-kollinen Tiefland bis zur Nivalstufe an der oberen Verbreitungsgrenze pflanzlichen Lebens.

Die meisten Gefäßpflanzen sind regional an relativ eindeutige Höhenintervalle gebunden (vgl. Fischer et al., 2008), die im Allgemeinen enger begrenzt sind als etwa bei Moosen und Flechten (Glime, 2007; Vittoz et al., 2010). Vereinzelt können höhere Pflanzen aber auch in lokalen Rückzugsgebieten weitab vom Hauptvorkommen existieren. Beispiele sind die Eislöcher und Kondenswassermoore und schattige Felsen in tiefen Schluchten. Diese Habitate werden auch bei Projektionen zu den Folgen des Klimawandels oftmals zu wenig beachtet. Begrenzte Migrationsrationsraten und schlechte Besiedelbarkeit von potentiell neuen Habitaten können die autonome Anpassung von Pflanzenarten an ein sich veränderndes Klima stark beeinflussen bzw. die Bildung potentieller Fluchtnischen behindern, bzw. sogar verhindern.

In Bezug auf den zentralen pflanzenökologischen Prozess der Photosynthese werden C3-und C4- Pflanzen unterschieden. C4-Pflanzen haben Vorteile im Vergleich mit dem C3Typ, da sich bei heißem und trockenem Wetter ihre Spaltöffnungen schließen, um einer zu hohen Verdunstung von Wasser vorzubeugen. Daher weisen sie unter diesen Bedingungen eine verringerte Photosyntheseleistung auf. Sie sind jedoch unter 
normalen Temperatur- und Lichtverhältnissen effizienter. Die meisten Pflanzen in den mittleren und hohen Breiten gehören zu den C3-Pflanzen.

Das jeweilige Verhalten von Pflanzen in Bezug auf Klimaparameter bzw. das Zusammenwirken mit anderen Arten über Ökosystemprozesse wie Konkurrenz und positive Interaktionen (Mutualismus und Kommensalismus) bestimmen wesentlich die Auswirkungen, die ein sich veränderndes Klima auf Zusammensetzung, Struktur und Funktionsweise von Ökosystemen hat.

\section{Sensitivität in Bezug auf Klimavariable}

Sowohl die Photosynthese als auch die Atmung sind von der Temperatur abhängig. Während die Photosynthese bei C3Pflanzen bereits bei ca. $15-30^{\circ} \mathrm{C}$ ihr Maximum erreicht, steigt die Kurve der Atmung weiter exponentiell bis zu einer Temperatur von ca. $45^{\circ} \mathrm{C}$ an. Somit sinken oberhalb einer Optimaltemperatur von etwa $15-25^{\circ} \mathrm{C}$ die Netto-Assimilation und damit die Biomassebildung der Pflanzen wieder ab. Für die an mitteleuropäische Bedingungen angepassten Nutzpflanzen liegt bei unbedecktem Himmel das Temperaturoptimum bei ca. $20^{\circ} \mathrm{C}$. Bei C4-Pflanzen liegt das Temperaturoptimum der Photosynthese höher, sodass auch das Optimum der NettoAssimilation in einem höheren Temperaturbereich liegt. Die durch höhere Temperaturen (bei gleichzeitig anderen begünstigenden Faktoren) bedingte höhere Assimilationsleistung führt bei manchen Pflanzen auch zu den gewünschten höheren Zuckerkonzentrationen, wie z. B. bei der Zuckerrübe. Mais ist eine wärmeliebende und relativ hitzeresistente C4Pflanze. Allerdings kann starker Trockenstress, kombiniert mit sehr hohen Temperaturen, während der Blühphase zu schlechterer Befruchtung und damit zu Ertragsausfällen führen (Eitzinger et al., 2009c). Nutzpflanzen unterscheiden sich auch in ihrer Frostresistenz oder den Keimtemperaturen sowie in ihrer Hitzeresistenz deutlich (z. B. Larcher, 1994).

Neben der regulativen Funktion des Wärmehaushaltes spielt die Wasserversorgung bei den biochemischen Prozessen in der Pflanze eine wichtige Rolle. Daher ist die Verfügbarkeit von Wasser einer der am häufigsten limitierenden Faktoren für das Pflanzenwachstum. Die Verfügbarkeit von Wasser bestimmt auch den Gasaustausch zwischen Atmosphäre und Blättern, da bei nicht ausreichender Wasserversorgung die Spaltöffnungen der Blätter geschlossen werden und somit auch der $\mathrm{CO}_{2}$ Fluss für die Photosynthese in das Blattinnere behindert wird. Die Biomassebildung ist daher eng mit dem Wasserverbrauch (oder der Transpiration) der Pflanze gekoppelt (Eitzinger et al., 2009c).
Wo Lichtmangel ein limitierender Faktor ist und die Temperaturen niedrig sind (in gemäßigten Klimazonen), sind C3Pflanzen im Vorteil. C4-Pflanzen sind dagegen im offenen Gelände wärmerer Klimazonen erfolgreicher.

Keine der Blütenpflanzen- und Farnarten Österreichs wächst isoliert sondern bildet mit anderen Arten Pflanzengesellschaften, deren Zusammensetzung aus den jeweiligen Standortfaktoren und den Interaktionen mit anderen Arten sowie der Tierwelt resultiert. Diese Pflanzengesellschaften sind nicht zufällig zusammengesetzt sondern bilden Typen, die für Österreich im Wesentlichen bekannt sind (Mucina et al., 1993). So sehr die Artengarnituren für bestimmte Pflanzengesellschaften konstant sein können, sind auch hier deterministische Prognosen bezogen auf einzelne Pflanzengesellschaften schwierig oder unmöglich, weil einzelne Arten auf klimatische Veränderung unterschiedlich reagieren. Ruderal- und Unkrautfluren, zum Beispiel, verändern sich rasch. Aber auch in den sehr persistenten Pflanzengesellschaften der hochalpinen Rasen wurden Veränderungen nachgewiesen (Gottfried et al., 2012).

Noch komplexer wird die Situation, wenn die Tierwelt und die Destruenten im Sinne des Ökosystemkonzepts einbezogen werden. Nahrungsnetze reagieren und verändern sich. Besonders diskutiert wird im Zusammenhang mit dem Klimawandel der sogenannte „mismatch“ zwischen Bestäubergilden (Gilden sind Arten, die vergleichbare Ressourcen nutzen) und den beobachteten Klimaänderungen. Arten beginnen früher zu blühen, zu einem Zeitpunkt, da die Bestäuber ihren Reproduktionszyklus noch nicht vollständig abgeschlossen haben. Beobachtungen dazu legen dies nahe, allerdings nicht in einem dramatischen Ausmaß.

Die alpin verbreitete Gämsheide (Loiseleuria procumbens) besiedelt extrem windgefegte, im Winter schneefreie Windkanten. Sowohl extremer Frost (Frosttoleranz bis unter $-40^{\circ} \mathrm{C}$ ) als auch Wasserentzug im Winter durch Frosttrocknis werden von der Gämsheide ertragen (Grabherr, 1977, 1979), bzw. führen nur zu einem partiellen Absterben von Pflanzenteilen. Der ökologische Gegenentwurf zur Gämsheide ist die Rostrote Alpenrose (Rhododendron ferrugineum), die an Standorten mit längerer Schneebedeckung vorkommt (Larcher und Wagner, 2004; siehe Box 3.2). Hochgebirgspflanzenarten, die an extrem kalte Lebensräume angepasst sind, können in wärmerer Umgebung durch Stoffwechsellimitierung beeinträchtigt werden. Die generell sehr hohe Atmungsintensität, etwa beim Gletscherhahnenfuß (Ranunculus glacialis) kann bei Temperaturzunahme die Kohlenstoffbilanz der Pflanze negativ beeinflussen (Cooper, 2004).

Eine ganz wesentliche Anpassung der höheren Pflanzenarten an Klimavariabilität ist im modularen Aufbau zu suchen. 


\section{Box 3.2: Beispiel Alpenrose \\ Box 3.2: Case study Rhododendron ferrugineum}

Die Rostblättrige Alpenrose (Rhododendron ferrugineum) ist die vielleicht am besten untersuchte Pflanzenart in Österreich (Larcher und Wagner, 2004). Sie ist in den Alpen im Bereich des Waldgrenzökotons weit verbreitet und bildet auf kalkfreien Substraten dichte Bestände mit einer verhältnismäßig geringen Zahl assoziierter Arten, vor allem Ericaceen-Zwergsträuchern, wie Heidelbeere, Rauschbeere, Zwergwacholder und Moosmatten im Unterwuchs auf sauren Rankern oder Podsolböden (Grabherr und Mucina, 1993). Die Aufschließung der Bodennährstoffe wird durch typische Ericaceen-Mykorrhiza angeregt.

Messungen an Standorten der Alpenrose ergaben ein Jahresmittel der Lufttemperatur von 0,2 bis $2,0^{\circ} \mathrm{C}$, die absoluten Minima betrugen -28 bis $-29^{\circ} \mathrm{C}$. Gemäß Ergebnissen von Untersuchungen zur Frosttoleranz wären diese Temperaturen für die Alpenrose letal. Allerdings treten Frostschäden nur in Ausnahmefällen auf, wenn die meist vorhandene Schneedecke gestört wird oder der Winter extrem schneearm ist. Dies deutet darauf hin, dass vor allem starke Veränderungen im Niederschlagsregime (vor allem Zunahme der zwischenjährlichen Variabilität) negative Auswirkungen auf Alpenrosenpopulationen haben würden.

Die Bodentemperaturen in Alpenrosenbiotopen können $10^{\circ} \mathrm{C}$ übersteigen und bestimmen die Atmungsverluste in den Wurzeln. Die relative Zunahme der Atmungsintensität bei Temperaturzunahme dürfte wie bei vielen Alpinpflanzen hoch liegen. Inwiefern wärmere Böden dadurch die Kohlenstoffbilanz der Alpenrose negativ beeinflussen, wie etwa beim Gletscherhahnenfuß (Cooper, 2004), ist noch ungeklärt. Sehr kalte Böden können hingegen das Wachstum verhindern, nachdem das Streckungswachstum der Zellen erst bei ca. $+5^{\circ} \mathrm{C}$ anspringt. Besonders wirksam ist mit Sicherheit Bodenfrost, der als Kammeis in Erscheinung treten kann. Durch die Ausdehnung des Eises übt Bodeneis vor allem eine mechanische Wirkung aus und führt zur Bodenauflockerung und folgender Winderosion.

In den dichten Beständen kommt es an Schönwettertagen im Sommer zu einer Erwärmung des Mikroklimas von im Durchschnitt $5-10^{\circ} \mathrm{C}$, nicht selten auch mehr (bis $35-38^{\circ} \mathrm{C}$, im Extrem sogar über $40^{\circ} \mathrm{C}$ ). Hitzeschäden sind nicht ausgeschlossen, eine gefährliche Schädigung ganzer Bestände ist allerdings kaum denkbar. Sommerschnee und Sommerfrost kann jedoch im Extremfall zur Vernichtung eines Großteils der Blüten und Jungtriebe führen.

Kombinierte Klimaeffekte sind vor allem in Zusammenhang mit dem Wasserhaushalt bedeutend. Die Laurophyllie der Alpenrosenblätter (laurophylle Blätter sind an warmes aber feuchteres Klima angepasst; besonderer Schutz vor Kälte oder Austrocknung ist nicht ausgebildet) ist gekoppelt mit einer sehr sensiblen Regulation der Spaltöffnungen (Stomata) und einem sehr effizienten kutikulären Widerstand. Zumindest in den österreichischen Bergen dürfte die Alpenrose nicht gefährdet sein. Im Winter sind die Stomata durchwegs geschlossen, die Reaktivierung erfolgt bei Exemplaren unter Schnee sehr rasch, bei exponierten Individuen dauert es länger (2 bis 3 Tage). Der Verlust an Wasser durch die Kutikula kann allerdings so groß werden, dass es zu Trockenschädigungen kommen kann. Wasserstress durch Frosttrocknis bis an die Letalgrenze kann im Spätwinter häufig auftreten. Schadpilze wie Chrysomyxa rhododendri, der Fichtenrost, dem die Alpenrose als Zwischenwirt dient, können auftreten.

Neben Eigenschaften wie Kohlenstoffautotrophie (d.h. auf anorganische Kohlenstoffverbindungen $\left[\mathrm{CO}_{2}\right]$ als Kohlenstoffquelle angewiesen) und der Fähigkeit der Wasser- und Mineralstoffversorgung durch das Wurzelsystem ist es die Regenerationsfähigkeit der Sprosspflanzen welche eine grundsätzlich sessile Lebensweise erlaubt, da Schäden durch Bildung neuer Triebe ausgeglichen werden können. Schäden durch Wetterextreme, Schadinsekten, Pilzparasiten und Herbivore sind im Zusammenhang mit der Erforschung von Klimafolgen für einzelne Arten ebenso zu berücksichtigen wie stetige, gerichte- te Veränderungen der Durchschnittstemperatur. Letztendlich ist aufgrund der vielen Einflussfaktoren eine kausal verankerte Prognose über die Reaktionsweise von Pflanzenpopulationen nur für eine geringe Anzahl von Arten möglich.

Ein Phänomen, das korrelative Zusammenhänge zwischen Auftreten von Pflanzenarten und Klimafaktoren kausal schwierig erklärbar macht, ist die Langlebigkeit von einzelnen Pflanzenarten, die dafür sorgt, dass Pflanzenarten auch unter einem „neuen“, wärmeren Klima beharrlich ihren Platz behaupten - sie sozusagen in "falschen“ bzw. ungeeigneten 


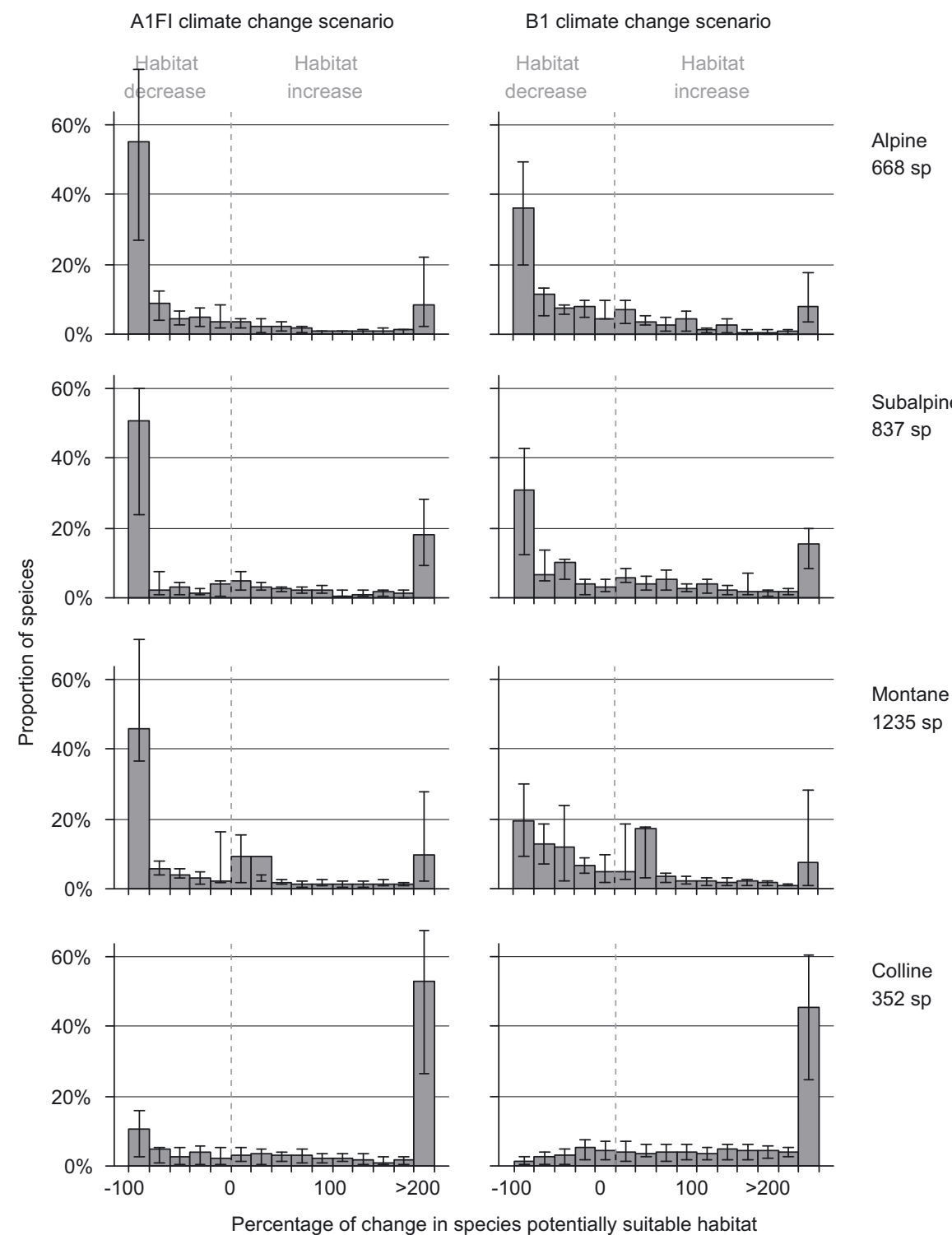

$21^{\text {st }}$ century climate change threatens mountain flora unequally across Europe, Engler et al., Global Change Biology, Volume 17/ 7; ๔ 2011 Blackwell Publishing Ltd.
Abbildung 3.2 Mit Nischenmodellen prognostizierte Habitat-Verluste von Gefäßpflanzen in europäischen Gebirgsökosystemen, inklusive der österreichischen Alpen, in den verschiedenen Höhenstufen. Die y-Achsen repräsentieren die Prozentsätze von allen pro Höhenstufe modellierten Arten, die x-Achsen den Anteil des aktuell für diese Arten geeigneten Areals, den sie bis zum Jahr 2080 verlieren oder gewinnen würden. Die modellierten Habitat-Verluste bzw. -Zugewinne sind für zwei verschiedene Klimawandelszenarien dargestellt. Beispiel: für ca. 55 \% der modellierten 668 alpinen Arten würde unter dem A1FI Szenario (Bezugszeitpunkt 2100) das geeignete Areal um mehr als $80 \%$ schrumpfen. Quelle: Engler et al. (2011)

Figure 3.2 Projected habitat losses of vascular plants in European mountain systems, including the Austrian Alps, in each elevation belt. The $y$-axes represent percentages of all modelled species per elevation belt, $x$-axes the proportion of losses or of gains of suitable habitats by 2080, relative to a species' current distribution. Projected habitat losses or gains are shown for two different climate change scenarios. Example: About $55 \%$ of the modelled 668 alpine species would lose more than $80 \%$ of the suitable area under the A1FI scenario (time reference 2100).

Source: Engler et al. (2011)
Habitaten überdauern können. Die große Bedeutung klonaler Populationen, die hunderte, ja tausende Jahre überdauern können, zeigt sich vor allem bei Zwergsträuchern, bei alpinen Rasenbildnern, aber auch Wasserpflanzen wie Schilf. De Witte et al. (2012) gelang vor kurzem mittels DNA-Fingerprinting die Bestätigung, dass die klonalen Systeme der Grasart Carex curvula ein Alter bis zu 5000 Jahre erreichen können. Bei den ältesten Klonsystemen fand das Keimereignis zu Zeiten des Ötztaler Eismanns, d.h. in einer klimagünstigen Phase statt.

In den tieferen Lagen könnten invasive gebietsfremde, häufig sehr anpassungsfähige und oft wärmeliebende Pflanzenarten, die durch den Menschen aus anderen Kontinenten einge- führt wurden, durch eine Klimaerwärmung gefördert werden (Rabitsch et al., 2013; IPCC, 2014). Am Südrand der Alpen konnte sich während des späten 20. Jahrhunderts etwa die Chinesische Hanfpalme (Trachycarpus fortunei) in Laubwäldern im Tessin etablieren (Walther et al., 2005).

\section{Klimawandelfolgen in Österreich}

Der Stand des Wissens zu Waldbaumarten und agrarisch genutzten Pflanzenarten wird in den Abschnitten 3.2.6, 3.2.7 und 3.2.8 dargestellt. Hier werden exemplarisch Klimawandelfolgen für andere Gefäßpflanzen beschrieben. 


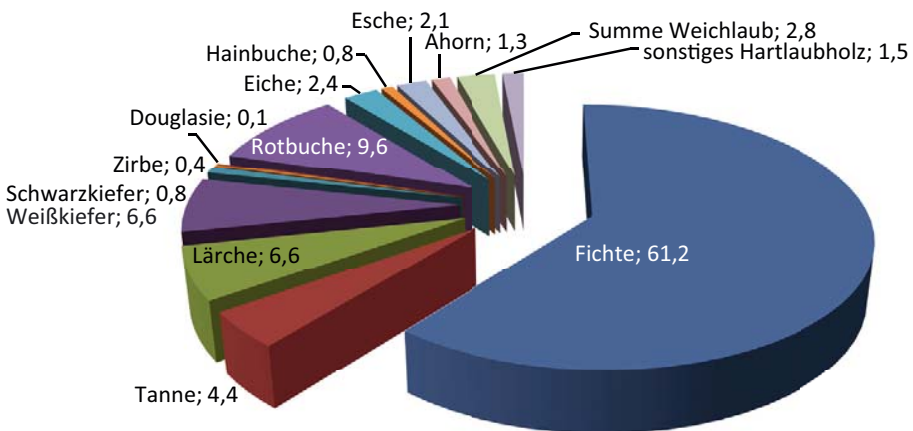

Die ohnehin kleinflächigen Vorkommen von Gebirgspflanzen könnten durch indirekte Erwärmungseffekte, etwa infolge von Konkurrenz durch nachrückende, rascher- und höherwüchsige Arten oder direkt durch physiologischen Stress, weiter eingeengt werden. Nischen-basierte Modelle prognostizieren das regionale Aussterben vieler alpiner und nivaler Arten oder zumindest starke Arealverluste und zunehmende Fragmentierung der überlebenden Populationen (z. B. Dirnböck et al., 2003; Engler et al., 2011; Abbildung 3.2). Gegen solche Prognosen wurden allerdings Vorbehalte geäußert: zum einen könnte die ausgeprägte Reliefenergie von Hochgebirgslandschaften das Überdauern der Arten in klimatischen Mikro-Nischen erlauben (Randin et al., 2009; Scherrer und Körner, 2010). Zum andern berücksichtigen die verwendeten Modelle keine transienten Migrationsbewegungen, sondern projizieren einen potentiellen Endzustand der Verteilung geeigneter Habitate unter einem hypothetischen neuen, stabilen Klimaregime.

Erste Simulationen mit Hybridmodellen legen nahe, dass die Arealdynamik von Hochgebirgspflanzen mit starker Verzögerung auf klimatische Trends reagieren wird und die von Nischenmodellen prognostizierten Arten- und Arealverluste daher eventuell mit einer Verspätung von Jahrzehnten eintreten werden (Dullinger et al., 2012). Diese Verzögerung resultiert aus der Fähigkeit der großteils langlebigen und klonalen Arten, ungünstige klimatische Bedingungen über längere Zeiträume als sogenannte „remnant populations“ zu überdauern. Längerfristig wird durch den Abtrag der entstehenden „Aussterbeschuld“ (Jackson und Saxon, 2010) die Biodiversitätsbilanz der höheren Lagen aber vermutlich deutlich weniger positiv ausfallen.
Abbildung 3.3 Relative Anteile der Baumarten an der Österreichischen Waldfläche (Ertragswald). Quelle: Österreichische Waldinventur (Anonymus, 2009)

Figure 3.3 Relative shares of tree species in Austrian production forests according to the Austrian Forst Inventory (Anonymus, 2009)

\subsubsection{Waldbaumarten}

\section{Abgrenzung und Charakterisierung}

Die im österreichischen Wald anteilsmäßig dominierenden Baumarten (ÖWI, 2007/09) sind bei den Nadelbäumen Fichte (Picea abies), Weisskiefer (Pinus sylvestris) und Lärche (Larix decidua), bei den Laubbäumen die Buche (Fagus sylvatica), Stieleiche (Quercus robur), Esche (Fraxinus excelsior) und Bergahorn (Acer psedoplatanus). Die Douglasie (Pseudotsuga menziesii) ist mit weniger als 0,2 \% Flächenanteil die häufigste nicht heimische Baumart (Abbildung 3.3). Natürlich dominierende Baumarten sind unter historisch-aktuellem Klima in der kollinen Höhenstufe die Eiche; submontan die Buche; in den montanen Höhenstufen je nach Bodentyp und Ausgangssubstrat die Buche, die Fichte und die Tanne; in den hochmontanen und subalpinen Höhenstufen die Fichte, die Lärche und fallweise die Zirbe. Durch intensive Bewirtschaftung ist der Anteil der Fichte erhöht und ihr Vorkommensbereich auf tiefgelegene Laubmischwaldstandorte ausgedehnt worden.

Baumarten sind potentiell besonders anfällig für Klimawandelfolgen. Ein Hauptgrund dafür ist der lange Generationszyklus von Bäumen, der in mitteleuropäischen Waldökosystemen mindestens mehrere Jahrzehnte, in der Regel jedoch noch deutlich längere Zeiträume umfasst. Dies ermöglicht nur relativ langfristig eine Anpassung an den aus der Sicht der Waldbäume sehr rasch fortschreitenden Klimawandel, die als genetische Anpassung oder in Bezug auf die Artenzusammensetzung erfolgen kann. Andererseits ist daraus auch ersichtlich, dass Baumarten aufgrund ihrer Langlebigkeit imstande sein müssen, die beträchtliche interannuelle Variabilität des Klimas zu tolerieren. Ist das Ausmaß der klimatischen Veränderung an einem Waldstandort allerdings größer als es die dort wachsenden Baumarten tolerieren können, führt dies zu einer physiologischen Schwächung und letztlich zum Absterben der betroffenen Baumindividuen entweder direkt durch klima- 
bedingte Faktoren wie z. B. Trockenheit, durch Krankheiten und Insekten (siehe Abschnitt 3.2.10) oder indirekt über die Verdrängung durch unter einem veränderten Klima konkurrenzkräftigere Baumarten.

\section{Sensitivität in Bezug auf Klimavariable}

Im Fall von einjährigen Intensivkulturen in der Landwirtschaft vermag die Kenntnis des Einflusses von Klimafaktoren auf produktionsökologische Prozesse (Photosynthese, Respiration) bereits ein relativ gutes Bild von den möglichen Auswirkungen einer Klimaänderung zu vermitteln. Im Gegensatz zu weitgehend künstlichen Agrarsystemen handelt es sich im Fall von Waldökosystemen in weiten Bereichen Zentral- und Mitteleuropas um relativ naturnahe, oftmals aus mehreren Baumarten bestehende, Mischwälder. Da Baumarten individuell auf Veränderungen in ihrer Umwelt reagieren und klimasensitive Prozesse wie Störungen zusätzlich auch die Dynamik auf ökosystemarer Ebene verändern, sind Auswirkungen einer Klimaveränderung auf die Entwicklungsdynamik in Wäldern bedeutend schwieriger abzuschätzen. Die Kenntnis, wie sich eine Klimaveränderung auf Prozesse der Nettoprimärproduktion und des Pflanzenwachstums auswirkt, reicht im Fall von Wäldern nicht aus. Zum Verständnis von naturnah bewirtschafteten Waldökosystemen sind darüber hinaus auch die populationsdynamischen Prozesse der Reproduktion und Verjüngung sowie der Baummortalität notwendig.

In Tabelle 3.4 sind Klimafaktoren und eine Auswahl von ihnen ausgehender Wirkungsmechanismen in Bezug auf Wachstum, Reproduktion und Mortalität von Waldbäumen dargestellt.

\section{Baumwachstum}

Ein Temperaturanstieg führt zu positiven Wachstumseffekten; bei gleichbleibenden oder abnehmenden Niederschlägen steigt aber auch die Evapotranspiration (Rebetez und Dobbertin, 2004). Pflanzen reagieren auf Trockenstress mit dem Schließen der Stomata um Wasserverlust und Blattwelke zu verringern (Larcher, 2003). Während die Verringerung der Stomata-Leitfähigkeit eine Anpassung an Trockenstress ist, reduziert das Schließen der Stomata die Photosynthese und die C-Aufnahme (Körner und Ohsawa, 2006). Durch die höhere Evapotranspiration bei wärmeren Temperaturen kann es in Gebieten mit geringeren Niederschlägen insbesondere im Sommerhalbjahr dazu führen, dass der Verdunstungsbedarf das Niederschlagsangebot übersteigt und, abhängig von der Wasserspeicherkapazität des Bodens, dies relativ rasch zu Tro- ckenstress führt. Diese Situation wird durch geringere Schneehöhen und kürzere Schneedeckendauer im Frühjahr noch verschärft.

Die größere Wassernutzungseffizienz bei erhöhtem $\mathrm{CO}_{2}-$ Gehalt der Atmosphäre vermag teilweise die schlechtere Wasserversorgung auszugleichen. Steigen jedoch gleichzeitig die Temperaturen, könnte dieser Effekt wieder durch den erhöhten Kühlungsbedarf der Blattorgane durch Transpiration verloren gehen. Der direkte $\mathrm{CO}_{2}$-Düngungseffekt durch höheren Partialdruck von $\mathrm{CO}_{2}$ im Blattinneren reduziert durch die Beeinflussung des Enzymsystems die Photorespiration und erhöht dadurch die Brutto-Photosynthese. Es ist jedoch noch immer unsicher, inwieweit die in Experimenten festgestellte Steigerung der Assimilationsleistung durch $\mathrm{CO}_{2}$-Düngung von kurzfristig bis zu 60 \% (z. B. Norby et al., 1999), bezogen auf einen $\mathrm{CO}_{2}$-Gehalt der Atmosphäre von 580 ppm, langfristig aufrecht erhalten werden kann (siehe dazu auch Körner und Ohsawa, 2003; Ainsworth und Long, 2005). Ein Grund für diese mögliche „Akklimatisierung“ von Wäldern könnten andere limitierende Faktoren sein (z. B. Nährstoffe). Außerdem wurde festgestellt, dass die Dichte der Spaltöffnungen an den Blattorganen seit etwa 200 Jahren kontinuierlich abgenommen hat. Dies könnte ebenfalls auf einen nicht nachhaltigen Effekt der $\mathrm{CO}_{2}$-Düngung hindeuten.

In Gebirgslagen ist allgemein von einem positiven Effekt einer Erwärmung auf die Biomasseproduktivität auszugehen. In inneralpinen Tälern und Becken könnten die positiven Auswirkungen von längeren Vegetationsperioden und günstigeren Temperaturverhältnissen (das Temperaturoptimum für die Brutto-Photosynthese liegt abhängig von der Baumart meist unter $30^{\circ} \mathrm{C}$ und wird damit an vielen Tagen während der Vegetationsperiode nicht erreicht) durch eingeschränkte Wasserversorgung aufgehoben werden. Während jedoch die BruttoPhotosynthese bei Temperaturen über dem Optimum wieder abnimmt, steigt die Atmung mit der Temperatur steil an (Larcher, 2003). Zusätzlich zur möglichen Beeinträchtigung des Enzymsystems wirken sich Hitzeperioden mit Temperaturen über $30^{\circ} \mathrm{C}$ generell negativ auf die Nettophotosynthese aus. Satellitengestützte und wachstumskundliche Untersuchungen in den Alpen zeigen z. B. für den europäischen Hitzesommer 2003, dass Hochlagen von diesen extremen Bedingungen profitieren konnten, während für weite Teile der Mittel- und Tieflagen deutliche Wachstumsrückgänge dokumentiert sind (Jolly et al., 2005).

Die tatsächliche Verlängerung der Vegetationsperioden wird durch phänologische Beobachtungen gestützt. Anhand der Periode 1971 bis 2000 konnten Menzel et al. (2006) ein früheres Austreiben bei Baumarten und teilweise eine spätere 
Tabelle 3.4 Sensitivität von Waldbaumarten in Bezug auf klimabedingte Umweltfaktoren. $B=$ Beobachtung, $E=$ Experiment, $S=$ Simulation Table 3.4 Sensitivity of forest tree species with regard to climate-related environmental factors. $B=$ observation, $E=$ experiment, $S=$ simulation

\begin{tabular}{|c|c|c|c|}
\hline Klimafaktor & Wirkungsmechanismus & $\mathrm{B} / \mathrm{E} / \mathrm{S}$ & Baumarten \\
\hline \multirow[t]{8}{*}{ höhere Temperatur } & $\begin{array}{l}\text { Besseres Wachstum durch höhere Netto-Photosynthese, da Temperatur- } \\
\text { Optima (ca. } 28-30^{\circ} \mathrm{C} \text { ) für viele Baumarten unter heutigem Klima noch } \\
\text { nicht erreicht sind }\end{array}$ & $B, E, S$ & \multirow[t]{3}{*}{$\begin{array}{l}\text { Alle heimischen Waldbaum- } \\
\text { arten }\end{array}$} \\
\hline & $\begin{array}{l}\text { Steigende C-Verluste durch Atmung - Atmungsrate steigt exponentiell } \\
\text { mit der Temperatur an }\end{array}$ & $B, E, S$ & \\
\hline & Verringertes Wachstum durch direkte Hitzeschäden & $E, B$ & \\
\hline & $\begin{array}{l}\text { Verringertes Wachstum durch Trockenstress wegen ungünstigerer } \\
\text { Wasserbilanz durch erhöhten Verdunstungsbedarf (insbesondere in } \\
\text { Sommermonaten) }\end{array}$ & $E, B, S$ & Buche \\
\hline & Direkte Hitzeschäden an Keimlingen & $E, B$ & \\
\hline & $\begin{array}{l}\text { Höheres Mortalitätsrisiko durch poikilotherme Schädlinge } \\
\text { (siehe Abschnitt 3.2.4) }\end{array}$ & $B, S$ & Fichte, Kiefer, Tanne \\
\hline & $\begin{array}{l}\text { Höhere Prädisposition gegenüber Winterstürmen durch geringere Bo- } \\
\text { denfrostdaver und -intensität }\end{array}$ & $\mathrm{B}, \mathrm{S}$ & $\begin{array}{l}\text { v. a. Koniferenarten, besonders } \\
\text { betroffen flachwurzelnde Arten } \\
\text { wie Fichte }\end{array}$ \\
\hline & $\begin{array}{l}\text { Erhöhte Waldbrandgefahr durch schnelleres Austrocknen von brennba- } \\
\text { rem Material im Wald }\end{array}$ & $\mathrm{B}, \mathrm{S}$ & Alle Baumarten \\
\hline \multirow[t]{2}{*}{ Spätfrost } & $\begin{array}{l}\text { Absterben von frischen Trieben (Wechselwirkung mit längerer Vegetati- } \\
\text { onsperiode) }\end{array}$ & $E, B$ & Buche, Eichen \\
\hline & Absterben von Jungpflanzen durch Frost & $\mathrm{B}, \mathrm{S}$ & $\begin{array}{l}\text { v. a. Spätfrost-gefährdete Arten, } \\
\text { z. B. Buche }\end{array}$ \\
\hline \multirow[t]{2}{*}{$\begin{array}{l}\text { längere Vegetations- } \\
\text { periode }\end{array}$} & $\begin{array}{l}\text { Besseres Wachstum durch verlängerte Vegetationsperiode, wo Tempera- } \\
\text { tur heute limitierender Faktor ist (z. B. Gebirge, nördliches Europa) }\end{array}$ & $B, S$ & \\
\hline & $\begin{array}{l}\text { Änderungen in Austriebs- und Blühzeitpunkt (Phänologie) können zu } \\
\text { einer abnehmenden Schädlingsgefährdung durch gestörte Synchroni- } \\
\text { sierung von Austriebszeitpunkt und Schädlingsauftreten führen }\end{array}$ & B5 & $\begin{array}{l}\text { z. B. im Fall des Graven } \\
\text { Lärchenwicklers }\end{array}$ \\
\hline \multirow[t]{7}{*}{$\begin{array}{l}\text { eingeschränkte } \\
\text { Wasserversorgung, } \\
\text { Trockenperioden }\end{array}$} & $\begin{array}{l}\text { Verringertes Wachstum durch Trockenstress; insbesondere bei Baumar- } \\
\text { ten die sensitiv auf sommerliche Trockenperioden reagieren; Nadelbau- } \\
\text { marten reagieren hydrostabil, die meisten Laubbaumarten hydrolabil } \\
\text { (Wohlfahrt und Mayr, 2012; Karrer et al., 2012) }\end{array}$ & $B, S, E$ & Buche, Fichte \\
\hline & $\begin{array}{l}\text { Verbesserte Habitatbedingungen (Brutmaterial) für einzelne Insek- } \\
\text { tenarten durch physiologische Schwächung von Wirtsbäumen wegen } \\
\text { Trockenstress }\end{array}$ & $E, B$ & Fichte, Buche \\
\hline & $\begin{array}{l}\text { Verringerte Gefährdung durch Schneeschimmel in Gebirgswäldern } \\
\text { wegen kürzerer Schneedeckendauer }\end{array}$ & B & Fichte, Zirbe \\
\hline & $\begin{array}{l}\text { Erhöhte Waldbrandgefahr durch geringere Feuchtegehalte von brenn- } \\
\text { barem Material im Wald }\end{array}$ & $\mathrm{B}, \mathrm{S}$ & Alle Baumarten \\
\hline & erhöhte Baummortalität durch Trockenheit & $B, S$ & \\
\hline & Baumartenwechsel in Folge von trockenheitsbedingten Mortalitätsevents & $B, S$ & $\begin{array}{l}\text { v. a. trockenheitsgefährdete } \\
\text { Baumarten wie Fichte }\end{array}$ \\
\hline & $\begin{array}{l}\text { Veriüngungsprobleme als Folge von Absterben von Jungpflanzen durch } \\
\text { Trockenheit }\end{array}$ & $B, S$ & $\begin{array}{l}\text { v. a. trockenheitsgefährdete } \\
\text { Baumrten, z. B. Fichte }\end{array}$ \\
\hline \multirow{2}{*}{$\begin{array}{l}\text { Höherer Nieder- } \\
\text { schlag, verbesserte } \\
\text { Wasserversorgung }\end{array}$} & $\begin{array}{l}\text { Verbessertes Wachstum durch günstigere Wasserbilanz wenn heute } \\
\text { wasserlimitiert }\end{array}$ & $\mathrm{B}, \mathrm{S}$ & Alle Baumarten \\
\hline & Höhere Infektionsgefahr durch Pilzsporen & E & \\
\hline \multirow[t]{3}{*}{$\begin{array}{l}\text { Erhöhter } \mathrm{CO}_{2} \text {-Gehalt } \\
\text { in der Atmosphäre }\end{array}$} & $\begin{array}{l}\text { Verbessertes Wachstum durch } \mathrm{CO}_{2} \text {-Düngungseffekt und bessere Was- } \\
\text { sernutzungseffizienz }\end{array}$ & $\mathrm{E}$ & \\
\hline & $\begin{array}{l}\text { Komplexe Interaktion zwischen Nahrungsqualität von Wirtsbäumen und } \\
\text { Insektenentwicklung }\end{array}$ & $E, B$ & \\
\hline & $\begin{array}{l}\text { Geändertes Verhältnis zwischen unter- und oberirdischer Biomasse } \\
\text { durch Änderung der Allokation von Photosyntheseprodukten zu Pflan- } \\
\text { zenorganen }\end{array}$ & $\mathrm{B}, \mathrm{S}$ & Alle Baumarten \\
\hline
\end{tabular}


Blattverfärbung im Herbst feststellen. Es stellt sich die Frage, ob generell mit der Komplexität der Klimawandeleinflüsse eine gegenseitige Verstärkung oder, wie von Leuzinger et al. (2011) postuliert, eine Überlagerung und eine gegenseitige Aufhebung von positiven und negativen Effekten wirksam werden.

Die in den Ergebnissen von nationalen Waldinventuren und Dauerversuchsflächen seit den 1980er Jahren festgestellten Zuwachssteigerungen (z. B. Spiecker (2000) für Dänemark, Deutschland, Österreich, Frankreich, Schweden und die Schweiz; Pretzsch und Utschig, 2000; Ciais et al., 2008) werden teilweise verbesserten Bewirtschaftungsmethoden, Stickstoffeinträgen in Waldökosystemen, verlängerten Vegetationsperioden und dem erhöhten $\mathrm{CO}_{2}$-Gehalt der Atmosphäre zugeschrieben. Bäume können sich jedoch steigenden $\mathrm{CO}_{2}$-Gehalten anpassen und dieser Effekt kann daher rasch aufgehoben werden (Bader et al., 2013).

Der derzeitige Stand des Wissens geht davon aus, dass auf einem Großteil der untersuchten Waldfächen dem Stickstoffeintrag die wichtigste Rolle bei der Erklärung der positiven Zuwachstrends zukommt. Analysen mit Physiologie-basierten Waldwachstumsmodellen zeigten, dass von den beobachteten Zuwachssteigerungen auf Versuchsflächen seit 1920 zwischen 2 und $4 \%$ auf den Anstieg des $\mathrm{CO}_{2}$-Gehalts in der Atmosphäre zurückzuführen sind (Kahle et al., 2008). Eine weitere Verdoppelung der $\mathrm{CO}_{2}$-Konzentration und höhere Temperaturen gemeinsam könnten zu zukünftigen Steigerungen in der Biomasseproduktivität von 15-25\% führen, wenn andere Faktoren nicht limitierend wirken (Cannell et al., 1998; Kellomäki und Leinonen, 2005). Ebenfalls in einer simulationsgestützten Analyse wurden die wärmeren Temperaturen der letzten Dekaden für die Veränderungen der Zuwachstrends im österreichischen Wald als zumindest mitverantwortlich identifiziert (Hasenauer et al., 1999). Eine zwischenzeitliche Reduktion der Zuwächse um das Jahr 1991 wurde in dieser Studie der verringerten Strahlung nach dem Ausbruch des Vulkans Pinatubo zugeschrieben.

\section{Reproduktion \& Waldverjüngung}

Während zu Wachstumsprozessen von Baumarten zahlreiche Forschungsergebnisse vorliegen, bestehen in Bezug auf die Sensitivität von Reproduktions- und Verjüngungsprozessen auf Klimafaktoren derzeit noch große Wissenslücken. In Aufforstungen zum Beispiel, die bisher meist im Frühjahr und Frühsommer durchgeführt werden, könnten durch häufigere Trockenperioden hohe Ausfälle auftreten. Empirische Studien, die Veränderungen in der Baumartenzusammensetzung analysieren, fokussieren in vielen Fällen auf die besser zu isolieren- den Prozesse Wachstum und Mortalität. Verjüngungsprozesse hingegen weisen oftmals eine große kleinstandörtliche Variabilität auf, sodass in vielen Fällen der Einfluss von klimatischen Faktoren kaum statistisch signifikant nachgewiesen werden kann. Im Gegensatz dazu konnten Pröll et al. (2011) am Standort Zöbelboden in Oberösterreich signifikante Einflüsse von Stickstoffeintrag und -mineralisierung auf die Reproduktion von Buchen und Bergahorn feststellen, während Effekte auf Eschen nicht nachweisbar waren.

\section{Störungen und Baummortalität}

Ob die oben beschriebenen potentiellen Zuwachssteigerungen durch eine Klimaänderung in der praktischen Waldbewirtschaftung tatsächlich realisiert werden können, wird zu einem wesentlichen Teil von dem zahlreiche potentielle Schadfaktoren abhängen, welche Störungen in Waldökosystemen verursachen können. Störungen sind Ereignisse die durch abiotische (z. B. Sturm, Schnee) oder biotische (z. B. Insekten, Pilze) Störfaktoren abrupt und teilweise großflächig Baummortalitäten verursachen. Störungsregime sind immanenter Bestandteil eines jeden Waldökosystems und nehmen u. a. durch das Schaffen von Verjüngungsnischen eine wichtige Rolle in der Selbstregulierung und Diversität von Ökosystemen ein. Infolge des Klimawandels und stark beeinflusst durch Bewirtschaftungseffekte (Baumartenzusammensetzung, Waldstrukturen) ist zu erwarten, dass sich die für bestimmte Regionen und Waldtypen bisher charakteristischen Störungsregime stark verändern werden (siehe Box 3.5. In den letzten Jahren sind etwa zunehmende Schäden durch Borkenkäfer in fichtendominierten Wäldern (insbesondere durch Ips typographus und Pityogenes chalcographus) - nicht mehr nur auf Tieflagen beschränk, was die Relevanz einer Klimaänderung für klimasensitive Störungsfaktoren deutlich demonstriert. Warme und trockene Jahre in Verbindung mit vorangegangenen großflächigen Störungen durch Sturm und Schnee ließen die Anteile von Kalamitätsnutzungen an den gesamten jährlichen Nutzungsmengen deutlich ansteigen. Folgen sind u. a. unmittelbare Entwertung von Sortimenten, sinkende Holzpreise durch plötzliches Überangebot auf den Holzmärkten sowie höherer Planungs- und Bewirtschaftungsaufwand. Der Einfluss von Klimaveränderungen auf Störungen wird auf der Ökosystemebene (Abschnitt 3.3.4) detaillierter dargestellt.

\section{Klimawandelfolgen in Österreich}

Von Steiner und Lexer (1998) wurde für Österreich zur Identifizierung von „hot spots“ die physiologische Nische von 


\begin{tabular}{|c|}
\hline Klimastress \\
sehr hoch \\
moderat \\
gering \\
\hline
\end{tabular}

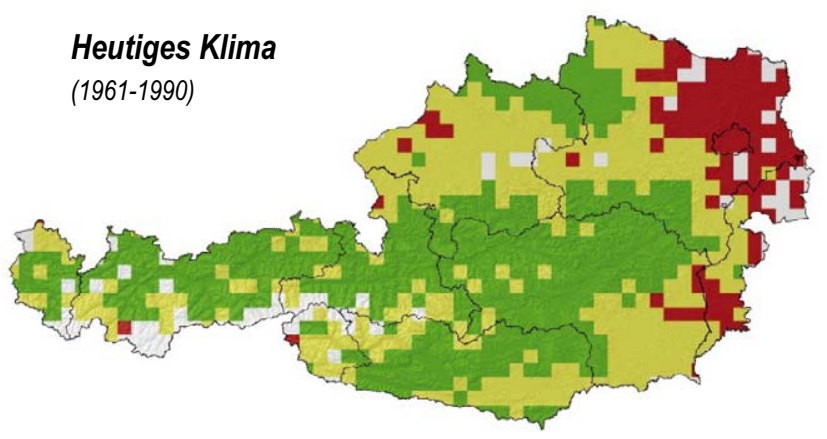

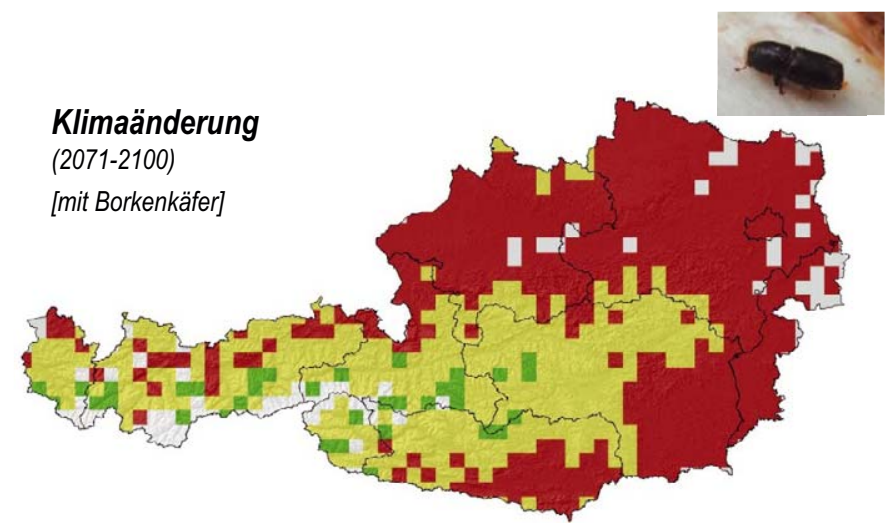

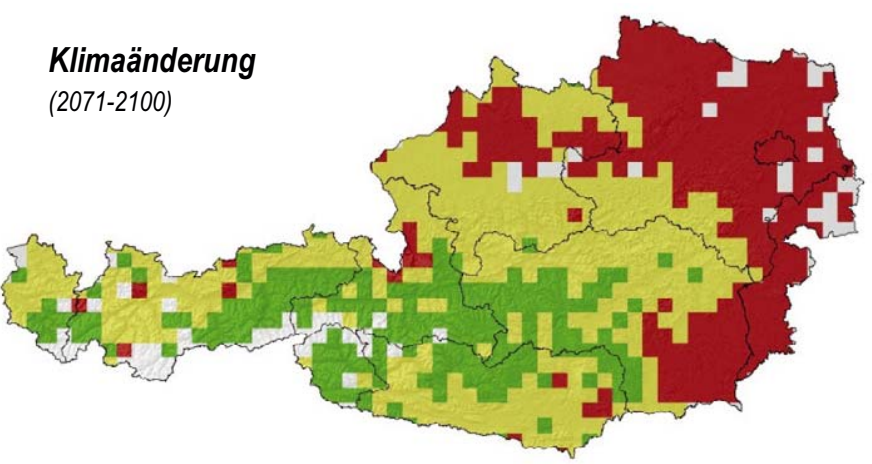

Abbildung 3.4 Modellierter Klimastress für die Fichte basierend auf dem Konzept der physiologischen Nische. Datenbasis: Standortdaten der Österreichischen Waldinventur (ohne Schutzwald außer Ertrag). Links unten: Heutiges Klima repräsentiert durch die Messperiode 1961 bis 1990; rechts unten: Klimaänderungsszenario A1B am Ende des 21. Jahrhunderts (Temperatur: bis $+4,5^{\circ} \mathrm{C}$, Niederschlag: bis -35 \% im Sommerhalbjahr); rechts oben: Klimaänderungsszenario A1B, physiologische Nische plus Berücksichtigung der potentiellen Generationen des Fichtenborkenkäfers Ips typographus. Rot $=$ Klimastress sehr hoch, gelb = Klimastress moderat, grün = Klimastress gering bzw. nicht vorhanden

Figure 3.4 Simulated climate-related stress index for Picea abies based on the physiological niche concept. Data: Site data from Austrian Forest Inventory (exluding protection forests with out yield). Left bottom panel: current climate represented by period 1961 to 1990; right bottom panel: climate change scenario $\mathrm{A} 1 \mathrm{~B}$ at end of $21^{\text {st }}$ century (temperature: up to $+4.5^{\circ} \mathrm{C}$, precipitation: up to $-35 \%$ during summer season). Right top panel: climate change scenario A1B incl. effects of potential generations of the spruce bark beetle Ips typographus. Red $=$ high stress, yellow $=$ moderate stress, green $=$ low $/$ no stress

Hauptbaumarten modellhaft anhand des Zusammenwirkens von Temperaturregime (Temperatursummen, Winterfrost, Sommerhitze), dem Sättigungsdefizit der Atmosphäre sowie der Wasserversorgung (Indikatoren für die Wasserverfügbarkeit während der Vegetationsperiode, Sommertrockenheit) beschrieben und das Auftreten von Klimastress unter heutigem Klima und einem Klimaänderungsszenario simuliert (Steiner und Lexer, 1998; Niedermair et al., 2007).

Abbildung 3.4 zeigt am Beispiel der Fichte die erwartete Entwicklung am Ende des 21. Jahrhunderts. Bei wärmerem und trockenerem Klima leidet die in Mitteleuropa von Natur aus auf montane bis subalpine oder inneralpine Lagen beschränkte Fichte zunehmend und häufiger unter periodischem Trockenstress. Unter Klimawandelbedingungen (für Details siehe die Bildunterschrift von Abbildung 3.4) werden große
Gebiete Nieder- und Oberösterreichs sowie der Steiermark und des Burgenlandes für die Fichte ungeeignet, wobei diese Verengung der Nische noch durch ein in wärmerem Klima öfter zu erwartendes Massenauftreten des Borkenkäfers Ips typographus verstärkt wird. Gebiete in denen die Fichte geringem Klimastress ausgesetzt ist reduzieren sich unter den angenommenen Szenariobedingungen auf höher gelegene Berglagen.

Für die Buche hätte eine deutliche Erwärmung zur Folge, dass diese Baumart in den Gebirgslagen des gesamten Ostalpenraumes vermehrt Standorte mit geeigneten klimatischen Bedingungen vorfindet und nur mehr in Hochlagen durch Kälte limitiert wird (Abbildung 3.5). Sollten jedoch Trockenperioden häufiger und intensiver werden, würde dies auch zu einer starken Zunahme der durch Trockenstress belasteten Gebiete vor allem im Waldviertel sowie entlang des Alpenostrands 

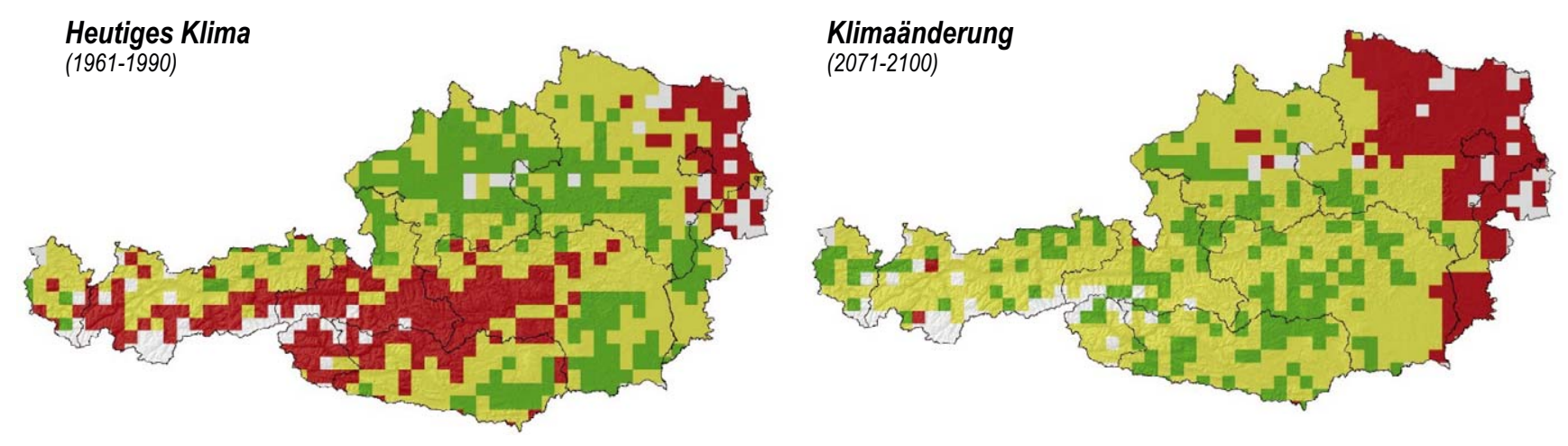

Abbildung 3.5 Modellierter Klimastress für die Buche basierend auf dem Konzept der physiologischen Nische. Datenbasis: Standortdaten der Österreichischen Waldinventur (ohne Schutzwald außer Ertrag). Links: Heutiges Klima repräsentiert durch die Messperiode 1961 bis 1990 ; rechts: Klimaänderungsszenario A1B am Ende des 21. Jahrhunderts (Temperatur: bis $+4.5^{\circ} \mathrm{C}$, Niederschlag: bis $-35 \% \mathrm{im} \mathrm{Sommerhalbjahr).}$ Rot $=$ hoher Klimastress, gelb $=$ mäßiger Klimastress, grün = geringer Klimastress

Figure 3.5 Simulated climate-related stress index for Fagus sylvatica based on the physiological niche concept. Data: Site data from Austrian Forest Inventory (exluding protection forests without yield). Left bottom panel: current climate represented by period 1961 to 1990 ; right bottom panel: climate change scenario $\mathrm{AlB}$ at the end of $21^{\text {st }}$ century (temperature: up to $+4.5^{\circ} \mathrm{C}$, precipitation: up to $-35 \%$ during summer season). Red $=$ high stress, yellow $=$ moderate stress, green $=$ low $/$ no stress

bis ins südliche Burgenland führen. In Summe aber wird die Buche das für sie potentiell besiedelbare Areal in Österreich als Folge der Klimaänderung ausdehnen können.

Während in Abbildung 3.4 und Abbildung 3.5 der potentielle Klimastress für einzelne Baumarten an Standorten in Österreich wissensbasiert abgeschätzt wird (Steiner und Lexer, 1998; Niedermayr et al., 2007), gibt es auch Ansätze, die anhand von Daten aus Großrauminventuren mit statistischen Methoden Beziehungen zwischen Standort- und Klimaparametern sowie dem Auftreten einer Baumart kalibrieren und diese Modelle dann zur Abschätzung des potentiellen Vorkommens unter Klimaänderungsbedingungen einsetzen (z. B. Zimmermann et al., 2013).

Der direkte Vergleich dieser beiden Nischenmodellansätze ist nur sehr schwer möglich. Teilweise zeigen die statistisch ermittelten Nischenmodelle (Zimmermann et al., 2013) mit ökophysiologischen Nischenansätzen idente Ergebnisse. Es treten jedoch auch widersprüchliche Ergebnisse auf. Die Fichte etwa ist im statistischen Modellkonzept in Abbildung 3.6 in der zweiten Hälfte des Jahrhunderts im Mühlviertel vertreten während im ökophysiologischen Konzept (Abbildung 3.4) praktisch nur mehr der Alpenhauptkamm befriedigende Bedingungen für Fichten aufweist. Die Interpretation der wissensbasierten ökophysiologischen Nischenmodelle ist sehr einfach möglich (d.h. im Sinne der „Eignung einer Baumart"), bei den statistischen Nischenmodellen bleiben Ursache-Wirkungsbeziehungen und der Interpretationsspielraum bei der geschätzten „Auftretenswahrscheinlichkeit“ vielfach unbekannt.

Ein weiteres quantitatives Modell der ökologischen Nische von Waldbaumarten wurde von Kölling (2007) für Deutsch- land vorgestellt. Hierzu wurden Karten von Vegetationstypen verwendet um einen Datensatz zu Absenz bzw. Präsenz von Baumarten zu generieren, der wiederum dazu verwendet wurde, sogenannte baumartenspezifische Klimahüllen zu entwickeln.

\subsubsection{Einjährige landwirtschaftliche Nutzpflanzen}

\section{Abgrenzung und Bedeutung}

Winterungen einjähriger Nutzpflanzen, wie diverse Wintergetreidearten oder Raps, werden typischerweise im Herbst angebaut, überwintern in weiterer Folge und starten als Jungpflanzen in die Wachstumsperiode des neuen Jahres. Dies bedingt einen Entwicklungsvorsprung gegenüber Sommerungskulturen mit früherer Reife und Ernte. Viele Winterungskulturen, wie Wintergetreide, sind im Jugendstadium auf niedrige Temperaturen als Voraussetzung für ihren Entwicklungszyklus angewiesen („Vernalisation“), profitieren in trockenen Regionen wesentlich von der Winterfeuchte, also den höheren Bodenwassergehalten während ihrer Wachstumsphase, sind aber auch Frost und Nässe mehr ausgesetzt als Sommerungskulturen (Kersebaum und Eitzinger, 2009).

Sommerungen werden als einjährige Nutzpflanzen (Mais, Sommergetreide, Zuckerrübe, Sonnenblume, Gemüsearten, usw.) im Frühjahr angebaut und befinden sich je nach Kultur bis in den Sommer oder bis hin zum Herbst in der Wachstumsphase. Dadurch sind sie im Mittel häufiger Sommertrockenheiten und Hitzeperioden ausgesetzt als typische Winterun- 

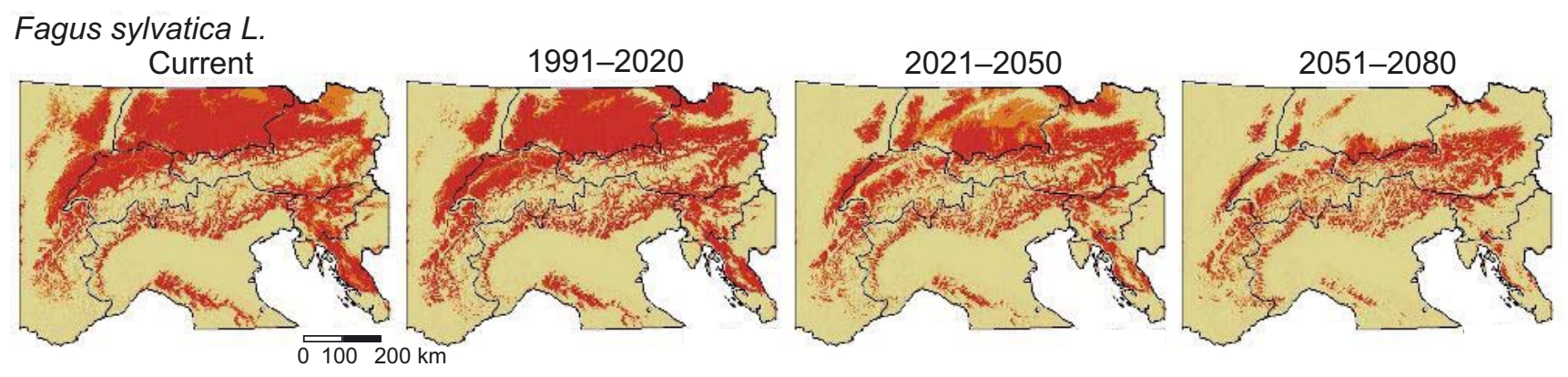

Picea abies $L$.
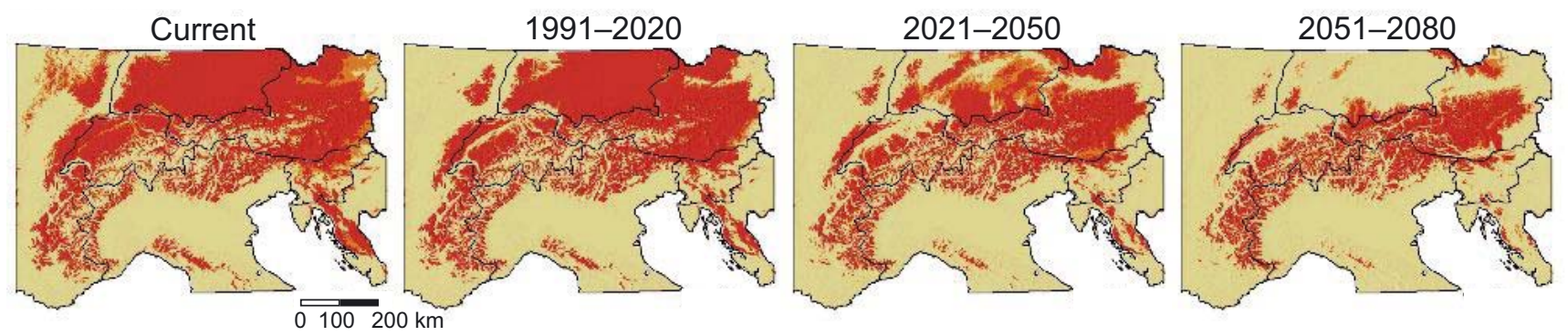

Abbildung 3.6 Potentielle Verbreitung von Buche und Fichte in mehreren Zeiffenstern während des 21. Jahrhunderts. Das verwendete Klimaänderungsszenario beinhaltet eine Erwärmung von etwa $3^{\circ} \mathrm{C}$ und eine $10 \%$ ige Abnahme der Sommerniederschlage bis $2051 / 80$. Rot = die Baumart kommt wahrscheinlich vor, orange $=$ die Baumart kommt möglicherweise vor, grau $=$ die Baumart kommt potentiell nicht vor. Quellen: Zimmermann et al. (2013), Jandl et al. (2012)

Figure 3.6 Potential future distributions of Fagus sylvatica and Picea abies during the $21^{\text {st }}$ century. The climate scenario assumes a warming of $3^{\circ} \mathrm{C}$ and a decline in summer precipitation by $10 \%$ until $2051 / 80$. Red $=$ presence of tree species is very likely, orange $=$ moderate likelihood of tree species presence, grey = presence of tree species is unlikely. Source: Zimmermann et al. (2013), Jandl et al. (2012)

gen. Mehrjährige Kulturen, wie im Futterbau, können unter diesem Aspekt zu Sommerungen gezählt werden, obwohl sie durch die Überwinterung auch vom Winterhalbjahr beeinflusst werden. Ihr Vorteil kann jedoch eine tiefere Durchwurzelung und die damit verbundene bessere Erschließung von Wasservorräten sein.

Im Jahr 2012 wurde in Österreich eine Ackerfläche von 1,35 Mio. ha bewirtschaftet (vgl. landwirtschaftliche Landnutzung, Band 3, Kapitel 2). Das entspricht 16,2 \% der österreichischen Staatsfläche. Den größten Anteil des Ackerlandes nahm der Getreideanbau mit rund $60 \%$ ein, wobei hier der Winterweichweizen mit ca. 280000 ha vor Körnermais mit ca. 220000 ha die bedeutendste Rolle spielt (BMLFUW, 2013).

Feldfutterbau beansprucht nach Angaben im Grünen Bericht (BMLFUW, 2013) 18,0 \% des Ackerlandes, Ölfrüchte (inkl. Raps) 10,6 \%. Hackfrüchte (inkl. Zuckerrübe mit ca. 50000 ha) sind auf $5 \%$ der Ackerflächen zu finden, während Körnerleguminosen (Erbsen und Pferdebohnen) nur 1,6\% des Ackerlandes ausmachen. 3,0 \% des Ackerlandes liegen brach.

Raps hat in den vergangenen Jahren in Mitteleuropa vor allem durch seine Verwendung als Energiepflanze flächenmäßig an Bedeutung gewonnen. Spezialkulturen, wie zahlreiche Nutzpflanzen im Gemüsebau, sind flächenmäßig weitaus we- niger bedeutend und in den jeweiligen Anbauregionen (Eferdinger Becken oder Marchfeld) konzentriert vorzufinden.

\section{Sensitivität in Bezug auf Klimavariable}

Eine allgemeine Charakterisierung der physiologischen Reaktion von C3- und C4-Pflanzen auf Umweltfaktoren, insbesondere das Temperatur- und Wasserversorgungsregime findet sich in Abschnitt 3.2.5 gegeben. Beispiele für C3-Nutzpflanzen sind Weizen, Roggen, Hafer oder Reis, für C4-Pflanzen Mais, Zuckerrohr oder Hirse.

Die Produktivität von Nutzpflanzen kann insbesondere von Wetterextremen negativ beeinflusst werden. Zum Beispiel können leichte Hagelschäden oder mechanische Schäden durch starke Windböen vermehrt Fusariumbefall auslösen und damit die Toxinbelastung des Ernteproduktes erhöhen.

Auch Gasbestandteile der Luft beeinflussen das Pflanzenwachstum. Bodennahes Ozon, das während Hitzeperioden verstärkt auftritt, schädigt zum Beispiel den Spaltöffnungsmechanismus. Kohlendioxid hingegen wirkt stimulierend auf die Photosyntheseleistung. C3-Pflanzen reagieren stärker auf einen steigenden Kohlendioxidgehalt der Atmosphäre, als C4Pflanzen. Allerdings ist diese Reaktion von Umweltfaktoren 
und genetischen Faktoren abhängig. Zum Beispiel zeigte die Zuckerrübe in Experimenten geringere Reaktionen auf eine höhere $\mathrm{CO}_{2}$-Konzentration der Atmosphäre (Schaller und Weigel, 2007) als Getreidearten, wobei es auch hier Sortenunterschiede gibt.

\section{Klimawandelfolgen in Österreich}

Die in den nationalen Ertragsstatistiken europäischer Länder der vergangenen Jahrzehnte sichtbaren Ertragssteigerungen sind primär dem Fortschritt bei Agrartechnik, agro-chemischen Maßnahmen und in der Pflanzenzüchtung zuzuschreiben (Kersebaum und Eitzinger, 2009). Neben diesem positiven Ertragstrend zeigt sich vor allem in der Schweiz und Österreich eine Zunahme der zwischenjährlichen Ertragsvariabilität (Peltonen-Sainio et al., 2010), die zum Teil auf klimawandelbedingte Faktoren zurückgeführt wird. Es muss allerdings bei nationalen Ertragsstatistiken darauf hingewiesen werden, dass es sich dabei um aggregierte Werte handelt, die für regional differenzierte Aussagen wenig geeignet sind. So ist durchaus anzunehmen, dass in den humideren bzw. höher gelegenen kühleren Regionen das Ertragspotenzial beispielsweise für Getreide oder im Futterbau durch den Klimawandel im Gegensatz zu heute schon trockeneren und wärmeren Regionen in Mitteleuropa zunimmt (Fuhrer et al., 2007; Eitzinger et al., 2013).

Nicht bewässerte Sommerkulturen mit geringeren Temperaturansprüchen (Sommergetreide, Zuckerrübe, Kartoffel, usw.) werden zunehmend von Hitzestress und Trockenschäden betroffen sein, ihr Ertragspotenzial wird stagnieren bis zurückgehen, insbesondere auf leichten Böden mit geringer Wasserspeicherkapazität. Wärme liebende Sommerkulturen wie Mais, Sojabohne oder Sonnenblume können durch die zunehmenden Temperaturen im Ertragspotenzial profitieren, solange die Wasserversorgung nicht limitierend wirkt. Winterkulturen, wie z. B. Winterweizen, könnten tendenziell ein ansteigendes Ertragspotential aufweisen, da sie die Winterfeuchte in den Böden besser nutzen. Allerdings besteht an nassen Standorten oder in niederschlagsreichen Regionen zunehmend auch die Gefahr von Staunässe wegen zunehmender Niederschläge im Winterhalbjahr. Auch droht Winterkulturen bei wärmeren Wintern zunehmend Gefahr von Seiten der Schädlinge und Krankheiten. Bei bewässerten Kulturen besteht ein zunehmender Wasserbedarf, möglicherweise müssen bisher nicht bewässerte Kulturen regional zunehmend bewässert werden.

Die erwartete Zunahme der Vegetationsperiodenlänge um durchschnittlich ca. 8 Tage/Jahrzehnt in den nächsten Jahrzehnten (Band 1, Kapitel 4) bedingt eine entsprechende
Vorverschiebung der Pflanzenphänologie als auch der damit verbundener Feldarbeiten (Anbau, Düngung, Ernte). Die Entwicklung der Pflanzen beschleunigt sich, damit werden an die Phänologie gebundene Arbeiten immer früher stattfinden (früherer Anbau, frühere Erntetermine, Verschiebung bei den Pflegemaßnahmen). Durch heißere Sommer wird es insgesamt zwar mehr Feldarbeitstage im Sommer geben, die Arbeitsspitzen werden aber immer früher stattfinden. Dadurch könnten sich schlechtere Bedingungen für Feldarbeiten, insbesondere bei frühem Anbau einstellen (Eitzinger et al., 2013).

Eine mögliche Zunahme von klimatischen Extremereignissen bewirkt eine Zunahme der jährlichen Ertragsschwankungen in der landwirtschaftlichen Produktion. Dazu zählen insbesondere Hitzeperioden und Trockenheit, aber auch durch Starkniederschlag verursachte Bodenerosion oder Auswinterungsschäden, regionale Sturmschäden (vor allem durch heftigere Gewitter) sowie regional Frost- und Hagelschäden.

Es sind deutliche Änderungen bei Unkräutern, Schädlingen und Krankheiten zu erwarten (Weigand und Tischner, 2007; Glauninger und Kersebaum, 2009; Kocmancova et al., 2010). Vor allem wärmeliebende Insekten können sich stärker ausbreiten (neue Schädlinge, höhere Überwinterungsraten, raschere Ausbreitung oder zusätzliche jährliche Generationen). Viele Pilzkrankheiten könnten in den trockeneren Regionen eher zurückgehen, allerdings haben auch andere Faktoren, wie eine schnellere Entwicklung der Pflanzen einen Einfluss auf den Befallsdruck. Es könnte zu einer Ausbreitung wärmeliebender und wurzelbetonter Unkrautarten (vor allem hitze- und trockentolerante Arten) kommen. Siehe auch Abschnitt 3.2.9 (,Schadorganismen an Nutzpflanzen“).

Die nachfolgend genannten Erkenntnisse zu den Auswirkungen von Klimaszenarien auf die Produktivität von Nutzpflanzen in Österreich basieren meist auf den A1B- und A2-Szenariosimulationen mehrerer globaler Klimamodelle. Die saisonalen Klimasignale (im Vergleich zur Bezugsperiode 1961 bis 1990) der verwendeten Klimaszenarien (Kombinationen von Klimamodell und Emissionsszenario) liegen in den weiter unten diskutierten Studien für 2050 (als Orientierungshilfe) bei der Temperatur bei +2 bis $+3^{\circ} \mathrm{C}$ (ganzjährig) und beim Niederschlag bei ca. +4 bis $+20 \%$ (Okt. bis Apr.) sowie -1 bis $-40 \%$ (Mai bis Sept.).

\section{Winterweizen}

Für verschiedene Standorte in Nord-Österreich zeigen Simulationsrechnungen für Weizen in der Periode um 2050 gegenüber dem Referenzzeitraum 1961 bis 1990 einen Rückgang der Erträge um -2 bis $-8 \%$ (Alexandrov et al., 2002) ohne 
Berücksichtigung des $\mathrm{CO}_{2}$-Düngungseffekts. Mit Berücksichtigung der Wirkung einer erhöhten atmosphärischen $\mathrm{CO}_{2}$-Konzentration auf die Photosynthese verschiebt sich die Schätzung in den positiven Bereich und zeigt Ertragszuwächse von +4 bis $+11 \%$ (Kersebaum et al., 2008; Fuhrer, 2003; Strauß et al., 2012). Die weiteren Aussichten für den Zeitraum bis 2080 weisen eine weitere Verstärkung der Trends sowohl in negativer wie auch in positiver Richtung mit $\mathrm{CO}_{2}$-Effekt aus (Eitzinger et al., 2003).

Neuere Studien für Österreich (Thaler et al., 2012; Eitzinger et al., 2013) berücksichtigen auch den Einfluss verschiedener Bodenklassen und bereits angepasster Saattermine auf die Erträge. Die raschere Abtrocknung der flachgründigen Böden kann vermehrt Trockenstress während der besonders empfindlichen Phasen der Blüte und Kornfüllung verursachen. Auf den besseren landwirtschaftlichen Böden verliert die nutzbare Feldkapazität als limitierender Faktor an Bedeutung. Eine Steigerung der nutzbaren Feldkapazität von 200 auf 300 mm im gesamten Wurzelraum führt hier kaum mehr zu einer Ertragssteigerung. Auch auf diesen Böden stellt Wasser einen wesentlichen limitierenden Faktor dar, wobei hier jedoch die Witterung ausschlaggebend ist. Trotz möglicherweise steigender Sommertrockenheit nimmt die durchschnittliche Belastung von Winterweizen durch Trockenstress ab und es kann für fast jede Bodenklasse mit einem Anstieg des Winterweizenertrags gerechnet werden. Der negative Effekt der verkürzten Wachstumsperiode des Winterweizens wird durch den simulierten $\mathrm{CO}_{2}$-Düngungseffekt bzw. den früheren Wachstumsbeginn überkompensiert. Trotz dieses positiven Bildes zeigt sich aber auch, dass die Unterschiede im Ertragspotenzial zwischen den Bodenklassen und damit die regionalen Unterschiede tendenziell zunehmen.

Der fallweise simulierte positive Effekt auf das Ertragspotenzial sagt jedoch noch nicht aus, dass dies auch für die realen Erträge gelten muss, wenn bisher nicht berücksichtigte aber potentiell stärker werdende Schadfaktoren wirksam werden, wie deutlich zunehmende Witterungsextreme oder Schädlingsbefall. Simulationsstudien für Trockengebiete in Tschechien, Slowakei, Österreich und Deutschland weisen auf zusätzlichen Wasserbedarf der Nutzpflanzen zur Erhaltung eines optimalen Ertrages hin (Thaler et al., 2012; Eitzinger et al., 2013; Kersebaum und Eitzinger, 2009). Für das Marchfeld in Österreich ergab sich ein Zusatzwasserbedarf bei Winterweizen von ca. $30 \mathrm{~mm}$ (entspricht ungefähr einer Beregnungsgabe) für die 2050er Jahre (mit $\mathrm{CO}_{2}$-Effekt, auf mittelschwerem Boden). Auch weisen manche Simulationen auf steigende Nitratauswaschung unter Klimaszenarien hin (Strauß et al., 2012; Thaler et al., 2012).

\section{Wintergerste}

Für Wintergerste liegen nur wenige Abschätzungen für die zukünftige Entwicklung vor. Obwohl die Reaktionen auf Klimafaktoren und steigende $\mathrm{CO}_{2}$-Konzentration grundsätzlich ähnlich wie bei Weizen sind, ist durch die frühere Entwicklung der Wintergerste eine etwas geringere Empfindlichkeit gegenüber sommerlichen Hitze- und Trockenperioden zu erwarten. Andererseits ist bei niedrigeren Temperaturen auch mit einer geringeren Stimulierung des Wachstums durch die höhere $\mathrm{CO}_{2}$-Konzentration zu rechnen (Schaller und Weigel, 2007). Durch langfristig wärmere Wintermonate unter Klimaszenarien besteht die Gefahr, dass die Winterhärte der Gerste abnimmt und dadurch die Auswinterungsgefahr (neben zunehmender Gefahren durch Krankheiten) in einzelnen Jahren steigt (Schaller und Weigel, 2007).

Raps

Für Raps liegen keine Untersuchungen vor. Die Entwicklung von Winterraps könnte jedoch durch wärmere Winter begünstigt werden. Frostschäden sollten eher zurückgehen, vorausgesetzt es treten keine Anpassungen bezüglich der Winterhärte ein. Allein die schnellere Entwicklung durch die höheren Temperaturen könnte im Frühsommer zu einer Beschleunigung der Abreife und damit zu geringeren Erträgen führen. Bei Zunahme der Sommertrockenheit könnte der Winterraps vor allem nach relativ spät räumenden Vorfrüchten in der Anfangsphase betroffen sein, da zu trockene Bodenverhältnisse das Auflaufen und die Etablierung des Vor-Winterbestandes behindern könnten.

\section{Weitere Winterungskulturen}

Andere eher frostempfindliche Winterformen von Kulturarten wie Ackerbohnen könnten in Zukunft deutlich an Produktionspotenzial gewinnen und zunehmend auch typische Sommerungsfrüchte ersetzen. Neue Zuchtformen, die zukünftigen Klimabedingungen angepasst sind, lassen in Zukunft ein entsprechend größeres Sortenspektrum erwarten, das für den Anbau zur Verfügung steht.

\section{Mais}

In den meisten Klimawandelstudien wird Mais, abgesehen von einigen trockenen Regionen, als Gewinner des Klimawandels in Mitteleuropa beschrieben (d.h. mit steigendem Ertragspotenzial, vorausgesetzt man steigt auf späterreifende 
Sorten um), obwohl beim Mais als $\mathrm{C}_{4}$-Pflanze eine höhere atmosphärische $\mathrm{CO}_{2}$-Konzentration kaum ertragssteigernd wirkt (Eitzinger et al., 2009a).

$\mathrm{Da}$ in Österreich in den wichtigen Maisanbaugebieten später reifende Sorten angebaut werden könnten, wäre eine Erwärmung im langjährigen Mittel hinsichtlich des Ertragspotenzials bei Mais positiv zu beurteilen. Dies bestätigen auch zahlreiche europaweite Simulationsstudien, welche für die temperaturlimitierten Maisanbaugebiete vorwiegend zunehmende Ertragspotenziale vorhersagen, vorausgesetzt, die Wasserversorgung während der Vegetationsperiode ist weitgehend sichergestellt.

Ein hohes Schadpotenzial haben bei Mais allerdings Witterungsextreme, welche regional unter den Bedingungen von Klimaszenarien durchaus zu einem zunehmenden Problem werden könnten (vgl. Sensitivität der Nutzpflanzen in Abschnitt 3.2.7).

Das Produktionspotential von Mais dürfte in Österreich unter Klimawandelszenarien der nächsten Jahrzehnte insbesondere in den derzeit kühleren und niederschlagsreicheren Regionen, wie Oberösterreich, stark ansteigen (Eitzinger et al., 2009b). Aber auch Regionen mit zusätzlich nötiger Bewässerung für Mais dürften sich in den kommenden Jahrzehnten in Österreich ausweiten, bzw. neu entwickeln (zum Beispiel Teile der Südoststeiermark, auf Schotterböden der Welser Heide im zentralen Oberösterreich). Dort wo schon bewässert wird, wird mit wärmeren und trockeneren Bedingungen der Bestandswasserbedarf von Mais weiter ansteigen.

Die Grenze für den Körnermaisanbau dehnt sich in Österreich langsam in größere Höhenlagen aus. So könnte Körnermais von den klimatischen Bedingungen her zunehmend in jetzt typische Silomaisgebiete (vorwiegend Futterbauregionen) des Alpenvorlandes (etwa über $500 \mathrm{~m}$ Seehöhe, zum Beispiel die „Bucklige Welt“ am Ostalpenrand Österreichs) oder von Mittelgebirgen (zum Beispiel der böhmischen Masse) vordringen, soweit dies sonstige Bedingungen zulassen.

Hinterholzer (2004) berichtet über zunehmende Jahrestemperatursummen (um $200-300^{\circ} \mathrm{C}$ ) in drei klimatisch unterschiedlichen österreichischen Maisanbaugebieten von Oberösterreich, der Steiermark und dem Burgenland im Zeitraum 1970 bis 2000. Am kühleren Standort Lambach erhöhte sich die Temperatursumme für die Wachstumsperiode des Maises zum Beispiel von 900 auf $1200^{\circ} \mathrm{C}$ mit bis heute weiter steigender Tendenz. An allen drei Versuchsstandorten wurden in diesem Zeitraum deutlich abnehmende Kornfeuchtigkeiten bei der Abreife in der jeweiligen Reifeklasse gemessen. Der praktische Anbau hat in diesen Regionen bereits darauf reagiert, sodass heute bereits Sorten mit höheren Reifezahlen angebaut werden als in den kühleren 1970er-Jahren.

Die Erwärmung hat auch deutliche Auswirkungen auf den Krankheits- und Schädlingsbefall von Mais (Zunahme der Blattflecken [H. turcicum], des Maiszünslers, Verschiebung der Artenspektren bei Fusarium) und auf die Ausbreitung bestimmter Beikräuter (Glauninger und Kersebaum, 2009; Grünbacher et al., 2006). In den letzten Jahren hat sich insbesondere der Maiswurzelbohrer (Pilz und Kahrer, 2012; AGES, 2012) in Österreich ausgebreitet. Maßnahmen in Bezug auf Fruchtfolge und Anbaudichte sind ausstehend.

\section{Sommergetreide}

Für Sommergetreide wie Sommerweizen oder -gerste dürften sich in den trockenen Regionen unter Klimawandelszenarien auch trotz. Berücksichtigung des $\mathrm{CO}_{2}$-Effektes leicht abnehmende Erträge ergeben, vor allem wegen zunehmender Wasserknappheit während des Sommers. Als Beispiel sei hier das Marchfeld angeführt, wo Simulationsanalysen für die Periode um 2050 für Sommergerste eine je nach Bodenwasserspeicherfähigkeit unterschiedlich starke Ertragsabnahme bzw. Zunahme von Trockenstress der Gerste zeigen; der Effekt ist umso stärker je weniger Wasserspeichervermögen der Boden hat (Thaler et al., 2012; Eitzinger et al., 2013). Für andere Getreidearten wie für Hafer gelten dieselben Prinzipien hinsichtlich der Auswirkungen.

\section{Zuckerrüben}

Für Zuckerrüben bedeutet die Erwärmung zunächst eine Verlängerung der mittleren Wachstumsperiode, da die Erwärmung keine vorzeitige Abreife verursacht wenn sich die Pflanze im gesamten Jahr im vegetativen Stadium befindet. Limitierend könnte sich jedoch das Wasserangebot auswirken, da bei abnehmenden Sommerniederschlägen zunehmend mit Trockenstress zu rechnen ist. Auch könnten sich höhere Nachttemperaturen insbesondere im Herbst negativ auf die $\mathrm{Zu}$ ckerausbeute auswirken. Europaweit wird eine Verschiebung der Anbauflächen in Richtung Norden erwartet (Jones et al., 2003). In Österreich zeichnet sich in den trockenen Regionen, wie im Marchfeld bereits ein Rückgang des Zuckerrübenanbaues ab, vor allem im Zusammenhang mit einer entweder nicht mehr kostendeckenden Bewässerung oder mangelnder Infrastruktur für zusätzliche Bewässerung. An diesem Beispiel zeigt sich, dass Klimawandelfolgen anhand von Verhaltensindikatoren meist vieldeutig zu interpretieren sind. 


\section{Kartoffel}

Ähnlich wie für die Zuckerrübe sind die Auswirkungen für den Kartoffelanbau einzuschätzen. Die Verlängerung der Vegetationszeit dehnt die potenzielle Anbauperiode aus und erlaubt eine höhere Flexibilität. Da Kartoffeln im Gegensatz zu Zuckerrüben an Standorten mit leichteren, sandigen Böden zu finden sind, dürfte die Anfälligkeit gegenüber sinkenden Sommerniederschlägen tendenziell höher sein bzw. die Notwendigkeit für Bewässerung bzw. die Bewässerungsmenge stärker ansteigen. Dies gilt vor allem für die wärmeren Anbauregionen, wie das Marchfeld im Osten Österreichs, aber auch für die höher gelegenen, kühleren Standorte mit sehr flachgründigen Böden, wie zum Beispiel im Waldviertel, und generell für Gebiete nördlich der Donau in Österreich. Im Waldviertel kann es zum Beispiel notwendig werden, zusätzlich Bewässerung einzuführen, wobei in dieser Region die Verfügbarkeit von Bewässerungswasser zu einem Problem werden könnte (geringe Grundwasserreserven, hügeliges Terrain).

Der Kartoffelanbau ist bezüglich möglicher Auswirkungen im Schädlings- und Krankheitsauftreten stark betroffen. Es könnte sein, dass sogenannte "Gesundungsgebiete“ in den kühleren Regionen (oft als Vermehrungs- und Züchtungsstandorte genutzt) aufgrund der zunehmenden Verbreitung von Viruskrankheiten bzw. derer Vektoren ihre Funktion nicht mehr zufriedenstellend erfüllen können (zum Beispiel Gebiete im Wald- und Mühlviertel Österreichs). Andererseits können trockenere Bedingungen durch schlechtere Ausbreitungsmöglichkeiten für Pilzkrankheiten dem Gesundheitszustand der Kartoffel nützen und den Pflanzenschutzaufwand verringern, der allein zur Bekämpfung bzw. Vorbeugung der Kraut- und Knollenfäule einen beträchtlichen Einsatz erfordert.

\section{Weitere Sommerkulturen}

Für andere Sommerkulturen liegen nur wenige regionale Simulationsstudien vor. Europäische Untersuchungen, wie ACCELLERATES (Audsley et al., 2006), welche die Auswirkungen des Klimawandels auf verschiedene Kulturen auf einer größeren räumlichen Skala abschätzen, bestätigen regionale Studien, dass wärmeliebende Kulturen insgesamt ein größeres Produktionspotenzial unter Klimaszenarien aufweisen werden. Für Mitteleuropa wird unter Berücksichtigung des $\mathrm{CO}_{2}$-Düngungseffektes in Szenarien mit maximal moderatem Niederschlagsrückgang im Sommerhalbjahr zum Beispiel eine deutliche Zunahme der Sojabohnenerträge erwartet. Aber auch Mais, und Sonnenblume würden demnach mit Ertrags- steigerungen von bis zu $30 \%$ und mehr bis zu den 2050erJahren deutlich profitieren. Trockenstressempfindliche Sommerkulturen würden in den Erträgen eher nachgeben oder weniger zunehmen, wie vor allem Sommergetreide, Kartoffel oder Grünland. Dies kann allerdings regional, in einer kleineren räumlichen Skala, je nach Standortbedingungen und zugrunde gelegtem Klimaszenario ein sehr unterschiedliches Bild ergeben.

\section{Gemüsekulturen}

Diese Kulturen zeichnen sich, von einigen Ausnahmen abgesehen, durch eine relativ kurze Wachstumsperiode, hohen Wasserbedarf und notwendige gleichmäßige Wasserversorgung (wegen des meist nur flachgründigen Wurzelsystems) aus. Sie erfordern hohe Investitionen pro Flächeneinheit, weisen dafür einen hohen Deckungsbeitrag auf und werden intensiv betreut, um alle Wachstumsfaktoren zu optimieren. So werden diese Kulturen, wenn nötig, größtenteils bewässert, so dass die in den Klimaszenarien angegebenen abnehmenden Niederschläge keine direkte Schadwirkung hervorrufen werden. Lediglich der durch die zunehmenden Verdunstungsraten erhöhte Wasserbedarf für die Bewässerung könnte regional zu einem Problem werden, wenn zum Beispiel Grundwasserstände langfristig zu stark absinken und damit zusammenhängende Nutzungsbeschränkungen erlassen werden bzw. sich die Wassernutzung verteuert (EEA, 2008).

Der größte Vorteil beim Anbau von Gemüsekulturen wird wahrscheinlich aus einer Verlängerung der Vegetationsperiode resultieren, die unter Umständen wegen der kurzen Vegetationszeit der Kulturen einen zusätzlichen Anbauzyklus pro Jahr erlaubt. Die bei einem sehr frühen Anbau notwendige Verwendung von Folien zur Förderung des Jugendwachstums durch Erhöhung der Bodentemperatur könnte teilweise entfallen (außer Bodenfolien oder Folientunnel werden als Verdunstungsschutz eingesetzt). Auf der anderen Seite ist vor allem der deutlich zunehmende Trend zu mehr Hitzeperioden mit damit verbundenem Hitzestress zu nennen, der insbesondere in Folientunneln und schlecht regulierbaren Glashäusern zu zunehmenden Problemen durch Überhitzung führen kann. Extrem hohe Bodentemperaturen könnten wegen der oft nicht geschlossenen Bestände beim Gemüse (offener, abgetrockneter oder dunkler Boden erhitzt wesentlich stärker bei Sonneneinstrahlung als bedeckter Boden) zunehmend zu einem Problem für die Pflanzen werden. Hier spielen negative Auswirkungen auf das Wurzelwachstum oder mögliche Förderung von Wurzelkrankheiten und Schadinsekten eine wichtige Rolle. Die Kombination von durchschnittlich erhöhten Temperaturen 
und vermehrter Bewässerung schafft ein feucht-warmes Mikroklima, welches das Auftreten von bestimmten Pilzkrankheiten begünstigt, die wegen der hohen Flächenproduktivität ein besonders hohes Schadpotenzial aufweisen.

\subsubsection{Landwirtschaftliche Daverkulturen}

\section{Abgrenzung und Bedeutung}

Der Obst- und Weinbau hat in Österreich regionale Schwerpunkte: Der Weinbau in den klimatisch warmen Regionen der Steiermark, Niederösterreichs und des Burgenlandes, der Obstbau in den humid warmen Klimaregionen der Steiermark. Der Erwerbsobstbau wird in Österreich auf etwa 11000 ha (großteils in Form von Apfelproduktion) betrieben. Der Weinbau umfasst für 2012 eine Anbaufläche von etwa 43600 ha (BMLFUW, 2013).

\section{Sensitivität in Bezug auf Klimavariable}

Die mehrjährigen, landwirtschaftlich genutzten Wein- und Obstbaukulturen weisen im Allgemeinen eine höhere Sensitivität in Bezug auf den Klimawandel auf. Dauerkulturen sind der ganzjährigen Witterung ausgeliefert und ökonomisch meist durch hohe und längerfristig gebundene Investitionen gekennzeichnet, was eine mittelfristig nur wenig oder nur mit hohem Aufwand veränderbare Produktionstechnik bedingt. Auswirkungen des Klimawandels auf Dauerkulturen müssen daher aufmerksam verfolgt werden, um rechtzeitig kurz- und langfristig sinnvolle Anpassungsmaßnahmen setzen zu können (siehe dazu Band 3).

Bei Dauerkulturen werden die Wachstumsperiode und die phänologische Entwicklung der Pflanzen in Abhängigkeit ihrer Bedürfnisse stark von der Temperatur bzw. den Temperatursummen gesteuert. Höhere Temperaturen lassen einen Trend zur früher einsetzenden und insgesamt schneller ablaufenden phänologischen Entwicklung erkennen. Insbesondere milde Winter und Frühjahre beschleunigen die phänologische Entwicklung in den frühen Entwicklungsphasen, begünstigen andererseits aber auch das Potenzial für Frostschäden. Auf den Blühbeginn des Weines zum Beispiel haben vor allem die Temperaturen im Mai einen großen Einfluss. Die Temperaturen beeinflussen auch die Inhaltsstoffe, wie z. B. den steigenden Zuckergehalt der Trauben bei höheren Temperaturen. Eine frühe Rebenphänologie bedeutet auch, dass die reifenden Beeren insgesamt höheren Temperaturen am Stock ausgesetzt sind. Dies führt in Kombination mit höheren Zuckergehalten und niedrigeren Säuregehalten der Beeren bei feuchten Wit- terungsbedingungen zu einem erhöhten Befallsdruck durch Fäulniserreger (Eitzinger et al., 2009c).

Während Wein abgesehen vom Jugendstadium relativ trockenresistent ist, reagieren Obstkulturen (vor allem Apfelkulturen) empfindlich auf Trockenheit und sind daher eher auf Bewässerung oder humide Regionen angewiesen. Dauerkulturen sind insbesondere durch Extremwetterereignisse gefährdet, was gerade aufgrund des hohen flächenbezogenen Deckungsbeitrags von großer ökonomischer Bedeutung ist. Hierbei sind insbesondere Schäden durch Hagel oder Extremniederschläge zu nennen, im Obstbau auch Hitze- und Frostschäden.

\section{Klimawandelfolgen in Österreich}

Auswirkungen des Klimawandels auf landwirtschaftliche Dauerkulturen (Wein- und Obstbau) zeichnen sich bereits seit längerer Zeit ab.

Weinbau

In Österreich würde ein weiterer Temperaturanstieg in den nächsten Jahrzehnten den Weinbau begünstigen. In den bestehenden Weinanbaugebieten würde sich ein Temperaturanstieg besonders günstig auf Rotweinsorten bzw. auf die Rotweinqualität auswirken. Weißweinsorten, bei denen der Säuregehalt ein wesentliches Qualitätsmerkmal ist, könnten in kühleren oder neuen Anbaugebieten an Qualität gewinnen bzw. in bisherigen Anbaugebieten an Qualität einbüßen.

Welche Veränderungen der flächenmäßigen Ausweitung des klimatischen Potenzials für den Weinanbau sich für Klimaänderungsszenarien ergeben, kann aufgrund von für den Weinbau abgestimmten klimatischen Indizes, wie dem HUGLIN Index (Wärmesumme über $10^{\circ} \mathrm{C}$ von April bis September), abgeschätzt werden. Abbildung 3.7 zeigt den historischen Trend des Huglin-Index für einige repräsentative Wetterstationen typischer Weinbauregionen seit 1961.

Für eine genauere Bewertung von Standorten und eine optimale Abstimmung der Produktionstechnik müssen alle Standortfaktoren berücksichtigt werden. Einen Eindruck dazu liefert eine aktuelle, räumlich hoch aufgelöste Analyse des Weinanbaugebietes "Carnuntum“ in Ostösterreich (Eitzinger et al., 2012b). Der tatsächliche Weinanbau wird durch frostgefährdete Tallagen beschränkt. Diese haben zwar im Normalfall die höchsten Temperatursummen und simulierten Mostgewichte, der Weinanbau kann aber aufgrund der bisherigen Frostgefährdung zum größten Teil nicht dauerhaft, oder nur unter Inkaufnahme von Frostschäden stattfinden. Deutlich kommt der Einfluss der Hangausrichtung und des 


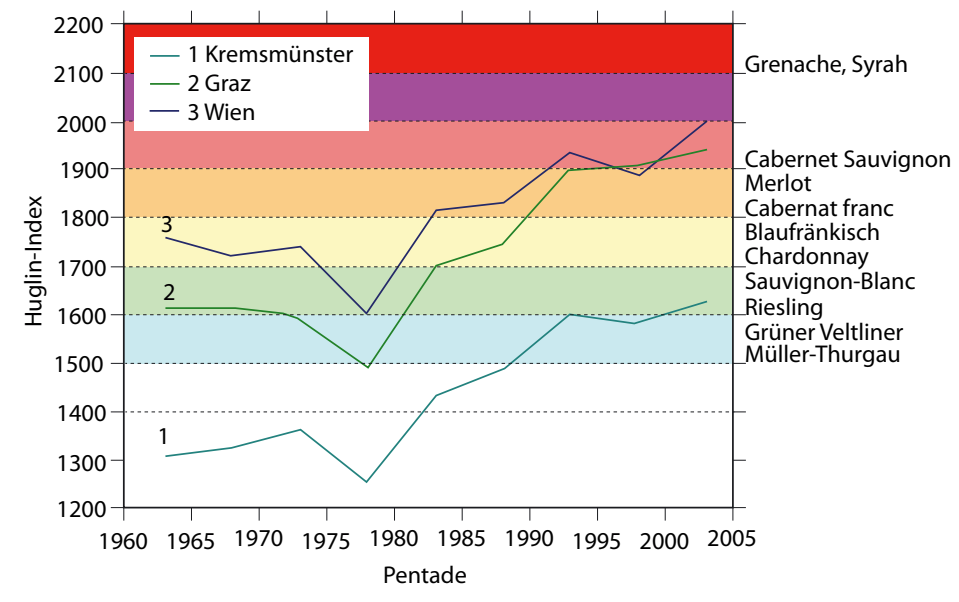

Abbildung 3.7 Entwicklung des Huglin-Index (Wärmesumme über $10^{\circ} \mathrm{C}$ von April bis September) seit 1961 für verschiedene meteorologische Stationen in Österreich. Farbgebung charakterisiert the Huglin-Bereich für spezifische Rebsorten. Quelle: Eitzinger et al. (2009c)

Figure 3.7 Development of Huglin-Index (heat sum $>10^{\circ} \mathrm{C}$ from April to September) since 1961 for a set of weather stations in Austria. Colours denote Huglin categories for specific grapes. Source: Eitzinger et al. (2009c)
Geländes auf die Temperatursummen und andere klimatische Parameter, wie Windgeschwindigkeit oder Luftfeuchte, zum Ausdruck. Daneben kann es durch eine mögliche Zunahme von Extremwetterereignissen zu Schäden kommen, deren Entwicklung schwer abzuschätzen ist. Eine zunehmende Häufigkeit von Starkregenereignissen kann in Hanglagen zu einer verstärkten Erosion zwischen den Reben führen.

Über die letzten 20 Jahre zeigt sich in den mitteleuropäischen Anbaugebieten ein im Mittel 10 bis 20 Tage früherer Ablauf der phänologischen Entwicklungsphasen wie Austrieb, Blüte und Reife. Abbildung 3.8 zeigt den langjährigen Trend zeitlich früheren Lesereife und der früheren Lesetermine an unterschiedlichen Weinbaustandorten in Europa. Der Trend zu früherer Reife in Österreich wird durch steigende Zuckergehalte (zunehmendes Mostgewicht) und abnehmende Säuregehalte zum selben Messtermin sowie durch eine immer frühere Blüte bestätigt (Eitzinger et al., 2009b). Aber auch die Dauer der einzelnen Entwicklungsphasen verkürzt sich, wie zum Beispiel die Dauer der Rebblüte (Bauer, 2008; Koch, 2008).

Beim Wein wirkt sich die Veränderung beim Blühtermin direkt auf das Mostgewicht der Trauben aus. Der mit steigenden Temperaturen prognostizierte frühzeitige Reifebeginn lässt zwar hohe Mostgewichte erwarten, könnte sich aber negativ auf andere qualitätsbestimmende Inhaltstoffe auswirken. Neben zu niedrigen Säurewerten können sich bei einer zu frühen Reife die subjektiven Geschmackskomponenten (durch zu hohen Alkoholgehalt, wenig Säure, höheren Gerbstoffanteil u. a.) negativ verändern, was bisher in Mitteleuropa vor allem beim Weißwein beobachtet wird.

Die Reifephase der Beeren erfolgt in einem wärmeren Klima unter höheren Temperaturbedingungen, wodurch wegen der höheren Tages- und Nachttemperaturen ein verstärkter Säureabbau (Wein- und Apfelsäure) erfolgt, was zur Ausbildung veränderter Fruchtaromen führt. Es wird wahrscheinlich zur Verschiebung des Rebsortenspektrums kommen, hin zu später reifenden Rebsorten. Eine Veränderung der Weinqualität in Richtung reiferer, extrakt- und alkoholreicherer Weine ist zu erwarten.

Die Verfrühung der Rebenphänologie bedeutet, dass die reifenden Beeren insgesamt höheren Temperaturen am Stock ausgesetzt sind. Dies führt in Kombination mit höheren $\mathrm{Zu}-$ ckergehalten und niedrigeren Säuregehalten der Beeren bei feuchten Witterungsbedingungen zu einem erhöhten Befallsdruck durch Fäulniserreger, wie Pilzbefall durch Botrytis (Botrytis wird allerdings auch stark von Erziehung, Nährstoffversorgung und Bodenpflege beeinflusst) und Grünfäule (Penicillum sp.) sowie andere Schaderreger, wie Essigsäurebakterien (Petgen, 2007). Zusätzlich behindert die höhere Temperatur des Leseguts eine optimale Gärung. Um diese zu gewährleisten, müssten zukünftig die Trauben in den kühleren Abend- und Nachtstunden geerntet oder vor der weiteren Verarbeitung gekühlt werden (Hoppmann, 2005).

Eine große Unbekannte ist das neue oder veränderte Auftreten von klimasensitiven Schädlingen oder Krankheiten im Weinbau. So konnte in Österreich in den letzten Jahren das Auftreten der besonders rebenschädigenden amerikanischen Rebzikade (Scaphoideus titanus) beobachtet werden, die als Überträger einer gefährlichen und in Österreich meldepflichtigen Rebkrankheit gilt, der Goldgelben Vergilbung (Blondes Gold) - oder auch „Flavescence dorée“ genannt (vgl. Abschnitt 3.2.10). In Slowenien hat die Goldgelbe Vergilbung, welche zu starken Blattvergilbungen führt, bereits erste Rebbestände vernichtet. Beim Traubenwickler besteht zunehmend die Gefahr der Ausbildung einer dritten Generation (wie im Burgenland schon zu beobachten; vgl. Glauninger und Kersebaum, 2009).

Ein weiteres Beispiel für den Einfluss des Klimawandels ist der kalifornische Blütenthrips. Der Schädling, der Nektarinen 


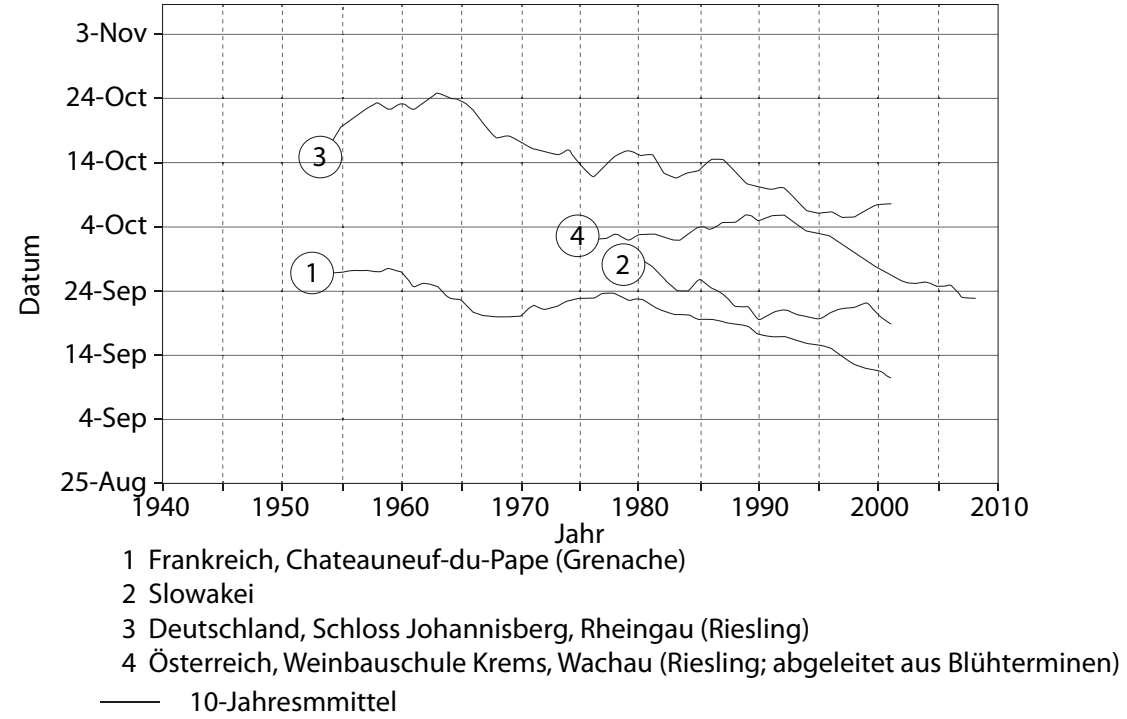

Abbildung 3.8 Trend zur früherer Lesereife und Leseterminen bei Wein in den vergangenen Dekaden an verschiedenen Standorten und bei verschiedenen Sorten in Deutschland, Frankreich, Österreich und der Slowakei. Nach: Koch (2008), in: Eitzinger et al. (2009b). Gleitendes 10-Jahresmittel des Lesetermins nach Julianischen Tagen

Figure 3.8 Trend towards earlier vintage at different sites and for different grapes in Germany, France, Austria and Slovakia (Koch, 2008, in: Eitzinger et al. 2009b). Moving 10year average of vintage dates in Julian days und Wein befällt und derzeit nur in Gewächshäusern überwintern kann, könnte bereits Mitte des 21. Jahrhunderts in Österreich und Süddeutschland imstande sein, im Freiland zu überwintern und in weiterer Folge Freilandkulturen schädigen. Die Temperaturerhöhung der letzten Jahre wird bei ausreichender Feuchtigkeit mit einem vermehrten Auftreten von pilzlichen und bakteriellen Krankheitserregern, nicht nur beim Wein, in Verbindung gebracht. So führte der feucht-heiße Sommer 2006 im Weinbau vielerorts zu verstärktem Befall durch Fäulniserreger wie Grünfäule (Pilz) und Essigfäule (Bakterium; vgl. Petgen, 2007). Auch andere Pilzkrankheiten werden durch Beobachtungen in der Praxis in Verbindung mit dem Klimawandel gebracht, wie Krankheiten durch holzzerstörende Pilze (ESCA, Eutypiose). Stressbedingte physiologische Krankheiten (durch Trockenheit, erhöhte Temperaturen), wie die Traubenwelke, können durch verstärkten Nährstoffstress oder unausgeglichene Nährstoffversorgung (durch Trockenheit bedingt) zum Teil auch auf veränderte Klimabedingungen zurückgeführt werden (Fardossi, 2007). In Verbindung mit Trockenstress verschlechtert sich die Nährstoffaufnahme der Reben. Eine Folge davon kann zunehmende Traubenwelke sein (zusätzlich verstärkt bei Kaliummangel).

In kontinental geprägten Klimazonen kommt es möglicherweise zu einer Zunahme der Spätfrostgefahr durch früheren Austrieb. Die Winterfrostgefahr durch zu tiefe Wintertemperaturen (unter ca. $-30^{\circ} \mathrm{C}$ ) könnte in den derzeit gefährdeten Anbauregionen abnehmen, ist aber schwer einzuschätzen, da zum Beispiel längere warme Perioden im Winter die Frosthärte (sortenspezifisch) herabsetzen können.

Manche Spezialprodukte, wie zum Beispiel Eiswein, werden wegen zu hoher Temperaturen im Herbst und Winter an ihren klassischen Standorten schwieriger oder seltener zu produzieren sein.

Erhöhte Starkniederschläge (intensivere Gewitterniederschläge und zunehmende Winterniederschläge) führen zu zunehmender Bodenerosionsgefahr, vor allem bei zwischen den Reihen unbedeckten Böden und in hügeligem Gelände. Dies ist vor allem dann begünstigt, wenn die Rebreihen aus Bewirtschaftungsgründen entlang der Falllinie angelegt sind. Eine mögliche regional erhöhte Wahrscheinlichkeit von Hagelereignissen birgt eine steigende Gefahr von Ernteausfällen bis hin zu Stockschäden und -verlusten.

\section{Obstbau}

Die Auswirkungen eines wärmeren Klimas auf die Phänologie gelten allgemein auch für den Obstbau, je nach den klimatischen Ansprüchen der jeweiligen Kulturart. Bei Obstkulturen sind insbesondere zunehmende Trockenheit und Bewässerungsbedürftigkeit problematisch, da Obstkulturen generell einen höheren Wasserbedarf haben sowie hitze- und trockenstressempfindlicher sind als zum Beispiel der Wein. Auch eine Zunahme der Gewittertätigkeit bzw. der Heftigkeit von Gewittern, wie es unter einem wärmeren Klima erwartet wird, könnte die Schadensgefahr, insbesondere von Hagel in den wichtigsten österreichischen Anbauregionen der Steiermark weiter steigen lassen.

In Tal- und Beckenlagen besteht regional die Zunahme der Gefahr von Spätfrostschäden bei Obstgehölzen, insbesondere während der Blüte. Zusätzlich können durch extreme Witterungsphasen Störungen im Wachstumsrhythmus eintreten. So können zum Beispiel warme Witterungsabschnitte im Winter 
zu einer Frostenthärtung der Gehölze führen und damit die nachfolgende Frostschadensgefahr erhöhen (Chmielewski et al., 2007).

Im Obstbau sind viele Schädlinge, insbesondere Insekten, in ihrer Entwicklung von der Temperatur abhängig, wobei hier nur der Apfelwickler genannt sei, der große wirtschaftliche Bedeutung hat (Chmielewski et al., 2007) und der je nach Region eine zusätzliche Generation ausbilden könnte. Modellrechnungen auf der Basis von Klimaszenarien für die Bodenseeregion weisen zum Beispiel eine deutlich höhere Wahrscheinlichkeit einer zweiten Larvengeneration pro Jahr für die kommenden 50 Jahre im Vergleich zu den letzten 50 Jahren aus (Stock et al., 2005).

Auch der Befallsdruck für Apfelschorf, der zu hohen Ertragsverlusten und Qualitätseinbußen im Apfelanbau führen kann, wird in Regionen ansteigen, wo trotz der erhöhten Temperaturen mit einer noch ausreichenden Feuchte für die Entwicklung des Pilzes gerechnet werden kann (niederschlagsreichere Anbauregionen).

\subsubsection{Schadorganismen an Nutzpflanzen}

Der Klimawandel beeinflusst eine Vielzahl abiotischer und biotischer Faktoren, die sich direkt oder indirekt auf die Pflanzengesundheit auswirken (Blümel, 2007). Änderungen im Klima können zur Verschiebungen des Wirtspflanzenspektrums von Schaderregern führen sowie das zunehmende Auftreten neuer Schaderreger unterstützen bzw. ermöglichen (Chakraborty et al., 2000; Garret et al., 2006; Garret, 2008; MacLeod et al., 2010; Salinari et al., 2006; Scherm, 2004; Shaw, 2009), deren Einschleppung, Etablierung und Ausbreitung durch die wachsende Globalisierung des Welthandels zusätzlich begünstigt wird. Extreme Wetterereignisse wie Dürre, Hitze, Starkregen oder Hagel können durch eine Schwächung der Pflanzen eine erhöhte Anfälligkeit gegenüber Schaderregern und eine verstärkte Schadwirkung auf Wirtspflanzen bewirken. Die Synchronisation der Entwicklung von Wirtspllanzen mit dem Auftreten von Schaderregern und deren natürlichem Gegenspielern kann sich verschieben und steigende Temperaturen zu einer Zunahme des Auftretens, einer rascheren Generationsfolge, der Zunahme der Migration und der Überwinterung bei Schadarthropoden führen (siehe auch Band 2, Kapitel 2). Ein Trend zu noch wärmeren Temperaturen kann die Situation zunehmend verändern und einen signifikanten Einfluss auf die Biodiversität haben, wobei Schaderreger sich regional stärker ausbreiten oder jene mit kühleren Temperaturansprüchen zurückgedrängt werden können (Eitzinger et al., 2013).
Eine Veränderung der Bedeutung von Pflanzenkrankheiten, Schädlingen und Unkräutern aufgrund des Klimawandels (Verstärkung oder Verminderung der Schadwirkung) deutet sich bereits durch zahlreiche Beobachtungen in der Praxis an (Glauninger et al., 2010; Grausgruber et al., 2010; Huss, 2012). Siehe dazu auch Details bei einzelnen Nutzpflanzenarten.

In den vergangenen Jahren wurden neue oder schadensauffällige Organismen (Krankheiten, Schädlinge, Unkräuter) in Österreich besonders intensiv untersucht, wobei aber ein kausaler Zusammenhang der Ausbreitung oder Häufigkeit dieser Schadorganismen mit dem Klimawandel oft noch ungeklärt und Gegenstand von Vermutungen ist (Blümel, 2007; Kahrer und Formayer, 2007). Als Beispiel seider Maiswurzelbohrer (Cate et al., 2006; Grabenweger, 2007, 2009) genannt, dessen rasche Ausbreitung als neuer Schädling in Europa nicht nur auf den Klimawandel zurückzuführen ist.

Unter den Krankheiten bildeten z. B. die Phytoplasmose (zellwandfreie Bakterien, die als Parasiten in Pflanzen leben) Flavescence dorée mit ihrem Überträger, der Amerikanischen Rebzikade (Reisenzein et al., 2010; Steffek et al., 2006, 2012; Zeisner und Hausdorf, 2006, 2010), die Kraut- und Knollenfäule und die Alternaria-Dürrfleckenkrankheit bei Kartoffeln (Thenmayer et al., 2006; Glauninger et al., 2010) sowie die Viröse Gelbverzwergung bei Wintergetreide mit verschiedenen Blattlausarten als Überträgern (Jungmeier et al., 2009; Jungmeier, 2010) wichtige Arbeitsschwerpunkte. Unter den neuen Unkräutern werden gegenwärtig ca. 30 bis 40 Arten bearbeitet. Hierzu zählen u. a. einige Unkrauthirsen, die Pferdenessel, die Große Knorpelmöhre, das Drüsige Springkraut, die Giftbeere, die Ambrosie (Follak et al., 2013), die Samtpappel und die Seidenpflanze (Burger und Glauninger, 2007; Follak, 2007, 2008; Fragner, 2010; Glauninger et al., 2006; Glauninger, 2011; Huemer und Glauninger, 2010).

\subsubsection{Fauna}

\section{Abgrenzung und Interaktion mit anderen Biotop- elementen}

In Österreich leben rund 46000 Tierarten (Geiser, 1998). Die Zahl der jedes Jahr erstmals neu im Bundesgebiet festgestellten Arten (bisher übersehene, eingewanderte oder eingeschleppte, neu beschriebene Arten) ist unbekannt. Seit 1990 wurden beispielsweise jährlich rund sieben Tierarten neu für die Wissenschaft beschrieben (Rabitsch und Essl, 2009). Bei der Insektengruppe der Wanzen (Heteroptera) beträgt der durchschnittliche Zuwachs durch übersehene, eingewanderte 


\section{Box 3.3: FFH-Tierarten und Klimawandel}

\section{Box 3.3: Animal species in the Habitat Directive and climate change}

Die Tierarten der Fauna-Flora-Habitat-Richtlinie (FFH-RL) sind in besonderem Maße EU-weit geschützt. In Österreich kommen rund 164 Tierarten (Anhang II, IV, V der Fauna-Flora Habitatrichtlinie; inklusive Arten der EU-Osterweiterung, aber ohne Berücksichtigung taxonomisch problematischer Fälle) der FFH-RL vor. Gezielte Untersuchungen zu den Auswirkungen eines Klimawandels auf die FFH-Tierarten in Österreich liegen nicht vor. Im letzten Bericht über den Erhaltungszustand der Arten und Lebensräume (Artikel 17 FFH-RL) wurde auf Grundlage der Angaben der einzelnen Länder jedoch angegeben, dass sich der Klimawandel besonders negativ auf Amphibien in Europa auswirken könnte (EC, 2009).

Box 3.3 Tabelle 1 Artengruppen und Anteil der durch den Klimawandel gefährdeten Arten auf Grundlage der Artikel 17-Berichte der EU-Mitgliedsländer

Box 3.3 Table 1 Species groups and percentages of species at risk under climate change according to Article 17-reports of EU Member States.

\begin{tabular}{|lcc|}
\hline Artengruppen & $\begin{array}{l}\text { Summe der Arten in dieser } \\
\text { Gruppe }\end{array}$ & $\begin{array}{l}\text { \% vom Klimawandel beeinflusste } \\
\text { Arten }\end{array}$ \\
\hline Amphibien & 51 & 45 \\
\hline Arthropoden & 118 & 29 \\
\hline Säugetiere & 125 & 26 \\
\hline Weichtiere & 35 & 17 \\
\hline Reptilien & 87 & 13 \\
\hline Fische & 100 & 4 \\
\hline
\end{tabular}

Die möglichen Auswirkungen des Klimawandels auf Tierarten der Anhänge der FFH-RL sowie Interaktionen zwischen ausgewählten Arten wurden von Beierkuhnlein et al. (2012) für Europa untersucht. Beispielhaft ist hier die Interaktion zwischen der Großen Mosaikjungfer, Aeshna viridis und der Krebsschere (Stratiotes aloides). Die Grüne Mosaikjungfer ist in Mitteleuropa an Gewässer mit Vorkommen der Krebsschere gebunden, die die einzige Eiablagepflanze dieser Art darstellt. Die Modellierung der zukünftigen Verbreitung beider Arten im Klimawandel projiziert für beide Arten einen Verlust an der südlichen Verbreitungsgrenze und eine Ausbreitung nach Norden, sodass sich auch die zukünftigen Verbreitungsgebiete überlappen. Eine räumliche Desynchronisation wird von dem Modell nicht projiziert.

Aufgrund der zu erwartenden kleinräumigen regionalen Unterschiede wäre eine konkrete Untersuchung der Auswirkungen des Klimawandels auf FFH-Arten für Österreich wünschenswert. Derzeit liegen keine solchen Untersuchungen vor.

oder eingeschleppte Arten seit 1990 rund drei Arten pro Jahr (Rabitsch, 2008). Auch wenn der Wissensstand zum Inventar der europäischen Fauna gut ist, bestehen bei vielen Tiergruppen noch Lücken, insbesondere bei kleinräumig verbreiteten, endemischen Arten (Essl et al., 2012), der Kenntnisstand zu den Tierarten Österreichs ist daher sehr heterogen. Während Verbreitung und Biologie einiger Arten sehr gut bekannt sind, liegen für die Mehrzahl der Arten kaum Informationen vor. Dies gilt auch für Teile der Biodiversität mit hoher Verantwortung (siehe dazu Box 3.3). Aussagen über die Auswirkungen des Klimawandels beschränken sich daher zwangsläufig auf wenige „Modellarten oder -gruppen“, die nicht immer repräsentativ für alle Tiergruppen sein müssen, oder auf Untersu- chungen aus anderen Regionen. Die grundlegenden Auswirkungen des Klimawandels auf Organismen lassen sich jedoch auf dieser Grundlage ableiten. Die Populationen können sich durch phänotypische Plastizität oder evolutionäre Selektion in Raum und Zeit anpassen: Populationsbiologie (Phänologie, Lebenszyklus) und Verhaltensökologie (Abwanderung in klimatisch geeignete Räume) stellen die wichtigsten Dimensionen möglicher Anpassungsmechanismen dar (Bellard et al., 2012). Näheres zu autonomer und geplanter Anpassung ist in Band 3 zu finden.

Der allgemeine Ansatz, zuerst Arten (bzw. Artengruppen) zu diskutieren und daran anschließend deren Verhalten im ökosystemaren Kontext zu betrachten, lässt sich bei vielen Ar- 
ten der Fauna nur schwer einhalten. Einer der Hauptgründe dafür ist, dass viele Tierarten eine ganze Reihe an unterschiedlichen Vegetations- bzw. Habitattypen in ihrem Lebensraum benötigen, d.h. unterschiedliche funktionale und taxonomische Ebenen simultan berücksichtigt werden müssen. Inwiefern die aktuell beobachtbare Korrelation von Habitat und Artvorkommen eine wirkliche Habitatbindung darstellt, ist vielfach ungeklärt. Für diesen Fall sind sowohl die mögliche Veränderung des Habitats als auch die direkten Auswirkungen eines Klimawandels auf den Organismus relevant. Es werden daher in diesem Kapitel, wo nötig, simultan Artenebene und Ökosystemebene berücksichtigt.

Von besonderer Bedeutung für die Funktionalität der Lebensgemeinschaften sind Interaktionen zwischen den Arten, zum Beispiel Räuber-Beute-, Wirt-Parasit- sowie PflanzenBestäuber-Beziehungen. Solche Interaktionen können auf verschiedene Weise durch den Klimawandel beeinflusst werden, z. B. durch zeitliche Desynchronisation zwischen Blühzeitpunkt und Entwicklungsstadium der Bestäuber oder durch die räumliche „Auseinanderverschiebung“ der Areale von Arten (Hegland et al., 2009; Schweiger et al., 2010; Van der Putten et al., 2010).

Die Bandbreite möglicher Klimaänderungsszenarien ergibt dabei in Kombination mit der natürlichen Variabilität biologischer Prozesse ein hohes Maß an Unsicherheit in Bezug auf Klimawandelfolgen für Arten der Fauna. Dennoch lassen sich klimasensible Arten und Lebensgemeinschaften bzw. Lebensräume identifizieren, Klimawandelfolgen abschätzen und mögliche Anpassungsmaßnahmen für die Erhaltung von Ökosystemleistungen und den Naturschutz ableiten (siehe dazu auch Band 3).

In diesem Abschnitt zur Fauna werden neben Arthropoden, Amphibien und Reptilien, Fischen und Vögeln auch Nutztiere und die Auswirkungen eines Klimawandels auf deren Befinden, Produktivität und Gefährdung durch Krankheiten behandelt.

\section{Sensitivität in Bezug auf Klimavariable}

Klimatische Parameter haben die Entstehung der Fauna Österreichs in besonderem Maße geprägt. Die pleistozänen Eiszeiten haben wiederholte Wanderungen und Extinktionen von Populationen verursacht, die sich bis heute in Verbreitungsmustern und im Genpool der Arten widerspiegeln (Schmitt, 2007; Graf et al., 2007). Dies deutet eine hohe Sensitivität in Bezug auf klimatische Veränderungen an.

Auf der Artenebene relativ gut identifizierbare und auch gut dokumentierte Reaktionen auf klimatische Veränderun- gen sind phänologische und verhaltensbiologische Anpassungen. $\mathrm{Zu}$ nennen sind insbesondere veränderte Ankunfts- und Abflugzeiten sowie verkürzte Flugstrecken der Zugvögel (z. B. Dunn und Winkler, 2010). Auch veränderte Reproduktionszyklen bei ektothermen Organismen, wie das Auftreten zusätzlicher Generationen bei Insekten, sind vielfach belegt (z. B. Ott, 2008). Die Auswirkungen sind art- und situationsspezifisch verschieden und können positiv oder negativ sein: Mildere Wintertemperaturen können die Mortalitätsraten verringern (wenn Extremwerte ausfallen) oder erhöhen (wenn im Winter keine Nahrung zur Verfügung steht) und sind kontextabhängig zu untersuchen und zu bewerten.

Arealverschiebungen als Folge des rezenten Klimawandels sind bereits heute zu beobachten und verschiedene Modelle lassen für unterschiedliche Tiergruppen in Europa teilweise bedeutende Änderungen bis Ende des Jahrhunderts erwarten. Voraussetzung dafür ist jedoch die Fähigkeit der Arten in der zukünftigen Landschaftsmatrix zu wandern und sich gegenüber den in den neuen Gebieten vorkommenden Arten durchzusetzen. Araújo et al. (2006) projizierten Arealerweiterungen für Amphibien und Reptilien in Europa bei ungehinderter Ausbreitung, jedoch Arealverluste bei fehlender Ausbreitung. Settele et al. (2008) erwarten, basierend auf der Annahme fehlender Ausbreitung, bis 2050 für rund $31 \%$ der Tagfalter Europas substanzielle Populationseinbrüche. Nach Huntley et al. (2008) könnten sich die Areale vieler europäischer Brutvögel bei einer Erwärmung um $3{ }^{\circ} \mathrm{C}$ mehrere hundert Kilometer nach Norden verschieben und zugleich um rund $20 \%$ an Fläche verlieren. Devictor et al. (2012) konnten zeigen, dass die Geschwindigkeit der Arealverschiebungen von Vögeln und Schmetterlingen in Europa jedoch nicht mit der Geschwindigkeit der Temperaturerhöhungen mithalten kann. Maiorano et al. (2011) projizierten modellbasiert signifikante Diversitäts-Rückgänge für Säugetiere im Mediterrangebiet, trotz der Annahme ungehinderter Ausbreitung in ihren Modellen. Für Wildschweine wird hingegen eine Zunahme der Häufigkeiten sowie eine Arealerweiterung nach Norden und Nordosten in Europa prognostiziert (Melis et al. 2006). Arealverluste werden hingegen für verschiedene aquatische Arthropodengruppen in Mitteleuropa (Domisch et al., 2011) und endemische Tiergruppen in Österreich (Dirnböck et al., 2011) erwartet. In allen Modellen steigen die Verluste mit der Stärke des Klimawandels (IPCC, 2014). Eine nordwärts gerichtete Arealverschiebung führt zu einer Mediterranisierung der Fauna Europas, wie sie anhand von Libellen (Ott, 2008), Süßwasser-Makroinvertebraten (Bonada et al., 2007) und Wanzen (Rabitsch, 2008) bereits beschrieben wurde. Die Analyse klimaanaloger Räume (Gebiete, die derzeit ein Klima aufweisen, 
das dem zukünftigen Klima anderer Gebiete vergleichbar ist) hat gezeigt, dass für südliche Arten die Wahrscheinlichkeit, in Zukunft in Mitteleuropa passende Umweltbedingungen vorzufinden, hoch ist (Bergmann et al., 2010). Während die nordwärts gerichtete Arealerweiterung gegenwärtig zu einer Zunahme der Artenzahlen in Mitteleuropa führt, ist in $\mathrm{Zu}$ kunft mit einem Rückgang und Arealverlust in den südlichen Arealteilen zu rechnen. Dasselbe gilt für Arealgewinne und -verluste in entsprechenden Höhenlagen. Die zukünftigen Auswirkungen auf aktuelle Vergesellschaftungen, die Entstehung neuer Artengemeinschaften und Interaktionen zwischen den Arten sind jedoch großteils unbekannt. Entsprechende Vorsicht ist daher bei der Interpretation von modellbasierten Sensitivitäts- und Impaktstudien geboten.

Vereinfachende Aussagen hinsichtlich der "Gewinner und Verlierer" des Klimawandels gehen oftmals auf die ökologischen Eigenschaften der Arten zurück. In vielen Biotopen lebensfähige, opportunistische und anpassungsfähige Arten werden eher profitieren, als stenöke, spezialisierte Arten mit kleinen Arealen. Xerothermophile oder hoch mobile Arten haben vermutlich Vorteile gegenüber hydro- oder hygrophilen Arten mit geringem Ausbreitungspotenzial (Ott, 2008; Rabitsch et al., 2010). Besonders vom Klimawandel betroffene Lebensraumtypen - und in der Folge deren Zönosen - sind jene mit langer Entwicklungsdauer, wie Moore, altholzreiche Wälder, Lebensräume oberhalb der Waldgrenze, wie alpine Rasen und Schneebodengesellschaften, Gebirgsseen und Fließgewässer-Oberläufe, sowie kleinflächige Lebensräume mit stabilen Umweltbedingungen (z. B. Quellen). Der Klimawandel stellt somit eine Bedrohung, aber auch ein „window of opportunity" für Arten dar und es ist kaum möglich, exakt vorherzusagen, welche Arten in der Lage sein werden, die (für sie) verbesserten Umweltbedingungen zu nutzen und welche nicht.

Inwieweit sich die Zunahme klimatischer Extremereignisse auf die Tierwelt auswirken wird, ist - auch wegen der Unregelmäßigkeit der Ereignisse - noch ungenügend bekannt. Eine Förderung biologischer Invasionen wird vermutet, u. a. durch die Herabsetzung der Widerstandsfähigkeit („biotic resistance) natürlich angepasster Artengemeinschaften gegenüber eingeschleppten, gebietsfremden Arten (Diez et al., 2012). Der Klimawandel kann gebietsfremde Arten begünstigen, die bislang nicht in der Lage waren sich selbständig in der freien Natur zu vermehren (z. B. Arten in Glashäusern, wie der Kalifornische Blütenthrips Frankliniella occidentalis, vgl. Kahrer und Formayer, 2006), deren Bestände durch regelmäßige kalte Winter reguliert wurden (z. B. Nutria Myocastor coypu, vgl. Doncaster und Micol, 1990) oder deren Reproduktion direkt von der
Temperatur abhängt (z. B. die Rotwangen-Schmuckschildkröte Trachemys scripta elegans, vgl. Ficetola et al., 2009; vgl. auch die Übersicht bei Rabitsch und Essl, 2010). Die Entkopplung von Wirt-Parasitoid-Interaktionen ist möglich und kann das Risiko einer Zunahme von Schadinsekten erhöhen (Hance et al., 2007). Extremereignisse sind schwierig vorherzusagende Stressfaktoren, die jedoch, wenn sie in Kombination mit anderen Faktoren wirken, das Vorkommen und die Verbreitung von Arten wesentlich beeinflussen können (Jentsch et al., 2007).

Der anthropogene Klimawandel wirkt nicht in Isolation auf die Umwelt. Eine Vielzahl weiterer Faktoren, wie die Zerstörung und Degradation natürlicher und naturnaher Lebensräume durch intensive Landnutzung, infrastrukturelle Maßnahmen sowie die daraus folgende Fragmentierung und zunehmende Isolation geeigneter Habitate und neue Konkurrenzverhältnisse durch absichtlich oder unabsichtlich ausgebrachte gebietsfremde Arten bedrängen die biologische Vielfalt (MEA, 2005; Brook et al., 2008; Walther et al., 2009; IPCC, 2014).

Die zahlreichen, auf Rasterdaten mit geringer räumlicher Auflösung beruhenden, modellbasierten Analysen liefern zwar vereinfachte Anhaltspunkte, die realen Bedingungen sind jedoch wesentlich komplexer und kleinräumlich kaum vorhersagbar. Mikroklimatische Gegebenheiten, insbesondere in orographisch reich strukturierten Regionen in Österreich, wirken als Puffer gegenüber makroklimatischen Veränderungen. Synökologische Faktoren (Konkurrenz, Mobilität, Populationsdynamik) beeinflussen Ausbreitungsvorgänge in grundlegender Weise, sodass rein statische Analysen, die diese Faktoren nicht berücksichtigen, nur aus theoretischer Sicht interessant sind (vgl. Abschnitt 3.1.2). Die Komplexität der Vorgänge erzwingt zwar eine Vereinfachung und kann zumindest teilweise in aufwendigen, prozessbasierten Modellen (Kühn et al., 2009) oder in der Kombination verschiedener Methoden (Dawson et al., 2011) berücksichtigt werden, die Grenzen der Gültigkeit der Interpretationen sollten jedoch immer deutlich gemacht werden.

Neben beobachtbaren Änderungen der Areale oder der Phänologie der Arten, geschehen eine Reihe von weniger offensichtlichen, oft nur durch spezielle Methoden nachweisbare Änderungen, die langfristig die mögliche Anpassung und damit die Auswirkungen des Klimawandels wesentlich beeinflussen werden. Keine Art (mit wenigen Ausnahmen) besteht aus genetisch homogenen Populationen. Mit dem Arealverlust lokaler Populationen gehen somit auch bestimmte genetische Informationen verloren, d. h. der Verlust an genetischer Vielfalt ist höher als der Verlust an Artenvielfalt (Abbildung 3.9). Habel et al. (2010) haben diesen Effekt für den Blauschillern- 

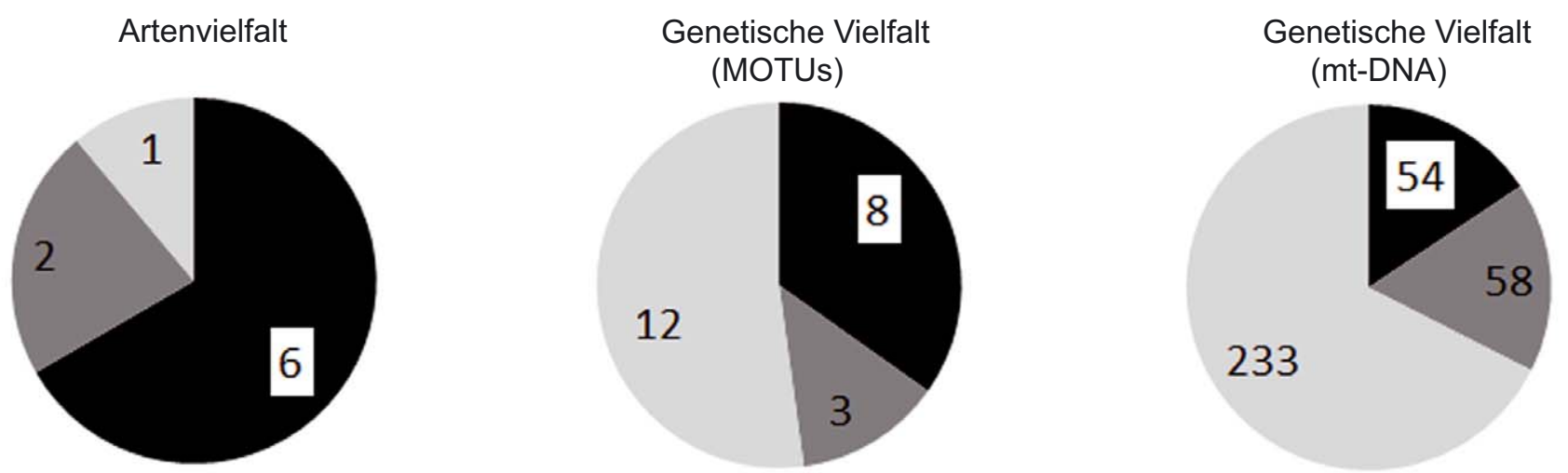

Mit freundlicher Genehmigung von Macmillan Publishers Ltd.:Nature Climate Change Vol. 1, Bálint et al., Cryptic biodiversity loss linked to global climate change, (C) $2011 \mathrm{http}: / /$ www.nature.com/

Abbildung 3.9 Unterschiedliche Verlustraten auf verschiedenen Ebenen der Biodiversität: Keine Änderung durch Klimawandel (schwarz), Verlust bei anhaltendem Klimawandel (dunkelgrau; IPCC-Szenario A2a, $+2,0$ bis $+5,4^{\circ} \mathrm{C}$ ), Verlust bei moderatem Klimawandel (hellgrau; IPCC-Szenario B2a, $+1,4$ bis $+3,8^{\circ} \mathrm{C}$ ). Die Projektionen beruhen auf den Durchschnitten der Klimamodelle CSIRO, HadCM3, CCCMA für das Zieljahr 2080. Untersucht wurden sieben Köcherfliegen, eine Eintagsfliege und eine Steinfliege aus montanen Lebensräumen in Europa. Während die Artenvielfalt bei beiden Szenarien zu zwei Dritteln unverändert bleibt, gilt dies nur für rund ein Drittel der MOTUs (Molecular operational taxonomic units) und weniger als ein Viertel der Mitochondrien-DNA Haplotypen (Bálint et al., 2011)

Figure 3.9 Different loss rates at various levels of biodiversity. Black = no loss due to climate change; dark gray = loss in climate change scenario $\mathrm{A} 2 \mathrm{a}$ (between +2.0 and $+5.4{ }^{\circ} \mathrm{C}$ warming); light gray = loss in climate change scenario $\mathrm{B} 2 \mathrm{a}\left(+1.4\right.$ up to $+3.8^{\circ} \mathrm{C}$ increase in temperature). Projections are mean values from the climate models CSIRO, HadCM3, CCCMA for the year 2080. Seven Trichoptera, and one Ephemeroptera and Plecoptera species were analysed. While species diversity remained unchanged (in blue) for about two thirds in both scenarios, in MOTUs (molecular operational taxanomic units) just one third, and in mt-DNA haplotypes even less remained unchanged (Bálint et al., 2011)

den Feuerfalter Lycaena helle in Westeuropa im Klimawandel projiziert, Bálint et al. (2011) konnten einen solchen Verlust für mehrere montane aquatische Insektenarten nachweisen. Dieser mögliche Verlust kryptischer (versteckter) evolutionärer Linien wurde bislang noch kaum untersucht, ist jedoch für die Strategien und Optionen des Naturschutzes von hoher Bedeutung.

\section{Arthropoden}

\section{Abgrenzung und Charakterisierung}

Arthropoden stellen die mit Abstand artenreichste Tiergruppe in Österreich dar. Rund 85 \% der in Österreich vorkommenden Tierarten sind Spinnentiere, Tausendfüßer, Insekten und Krebstiere (Geiser, 1998). Arthropoden leben in allen terrestrischen und aquatischen Lebensräumen und besitzen die unterschiedlichsten Ernährungsgewohnheiten. Sie besitzen in vielen Ökosystemen Schlüsselfunktionen als Räuber (inkl. Parasiten) oder Beute, Destruenten oder Bestäuber und sind mitunter von großer wirtschaftlicher Bedeutung.

\section{Sensitivität in Bezug auf Klimavariablen und Kli- mawandelfolgen in Österreich}

Während die Kenntnis zu Biologie und Verbreitung bei einigen Gruppen als sehr gut bezeichnet werden kann, ist über viele Arten sehr wenig bekannt. Dies gilt auch für die möglichen Auswirkungen des Klimawandels. Dokumentiert sind vor allem Änderungen der Areale und der Phänologie, wenngleich nur selten Langzeitdatenreihen aus standardisierten Erhebungen vorliegen. Medienwirksam aufbereitete „Signale“ des Klimawandels, wie die Ausbreitung des Ammen-Dornfingers (Cheiracanthium punctorium) oder von Sandfliegen (Phlebotominae) halten bei genauerer Analyse nicht immer einer kritischen Analyse stand und lassen sich zumindest teilweise durch andere Faktoren erklären (Muster et al., 2008; Naucke et al., 2011). Es liegen aber auch eine Reihe gut dokumentierter Fälle vor, wobei die Ausbreitung bei mobilen Arten sehr schnell ablaufen kann. Dies belegen beispielsweise die rasche Besiedlung Mitteleuropas durch die Feuerlibelle (Crocothemis erythraea) und die Wespenspinne (Argiope bruennichii) in den 1990er-Jahren (Ott, 2008, 2010; Kumschick et al., 2011) und die aktuell rasante Ausbreitung der Efeu-Seidenbiene (Colletes hederae), die möglicherweise mit den verringerten Frostschäden des Efeus zusammenhängt, dessen Pollen als Larvennahrung dient (Frommer, 2010, siehe dazu Box 3.4). Da neben 
der Ausbreitungsfähigkeit auch die entsprechenden Habitate im neuen Areal verfügbar sein müssen, ist die Ursache einer rasanten Ausbreitung aber oft nicht eindeutig, sondern multifaktoriell zu begründen. Eine entsprechende zusammenfassende Auswertung mit österreichischen Daten steht noch aus.

Prognosen über zukünftige Entwicklungen aufBasisvon Modellen sind aufgrund der beschränkten Datenlage nur für wenige Gruppen (vor allem Tagfalter, Libellen) möglich. Für Arten in aquatischen Lebensräumen spielt neben der lückenhaften Kenntnis der Verbreitung auch die Frage der Übertragbarkeit terrestrischer Umwelt- und Klimadaten eine wichtige Rolle.

Der „Klima-Risiko-Atlas“ der Tagfalter Europas von Settele et al. (2008) zeigt deutliche Verschiebungen klimatisch geeigneter Gebiete für viele europäische Arten nach Norden. Der grobe Maßstab von $50 \times 50 \mathrm{~km}^{2}$ erlaubt jedoch keine detaillierten Aussagen über kleinräumige Anpassungsoptionen, insbesondere in orographisch reich strukturierten Landschaften wie Österreich. Es ist anzunehmen, dass hier eine größere Vielfalt an Klein-Habitaten zur Verfügung steht, wodurch Abwanderungen und schließlich das lokale Aussterben von Populationen verzögert werden. Bei Tagfaltern sind aktuell Arealverschiebungen und Änderungen der Höhenverbreitung zu beobachten und z. B. im Schweizer Biodiversitätsmonitoring dokumentiert (Vittoz et al., 2010). Wie bereits oben festgestellt, ist jedoch einschränkend festzuhalten, dass für viele Arten die tatsächliche Ausbreitungsfähigkeit nicht bekannt ist und kleinräumig verbreitete Arten (z. B. alpine Tagfalter oder Moor-Spezialisten) sich einer Modellierung aufgrund der Datenlage entziehen.

Taubmann et al. (2011) projizierten deutliche Arealverluste für die boreo-alpin verbreitete Eintagsfliege Ameletus inopinatus in Europa. In Kombination mit genetischen Daten wurden von den Autoren Regionen (überwiegend in Ost-Europa) identifiziert, die eine hohe genetische Vielfalt und geeignete Klimaräume im Klimawandel vereinen und daher aus Sicht des Naturschutzes besondere Aufmerksamkeit erfahren sollten. Isolierte inneralpine Vorkommen in Österreich (Andertal-Moor, Kärnten) besitzen ebenfalls eine große genetische Vielfalt, die eine Anpassung an den Klimawandel erlaubt und als Ausgangspopulation für eine zukünftige Besiedlung klimatisch geeigneter Räume in den Zentralalpen dienen könnte.

Untersuchungen zu veränderten Flugzeiten und phänologischen Änderungen verschiedener Tiergruppen liegen für zahlreiche Länder Europas vor (Essl und Rabitsch, 2013). Eine gruppenspezifische oder übergreifende Auswertung innerhalb der Arthropoden Österreichs gibt es bisher jedoch nicht.
Bei wirtschaftlich relevanten Arthropoden (z. B. Schadinsekten in der Land- und Forstwirtschaft) können klimawandelbedingte Veränderungen in der Populationsdynamik bzw. Habitatveränderungen zu erhöhten Ertragsverlusten und Bekämpfungs- bzw. Kontrollaufwand führen. Besonders gut untersucht sind Borkenkäfer (Scolytidae) und die Auswirkungen des Klimawandels auf ihre Phänologie und Areale (siehe dazu Box 3.5). Borkenkäferkalamitäten in Waldbaumpopulationen sind in wärmerem Klima häufiger, da ein entsprechendes Temperaturregime den wechselwarmen Insekten eine Massenvermehrung ermöglicht (Netherer und Schopf, 2010; Seidl et al., 2009). Eine Erhöhung der Temperatur innerhalb artspezifischer Grenzwerte steigert die Entwicklungsgeschwindigkeit, was unter anderem eine verringerte Exposition empfindlicher Entwicklungsstadien gegenüber natürlichen Gegenspielern mit sich bringt. Plastische Arten können darüber hinaus die Zahl der Generationen pro Jahr erhöhen. Das häufigere oder seltenere Über- oder Unterschreiten letaler Temperaturgrenzwerte wird sich auf die Mortalität auswirken (Moore und Allard, 2008; Netherer und Schopf, 2010). Letzteres wird vor allem an den derzeitigen Verbreitungsgrenzen wichtig sein (z. B. Jepsen et al., 2008; Bentz et al., 2010) und sich besonders bei Arten oder Stadien mit geringer Frosthärte oder bei winteraktiven Insekten auswirken (Netherer und Schopf, 2010). Diese können im Falle von zunehmenden Wintertemperaturen mit einer Ausweitung ihres Verbreitungsgebietes reagieren, wie es etwa für den Pinienprozessionsspinner sehr gut dokumentiert ist (Battisti et al., 2005; Robinet et al., 2007). An der Südgrenze oder am unteren Verbreitungsrand können letale hohe Temperaturen eine analoge Rolle spielen (Rouault et al., 2006).

Auf herbivore Insekten kann eine Klimaänderung auch indirekt wirken, etwa über verringerte Abwehrfähigkeit von Bäumen gegen Borkenkäfer nach Trockenheit oder über eine Änderung der Nahrungseignung von Nadeln und Blättern, die positiv oder negativ ausfallen kann (Rouault et al., 2006; Netherer und Schopf, 2010; Bentz et al., 2010). Temperaturänderungen können auch zu einer Störung der Synchronisation von Insekten und ihren Wirtspflanzen führen (Baltensweiler, 1993). Co-evolvierte Wechselbeziehungen werden gestört: es kann das Insekt, die Pflanze oder keiner von beiden davon profitieren.

Generell bestehen noch beachtliche Wissenslücken über die spezifische Bedeutung der Temperatur bei vielen Insekten, auch bei vermeintlich gut untersuchten Schädlingen (Netherer und Schopf, 2010). Über die Auswirkung sich ändernder Niederschlagsmuster liegen überhaupt nur sehr fragmentarische Informationen vor (Moore und Allard, 2008). Beispielsweise 


\section{Box 3.4: Nördlicher, höher, häufiger! Arealausweitung ausgewählter Insektenarten in der Steiermark}

\section{Box 3.3: Northwards, upwards, more frequent! Area expansion of selected insect species in} Styria

Am Südostrand der Alpen, speziell im Steirischen Hügelland, sind die Jahresmittelwerte seit der Jahrtausendwende flächig um rund $1{ }^{\circ} \mathrm{C}$ gestiegen, lokal um bis zu $3^{\circ} \mathrm{C}$. Die Gottesanbeterin (Mantis religiosa) war seit 1950 für zumindest drei Jahrzehnte im Beobachtungsgebiet eine Rarität. Heute besiedelt sie das gesamte Ost- und Weststeirische Hügelland mit lokal stabilen Populationen. Durch Zeitungsumfragen konnten tausende Einzelmeldungen mit den Witterungsdaten vergleichend dargestellt werden. Demnach kommt die Gottesanbeterin in überdurchschnittlich trockenwarmen Jahren deutlich häufiger vor als in Normaljahren und besiedelt über die warme Hangstufe ansteigend sonnenexponierte Wiesenhänge bis in $1200 \mathrm{~m}$ Seehöhe. Demgegenüber reduzieren durchschnittliche und kühle Sommer ihre Häufigkeit und drängen sie wiederum auf eine Höhenverbreitung zwischen 400 und 800 m zurück. Wesentliche Einflussgrößen der Jahreshäufigkeiten sind Spätfröste, die früh schlüpfende Larven reduzieren, aber auch längere Regenperioden während des Sommers. Demnach konnte Mantis religiosa in den letzten 25 Jahren vom Süden kommend 20-30 km in Richtung Grazer Bergland, also in alpine Regionen und sporadisch sogar über $50 \mathrm{~km}$ weit in Richtung Zentrum der Ostalpen vordringen. Ähnliche Ausbreitungstendenzen zeigten unter anderen Prämissen in den vergangenen drei Jahrzehnten die Zebraspinne (Argiope bruennichi) sowie der vor 180 Jahren eingebürgerte Japanische Seidenspinner (Antherea yamamai). Frühere Raritäten wie der Steirische Fanghaft (Mantispa styriaca) oder der Schmetterlingshaft (Libelloides macaronius) sowie der Osterluzeifalter (Zerynthia polyxena) weiteten ihre Areale ebenfalls in Richtung Norden aus und gewannen an Höhe - aber vor allem wurden sie deutlich häufiger. Die vom Buchdrucker (Ips typographus) bekannte Steigerung der Generationenzahl ist von mehreren waldbewohnenden Neuropterenarten nachgewiesen und lokal auch von der Orientalischen Mauerwespe (Sceliphron curvatum, früher eine, jetzt mitunter zwei Generationen) sowie von der Gefleckten Ameisenjungfer (Euroleon nostras, früher zweijährig, jetzt partiell einjährig belegt).

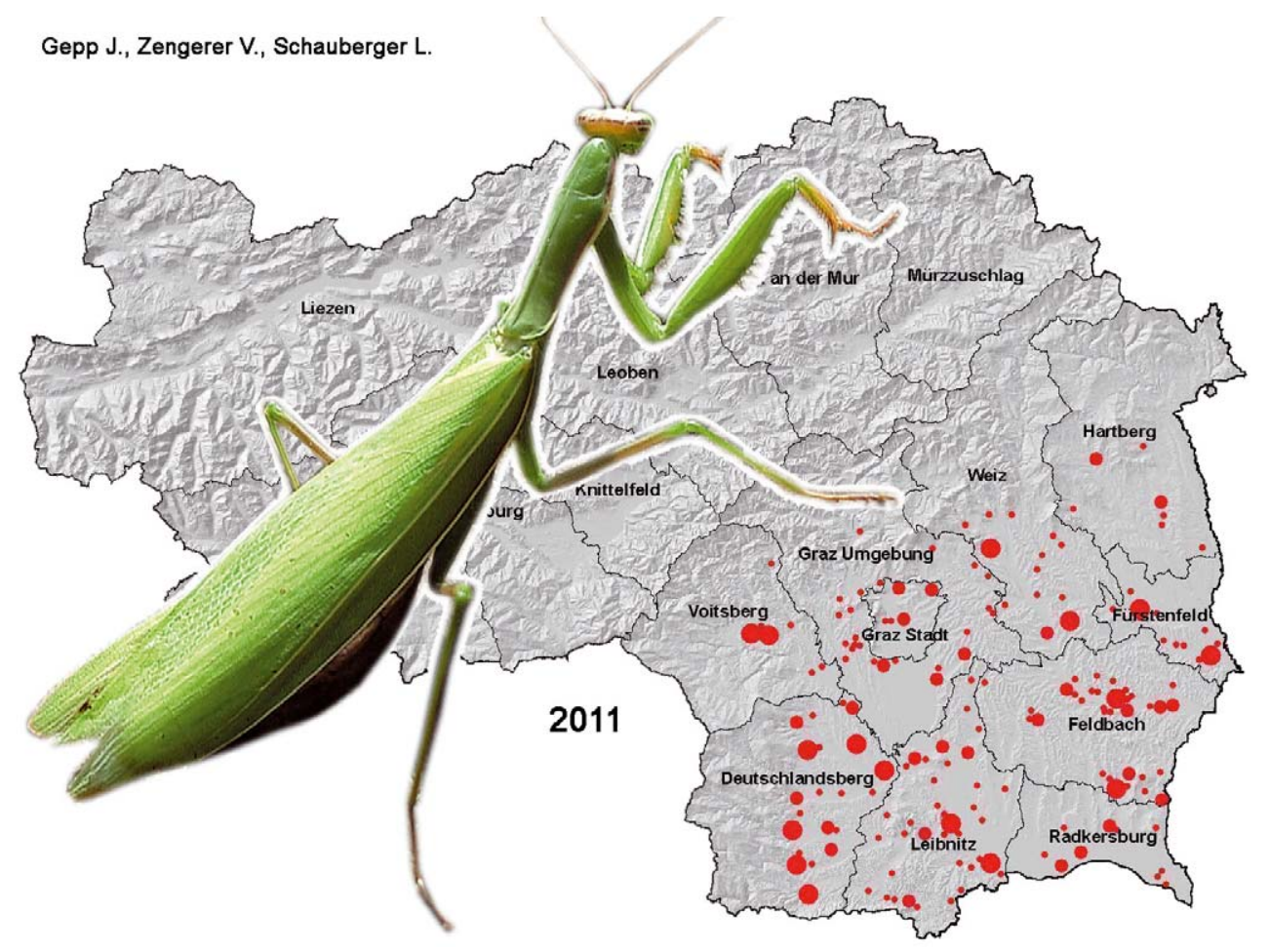

Box 3.4 Abbildung 1 Verbreitung der Gottesanbeterin (Mantis religiosa) 2011 in der Steiermark, nach Daten einer Zeitungsumfrage. Autor: Johannes Gepp

Box 3.4 Figure 1 Distribution of praying mantis (Mantis religiosa) in Styria, Austria. Based on data from a survey in regional newspapers. Author: Johannes Gepp 


\section{Box 3.5: Borkenkäfer-Phänologie: Beobachtungen und Modelle Box 3.5: Bark beetle phenology: Observations and models}

Borkenkäfer sind ein natürlicher und unverzichtbarer Bestandteil im Stoffkreislauf von Waldbiozönosen. Sie besiedeln meist sekundär bereits stark geschwächte Baumindividuen. Nur wenige Arten haben das Potential, im Zuge von Massenvermehrungen vitale Bäume zu befallen, somit das Gleichgewicht von Waldbeständen zu stören und in Folge Sukzessionsprozesse zu initiieren. Als prominentester biotischer Störungsfaktor fichtendominierter Wälder Mitteleuropas gab der Buchdrucker (Ips typographus) in den vergangenen 20 Jahren den Anstoß für eine großflächige Verjüngung der Fichtenbestände im Nationalpark Bayerischer Wald (Heurich und Rall, 2006). Für Wirtschaftswälder stellen Gradationen ein immenses Gefährdungspotential dar. In Österreich dokumentierte das BFW 11,7 Mio. Erntefestmeter Käferholz für den Zeitraum 1991 bis 2000 , bzw. 20,5 Mio. in den Jahren 2001 bis 2010. Dies bedeutet, dass 10-15\% des Einschlags im genannten Zeitraum Borkenkäferkalamitäten als Auslöser hatten. Auslöser der Gradationen waren zumeist Sturmschadensereignisse (z. B. Vivian und Wiebke im Jahr 1990 oder Kyrill im Jahr 2007), in deren Zuge ein großes Angebot an bruttauglichem Holz bereitlag, gefolgt von günstigen Temperaturen für die Käferentwicklung.

Die unmittelbare Abhängigkeit der Phänologie von den mikroklimatischen Umgebungsbedingungen ermöglicht eine genaue Abschätzung des Schwärmbeginns, der Entwicklungsrate und der potentiellen Generationsanzahl des Buchdruckers. Entwicklungsmodelle wie PHENIPS (Baier et al., 2007) prognostizieren eine Häufung von drei Filialgenerationen in den Tieflagen Mitteleuropas bzw. von zwei Generationen auf Gebirgsstandorten (Krenn, 2007), im Falle steigender Frühjahrs- und Sommertemperaturen bis in die zweite Hälfte dieses Jahrhunderts (Hlásny und Turcáni, 2008). Kleinräumige Untersuchungen stellten jedoch keinen direkten oder zeitlich verzögert wirkenden Zusammenhang zwischen Temperaturbedingungen und der Neubefallsrate von Bäumen fest. Inwieweit die prognostizierte Temperaturzunahme die vorherrschende univoltine Entwicklung des Buchdruckers im alpinen Raum wirklich beeinflusst, bedarf daher weiterer Untersuchungen (Schopf et al., 2012). Für den Norden Europas wird eine Verschiebung von primär univoltiner auf bivoltine Populationsentwicklung als sehr wahrscheinlich erachtet (Lange et al., 2006; Jönsson und Bärring, 2011). Das erhöhte Vermehrungspotential von Borkenkäfern trifft auf Nadelwaldbestände, die zunehmend durch Trockenheitsperioden und Extremtemperaturen geschwächt und damit auch gegenüber sekundären Arten disponiert sind. So treten im südalpinen Raum in den letzten Jahren verstärkt Massenvermehrungen des Sechszähnigen Kiefernborkenkäfers (Ips acuminatus) auf (Colombari et al., 2012).

wird bei Borkenkäferarten die Reaktion auf Klimaänderungen durch einen „hohen Grad an Komplexität und Unsicherheit" (Bentz et al., 2010) gekennzeichnet sein. Es muss davon ausgegangen werden, dass es durch Klimaänderungen zu Arealverschiebungen oder Ausweitungen der Zonen mit Massenvermehrungen forstschädlicher Insekten kommt. Neue Assoziationen mit bislang nicht betroffenen Wirtspflanzen sind eine mögliche Folge (Netherer und Schopf, 2010; Bentz et al., 2010). Zusätzlich werden invasive gebietsfremde Arten (Neozoen) zunehmende Bedeutung erlangen (Rabitsch, 2010). Es ist zu erwarten, dass Klimaänderungen expansive Schädlingsarten begünstigen werden. Die erfolgreiche Bekämpfung des Asiatischen Laubholzbockkäfers (Anoplophora glabripennis) in Braunau / Oberösterreich hat rund 2 Mio. Euro gekostet, aber dadurch forstwirtschaftliche und ökologische Schäden viel höheren Ausmaßes vermieden.
Diese Insekten sind meist plastischer in ihrer Lebensweise und von breiterer ökologischer Amplitude, so dass sie unter sich wandelnden Umweltbedingungen den angepassten, spezialisierten Arten konkurrenzüberlegen sein werden (Rabitsch, 2010). Mit zunehmendem internationalem Handel erhöht sich das Risiko für die Einschleppung neuer Arten, graduelle Änderungen der Klimabedingungen können die Möglichkeiten zur Etablierung auch in vormals ungeeigneten Gebieten bringen. Verstärkt werden können negative Auswirkungen von wirtschaftlich bedeutsamen Arten durch mögliche Entkopplungen bestehender Interaktionen mit Parasiten und Pathogenen (z. B. Hance et al., 2007). Siehe dazu auch „Störungsregime" in Abschnitt 3.3.4.

Manche Schadinsekten im Intensivgrünland werden durch wärmeres Klima begünstigt, z. B. die Wurzeln fressenden Larven verschiedener Blatthornkäfer, wie Feldmaikäfer $(M e$ - 
lolontha melolontha) und Junikäfer (Amphimallon solstitiale), oder auch manche Kurzfühlerheuschrecken, die kurzfristige Massenvermehrungen durchlaufen könnten (Eitzinger et al., 2009c). Auch für human- und veterinärgesundheitlich relevante Arthropoden sind Änderungen der Vorkommen zu erwarten. In Süd- und Westeuropa haben z. B. Prozessionsspinner an Häufigkeit zugenommen und ihr Areal erweitert (Netherer und Schopf, 2010). Es ist insgesamt damit zu rechnen, dass sich das Spektrum an medizinisch relevanten Arten in Mitteleuropa ändern wird (Aspöck, 2007).

Es ist zu erwarten, dass die komplexen ökologischen Beziehungen zwischen Arten, wie Herbivorie, Prädation, Bestäubung, Parasitismus und Konkurrenz, durch den Klimawandel beeinflusst werden. Ein Beispiel ist die projizierte räumliche Entkopplung des Natternwurz-Perlmutterfalters (Boloria titania) und seiner Hauptnahrungspflanze, dem Schlangen-Knöterich (Polygonum bistorta, vgl. Schweiger et al., 2008). Modellberechnungen zeigen, dass es bis 2080 zu einer Verlagerung der klimatisch günstigen Gebiete des Falters in den Norden kommt, während der potenzielle Klimaraum der Pflanze stark reduziert wird. Das hat zur Folge, dass Klimagebiete, in denen beide Arten gemeinsam vorkommen, stark eingeschränkt werden. Selbstverständlich reagieren nicht alle Arten in derselben Weise, wodurch Prognosen weiter erschwert werden (Pöyry et al., 2009). Nach Schweiger et al. (2011) ist nicht die Arealgröße oder Nischenbreite von Faltern für eine mögliche Entkopplung entscheidend, sondern die Arealgröße der Futterpflanzen. Modellierungen der potenziellen Arealveränderung einzelner Arten der Wildbienengattung Colletes in Europa zeigten für Generalisten und für Spezialisten Arealverluste und erhöhte Isolation zwischen geeigneten Klimaräumen (Roberts et al., 2011). Auch bei aquatischen Arten deuten Klimamodelle eine Arealverschiebung in höhere Bereiche an, aufgrund der Mikrohabitat-Einnischung, insbesondere die Bindung an spezifische Substrate, ist jedoch mit Populationseinbußen durch fehlende Mikrohabitatverfügbarkeit zu rechnen. Hinzu kommt, dass viele aquatische Insektenendemiten (vor allem Plecoptera und Trichoptera) am Südwest-, Süd- bzw. Südostrand der Alpen aufgrund der geringen Höhe der Gebirge kaum Möglichkeiten haben, bei einer Temperaturerhöhung in höhere, kühlere Lagen auszuweichen (siehe dazu Box 3.6).

Durch den zunehmenden globalen Waren- und Güterverkehr, insbesondere durch den Zierpflanzenhandel und Holzimporte, gelangt eine steigende Zahl an gebietsfremden Arthropoden nach Mitteleuropa, von denen einige in der Lage sein werden, von einem geänderten Klima zu profitieren. Darunter sind wirtschaftlich relevante Arten, wie z.B. die Amerikanische Rebzikade (Scaphoideus titanus). Diese aus Nordamerika eingeschleppte Kleinzikade überträgt Phytoplasmen, die bei Weinstöcken die Vergilbungskrankheit „Flavescence dorée“ verursachen. Die Zikade hat sich in den letzten Jahren von Slowenien her in die Südoststeiermark (Zeisner, 2006) und weiter in das Süd- bzw. Mittelburgenland ausgebreitet. Mit einer weiteren Ausbreitung ist zu rechnen (Steffek et al., 2007). Eine Studie zur Auswirkung einer durchschnittlichen Temperaturerhöhung um $2,8^{\circ} \mathrm{C}$ auf die Verbreitung zeigte indes, dass sich die Zikade im Norden besser etablieren könnte, im Süden jedoch durch Hitze- und Trockenstress limitiert wäre, wodurch es zu einer Verschiebung ihrer südlichen Verbreitungsgrenze kommen würde (Strauss et al., 2012).

Neben den unabsichtlich durch den Menschen eingeschleppten invasiven Arten sind auch Pflanzenschädlinge aus Südeuropa von Bedeutung, welche ihr Areal ohne menschliche Hilfe nach Norden ausdehnen, sobald das Klima es zulässt: Hierbei hat sich gezeigt, dass dieser Vorgang stufenweise vor sich geht. Zunächst ermöglichen mildere Winter einen ausreichenden Überwinterungserfolg einzelner bisher nur weiter südlich auftretender Arten. Eine erfolgreiche Überwinterung allein führt jedoch nicht notwendigerweise zu Schäden für die Landwirtschaft, da in diesem Stadium noch mit keinem Massenauftreten gerechnet werden muss. Erst bei entsprechend hohen Sommertemperaturen sind südliche Arten infolge ihrer hohen Temperaturansprüche in der Lage, sich ausreichend fortzupflanzen und dann auch in Österreich eine Massenvermehrung zu verursachen. Offenbar findet die Baumwollkapseleule (Helicoverpa armigera) derzeit solche Bedingungen vor. Nur in den besonders heißen Sommermonaten der Jahre 2003 und 2012 wurden ihre Raupen an Mais, Tabak, Paradeiser, Paprika, Fisolen und verschiedensten Blumen schädlich. Dies hängt offenbar hauptsächlich mit den in diesen Jahren herrschenden tropischen Sommertemperaturen zusammen und weniger mit den milderen Wintermonaten. Dieser Zusammenhang bietet eine gute Erklärung dafür, dass die Puppen der Baumwollkapseleule nicht nur in ihrem normalen Fluggebiet im Flachland (Andau, Seewinkel, 300 m Seehöhe), sondern auch in Mittelgebirgslagen (Mönichkirchen, $1000 \mathrm{~m}$ Seehöhe) im Experiment gut überwintern konnten (Kahrer et al., 2012), obwohl sie dort nicht vorkommen oder zumindest nicht schädlich werden.

Besonderes Augenmerk wird in Zukunft auch auf Gewächshausschädlinge (z. B. Frankliniella occidentalis, Trialeurodes vaporariorum, Liriomyza huidobrensis, Tuta absoluta) oder Vorratsschädlinge zu lenken sein, die in Österreich bereits vorhanden sind und bei fortschreitender Klimaänderung zunächst im Freien überwintern und sich später massenhaft vermehren könnten (Kahrer und Formayer, 2006). 


\section{Box 3.6: Endemiten und Klimawandel Box 3.6: Endemics and climate change}

Endemiten sind Arten oder andere taxonomische Einheiten, die nur in einem eingeschränkten Gebiet vorkommen. In Österreich kommen 748 (sub)endemische Tier- und Pflanzenarten vor (1,2 \% der Gesamtbiodiversität), der Großteil davon in den nicht eiszeitlich vergletscherten, randlichen Refugialgebieten der Ost- und Südalpen (Rabitsch und Essl, 2009). Viele Endemiten besitzen geringe Populationsgrößen, haben eine geringe Ausbreitungsfähigkeit und sind ökologisch anspruchsvoll. Dadurch besteht für sie bei veränderten Umweltbedingungen ein erhöhtes Aussterberisiko als Folge stochastischer Zufallsereignisse, fehlender Migrationskapazität und geringem Anpassungspotenzial. In einer Studie, welche die österreichischen Endemiten alpiner Lebensräume aus fünf Tier- und einer Pflanzengruppe (Schmetterlinge, Spinnen und Weberknechte, Laufkäfer, Schnecken, Gefäßpflanzen) umfasste, wurden diese Risiken quantifiziert (Dirnböck et al., 2011). Mit einem Modell wurde die potenziell mögliche Verschiebung der Waldgrenze bei verschiedenen Klimawandelszenarien simuliert. Es zeigte sich, dass jene Gebiete, in denen die meisten Endemiten vorkommen, den stärksten Verlust waldfreier, alpiner Flächen erleiden werden. Schon unter dem schwächsten Klimawandelszenario $\left(+1,8^{\circ} \mathrm{C}\right.$ bis zum Jahr 2100$)$ gehen der Modellanalyse nach $77 \%$ dieser Gebiete verloren. Bei einem stärkeren Temperaturanstieg $\left(+4^{\circ} \mathrm{C}\right.$ bis zum Jahr 2100$)$ würden kaum alpine Flächen in diesen Gebieten übrig bleiben. Die weltweit nur in den Alpen vorkommenden endemischen Arten sind als einzigartiger Beitrag zur globalen Biodiversität für den Naturschutz von besonderer Bedeutung und einem besonders hohen Aussterberisiko ausgesetzt.
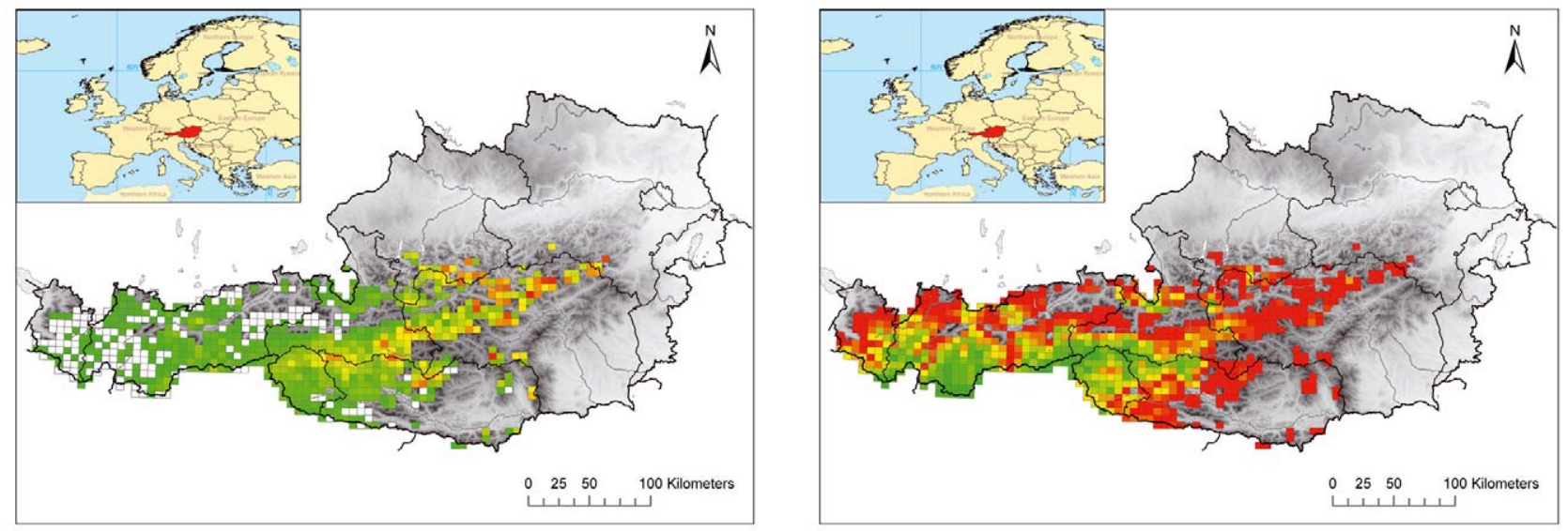

Verändert nach Dirnböck et al., Disproportional risk for habitat loss of high-altitude endemic species under climate change, Global Change Biology, Volume17/2. (c) 2011 Blackwell Publishing Ltd.

Box 3.6 Abbildung 1A Endemiten-Vielfalt in den österreichischen Alpen: Summe endemischer Gefäßpflanzen, Schmetterlinge, Spinnen und Weberknechte, Laufkäfer und Schnecken, zunehmend von grün über gelb nach rot; weiße Rasterzellen kennzeichnen Gebiete ohne Endemiten. Verändert nach Dirnböck et al. $(2011)$

Box 3.6 Figure 1A Diversity of endemic species in the Austrian Alps: sum of endemic vascular plants, butterflies, spiders, beetles and snails (increasing diversity from green to red; white grid cells represent areas without endemic species). Modified after Dirnböck et al. (2011)

Box 3.6 Abbildung 1B Relativer Verlust alpiner, waldfreier Habitate bei angenommenen $+1,8^{\circ} \mathrm{C}$ Erwärmung im Jahr 2100 (zunehmender Verlust von grün über gelb nach rot). Verändert nach Dirnböck et al. (2011)

Box 3.6 Figure 1B Relative loss of alpine, non-forested habitats under $a+1.8^{\circ} \mathrm{C}$ warming scenario in 2100 (increasing loss from green to red). Modified after Dirnböck et al. (2011) 


\section{Amphibien und Reptilien}

\section{Abgrenzung und Charakterisierung}

Für Österreich sind derzeit 21 Amphibien- und 14 Reptilienarten bekannt. Ihre Verbreitung ist gut dokumentiert und es liegen zahlreiche Arbeiten zur Populationsbiologie und zur Gefährdung vor (Cabela et al., 2001; Gollmann, 2007). Hinzu kommen einige absichtlich ausgesetzte Arten und Unterarten, darunter südeuropäische Mauereidechsenvorkommen in Oberösterreich, die als etabliert gelten (d.h. selbständig reproduzierende Populationen ausbilden, vgl. Grillitsch und Cabela, 2001) und gebietsfremde Schildkrötentaxa, die sich bislang nicht dauerhaft im Freiland fortpflanzen, aber aus naturschutzfachlicher Sicht als problematisch bewertet werden (Kleewein und Wöss, 2010). Amphibien und Reptilien spielen eine wichtige Rolle als Räuber von Wirbellosen und als Beute für andere Tiere in aquatischen und terrestrischen Lebensräumen. Sie gelten auch als ausgezeichnete Indikatoren für den Zustand von Ökosystemen.

\section{Sensitivität in Bezug auf Klimavariablen und Kli- mawandelfolgen in Österreich}

Aufgrund ihrer Lebensraumansprüche und geringen Mobilität gelten Amphibien als besonders durch den Klimawandel gefährdet (z.B. Henle et al., 2008; Blaustein et al., 2010; Rödder und Schulte, 2010). Die projizierte Änderung der Niederschlagsverteilung ist als Gefährdungsfaktor vermutlich von größerer Bedeutung als Temperaturveränderungen (Gollmann, 2007). Im Vordergrund stehen indirekte Auswirkungen als Folge von Lebensraumverlust, z. B. der mögliche Rückgang von ephemeren und periodischen Kleingewässern und der Verlust von Feuchtlebensräumen als Folge häufiger auftretender oder verlängerter Trockenperioden (z. B. McMenamin et al., 2008). Direkte Auswirkungen auf die Phänologie, Populationsbiologie und Verbreitung sind bekannt oder werden vermutet, sind bisher aber bei europäischen Arten noch kaum genauer untersucht.

Der Lebenszyklus von Amphibien erfordert eine gesonderte Betrachtung des Risikos für die jeweiligen Lebensabschnitte. Generell beschleunigen höhere Wassertemperaturen die Entwicklung von Amphibienlarven. Durch die geringere Sauerstofflöslichkeit bei höheren Temperaturen kann aber die Sauerstoffaufnahme negativ beeinflusst und die Entwicklung gestört werden. Die mögliche Folge ist eine verringerte Körpergröße bei der Metamorphose. Die Überlebensraten der Larven sind jedoch auch von anderen Faktoren, insbesondere ihrer Häufigkeit und der Nahrungsverfügbarkeit im Gewässer, abhängig (Blaustein et al., 2010). Beim Fadenmolch vermin- dert eine höhere Wassertemperatur die Anzahl der abgelegten Eier (Galloy und Denoel, 2010). Neben den Auswirkungen in den Laichgewässern sind mögliche Änderungen der Sommer- und Winterlebensräume sowie deren Konnektivität zu beachten (Kyek et al., 2003).

Physiologische Reaktionen auf veränderte Temperaturbedingungen und negative Auswirkungen von Extremereignissen, wie z.B. Hitzewellen (Neveu, 2009), sind zu erwarten. Die Wahrscheinlichkeit, von Spätfrösten überrascht zu werden, erhöht sich für Frühjahrsarten. Ein erhöhter Energieverbrauch in wärmeren Winterquartieren wurde für die Erdkröte in England festgestellt und mit verringerter Fitness und erhöhter Krankheitsanfälligkeit in Verbindung gebracht (Reading, 2007). Wird das Geschlecht der Nachkommen durch die Inkubationstemperatur während der Embryogenese bestimmt, wie es bei vielen Reptilien der Fall ist, sind Verschiebungen des Geschlechterverhältnisses möglich (Hulin et al., 2009). Auch verhaltensbiologische Anpassungen sind zu erwarten, vor allem reduzierte Aktivitätsphasen bei zunehmender Trockenheit, die negative Auswirkungen auf Nahrungssuche, Fortpflanzung, Ausbreitung und damit die Populationsentwicklung haben können. Nach einem schneearmen Winter entstehen im Frühjahr weniger Tümpel. Die Springfrösche und Gelbbauchunken im Lainzer Tiergarten haben daher z. B. im Jahr 2012 vermehrt in den Wienerwaldbächen abgelaicht, wo die kühleren Bedingungen die Entwicklung - trotz eines überdurchschnittlich warmen Jahres verzögern.

Eine phänologische Verschiebung hin zu vorverlegten Ablaichterminen ist aus mehreren Regionen Europas bekannt, z.B. 2 bis 5 Tage pro Grad Celsius Temperaturerhöhung für Fadenmolch und Teichmolch in Wales (Chadwick et al., 2006), 5 bis 10 Tage beim Grasfrosch in England (Carroll et al., 2009) und rund einen Monat in Frankreich (Neveu, 2009), 8 bis 9 Tage bei Grasfrosch und Erdkröte in Polen (Tryjanowski et al., 2003) und rund ein Monat bei einer subalpinen Erdkrötenpopulation in der Schweiz (Vittoz et al., 2010; vgl. Abbildung 3.10). Für Österreich liegen bislang keine Untersuchungen vor (Kyek et al., 2003). Phillimore et al. (2010) konnten zeigen, dass eine Vorverlegung des Ablaichtermines um 5 bis 9 Tage für den Grasfrosch (Rana temporaria) in Großbritannien je nach lokalen Wetterbedingungen möglich ist, für eine Anpassung an die prognostizierten Temperaturerhöhungen bis 2070 aber eine Vorverlegung um 21 bis 39 Tage erforderlich sein könnte.

Zeitliche Verschiebungen des Wanderverhaltens sind ebenfalls zu vermuten, für Mitteleuropa bislang jedoch nicht eindeutig festzustellen (Kyek et al., 2003). Es ist zu erwarten, dass 


\section{Box 3.7: Chytridiomykose - eine neuartige Bedrohung für Amphibien Box 3.7: Chytridiomycosis - an emerging threat to amphibians}

Der Chytridpilz (Batrachochytrium dendrobatidis) verursacht das Krankheitsbild der Chytridiomykose und wurde 1998 bei tropischen Fröschen in Australien und Mittelamerika entdeckt. Der Pilz stammt vermutlich aus Afrika und wurde mit der Verwendung des Krallenfrosches (Xenopus laevis) als Versuchstier und in weiterer Folge durch den Handel mit Amphibien in alle Kontinente verschleppt (Measey et al., 2012). Zwischen Gewässern erfolgt die Ausbreitung durch mit Zoosporen belastetes Wasser, das zum Beispiel mit Angelzubehör transportiert wird. In Europa wurde der Pilz bereits in mehreren Ländern nachgewiesen, in Spanien wird der Rückgang von Geburtshelferkröte, Erdkröte und Feuersalamander direkt mit dem Pilz in Verbindung gebracht (Bosch et al., 2001). Der Pilz ernährt sich vom Keratin in der Hornsubstanz der Amphibienhaut und führt zu deren Ablösung. Die Tiere stellen häufig die Nahrungsaufnahme ein und in Verbindung mit anderen Stressfaktoren endet die Infektion oft tödlich. Das weltweit beobachtete Amphibiensterben wird - unter anderem - mit der Chytridiomykose in Verbindung gebracht. Die Auswirkungen sind jedoch sehr variabel und können - auch innerhalb einer Art - von 0 bis nahezu $100 \%$ Mortalität reichen; offenbar sind dafür verschiedene Faktoren verantwortlich, wie zum Beispiel Immunabwehr oder Habitatbeschaffenheit (Daszak et al., 2003).

Studien zu den Auswirkungen des Klimawandels auf die Ausbreitung und Mortalität des Chytridpilzes zeigen unterschiedliche Ergebnisse. Während Pounds et al. (2006) und Bosch et al. (2007) eine Förderung der Ausbreitung feststellten, konnten Lips et al. (2008) keinen Zusammenhang nachweisen. Garner et al. (2011) konnten experimentell zeigen, dass bei Erdkröten (Bufo bufo) höhere Überwinterungstemperaturen die Infektionsrate erhöhen. Sie stellten aber auch fest, dass die Überlebensrate der Tiere vor allem von ihrem Körpergewicht im Winter abhängt und nicht von der Umgebungstemperatur oder der Infektionsrate. Die höchsten Mortalitätsraten wurden bisher in montanen Höhenlagen festgestellt, alpine Lebensräume scheinen aber für den Chytridpilz ungeeignet und könnten so potentielle Refugialräume für Amphibien schaffen (Sztatecsny und Hödl, 2009), die durch den Klimawandel in höhere Lagen abwandern müssen. Aufgrund der komplexen Wechselbeziehungen in Wirt-Parasit-Systemen unter Klimawandelbedingungen sind weitere Studien für mitteleuropäische Lebensräume erforderlich, um die möglichen Auswirkungen dieser Krankheit beurteilen zu können.

die Auswirkungen art- und populationsspezifisch verschieden stark ausfallen und Adaptation sowie Akklimatisation wichtige Rollen bei der Bandbreite möglicher Reaktionen der Arten spielen (Blaustein et al., 2010).

Araújo et al. (2006) projizierten großmaßstäbliche Arealerweiterungen für Amphibien und Reptilien in Europa bei ungehinderter Ausbreitung und Arealverluste bei fehlender Ausbreitung. Die Übertragbarkeit der Projektionen auf kleinere räumliche Skalen ist jedoch schwierig. Während eine großräumige Einwanderung wärmeliebender Arten aus dem Mittelmeergebiet nach Österreich aufgrund der in der Regel geringen Ausbreitungsfähigkeit der Arten, der Fragmentierung geeigneter Habitate und bestehender Migrationsbarrieren kaum zu erwarten ist, ist eine kleinräumige Erweiterung (oder Verschiebung) der Areale von Tieflandarten in höhere Lagen denkbar, wie sie in der Schweiz bereits beobachtet wird (Vittoz et al., 2010).

Die Lebensräume kälteadaptierter Arten (z. B. Alpensalamander, Bergmolch) könnten zurückgehen, detaillierte Un- tersuchungen zu Änderungen der Areale oder Höhenverbreitung der Amphibien und Reptilien in Österreich liegen aber nicht vor. In einer auf biologischen Eigenschaften der Arten beruhenden Klimasensitivitätsanalyse (Rabitsch et al., 2010) und bei Habitatmodellierungen (mit bis zu $75 \%$ projiziertem Arealverlust bis 2100; ohne Ausbreitung; Beierkuhnlein et al., 2012) wurde für den Alpensalamander in Deutschland ebenfalls ein hohes Risiko durch den Klimawandel festgestellt. D’Amen und Bombi (2009) konnten einen Zusammenhang zwischen Temperaturerhöhung und Artenrückgang in Italien feststellen.

Der mögliche Zusammenhang zwischen dem weltweit beobachteten Amphibiensterben, dem Klimawandel und der Ausbreitung des Chytridpilzes wurde in den letzten Jahren besonders intensiv erforscht (siehe Box 3.7), wobei Kombinationen verschiedener Ursachen für den Artenrückgang als Erklärung am wahrscheinlichsten sind.

Reptilien gelten allgemein eher als potentieller Gewinner des Klimawandels, vor allem wegen der meist thermophilen 


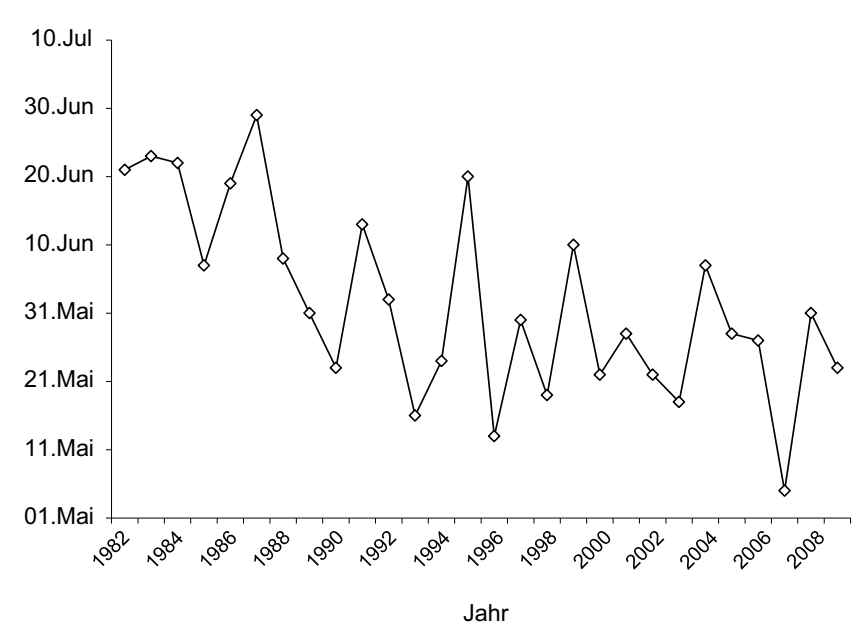

Abbildung 3.10 Zeitliche Verschiebung der Maxima der Laichwanderung einer Erdkrötenpopulation auf der Großen Scheidegg (1.850 m Seehöhe) im Berner Oberland (Schweiz). Quelle: Verändert nach Vittoz et al. (2010)

Figure 3.10 Temporal shift of spawning maxima of common toads at Großer Scheidegg (1850 m asl) in Switzerland. Source: Modified after Vittoz et al. (2010)

Habitatansprüche. Chamaillé-Jammes et al. (2006) konnten einen Anstieg der Körpergröße und des Reproduktionserfolges sowie verringerte Abwanderungstendenzen der Jungtiere für die Waldeidechse (Zootoca vivipera) in den französischen Alpen feststellen. Mit verlängerten sommerlichen Bedingungen ist für Reptilien- und Amphibienarten in Österreich ein Anstieg des Reproduktionserfolges zu erwarten. Eine zukünftig erfolgreiche Reproduktion gebietsfremder Schildkrötenarten im Freiland wird für Mitteleuropa erwartet (Ficetola et al., 2009) bzw. vereinzelt bereits beobachtet (Kleewein und Wöss, 2011).

\section{Fische}

\section{Abgrenzung und Charakterisierung}

Das heimische Artenspektrum umfasst inklusive Neunaugen 84 Arten, wovon 4 Arten nur in Seen, 43 Arten in Fließgewässern und 18 Arten in beiden Ökosystemen anzutreffen sind (Wolfram und Mikschi, 2007). In Österreich kommen entsprechend der gemäßigten Klimazone und der topographischen Verhältnisse Fischarten vor, die an den unteren und mittleren Temperaturbereich angepasst sind. Als Endglieder der Nahrungskette spiegeln sie wesentliche Prozesse der gesamten Nahrungskette wider.

\section{Sensitivität in Bezug auf Klimavariable}

Fische benötigen als wechselwarme Organismen mehrfach ungesättigte Strukturlipide, um ihre Zellmembranen für physiologische Prozesse elastisch und funktionell zu halten. Obwohl kürzlich erfolgte Forschung unser Wissen über die Retention von Fetten in verschiedenen aquatischen Taxa österreichischer Gewässer erweitert hat (z. B. Heissenberger et al., 2010; Schultz et al., 2012), wissen wir noch nicht, welche Effekte unterschiedliche Temperaturen auf die Lipidzusammensetzung der Zellmembranen von aquatischen Organismen, ihr somatisches Wachstum, Reproduktion und Überleben haben.

\section{Klimawandelfolgen in Österreich}

Detaillierte und umfassende Informationen hinsichtlich der Temperaturpräferenzen heimischer Fischarten liegen nur für Salmoniden vor (siehe Beispiel Bachforelle Abbildung 3.11). Hohe Temperaturen können sich sowohl auf das Verhalten von Bachforellen, als auch auf ihr Wachstum, Reproduktion und Sterberate auswirken, was schließlich zu einer Verdrängung durch besser angepasste Fischarten führt. Beobachtungen an der Oberen Traun im Sommer 2012 zeigten, dass hohe Temperaturen (bis zu $21^{\circ} \mathrm{C}$ an der Bachsohle) vor allem große Bachforellen, welche einen besonderen ökologischen und ökonomischen Wert darstellen, negativ beeinflussen können (H. Ficker, pers. Mitt.; StartClim2013.A'). Bei anderen Arten ist der Wissensstand äußerst lückenhaft. Daher ist derzeit nur eine vergleichsweise grobe Einteilung möglich in obligatorische Kaltwasserfischarten (oligo-stenotherm) - die auf kalte Gewässer beschränkt sind - und Arten, die an wärmere Temperaturen angepasst sind (meso-eurytherm).

Während bei den oligo-stenothermen Arten der gesamte Lebenszyklus auf einen vergleichsweise niedrigen Temperaturbereich beschränkt ist, variieren die Temperaturansprüche und Toleranzen bei den meso-eurythermen Arten in Abhängigkeit von Lebensstadium und Jahreszeit beträchtlich. So sind z. B. für eine erfolgreiche Reproduktion der meso-eurythermen Arten im Frühjahr bzw. Sommer bestimmte Minimaltemperaturen erforderlich. Im Sommer werden wesentlich höhere Temperaturen präferiert und toleriert als von Kaltwasserfischarten. Auch bezüglich der Verbreitung von nicht heimischen Fischarten sind in Österreich Veränderungen dokumentiert, die in Zusammenhang mit einer Klimaänderung stehen können. Von den fünfzehn in Österreich etablierten nicht heimischen Fischarten (Wiesner et al., 2010; Rabitsch et al., 2013) ist nur die Regenbogenforelle weit verbreitet, die im Vergleich zu den heimischen Salmoniden etwas toleranter gegenüber höheren

1 http://www.austroclim.at/index.php?id=startclim 2013 


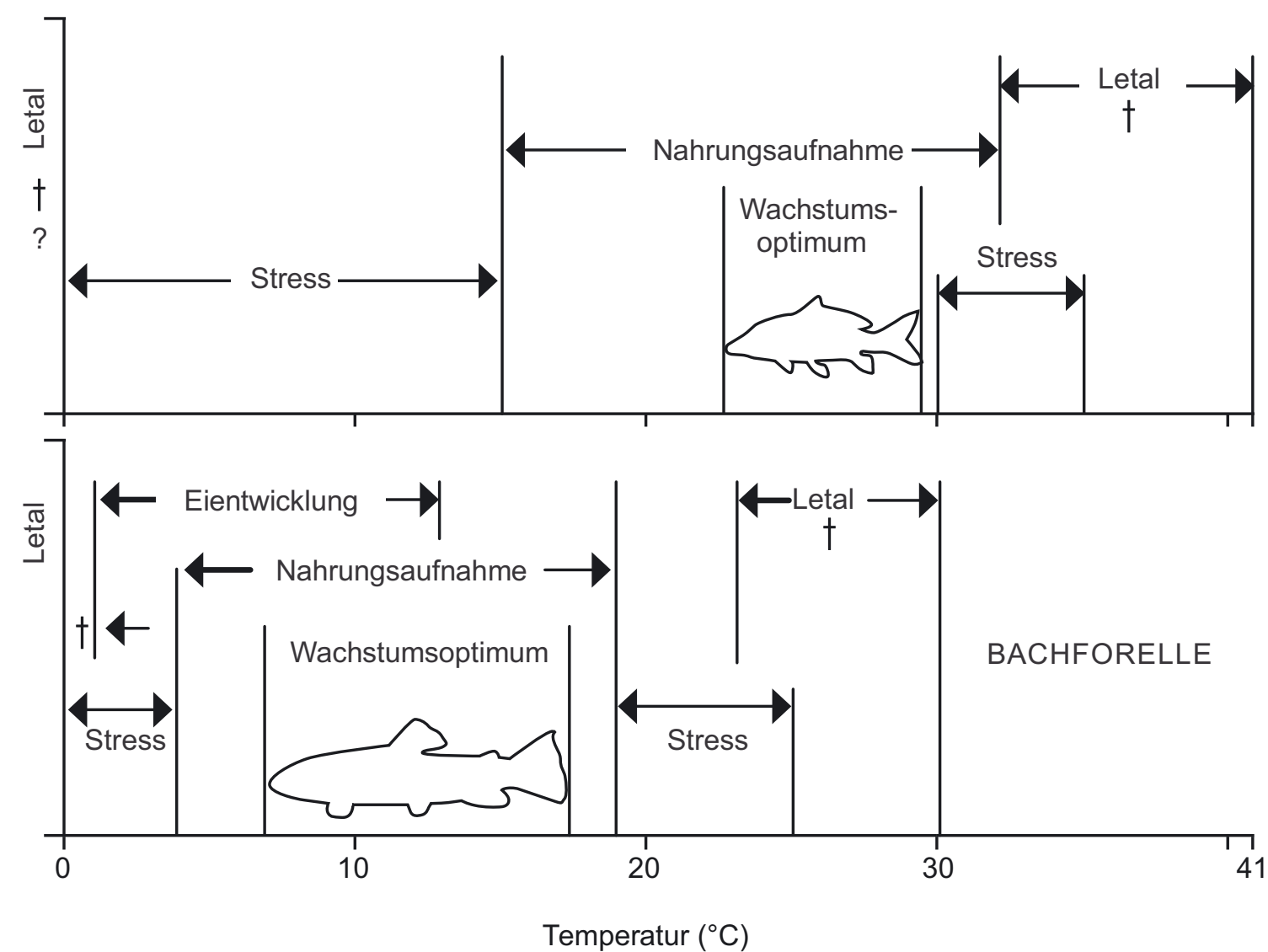

Abdruck mit freundlicher Genehmigung von Springer Science+Business Media:Klima als Umwelt- und Überlebensfaktor, F. Essl und W. Rabitsch (Hrsg.), Abb. 2-3, (c) Springer Berlin Heidelberg 2013

Abbildung 3.11 Unterschiedliche Temperaturansprüche im Lebenszyklus von Karpfen (Cyprinus carpio) und Bachforelle (Salmo trutta). Aus Essl und Rabitsch (2013). Verändert nach Langford (1990)

Figure 3.1 Diverging temperature requirements within the life cycle of common carp (Cyprinus carpio) and brown trout (Salmo trutta) Essl and Rabitsch (2013). Adapted from Langford (1990)

Wassertemperaturen ist. In den letzten Jahren sind in der österreichischen Donau zwei invasive Fischarten eingewandert, die Kesslergrundel (Neogobius kessleri) und die Schwarzmundgrundel (Neogobius melanostomus), die nunmehr in weiten Bereichen den Fischbestand der Donau dominieren. Diese Arten bevorzugen ähnliche Habitate wie heimische Arten (z. B. Koppe [Cottus gobio]), sind jedoch temperaturtoleranter und können daher heimische Arten verdrängen (Wiesner et al., 2010). Auch der aus Nordamerika stammende Sonnenbarsch Lepomis gibbosus und der aus Ostasien stammende Blaubandbärbling Pseudorasbora parva bevorzugen wärmere Gewässer und könnten von einer Erwärmung profitieren (Rabitsch et al., 2013).

Als Folge der Wassertemperaturveränderungen ist eine Verschiebung von kaltwasserliebenden hin zu warmwasserliebenden Arten und folglich eine Verschiebung der Fischregionen zu erwarten (siehe auch Abschnitt 3.3.6). So könnte eine Erwärmung von $2,5^{\circ} \mathrm{C}$ (Jahresmitteltemperatur) eine höhenzonale Verschiebung der Fischregionen von 70 m bzw. eine Verlagerung der Fischregionen flussaufwärts im Ausmaß von ca. $30 \mathrm{~km}$ bedeuten. Diese theoretische Verschiebung flussaufwärts wird aber in vielen Fällen nicht möglich sein, da die Gewässer flussaufwärts in vielen Fällen für Fische zu klein sind. Insgesamt ist daher mit einem Verlust an Forellen- und Äschengewässern zu rechnen. Innerhalb der Gruppe der Salmoniden würde das eine weitere Zunahme des Anteils der Regenbogenforelle bedeuten. Auch bei anderen Fischarten wird sich der Klimawandel indirekt über Konkurrenz mit exotischen Arten auswirken.

Mehr als die Hälfte der heimischen Fischarten scheint bereits in den Roten Listen auf (z. B. Wolfram und Mikschi, 2007). Zusätzliche Belastungen durch Klimaänderungen werden zu einer zunehmenden Gefährdung der heimischen Fischfauna führen. 
Vögel

\section{Abgrenzung und Charakterisierung}

In Österreich kommen etwas mehr als 200 regelmäßig nachgewiesene Brutvogel-Arten vor, davon 150 allein im Neusiedler See-Gebiet. Hinzu kommen rund 200 Gastvogelarten und Durchzügler, also Arten die im Gebiet nicht regelmäßig brüten. Vögel werden häufig als Indikatoren herangezogen, da sie empfindlich und rasch auf Umweltveränderungen reagieren und die Datenlage zur Verbreitung vergleichsweise gut ist. Aktuell werden Daten für eine Neubearbeitung des Österreichischen Brutvogelatlas erhoben.

\section{Sensitivität in Bezug auf Klimavariable}

Steigende Temperaturen führen bei Vögeln zu phänologischen Änderungen, dies betrifft insbesondere Ankunfts- und Abflugzeiten der Zugvögel (IPCC, 2014), weiters kommt es zu Änderungen der Vorkommensgebiete (Verschiebungen der Areale und Höhenvorkommen) sowie zu populationsbiologischen Änderungen. Je nach Ausbreitungsfähigkeit, Anpassungskapazität und physiologischer Toleranz reagieren die Arten und Populationen unterschiedlich. Standvögel, die zum Überwintern nicht in südliche Gebiete wandern, brüten früher und können dadurch Brutgebiete besetzen, noch bevor die Zugvögel aus dem Süden im Frühling heimkehren. Für Zugvögel sind veränderte phänologische Muster insbesondere wegen der möglichen Desynchronisation mit der Verfügbarkeit ihrer Nahrung problematisch.

Änderungen des Zugverhaltens bei Vögeln zählen zu den am besten dokumentierten biologischen Reaktionen auf globale Erwärmung in den letzten zwei Jahrzehnten (Root et al., 2003; Parmesan, 2007). So konnten z. B. Berthold et al. (1992) zeigen, dass kurze Strecken ziehende Mönchsgrasmücken (Sylvia atricapilla), darunter auch Exemplare aus Oberösterreich im Herbst nicht mehr Richtung Südwesten nach Spanien, sondern nordwestlich nach Großbritannien mit seinen milder werdenden Wintern ziehen und dort überwintern. Both und Visser (2001) zeigten anhand einer Langzeitstudie an Trauerschnäppern (Ficedula hypoleuca), dass diese im Schnitt 10 Tage früher beginnen Eier zu legen als noch vor 30 Jahren. Da aber die Ankunftszeit gleich geblieben ist, wird die Zeit für die Brutvorbereitungen immer kürzer, was den Stress erhöht und sich negativ auf das Brutgeschehen auswirkt. Weitere Beispiele gibt es nicht nur von Untersuchungen an ausgewählten Arten, sondern auch von Langzeit-Fangprogrammen an bestimmten Beringungsstationen. Anhand von Daten aus Nordamerika konnte gezeigt werden, dass Kurzstreckenzieher schneller auf Erwärmung reagieren als Mittel- oder Langstreckenzieher
(Miller-Rushing et al., 2008). Diese unterschiedlichen Ergebnisse zwischen Vögeln mit verschiedenen Zugstrategien waren noch stärker bei Untersuchungen, die sich mit dem Herbstzug auseinandersetzten. Jenni und Kery (2003) stellten fest, dass Langstreckenzieher, die südlich der Sahara überwintern, früher aus Europa wegziehen als noch vor 30 Jahren. Kurz- bzw. Mittelstreckenzieher (überwintern nördlich der Sahara) ziehen jedoch später ab bzw. versuchen sogar zu überwintern.

\section{Klimawandelfolgen in Österreich}

In Österreich gibt es kaum vergleichbare, über Jahrzehnte andauernde Untersuchungen. Winkler et al. (2004) konnten mittels Beobachtungsdaten an kurze Strecken ziehenden Vogelarten einen Trend zur höheren Anzahl an überwinternden Individuen zeigen, sowie bei Blaumeisen (Cyanistes caeruleus) einen Trend zu früherem Brutbeginn. In Summe fehlen in Österreich jedoch standardisierte ornithologische Untersuchungen, die durchgehend Daten über die letzten drei Jahrzehnte beinhalten. Einzig das von der deutschen Vogelwarte Radolfzell initiierte Mettnau-Reit-Illmitz-Programm, im Zuge dessen in Illmitz standardisiert Vögel während des Herbstzuges gefangen und markiert wurden, liefert zumindest teilweise entsprechende Daten über einen längeren Zeitraum. Für Populationen aus Österreich und aus anderen Teilen Europas ist das Gebiet des Neusiedler Sees ein wichtiger Rastplatz. Obwohl der Großteil der Datenauswertung und des Vergleichs mit den vorhergehenden drei Jahrzehnten noch nicht abgeschlossen ist, zeigt bereits der Vergleich von ausgewählten Arten interessante Veränderungen. Österreich ist aufgrund der Unterzeichnung von internationalen Richtlinien, wie zum Beispiel der EU-Vogelschutzrichtlinie und der Bonner-Konvention, zur wissenschaftlichen Bearbeitung und zum Monitoring wandernder Vogelarten verpflichtet. Aufgrund fehlender wissenschaftlicher Institutionen und langfristiger Finanzierungen kann diesen Aufgaben allerdings derzeit nicht nachgekommen werden.

\section{Nutztiere}

\section{Abgrenzung und Charakterisierung}

Höhere Temperaturen und trockenere Sommer können großen Einfluss auf die Leistung von Nutztieren und auf die Tiergesundheit in den gemäßigten Breiten haben. In diesem Kapitel werden mit Rindern, Schweinen und Geflügel die wichtigsten landwirtschaftlichen Nutztierartengruppen in Österreich behandelt. Zum größten Teil werden diese Nutztiere in Österreich ganzjährig oder temporär in geschlossenen Stallsystemen gehalten. Die Witterung (insbesondere Hitze) hat entweder direkten Einfluß auf die Tiere (Aufenthalt im Frei- 
en) oder indirekt, z. B. über die Raumtemperaturen und den Luftaustausch nach außen.

\section{Sensitivität in Bezug auf Klimavariable}

Neben direkten klimatischen Auswirkungen auf Nutztiere über das Temperaturregime werden zukünftig vermutlich eine Vielzahl an neuen bzw. exotischen Infektionskrankheiten zu berücksichtigen sein. Besonders Krankheitserreger, die von Arthropoden wie Stechmücken oder Zecken übertragen werden, werden zunehmende Verbreitung finden. Steigende Temperaturen und vermehrt auftretende Hitzewellen spielen dabei in Österreich eine bedeutende Rolle, insbesondere in den wärmeren Klimaregionen Österreichs, in denen Tierhaltung betrieben wird. Im Folgenden werden die Auswirkungen eines Klimawandels in den unterschiedlichen Teilaspekten dargestellt (nach: Grummer, 2009).

Landwirtschaftliche Nutztiere sind gleichwarme (homoiotherme) Tiere. Im Gegensatz zu wechselwarmen (poikilothermen) Tieren können sie ihre Körpertemperatur selbst regulieren, was sie in ihren Aktivitäten weitgehend unabhängig von der Umgebungstemperatur macht (Engelhardt und Breves, 2000). Abweichungen der Körperkerntemperatur oberhalb kritischer Werte führen zu erhöhter Wärmeabgabe und verminderter Wärmeproduktion bei Hitzebelastung bzw. erhöhter Wärmekonservierung und Wärmebildung bei Kältebelastung. In der Folge kann es in diesen Situationen zu einem Leistungsverlust anderer physiologischer Systeme kommen, was sich beispielsweise in einem Rückgang der Milchleistung bei Kühen oder in der Abnahme der Eigröße bei Legehennen äußern kann (Groth, 1984; Smith, 1973). Eine Klimaerwärmung mit häufigeren bzw. länger andauernden Hitzeperioden wird für Nutztiere deutliche Anforderungen bezüglich ihrer Stressbelastung bzw. ihrer Anpassungsmechanismen stellen. Jede Tierart besitzt in Abhängigkeit vom Alter eine thermoneutrale Zone, d. h. einen Temperaturbereich, der keine Energie zur Thermoregulation erfordert und das Optimum für eine hohe Leistungsfähigkeit darstellt (Poczopko, 1984). Neben der Umgebungstemperatur beeinflusst aber auch die Luftfeuchte und die Luftströmung das thermische Wohlbefinden der Tiere. Liegt die Umgebungstemperatur oberhalb der thermoneutralen Zone, wird die Wärmebildung herabgesetzt und die Wärmeabgabe erhöht. Dies geschieht durch die Erweiterung von Gefäßen und durch vermehrtes Schwitzen (Engelhardt und Breves, 2000). Das Tier kann, je nach Möglichkeiten der Haltungsform, auch durch ein verändertes Verhalten auf zu hohe Umgebungstemperaturen reagieren (z. B. Schattenplätze, Suhlen). Bei Tierarten ohne ausreichende Schweißbildung erfolgt die Abgabe von Wärme hauptsächlich über die Schleim- häute des Nasen-Rachen-Raums (z. B. durch Hecheln). Beide Reaktionen können bei den verschiedenen Tierarten unter thermischer Belastung unterschiedlich stark gesteigert werden.

Kann trotz aller Maßnahmen zur Wärmeabgabe die im Stoffwechsel erzeugte Wärme nicht abgeführt werden, kommt es zur Hyperthermie und Hitzestress. Die Schwere des Hitzestresses wird durch die aktuelle Temperatur und Luftfeuchtigkeit, aber auch durch die Länge der Hitzestress-Periode, das Ausmaß der Abkühlung in der Nacht sowie Ventilation und Luftgeschwindigkeit beeinflusst (Nienaber et al., 1999). Neben klimatischen Faktoren kommen individuelle Faktoren, wie die Größe des Tieres, Dichte und Farbe des Haarkleids und möglicherweise genetische / züchterische Merkmale hinzu.

\section{Rinder}

Besonders Milchvieh leidet aufgrund seiner hohen Leistung schnell unter zu hohen Temperaturen. Im Stoffwechsel der Rinder fällt viel Wärme durch die Aktivität der Pansenflora und durch die Milchbildung an (Engelhardt und Breves, 2000). Die Wärmeabgabe ist wegen des Verhältnisses von Körpervolumen zu Körperoberfläche eingeschränkt. Die Tiere halten sich bei Hitzestress vermehrt im Schatten auf und zeigen eine erhöhte Atemfrequenz, der Effekt auf die Milchleistung ist zunächst gering. Bei steigendem Hitzestress fangen die Tiere verstärkt an zu speicheln, die Atemfrequenz erhöht sich weiter und die Tiere schwitzen. Die Wasseraufnahme steigt an, um den durch das Schwitzen entstandenen Flüssigkeitsmangel auszugleichen. Die Futteraufnahme wird hingegen reduziert, obwohl durch die Veränderungen der Körpertemperatur und der Atemfrequenz ein erhöhter Energiebedarf besteht, weshalb die Energiebereitstellung für die Milchproduktion sinkt. Bei einem ausgeprägten Hitzestress sind die Tiere in ihrem Verhalten und Wohlbefinden deutlich eingeschränkt und es können fieberhafte Temperaturen erreicht werden (beim erwachsenen Rind $>39^{\circ} \mathrm{C}$ ). Die Milch- und Reproduktionsleistungen fallen erheblich $a b$ und es besteht Gefahr für das Leben des Tieres. Durch vermehrtes Schwitzen und Abatmen besteht ein erhöhter Bedarf an Mineralstoffen wie Natrium und Kalium. Wird dieser Bedarf nicht gedeckt, kann es zu einer tödlichen Verschiebung im Säure-Basen-Haushalt kommen (respiratorische Alkalose, d.h. der pH-Wert des Blutes erhöht sich; vgl. Beatty et al., 2006).

\section{Geflügel}

Da Vögel keine Schweißdrüsen haben, sind sie in ihren Möglichkeiten zur Wärmeabgabe erheblich eingeschränkt. Tagestemperaturen von über $30^{\circ} \mathrm{C}$ und fehlende Abkühlung in der Nacht verursachen bei allen Geflügelarten Hitzestress (Bogin 
et al., 1996). Besonders bei gleichzeitig hoher Luftfeuchtigkeit wird der Temperaturausgleich für die Tiere erschwert und sie versuchen sich über locker gespreizte und herabhängende Flügel und eine stärkere Durchblutung der unter der Haut gelegenen Blutgefäße abzukühlen. In der Folge sinkt die Futteraufnahme und der Wasserverbrauch steigt an. Durch die benötigte Temperaturregulierung steigt der Energieverbrauch, so dass weniger Energie für andere Körperfunktionen zur Verfügung steht und Stoffwechselfunktionen eingeschränkt werden. Dies äußert sich bei Legehennen zunächst in einer Abnahme der Eigröße, Rückgang der Legeleistung, Verschlechterung der Eischalenqualität und helleren Eidottern (Smith, 1973). Nähert sich die Umgebungstemperatur der Körpertemperatur der Hühner $\left(40-41^{\circ} \mathrm{C}\right)$, atmen die Tiere mit geöffnetem Schnabel, um über die Verdunstung von Wasser über die Atemwege Wärme abzugeben. Dabei erhöht sich die Atemfrequenz bis zum Hecheln. Wenn die Körpertemperatur trotzdem weiter ansteigt, werden die Vögel matt und sterben innerhalb weniger Stunden. Der Hitzetod kann bereits bei Stalltemperaturen von $35^{\circ} \mathrm{C}$ und über $75 \%$ Luftfeuchtigkeit auftreten (Bogin et al., 1996). Die genannten Risikobereiche bei den Temperaturen werden in allen Erwärmungsszenarien häufiger vorkommen und lassen die Notwendigkeit von baulichen Anpassungsmaßnahmen als sehr wahrscheinlich erscheinen.

\section{Schweine}

Auch Schweine können nicht schwitzen und sind bei höheren Temperaturen auf andere Abkühlungsmöglichkeiten angewiesen. Die Tiere beginnen bei Hitzestress zu hecheln und versuchen sich durch Ablegen an kühlen und wenn möglich feuchten Stellen der Hitze zu entziehen. Durch das Ablegen auf feuchten Stellen wird eine Benetzung des Körpers erreicht und Verdunstungskälte erzeugt. Wenn keine Suhle zur Verfügung steht, legen sich die Tiere gezwungenermaßen auch auf die Kotfläche der Bucht, was mit erheblichen Verschmutzungen der Tiere einhergeht. Bei Mastschweinen wird bei Hitzestress eine verminderte Futteraufnahme mit reduzierten Mastleistungen beobachtet, bei Zuchtschweinen leidet die Spermaqualität, die Umrauschquote (prozentueller Anteil der belegten Sauen) steigt und Verlustraten bei Ferkeln durch Erdrücken steigen an. Ungenügende Futteraufnahme hat unmittelbare Folgen beim nächsten Wurf und führt zu einer Beeinträchtigung der nächsten Brunst. Ferner haben Untersuchungen gezeigt, dass die Hitzebelastung das Immunsystem beeinträchtigt, was die Anfälligkeit für Krankheiten erhöht (SalakJohnson und McGlone, 2007). Durch die wenig behaarte und wenig pigmentierte Haut sind die meisten Schweinerassen anfällig für Sonnenbrand. Bei Schweinen kann Hitzestress in Abhängigkeit von der Luftfeuchtigkeit bereits ab $21^{\circ} \mathrm{C}$ einsetzen.

\section{Klimawandel und Infektionskrankheiten bei Nutz- tieren}

Ein Klimawandel kann die Voraussetzungen für das Neuauftreten oder die Rückkehr von Krankheitserregern in unsere Breitengrade schaffen. Durch eine Klimaerwärmung finden verschiedene Arthropodengruppen, wie Stechmücken, Fliegen oder Zecken, die bislang nur in Südeuropa heimisch waren, auch in Österreich klimatisch günstige Bedingungen vor, so dass die Alpen ihre Funktion als natürliche Nordgrenze des Vorkommens vieler durch Arthropoden übertragener Infektionskrankheiten verlieren werden. Verlässliche Voraussagen über das Auftreten neuer Infektionskrankheiten als Folge der Klimaerwärmung gestalten sich jedoch schwierig, denn erst das Zusammenspiel verschiedener Faktoren ermöglicht es Erregern von Infektionskrankheiten, sich in neuen geographischen Regionen zu etablieren und auszubreiten. Neben den direkten Umwelteffekten auf den Erreger und den Wirt, werden vor allem die Effekte auf die übertragenden Vektoren großen Einfluss nehmen.

\section{Klimawandeleffekte auf Krankheitserreger}

Für virale Krankheitserreger werden die direkten Effekte eines Klimawandels nur eingeschränkte Bedeutung haben, denn Viren sind obligat intrazelluläre Parasiten und benötigen für ihre Vermehrung lebende Zellen. Außerhalb von Organismen behalten die meisten von ihnen nur kurze Zeit ihre infektiösen Eigenschaften. Allerdings ist die Entwicklung von Viren, die von Insekten übertragen werden, temperaturabhängig. Der Vermehrungszyklus des Blauzungen-Virus (BTV) in der Überträger-Gnitze (verschiedene Arten der Mückenfamilie der Ceratopogonidae) dauert beispielsweise bei $25^{\circ} \mathrm{C} 6$ bis 8 Tage, bei $30^{\circ} \mathrm{C}$ nur mehr 4 Tage. Bei Temperaturen unter $10^{\circ} \mathrm{C}$ findet keine Virusvermehrung in den Gnitzen statt (Van Dijk und Huismans, 1982).

Bakterielle Infektionserreger könnten ebenfalls vom Klimawandel profitieren. Durch stärkere Niederschläge mit nachfolgenden Überschwemmungen können Abwässer und andere organische Abfälle in offene Gewässer wie Flüsse und Seen geschwemmt werden. Dadurch werden Nährstoffe in die Gewässer eingetragen, was unter gewissen Bedingungen die Massenentwicklung von Cyanobakterien (Blaualgen) begünstigt. Bei lange anhaltenden hohen Temperaturen, wie sie zukünftig in der warmen Jahreszeit erwartet werden, kommt es zu einer sehr raschen Vermehrung (Paul, 2008). Cyanobakterien bilden eine Reihe unterschiedlicher Gifte (Toxine) und stellen 
eine bisher unterschätzte Gefahr für Tiere, Pflanzen und für die Trinkwasserversorgung dar. Die Bedrohung ist spätestens seit dem Verenden von Schafen und Hunden in Großbritannien und dem Tod von über 50 Rindern im Bereich hochalpin gelegener Bergseen in der Schweiz sehr ernst zu nehmen (Eitzinger et al., 2009b).

Auch Parasiten werden vom Klimawandel profitieren, da häufig Entwicklungszyklen, die außerhalb des Wirtes ablaufen, durch höhere Temperaturen begünstigt werden. Generationszeiten werden verkürzt und die Anzahl der Generationen pro Jahr erhöht. In direkter Folge nimmt die Populationsgröße zu. Lange und extreme Kälteperioden in den Wintermonaten, in denen Eier oder Larven der Parasiten abgetötet werden, könnte es zukünftig immer weniger geben. Stattdessen werden mildere Winter mit ausgeprägten Niederschlägen erwartet. Auch dies könnte sich positiv auf die Entwicklungszyklen einiger Parasiten auswirken.

\section{Klimawandeleffekte auf Krankheitsüberträger}

$\mathrm{Zu}$ den bedeutendsten Vektoren von Infektionskrankheiten zählen blutsaugende Insekten (u. a. Stechmücken, Läuse, Flöhe), Spinnentiere (Zecken) und Nagetiere (Ratten, Mäuse). Eine Klimaänderung wird deutliche Auswirkungen auf die Verbreitung von Vektoren und der von ihnen übertragenen Erreger haben.

Voraussetzung für das Auftreten einer Vektor(Überträger)assoziierten Krankheit ist neben dem Vorhandensein eines geeigneten Vektors auch das Vorhandensein infizierter Wirte, an denen sich der Vektor infizieren kann (Reservoirwirte). Weiterhin müssen bestimmte klimatische Voraussetzungen erfüllt sein. In vielen Fällen ist eine Mindesttemperatur zur Entwicklung der Erreger im Vektor notwendig. Meist besteht eine positive Korrelation zwischen Entwicklungsgeschwindigkeit und ansteigender Temperatur, die aber einen Höchstwert nicht überschreiten darf, da es durch zu hohe Temperaturen zu Feuchtigkeitsverlusten und dem Eintrocknen von Biotopen kommt. Auch die Fähigkeit mancher Vektoren, sich mit Viren zu infizieren, variiert mit den Temperaturen (Lines, 1995).

Ein aktuelles Beispiel ist das Virus der Blauzungenkrankheit (BTV) und sein Arthropoden-Wirt, die Gnitzengattung Culicoides. Mit zunehmenden Temperaturen steigt die Wahrscheinlichkeit für die Gnitzenarten, sich mit BTV zu infizieren. Bei Temperaturen im Bereich von $27-30^{\circ} \mathrm{C}$ sinkt zwar die Lebensdauer der Gnitzen, aber die Frequenz der Nahrungsaufnahme steigt und damit die Wahrscheinlichkeit Blut eines mit BTV-infizierten Wiederkäuers aufzunehmen (Wittmann und Baylis, 2000). Die ursprüngliche Verbreitung im Mittelmeerraum und die spätere Ausbreitung des BTV nach Norden hin wird als Folge des Klimawandels angesehen (siehe auch IPCC, 2014): Der wichtigste Überträger ist Culicoides imicola, eine wärmeliebende Gnitzenart, die ursprünglich nur in Afrika und Südostasien beheimatet war. Culicoides imicola benötigt für ihr Überleben monatliche Durchschnittstemperaturen von mindestens $12^{\circ} \mathrm{C}$. ExpertInnen vermuten, dass C. imicola im Verlauf der aktuellen Klimaerwärmung nach Norden wandert (Purse et al., 2005). Es scheint, dass bei uns noch andere Gnitzenarten an der Übertragung des BTV beteiligt sind, die an andere klimatische Bedingungen angepasst sind. Wie das BTV seinen Weg nach Österreich gefunden hat, ist nach wie vor ungeklärt (Enserink, 2006).

Ähnliches gilt möglicherweise für das Virus der Afrikanischen Pferdepest. Diese bei Pferden fast immer tödlich verlaufende Infektion ist in Europa sporadisch in den Jahren von 1987 bis 1990 in Spanien und Südportugal aufgetreten. Wie bei BTV ist die Verbreitung abhängig vom Vorkommen der Culicoides-Spezies. Auch für das Virus der Afrikanischen Pferdepest ist $C$. imicola der Hauptvektor und es ist zu vermuten, dass der Erreger genauso wie BTV in zuvor virusfreie Regionen eingeschleppt werden könnte. Ob allerdings das Virus der Afrikanischen Pferdepest sich an einheimische CulicoidesArten adaptieren kann wie das BTV bleibt abzuwarten.

Das West Nil-Virus stammt ursprünglich aus Nordafrika und dem Vorderen Orient. Bis vor knapp zehn Jahren trat es nur in Afrika, Asien und Südeuropa in Erscheinung. 1999 kam es zu einem Primärausbruch in den USA. ExpertInnen vermuten, dass für die weitere Ausbreitung des West-NilVirus in Nordamerika eine besonders günstige Kombination von Wetterfaktoren verantwortlich war: Ein milder Winter, gefolgt von einem trockenen, heißen Sommer hat die Vermehrung der übertragenden Stechmücken begünstigt. Einmal aufgenommen, reifte das Virus dank der hohen Temperaturen rasch im Vektor heran (Dohm et al., 2002). Entsprechend schnell übertrugen die infizierten Stechmücken das Virus auf Vögel und eine Infektionslawine erfasste Mücken, Vögel und schließlich den Menschen. Heftige Regenfälle gegen Ende August erzeugten neue Wasserlachen, die den Mücken als Brutstätten dienten und schließlich eine weitere Welle an potenziellen Virus-Trägern freisetzten. Mittlerweile befindet sich das West-Nil-Virus auch in Europa auf dem Vormarsch. Zum ersten Mal seit 35 Jahren erkrankten 2007 wieder Pferde in der Camargue an dem Virus. Feucht-schwülere Bedingungen würden den Überträger des Virus stark begünstigen.

Durch den Klimawandel werden zukünftig nicht nur neue Infektionskrankheiten bei Nutztieren mit nachfolgenden potentiell schwerwiegenden ökonomischen Folgen zu erwarten sein, sondern es werden auch zunehmend sogenannte Zoono- 
se-Erreger Verbreitung finden. Hierbei handelt es sich um Viren, Bakterien oder Parasiten, die vom Tier auf den Menschen übertragen werden können. Die Übertragung dieser Erreger erfolgt durch direkten Kontakt mit infizierten Tieren (Kontaktzoonose) oder durch den Konsum von Lebensmitteln tierischer Herkunft („Foodborne Disease“).

Das durch ein Virus ausgelöste, mit Fieber und Gelenkbeschwerden einhergehende Chikungunya-Fieber wird durch die Asiatische Tigermücke (Aedes albopictus) übertragen, die sich in Europa ausgebreitet hat (siehe Band 2, Kapitel 6). In Europa ist das Chikungunya-Fieber als importierte Erkrankung bei rückkehrenden Tropenreisenden diagnostiziert worden und konnte sich kleinräumig in Italien ausbreiten. Nach verschiedenen Prognosemodellen ermöglicht ein Klimawandel die weitere Ausbreitung der Asiatischen Tigermücke in Europa, sodass theoretisch die Möglichkeit von Epidemien auch in Europa gegeben ist (Queyriaux et al., 2008).

\subsection{Gesellschaften und Ökosysteme \\ 3.3 Communities and ecosystems}

\subsubsection{Allgemeines}

In den bisherigen Abschnitten von Kapitel 3 wurde der Stand des Wissens zu Klimawandelauswirkungen aus der Perspektive einzelner Arten beschrieben. Wegen der auf multiplen Zeitund Raumskalen stattfindenden Interaktionen zwischen Arten und Habitaten können sich auf der Ebene von Artenvergesellschaftungen und Ökosystemen jedoch Reaktionsmuster ergeben, die bei artspezifischer Betrachtungsweise nicht erkannt werden können. Für einige besonders intensiv erforschte Ökosystemtypen sind die Auswirkungen eines Klimawandels bereits gut dokumentiert (z. B. alpine und nivale Habitate) oder durch Szenariosimulationen mit Ökosystemmodellen analysiert (z. B. Wälder, Agrarsysteme). Für den überwiegenden Teil der Lebensräume sind für Österreich jedoch keine entsprechenden Untersuchungen vorhanden. Nachfolgend wird für diejenigen Ökosysteme bzw. Gesellschaften, für die Literatur zu Klimawandelfolgen vorhanden ist, ein Überblick zu möglichen Auswirkungen von klimatischen Veränderungen gegeben.

\subsubsection{Moore}

Österreich weist aktuell ca. 21000 ha Moorflächen auf. Die Verbreitungsschwerpunkte der Moore in Österreich liegen in den feucht-kühlen Gebieten des Alpenvorlandes und der Alpen (Jungmeier et al., 2004).

Moore reagieren potenziell sensitiv auf Klimaerwärmung, insbesondere jene, deren Wasserhaushalt aus Regenfällen gespeist wird. Insgesamt sind dies die ca. 4000 ha sogenannter „Regenmoore“, von denen die Hochmoore ca. $95 \%$ umfassen (Niedermair et al., 2011). Selbst unter gemäßigten Klimaänderungsszenarien zeigen Simulationsstudien, dass ein großer Anteil der Moorgebiete in Österreich um die Mitte des 21. Jahrhunderts zunehmend Trockenheits- und Hitzestress ausgesetzt sein wird. Der erwartete Temperaturanstieg, gekoppelt mit Niederschlagsrückgängen, könnte insbesondere für die etwa 600 Hochmoore in Österreich kritisch werden (Walentowski et al., 2008; Essl et al., 2012).

Vor allem diejenigen Gebiete, die bereits durch andere Einflüsse in ihrem Wasserhaushalt gestört sind, werden durch zusätzliche negative Umwelteinflüsse einer erhöhten Gefährdung ausgesetzt. Für intakte Hochmoore stellen Temperaturerhöhungen von über $2^{\circ} \mathrm{C}$ ein hohes klimatisches Risiko dar. Niedermoore sind von Niederschlagsveränderungen weniger stark betroffen, da sie durch ihre Anbindung an das Grundwasser alternative Wasserspeisungsmöglichkeiten aufweisen. Niedermoore und Verlandungsmoore im Umfeld von stehenden Gewässern können daher als relativ widerstandsfähig eingeschätzt werden (Niedermair et al., 2011).

\subsubsection{Alpine und nivale Pflanzengesellschaften}

Hochgebirgs-Ökosysteme sind in Bezug auf eine Erwärmung des Klimas besonders sensitiv, weil einem Höherwandern ihrer kälteadaptierten Flora und Fauna topographische bzw. edaphische Grenzen gesetzt sind. Nischen-basierte Modelle prognostizieren das regionale Aussterben vieler alpiner und nivaler Arten oder zumindest starke Arealverluste und zunehmende Fragmentierung der überlebenden Populationen (z. B. Dirnböck et al., 2003, 2011; Engler et al., 2011). Gegen solche Prognosen wurden Vorbehalte geäußert. Zum einen könnte die ausgeprägte Reliefenergie von Hochgebirgslandschaften das Überdauern der Arten in klimatischen Mikro-Nischen erlauben (Randin et al., 2009; Scherrer und Körner, 2010). Zum anderen berücksichtigen die verwendeten Modelle keine tatsächlichen Migrationsbewegungen, sondern schätzen den potentiellen Endzustand der (Neu-)Verteilung geeigneter Habitate unter einem hypothetischen zukünftigen, stabilen Klimaregime ab. Mittelfristig ist daher vielmehr damit zu rechnen, dass die Vegetation höherer Lagen sich mit nachrückenden Arten mit höherem Wärmeanspruch anreichert, während viele Vertreter der kälte-adaptierten Flora diese Standorte 
noch längere Zeit besetzt halten werden. Eine solche Anreicherung wurde in Studien festgestellt, welche die Reaktion von Hochgebirgsvegetation auf die klimatischen Trends der letzten Jahrzehnte untersucht haben (Pauli et al., 2012). Längerfristig wird durch den Abtrag der entstehenden „Aussterbeschuld“ (Jackson und Saxon, 2010) die Biodiversitätsbilanz der höheren Gebirgslagen aber vermutlich deutlich weniger positiv ausfallen.

Wiederholungsuntersuchungen in den Alpen und in Nordeuropa bestätigen bisher die in Modellstudien prognostizierte Artenanreicherung. Neukartierungen hoher Alpengipfel, deren Gefäßpflanzenbestand bereits im 19. oder im frühen 20. Jahrhundert erhoben wurde, zeigten eine starke Zunahme der Artenzahlen (Grabherr et al., 1994, 2001; Bahn und Körner, 2003; Holzinger et al., 2008; Vittoz et al., 2008). Ganz ähnliche Ergebnisse liegen für die Skanden (Klanderud und Birks, 2003; Kullman, 2010) und die schottischen Gebirge (Britton et al., 2009) vor. Die längste Beobachtungsreihe stammt vom Piz Linard in der Silvretta / Graubünden (1835 bis 2010), mit einer sukzessiven Zunahme von einer auf 16 Arten (Wipf et al., 2012). Auf erosionsbelasteten, schuttreichen Standorten stagnierte die Artenzahl (Gottfried et al., 1994), ebenso am touristisch stark frequentierten Piz Julier in Graubünden (Pauli et al., 2001). Im Allgemeinen scheint die Artenanreicherung innerhalb der letzten zwei bis drei Jahrzehnte jedoch rascher abzulaufen als vor den 1980er-Jahren (Walther et al., 2009). Vergleichsdaten von 1994 und 2004 der Art-Deckungen (d.h. Prozentsatz der Bodenoberfläche, die von Pflanzenbiomasse bedeckt wird) in Dauerbeobachtungsflächen am alpin-nivalen Übergangsbereich des Schrankogel (Stubaier Alpen, Tirol) zeigten aber erstmals auch deutliche Rückgänge: Alle nivalen Arten verloren an ihrer Untergrenze an Deckung und gleichzeitig erfolgte eine Zunahme von alpinen Rasenarten (Pauli et al., 2007). Diese gerichtete Veränderung lässt auf eine aktuelle Höherverschiebung des alpin-nivalen Ökotons schließen, die einer Höherverlagerung der sommerlichen Schneegrenze folgt (Gottfried et al., 2011).

Das Höhersteigen der Arten in alpinen Gipfelzonen ist ein europaweit nachweisbarer Prozess, der im Zeitraum 2001 bis 2008 allerdings zu unterschiedlichen Artenzahlveränderungen führte: überwiegend Zunahmen im borealen und temperaten Europa, Stagnation oder Abnahmen im mediterranen Süden des Kontinents (Pauli et al., 2012). Letzteres könnte insbesondere durch eine Kombination von Erwärmung und verringerter Wasserverfügbarkeit bedingt sein. Eine weitere paneuropäische Studie zeigt eine Anreicherung wärmeliebender bzw. einen Rückgang kälte-adaptierter Arten in alpinen Pflanzengesellschaften. Diese „Thermophilisierung“ alpiner
Tabelle 3.5 Neun Moortypen und deren erwarteter Verlust unter Klimawandelbedingungen in Österreich. Quelle: verändert nach Essl et al. (2012)

Table 3.5 Nine mire types in Austria and projected loss under climate change conditions. Source: modified from Essl et al. (2012)

\begin{tabular}{|lrr|}
\hline Moor-Typ & \multicolumn{2}{l|}{$\begin{array}{l}\text { Erwarteter Verlust in \% } \\
(2080 \text { bis 2 100) }\end{array}$} \\
\cline { 2 - 3 } & $\begin{array}{l}\text { B2 } \\
\left(+2.5^{\circ} \mathrm{C}\right)\end{array}$ & A1F1 $\left(+4.4^{\circ} \mathrm{C}\right)$ \\
\hline saures Niedermoor & 61 & 61 \\
\hline karbonatisches Niedermoor & 6 & 6 \\
\hline alpines Niedermoor & 79 & 76 \\
\hline Schwingmoor & 86 & 75 \\
\hline Übergangsmoor & 24 & 36 \\
\hline Hochmoor & 60 & 72 \\
\hline Hochmoor mit Krummholz & 58 & 65 \\
\hline degradiertes Hochmoor & 97 & 100 \\
\hline Pioniergesellschaften auf Torf & 9 & 10 \\
\hline
\end{tabular}

Vegetation zeigt deutliche Unterschiede zwischen einzelnen Gebirgssystemen (Abbildung 3.12) und korreliert mit der regional variablen Frühsommer-Erwärmung von den 1990er- zu den 2000er-Jahren (Gottfried et al., 2012).

Die allgemeine Tendenz, mit zunehmender Erwärmung höherliegende Habitate zu erschließen gilt dementsprechend auch für Baumarten. In den Alpen waren bislang Nutzungsänderungen der wichtigste Faktor für die aktuell zu beobachtende Waldzunahme in Gebirgslagen. Nach den Ergebnissen der Österreichischen Waldinventur ist die fortschreitende Waldflächenzunahme in Seehöhen über $1800 \mathrm{~m}$ am stärksten ausgeprägt. So entfielen von den über 31000 ha Waldflächenzunahme zwischen 2000 und 2009 über $30 \%$ auf diese hochsubalpinen Bereiche (Russ, 2011). Dies kann einerseits durch die Extensivierung der Bewirtschaftung von Almflächen, andererseits über günstigere Klimabedingungen erklärt werden. Nicolussi und Patzelt (2006) prädizieren bei einem Fortbestand der gegenwärtigen Temperaturverhältnisse einen Anstieg der Baum- bzw. Waldgrenze um etwa 100-150 Höhenmeter über jener zur Mitte des 19. Jahrhunderts. Untersuchungen von Dullinger et al. (2004) in den Nördlichen Kalkalpen scheinen diesen Trend zu bestätigen, doch wurden wesentlich langsamere Veränderungen der Waldgrenze (Pinus mugo [Legföhre] als Waldgrenzbaumart) festgestellt, die stark von der zwischenartlichen Konkurrenzsituation abhängen. So könnte sich unter den Verhältnissen des Klimawandels unter den Waldgrenzbaumarten die Fichte besser etablieren als ihre beiden Konkurrenten Legföhre und Lärche (Dullinger et al., 2005). 


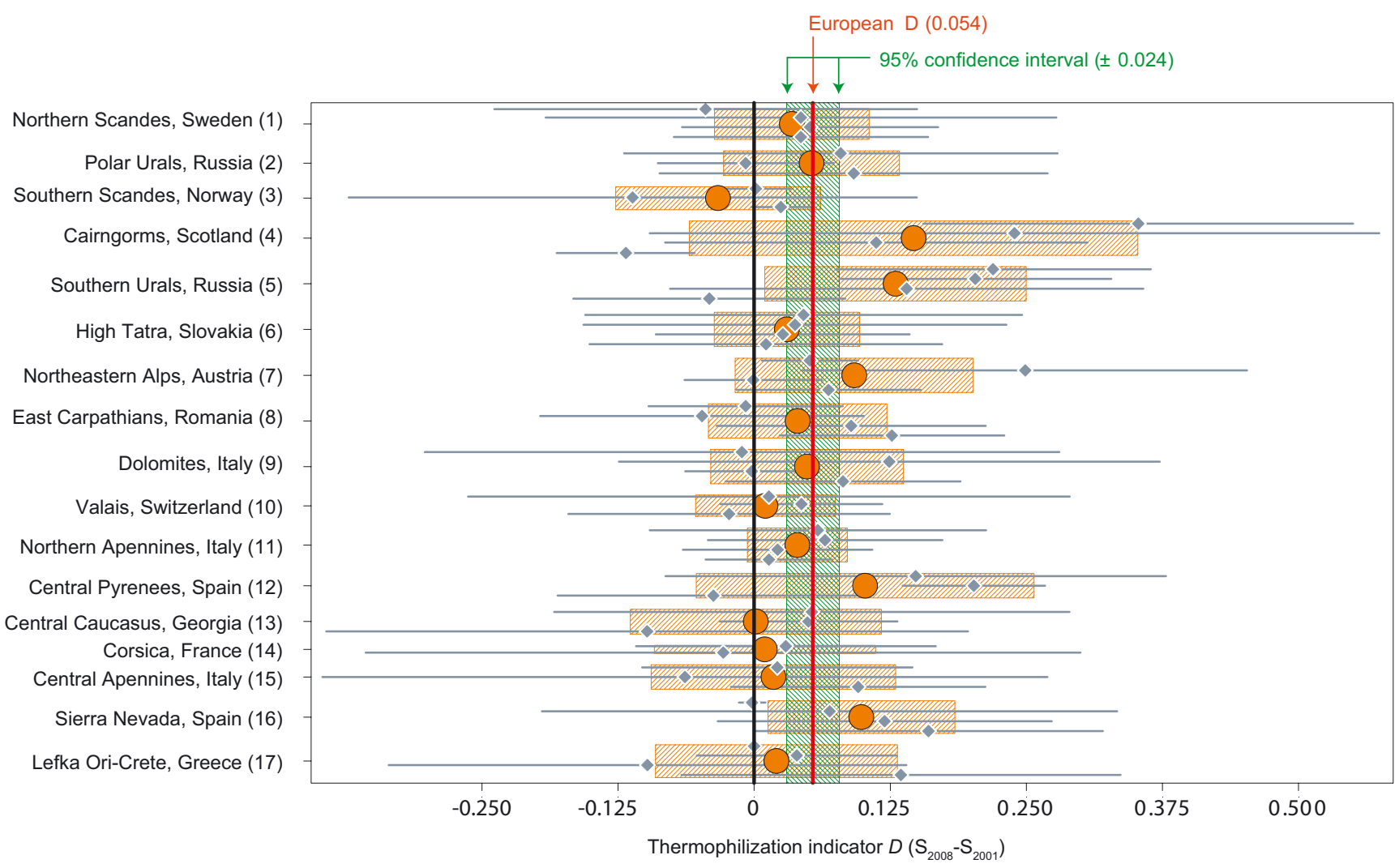

Mit freundlicher Genehmigung von Macmillan Publishers Ltd.:Nature Climate Change 2, Gottfried et al., Continent-wide response of mountain vegetation to climate change, (C) 2012 http://www.nature.com/

Abbildung 3.12 Die Thermophilisierung alpiner Gipfelvegetation in europäischen Hochgebirgen zwischen 2001 und 2008 (GLORIA-Beobachtungsgipfel). Der Thermophilisierungs-Indikator (D) zeigt die Veränderung der Artenzusammensetzung hinsichtlich wärmeliebender versus kälteadaptierter Arten. Positive D-Werte indizieren eine Deckungszunahme oder Einwanderung wärmeliebenderer Arten (die vorwiegend in tieferen Lagen vorkommen) und/oder einen Rückgang oder das Verschwinden von Arten, die vorwiegend in höheren Lagen vorkommen. Rauten und horizontale Linien: D und 95 \%-Konfidenzintervalle für die einzelnen Beobachtungsgipfel, orange Kreise und horizontale Balken: $D$ und 95 \%-Konfidenzintervalle für Gebirgssysteme, rote Linien und vertikaler grüner Balken: europäisches D und 95 \%-Konfidenzintervall, schwarze Linie: Referenzlinie bei $D=0$. Quelle: Gottfried et al. (2012)

Figure 3.12 The thermophilisation of alpine summit vegetation in European high mountain systems between 2001 and 2008 . The thermophilisation indicator $(D)$ shows the change in species composition with respect to warm-demanding versus cold-adapted species. Positive values of $D$ indicate an increase or immigration of warm-demanding species (which predominantly occur in lower elevations) and/or a decrease or disappearance of which usually occur in higher elevations. Diamonds and horizontal lines: $D$ and $95 \%$ confidence intervals for the summits, orange dots and horizontal bars: $D$ and $95 \%$ confidence intervals for the mountain regions, red line and green shading, European D and its $95 \%$ confidence interval, black line, reference line at $D=0$. Source: Gottfried et al. (2012)

In der Schweiz fanden nur $4 \%$ der Zunahme oberhalb des natürlichen ${ }^{2}$ Baumgrenz-Ökotons statt (Gehrig-Fasel et al., 2007). In einigen anderen Hochgebirgen (Ural, Rocky Mountains / SW-Yukon) konnte aber bereits ein massives Höhersteigen der natürlichen Baumgrenze beobachtet werden (Moiseev und Shiyatov, 2003; Danby und Hik, 2007; Kammer et al., 2009). Im aktuellen IPCC-Sachstandsbericht (IPCC, 2014) wird dieser Trend auch für europäische Gebirgshabitate beschrieben. Speziell in stark fragmentierten alpinen Lebensräumen mit einem hohen Anteil endemischer Arten, im Mediter-

\footnotetext{
2 www.gloria.ac.at
}

rangebiet, aber auch in den niedrigeren Randketten der Alpen (Pauli et al., 2003; Essl et al., 2009; Dirnböck et al., 2011) wirkt sich eine fortschreitende Thermophilisierung und Verwaldung alpiner Habitate wegen der geringen Höhenerstreckung der alpinen Stufe auf die Verbreitung von subalpinen, alpinen und nivalen Pflanzengesellschaften negativ aus.

\subsubsection{Wälder}

Die mit Nadelhölzern bestockte Fläche hat laut Österreichischer Waldinventur 2007 / 09 seit der letzten Erhebungsperiode 2000/2002 um rund 116000 ha abgenommen. Vor allem 


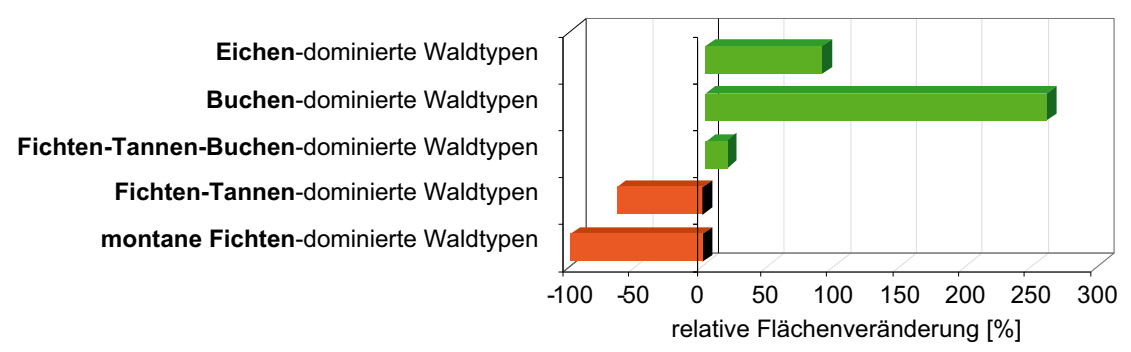

Abbildung 3.13 Mit einem dynamischen Ökosystemmodell simulierte relative Veränderung wichtiger potentiell natürlicher Waldtypen (d.h. PNV) auf Erhebungspunkten der Österreichischen Waldinventur unter einem Klimaänderungsszenario $\left(+2{ }^{\circ} \mathrm{C},-15 \%\right.$ Sommerniederschlag). Quelle: Lexer (2001)

Figure 3.13 Relative changes in area shares of selected potential natural vegetation types (i.e. PNV) at plots of the Austrian Forest Inventory as simulated with a dynamic forest ecosystem model. Climate change scenario: $+2{ }^{\circ} \mathrm{C}$ mean annual temperature, $-15 \%$ summer precipitation). Source: Lexer (2011)

die Fichte hat im Vergleich zur Vorperiode über 100000 ha an Fläche verloren, ein Grund dafür sind die Windwurfkatastrophen 2007 und 2008. Aber auch die mit Weißkiefer bestockte Fläche ist um rund 14000 ha zurückgegangen. Damit einher geht eine Zunahme der Laubholzflächenanteile. Aktive Maßnahmen in der Waldbewirtschaftung bzw. deren Unterlassung sind jedoch der bei weitem wichtigste Grund für diese beobachteten Veränderungen. Da der überwiegende Teil der Waldfläche in Österreich bewirtschaftet wird, ist der Anteil klimwandelabhängiger Ursachen schwierig zu quantifizieren. Teil der oben angesprochenen Bewirtschaftungsmaßnahmen können z. B. als Anpassungsmaßnahme an einen Klimawandel interpretiert werden (vgl. Band 3, Kapitel 2).

Für die Schweiz und für Österreich liegen Simulationsstudien vor, die davon ausgehen, dass artenreiche Laubwaldtypen ihr potentielles Areal im Klimawandel vergrößern werden (Kienast et al., 1998; Lexer et al., 2002). In Österreich würde es demzufolge bei einer Klimaerwärmung von $2{ }^{\circ} \mathrm{C}$ und geringfügig reduziertem Niederschlag auf knapp $80 \%$ der Waldfläche zu einer Veränderung der potentiell natürlichen Waldgesellschaft kommen, wobei vor allem Buchen-, aber auch Eichen- und Buchen-Tannen-Fichtenwaldtypen ihren Flächenanteil erhöhen würden (Abbildung 3.13). Ähnliche Einschätzungen liegen aus Slowenien vor (Kajfež-Bogataj, 1999). Courbaud et al. (2010) weisen am Beispiel der französischen Alpenwälder darauf hin, dass durch die starke Heterogenität der Gebirgswaldstandorte die Abschätzung, wie sich natürliche Waldtypen verändern würden, extrem schwierig ist.

Eine Klimaveränderung wird sich allerdings nicht in allen Regionen und selbst innerhalb von Regionen nicht auf allen Standorten gleich auswirken, sondern in Abhängigkeit des heutigen Ausgangszustands in Bezug auf Klima und Waldaufbau unterschiedliche Effekte bewirken. Theurillat und Gu- isan (2001) schließen etwa auf Basis einer umfassenden Literaturrecherche, dass in den Alpen die Waldökosysteme eine Temperaturerhöhung von $1-2^{\circ} \mathrm{C}$ im Allgemeinen tolerieren könnten, ohne dass wesentliche Arealveränderungen von aktuell bestehenden Waldtypen ausgelöst würden. Basierend auf Simulationsstudien sahen Lexer et al. (2002) diesen Schwellenwert in Bezug auf Temperaturerhöhungen bei etwa $+1^{\circ} \mathrm{C}$.

Die Annahmen, die zur Simulation der potentiell natürlichen Vegetation (PNV) zusätzlich getroffen werden müssen sowie die bestehenden Wissenslücken etwa bei Verjüngungsprozessen, führen zu beträchtlichen Einschränkungen in der direkten Verwertbarkeit der so generierten „zukünftigen“ PNV als Planungsgrundlage in der praktischen Waldbewirtschaftung. Außerdem muss berücksichtigt werden, dass eine Voraussetzung zur Simulation eines „Gleichgewichtszustandes zwischen Standort und Vegetation“ (d.h. PNV) ein konstant stabiles Klima ist. Sämtliche verfügbaren Klimaänderungsszenarien enden jedoch im Jahr 2100 mit sich fortsetzendem Erwärmungstrend. Damit entspricht die Verwendung eines "Gleichgewichtszustandes“ bei fortgesetztem Klimawandel nach 90 Jahren nicht einmal einem durchschnittlichen heutigen Umtrieb von Fichte oder Kiefer. Schließlich werden auch heute durchaus erfolgreich Baumarten, die nicht in der (heutigen) PNV vertreten sind, auf großen Flächen außerhalb ihrer „natürlichen" Nische in Wäldern mit prioritärer Produktionsfunktion favorisiert. Es ist selbstredend, dass potentiell interessante gebietsfremde Baumarten wie Douglasie oder Roteiche, die nicht der heimischen Flora angehören, im traditionellen PNV-Ansatz nicht berücksichtigt werden.

Der PNV-Ansatz ermöglicht die Analyse der Veränderung von ökologischen Potentialzuständen unter Klimawandeleinwirkung, ist aber nicht geeignet für die Analyse tatsächlich ablaufender kurz- bis mittelfristiger Klimawandeleffekte auf 


\section{Box 3.8: Intensivierung von Störungsregimen: Ist der Klimawandel schuld? \\ Box 3.8: Intensification of disturbance regimes: Is climate change to blame?}

Waldschäden durch Wind und Borkenkäfer haben in Europa in den letzten Jahrzehnten deutlich zugenommen (Schelhaas et al., 2003). In Österreich wurden in den Jahren 2002 bis 2010 im Durchschnitt 3,1 bzw. 2,2 Mio. $\mathrm{m}^{3}$ durch Wind und Borkenkäfer geschädigt, was dem zwei- bis neunfachen der Periode 1961 bis 1990 entspricht (Tomizcek et al., 2011). Klimafaktoren haben einen bedeutenden Einfluss auf Störungsprozesse: So treten z.B. Sturmereignisse in Österreich vor allem im Winter auf, wo eine Abnahme des Bodenfrosts die Baumstabilität negativ beeinflussen kann. Borkenkäferschäden sind sowohl von der Insektenpopulation als auch vom Abwehrvermögen der Bäume abhängig, wobei erstere durch Erwärmung ansteigt, während z. B. Trockenstress letztere verringert. Der bereits stattgefundene Klimawandel hat über derartige Prozesse bereits signifikant zum Ansteigen von Waldschäden in Österreich und Europa beigetragen (Seidl et al., 2011a; siehe auch Box 5).

Störungen werden jedoch auch von Waldaufbau und -zusammensetzung stark beeinflußt. Sowohl die forstwirtschaftlichen Erfolge der letzten Jahrzehnte - steigende Waldfläche und Waldvorrat in Österreich - als auch die waldbaulichen Fehler vergangener Jahrzehnte (z. B. der Anbau von Fichtenbeständen weit außerhalb ihres natürlichen Verbreitungsgebietes) haben zu einem Ansteigen der Waldschäden durch Störungen beigetragen - in Österreich ist dieser Effekt sogar stärker als jener des Klimawandels (Seidl et al., 2011a). Sowohl Klimawandel als auch Waldbewirtschaftung haben also zu einer europaweiten Intensivierung der Störungsregimes beigetragen.

Für die Zukunft kann erwartet werden, dass sich dieser Trend weiter fortsetzt, da sich das Klima weiter erwärmen wird und die Waldstruktur und -zusammensetzung nur sehr langfristig veränderbar ist. Für Borkenkäferschäden konnte z.B. anhand eines regionalisierten Klimawandelszenarios gezeigt werden, dass eine moderate Erwärmung von $+2.4^{\circ} \mathrm{C}$ zu einer Vervierfachung der Borkenkäferschäden in Österreich führen könnte (Seidl et al., 2009a). Hierzu tragen sowohl zunehmende Käferpopulationen als auch abnehmende Wirtsfitness bei, wobei die relativ größten Anstiege für höher gelegene Gebiete simuliert wurden, wo große, bisher aufgrund zu geringer Temperaturen nicht für den Käfer geeignete, Nadelholzpopulationen durch den Klimawandel zunehmend geschädigt werden (siehe auch Marini et al., 2012). Wie schon für die historische Schadentwicklung dokumentiert, kann durch Waldbewirtschaftung die Schadanfälligkeit maßgeblich beeinflusst werden (Seidl et al., 2008), wobei bedacht werden muss, dass waldbauliche Maßnahmen lange Vorlaufzeiten haben und zukünftige robuste Waldzustände schon heute begründet werden müssen.

Vegetationsstruktur und -zusammensetzung und kann auch keine Bewirtschaftungseffekte integrieren. Analysen mit dynamischen Waldökosystemmodellen, die sowohl Klima- als auch Bewirtschaftungseffekte abbilden können, erlauben hingegen eine direkte Beurteilung von Klimaänderungseffekten auf Waldökosystemstruktur und -funktionsweise. Seidl et al. (2011a) analysierten 160000 ha Wirtschaftswald der Österreichischen Bundesforste und kamen zum Schluss, dass bei Fortführung des derzeitigen Bewirtschaftungskonzeptes knapp $40 \%$ dieser Waldflächen in der 2. Hälfte des 21. Jahrhunderts als hoch vulnerabel in Bezug auf die weitere Erbringung von Ökosystemleistungen einzuschätzen sind. Primär dafür verantwortliche Wirkungsketten sind steigende Schäden durch Störungen (vgl. hierzu Box 3.5 zu Borkenkäfern, sowie Box 3.8 und 3.9) und negative Zuwachstrends, vor allem auf physiologisch flachgründigen Kalkstandorten.

\subsubsection{Grünland}

\section{Abgrenzung und Charakterisierung}

Das typische anthropogen bestimmte Dauergrünland besteht aus einer Anzahl unterschiedlicher Pflanzenarten, wobei hier aus Sicht der landwirtschaftlichen Nutzung die Artengruppen der Gräser, der Leguminosen und der Kräuter von besonderer Bedeutung sind. Dauergrünland wird im Verbund mit Wiederkäuerhaltung (Rinder, Schafe) betrieben und ist durch einen relativ höheren spezifischen Wasserbedarf für die pflanzliche Biomasseproduktion gekennzeichnet als die meisten Ackerkulturen. Dies liegt daran, dass die jeweils am besten für eine intensive Futternutzung geeigneten Artenzusammensetzungen (also jene mit einer insgesamt hohen Biomasseleistung bei gleichzeitig hoher Futterqualität) an niederschlags- 


\section{Box 3.9: Misteln - Gewinner des Klimawandels auf Kosten ihrer Wirtsbäume? Box 3.9: Mistletoes - winners of climate change at host plant expense?}

Die Gemeine Mistel (Viscum album) ist ein Halbparasit (d.h. sie entzieht ihren Wirtspflanzen Nährstoffe, kann aber selbst Photosynthese betreiben) an einer Vielzahl von Baumarten und schädigt diese durch den Entzug von Wasser und Mineralnährstoffen (Nierhaus-Wunderwald und Lawrenz, 1997; Butin, 2011). Sie wird in drei wirtsspezifische Unterarten unterteilt: Die Laubholzmistel (Viscum album ssp. album) befällt viele verschiedene Laubhölzer, die Tannenmistel (V. album ssp. abietis) die Weißtanne und die Kiefernmistel (Viscum album spp. austriacum), Weiß-, Schwarz- und Hakenkiefer und selten auch andere Nadelbäume (Nierhaus-Wunderwald und Lawrenz, 1997; Butin, 2011). Misteln haben hohe Licht- und Wärmeansprüche und es wird erwartet, dass sich aufgrund höherer Temperaturen ihre Verbreitungsgebiete erweitern und ihre Häufigkeit zunehmen werden (Kliejunas et al., 2009).

Im Schweizer Kanton Wallis kam die Kiefernmistel am Beginn des 20. Jahrhunderts nur selten über $1000 \mathrm{~m}$ Seehöhe vor, bei einer systematischen Erhebung 2002 / 03 wurde aber auch über $1000 \mathrm{~m}$ starker Mistel-Befall an Weißkiefern festgestellt (Hilker et al., 2005; Rigling et al., 2006). Obwohl der Anteil der Probeflächen mit Misteln und die Intensität des Befalls in tieferen Lagen höher waren, trat die Kiefernmistel auch noch in 1250 m Seehöhe auf der Hälfte der Untersuchungsflächen auf. Die höchste Fundstelle befand sich auf knapp 1500 m (Hilker et al., 2005). Für das Wallis konnte somit eine Erhöhung der Verbreitungsgrenze während des letzten Jahrhunderts um 200-250, an manchen Orten sogar um rund 300 Höhenmeter, dokumentiert werden (Hilker et al., 2005). Mithilfe eines statistischen Regressionsmodells konnte die Höhenverschiebung des Mistelvorkommens durch einen gleichzeitigen Anstieg der Winter- und Frühjahrstemperaturen erklärt werden (Dobbertin et al., 2005; Hilker et al., 2005; Rigling et al., 2006). Auch die Erhöhung der Befallsintensität von Misteln an Kiefern steht vermutlich in Zusammenhang mit wärmeren Temperaturen, und der Halbparasit ist auch ein wichtiger Faktor bei dem im Wallis beobachteten Weißkiefernsterben, das durch einen abiotisch-biotischen Schädigungskomplex verursacht wird (Dobbertin und Rigling, 2006; Rigling et al., 2006).

Kiefern- und Tannenmistel sind in Österreich gebietsweise wichtige Schädigungsfaktoren an ihren Wirtsbaumarten, meist in lichten Waldbeständen auf trocknen Standorten (Cech und Perny, 1998; Krehan und Cech, 1998). In talnahen Waldkiefernwäldern nördlich des Inns in Tirol wird seit 25 bis 30 Jahren eine Zunahme des Befalls durch die Kiefernmistel beobachtet (Cech und Perny, 1998). Ähnlich wie in der Schweiz ist zu erwarten, dass sich aufgrund einer Klimaerwärmung die Verbreitungsgebiete von Misteln ausdehnen sowie die Befallsintensität und ihre Bedeutung als Schädigungs- und Störungsfaktor zunehmen werden. Erhöhte Absterberaten von Mistel-befallenen Bäumen wurden nach Trockenperioden beobachtet (Dobbertin und Rigling, 2006; Rigling et al., 2006).
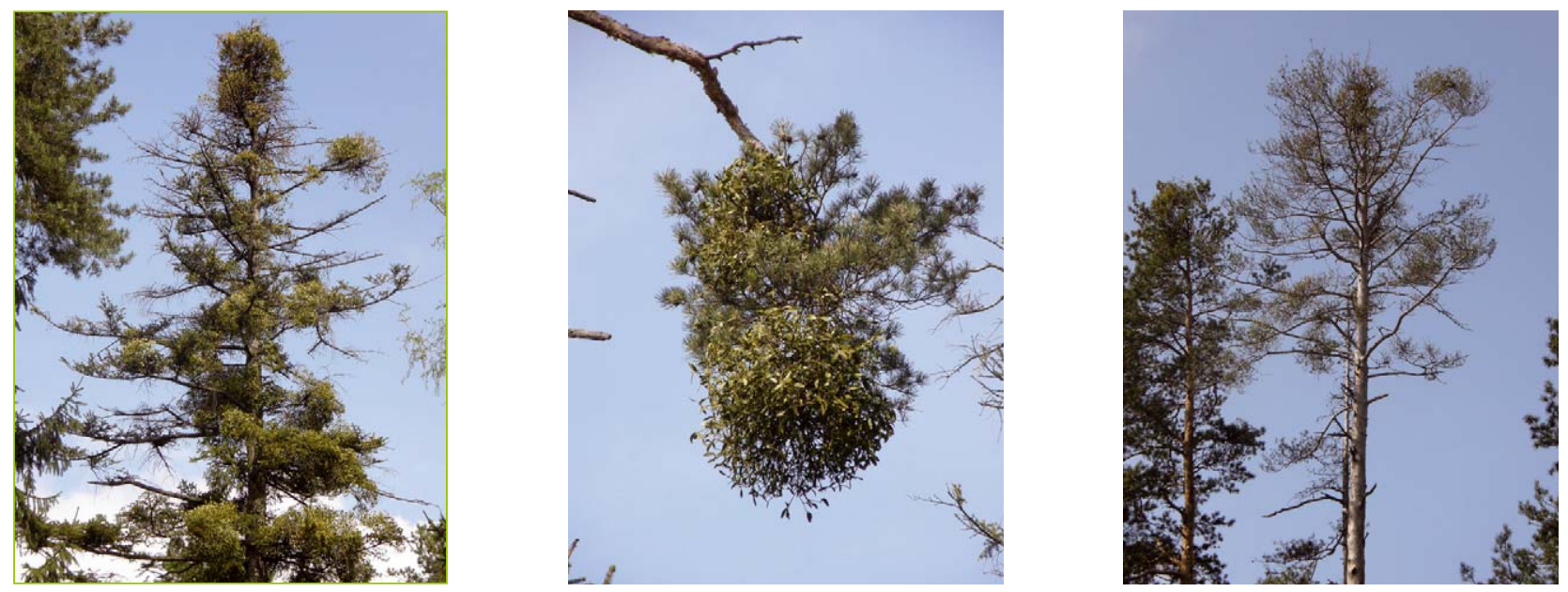

Box 3.9 Abbildung 1 Befall der Gemeinen Mistel an Weißtanne (Bild links) und an Weißkiefer (Bilder Mitte und rechts) in Niederösterreich Box 3.9 Figure 1 Common mistletoe on Silver fir (left) and on Scots pine (center, right) in Lower Austria 
reichere Verhältnisse angepasst sind (sogenannte „Fettwiesen“) und somit Wasser weniger effizient nutzen. Der pflanzliche Wasserbedarf im intensiv genutzten Grünland (mehr als drei Schnitte/ Jahr) beträgt ca. 600-900 1/ kg gebildeter Trockensubstanz, also ca. das Doppelte von Getreide. Andererseits ist aber der unproduktive Wasserverlust durch Bodenevaporation aufgrund der ständigen, ganzjährigen Bodenbedeckung geringer als im Ackerbau. Dies dürfte durch Interzeptionsverluste (d.h. Verdunstung von benetzten Pflanzenoberflächen), die bei geschlossenen Pflanzenbeständen im Mittel ca. $20 \%$ des Niederschlags betragen, zum Teil wieder kompensiert werden. Dauergrünland ist über die gesamte Vegetationsperiode im Wachstum wobei sich eine möglichst gleichmäßige Niederschlagsverteilung günstig auf die Biomasseproduktion auswirkt. Eine rentable Grünlandproduktion ist auf eine dauerhafte Erhaltung eines produktiven und leistungsfähigen Pflanzenbestandes ausgerichtet und braucht während der Sommermonate ausreichend und regelmäßigen Niederschlag (mind. 500-600 mm von April bis September).

\section{Klimawandelfolgen in Österreich}

Das landwirtschaftliche Grünlandproduktionspotenzial dürfte durch eine Klimaerwärmung insbesondere in den heute schon trockeneren Grünlandgebieten (mittlere Jahresniederschläge unter ca. $800 \mathrm{~mm}$ ) durch zunehmenden Trocken- und Hitzestress zurückgehen. Regional kann dieses Bild durch die Temperaturverhältnisse, die saisonale Niederschlagsverteilung, die Bodeneigenschaften (Nährstoff- und Wasserspeichervermögen) und die Produktionstechnik (Schnitthäufigkeit, Art und Höhe der Düngung usw.), welche das Produktionspotenzial wesentlich mitbestimmen, entsprechend differenziert sein.

Am Ostalpenrand ist in den Übergangsregionen von Grünland und Ackerbau mit sinkendem Produktionspotenzial zu rechnen, da sich unter den meisten Klimaänderungsszenarien im Osten Österreichs in den nächsten Jahrzehnten eher Niederschlagsabnahmen bei deutlich wärmeren Temperaturen abzeichnen. Nördlich der Alpen ist unter gegenwärtigen Klimabedingungen generell die zunehmende Entfernung zum Alpenrand mit abnehmenden Niederschlägen verbunden, was sich in geringerem Produktionspotenzial und höherem Ertragsrisiko äußert. In diesen Gebieten dürfte sich das Produktionspotenzial von Grünland weiter verschlechtern. $\mathrm{Zu}$ sätzlich werden vor allem Grünlandregionen mit Böden welche geringes Wasserspeichervermögen aufweisen relativ stärker betroffen sein. Nach Eitzinger et al. (2009c) zählen dazu das böhmische Massiv bzw. weite Teile Nordösterreichs und der angrenzenden Regionen Tschechiens (Abbildung 3.14).
Die Auswirkungen der klimatischen Verhältnisse des Jahres 2003 haben erkennen lassen, dass beim Auftreten von trockeneren Sommern das Schadensausmaß im Grünland beträchtlich sein kann (Zarzer, 2004). Dieser empirische Befund wird durch neue agroklimatische Studien (z.B. Eitzinger et al., 2009a; Schaumberger, 2012) bestätigt.

In Gunstlagen mit deutlich höheren Niederschlägen (mit über $800 \mathrm{~mm}$ Jahresniederschlag) würde durch die höheren Temperaturen das Produktionspotenzial ansteigen. In höheren Lagen, wo aktuell vor allem die Temperatur und die Länge der Wachstumsperiode begrenzend wirken, dürfte dieser Effekt stärker ausfallen, wenngleich kleinräumig durch die Exposition (Hangneigung und -ausrichtung) große Unterschiede gegeben sein können.

In den alpinen und subalpinen Lagen hat insbesondere die Dauer der Schneedecke im Frühjahr einen großen Einfluss auf die potenzielle Länge der Wachstumsperiode des Grünlandes und auf das Ertragspotenzial. Aus Schweizer Simulationsstudien (Calanca et al., 2005) ist bekannt, dass sich bei einer mittleren Temperaturzunahme um ca. $3{ }^{\circ} \mathrm{C}$ (entspricht dem Zeitfenster von 2071 bis 2100 in vielen Klimaänderungsszenarien) die Wachstumsperiode des Grünlandes in den mittleren und tiefen Lagen um 30 bis 40 Tage verlängern könnte, womit ein zusätzlicher Schnitt im Jahr möglich wäre. In den höheren Lagen würde es zu einer um 5 bis 8 Wochen früheren Ausaperung im Frühling und zu einer entsprechend früheren Bewirtschaftung kommen (Jasper et al., 2004). Da aber gleichzeitig unter den Klimaänderungsszenarien in Mitteleuropa zunehmende Winterniederschläge erwartet werden, könnte die im Frühjahr nötige Bewirtschaftung des Grünlandes und die Futterkonservierung insbesondere des ersten Schnittes in den niederschlagsreichen Bergregionen erschwert werden. Die in den Klimaszenarien durchwegs auftretende Abnahme der Sommer- und Frühherbstniederschläge dürfte die Erntebedingungen und arbeitswirtschaftlichen Bedingungen im übrigen Jahr im Grünland verbessern.

Höhere Wintertemperaturen können allerdings auch Schadfaktoren für das Grünland fördern. Hierzu zählen zum Beispiel Wechselfröste (Auffrieren und Austrocknen der Pflanzen), vorübergehende Wärmephasen (Frostenthärtung und Reservestoffverbrauch), undurchlässige Schneedecken mit Eisauflage wegen vermehrter Tauphasen (Schneeschimmel) und Spätfröste (Schädigung frühreifer Arten/Sorten), wobei die regionalen Auswirkungen bisher kaum abzuschätzen sind (Diepolder, 2007).

Durch klimatische Verschiebungen sind Änderungen in der Artenzusammensetzung des Dauergrünlands zu erwarten, da weiter zunehmende Trockenheit tendenziell die Bewirtschaf- 


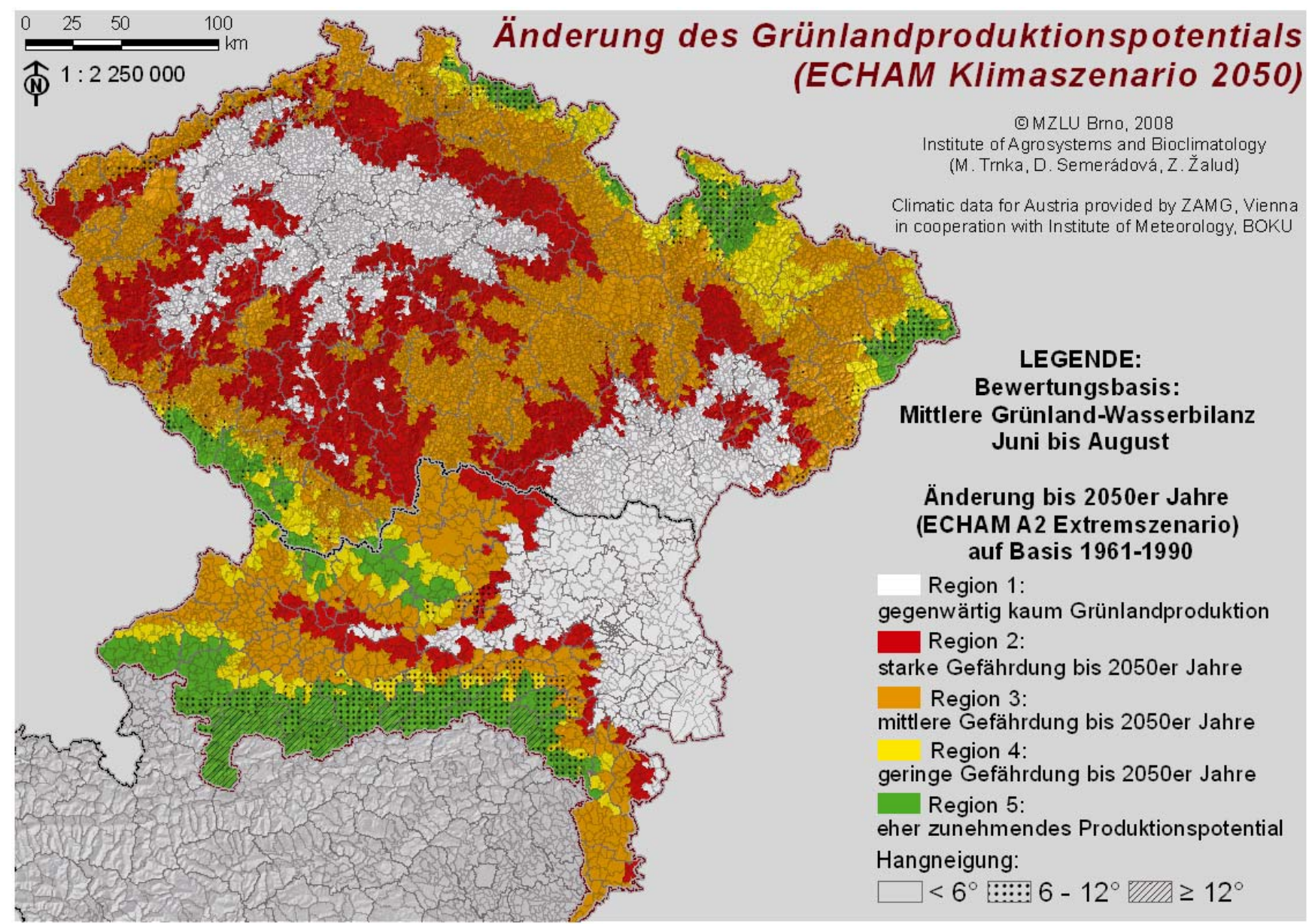

Abbildung 3.14 Die unter dem HadCM A2 Klimaänderungsszenario für 2050 negativ betroffenen Grünlandregionen nördlich der Alpen (in rot). Zugrundeliegende Klimasignale im Vergleich zur Bezugsperiode 1961 bis 1990: Temperatur $+2,7^{\circ} \mathrm{C}\left(\mathrm{Oktober}\right.$ bis April), $+3,8^{\circ} \mathrm{C}$ (Mai bis September); Niederschlag +7.1 \% (Oktober bis April), +23,8 \% (Mai bis September). Ursache ist eine zunehmend schlechtere Wasserbilanz im Sommer und damit sinkendes Produktionspotential bzw. deutlich höheres Ertragsrisiko. Quelle: Eitzinger et al. (2009c) verändert

Figure 3.14 Negative impacts on meadows north of the Alps (red) under climate change conditions in 2050 (temperature: $+2.7^{\circ} \mathrm{C}(\mathrm{Octo}-$ ber to April), $+3.8^{\circ} \mathrm{C}$ (May to September); precipitation: $+7.1 \%$ (October to April), $+23.8 \%$ (May to September) compared to the period from 1961 to 1990. Source: modified from Eitzinger et al. (2009c)

tung eher unerwünschte Arten mit meist niedrigerer Futterqualität und niedrigerem Ertragspotenzial fördert (Verschiebung der Artenzusammensetzung von einer „Fettwiese“ hin zu „Trockenrasen").

Insgesamt bewirkt eine intensivere Nutzung eine geringere Wurzelmasse und eine Dominanz der feuchteliebenden Fettwiesenarten, was insgesamt und zusätzlich in Kombination mit einem höheren Flächenertrag einen deutlich höheren Wasserbedarf im Vergleich zu extensiv genutztem Grünland ergibt. Bezüglich der Gefährdung durch Trockenheit ist daher mehrschnittiges, intensiv genutztes Grünland als empfindlicher einzustufen als extensiv genutztes Grünland (Karrer et al., 2010). Trockenschäden im Grünland, die mehrere Jahre nachwirken können, verursachen unter anderem Lücken in der Grasnarbe, welche Nachsaaten oder Neueinsaaten erfor- derlich machen oder die Verunkrautung mit Wurzelunkräutern fördern können.

Im Grünland ist, so wie bei vielen Ackerkulturen, bei verdoppeltem Kohlendioxidgehalt der Luft eine Zunahme der Biomasseleistung um ca. 10-20 \% zu erwarten. Es ist derzeit weitgehend unklar, in welchem Ausmaß diese Effekte sich im Grünland langfristig manifestieren, da es Wechselwirkungen mit vielen Umweltfaktoren und vor allem zahlreiche Anzeichen langfristiger Anpassungen (Akklimatisierungseffekte) gibt (Kammann et al., 2005).

Als Folge des steigenden $\mathrm{CO}_{2}$-Gehaltes der Atmosphäre werden Änderungen in der Bestandesarten-Zusammensetzung erwartet, wie etwa die Förderung der Leguminosen (Nösberger und Lüscher, 1995; Pötsch, 1998) und damit höhere N-Fixierungsraten des Pflanzenbestandes, wodurch andere Nährstoffe 
wie Phosphor eine zunehmende ertrags- und qualitätsbestimmende Rolle erhalten können (Diepolder, 2007). Ein steigender Kohlendioxidgehalt der Luft hat, so wie beim Getreide nachgewiesen, Auswirkungen auf die Inhaltsstoffbildung bei Pflanzen, wie etwa die Eiweißbildung und die Eiweißqualität (Veränderung des C:N-Verhältnisses in der Biomasse durch Zunahme des Kohlenstoffanteils). Die Stickstoffdüngung und eine mögliche Ausbreitung der Leguminosen im Grünland könnten den erwarteten Eiweißabfall nicht fixierender Arten aber auch kompensieren (Diepolder, 2007).

Für das Grünland bedeutende Schädlinge (vorwiegend Insekten; Kreuter, 2007), wie zum Beispiel Engerlinge, könnten wegen höherer Bodentemperaturen regional verstärkt auftreten und Schäden in der Futterproduktion verursachen. Aus der Praxis wird zum Beispiel berichtet, dass zunehmend mehrere Generationen nebeneinander auftreten und mehrere Arten beteiligt sind (Maikäfer, Gartenlaubkäfer, Junikäfer), allerdings mit stark regionalen Unterschieden. Neben Ertragseinbußen bewirken Engerlinge durch Grasnarbenschädigung auch eine Zunahme des Erosionsrisikos.

Durch zunehmend mildere Herbst- und Winterwitterung können verschiedene Gräserkrankheiten, wie Rostpilze, gefördert werden (Diepolder, 2007). Langandauernde Schneedecken können aufgrund von Eiskrustenbildungen durch Tauphasen zum Beispiel den Schneeschimmel, eine nicht nur im Grünland verbreitete Pilzkrankheit, fördern. Ein positiver Effekt auf die Grünlandwirtschaft dürften die besseren Erntebedingungen im Sommer sein, da sich unter den Klimaszenarien durchgehend zunehmende Sommertrockenheiten und eine niedrigere Luftfeuchte abzeichnen (mit hohen Unsicherheiten wegen der großen Variationen in den regionalen Niederschlagsszenarien). Dies ist nicht nur für die Bodenbefahrbarkeit sondern insbesondere für eine schnellere und günstige Anwelkung zur Silageproduktion bzw. Feldtrocknung zur Heugewinnung von Vorteil, was im Mittel die Qualität des Erntegutes wesentlich verbessern würde. Andererseits könnte eine zu schnelle Bodenabtrocknung durch hohe Temperaturen insbesondere bei Silierverfahren zusätzliche Probleme schaffen (zum Beispiel Hemmung der erwünschten Milchsäuregärung, schwierigere Verdichtung des Erntegutes, Entwicklung von Schimmelpilzen). Insgesamt gesehen sind die Einflüsse des Klimawandels auf das Grünland von sehr komplexer Natur, vor allem aufgrund der unterschiedlichen und standortvariablen Grünlandartenzusammensetzung und der komplexen Interaktionen zwischen Biozönose, Standort und Bewirtschaftungsaktivitäten.

\subsubsection{Gewässer}

\section{Allgemeines}

Wärmere Wassertemperaturen verursachen steigenden Stoffwechsel der aquatischen Organismen, von Primärproduzenten bis zu Fischen. Aquatische Primärproduzenten synthetisieren essentielle Nährstoffe, die positiv auf Wachstum, Reproduktion und Überleben von Konsumenten wirken. Für die heimische Makrophytenvegetation sind Gefährdungen vor allem in stehenden und langsam fließenden Gewässern oder Gewässerabschnitten gegeben (Janauer et al., 2003). Viele der neuen Arten haben starke Auswirkungen auf das befallene Gewässersystem, besonders aber auf die vorher dort wachsenden Wasserpflanzen. Daraus kann eine Gefährdung der heimischen Biodiversität mit Auswirkungen auf die Fisch und Wirbellosen-Zönosen sowie die Sportfischerei entstehen. Spezifische Auswirkungen auf Hydrologie und Abflussverhalten werden in Band 2, Kapitel 2 behandelt.

Als Folge der Temperaturzunahme ist ein Vordringen wärmeliebender aquatischer Makrophyten (Wasserpflanzen) zu erwarten. Die Verbreitung erfolgt dabei vorwiegend entlang der Donau, wobei sich thermophile Arten aus dem unteren Donauraum flussaufwärts und Arten aus dem atlantischen Bereich über den Rhein-Main-Donau-Kanal flussabwärts ausbreiten und von dort in die Seen gelangen. Diese Ausbreitung erfolgt aktiv durch Wanderungen bzw. passiv durch den Transport mit Schiffen. Wärmere Wassertemperaturen können für kälteliebende Arten limitierend werden, wenn art- und stadienspezifische physiologische Temperaturgrenzen überschritten werden. Dies kann zu einer Verschiebung des Artenspektrums von kälte- zu wärmeliebenden Arten führen.

\section{Fließgewässer}

Fließgewässer lassen sich von der Quelle bis zur Mündung in Fischregionen gliedern und die Fischlebensgemeinschaften anhand des Fischregionsindex (Schmutz et al., 2000) beschreiben. Dieser Index kann jeden Wert zwischen 1 und 7 annehmen (siehe Tabelle 3.6). Die Fischregionen werden durch eine Vielzahl von abiotischen Kenngrößen wie Abfluss und Wassertemperatur geprägt.

Veränderungen des Abflusses in Österreich fanden bislang nur in geringem Ausmaß statt und sind meist nicht auf klimabedingte, sondern auf andere Ursachen wie Kraftwerksnutzung zurückzuführen. Österreichweite Prognosen deuten auf saisonale Änderungen, aber auf keine wesentlichen Veränderungen in der Wasserbilanz hin (Holzmann et al., 2010). 
Tabelle 3.6 Fischregionen in Österreich

Table 3.6 Fish regions in Austria

\begin{tabular}{|ll|}
\hline Regionsindex & Fischregion \\
\hline 1 & Quellregion \\
\hline 2 & Untere Quellregion \\
\hline 3 & Obere Forellenregion \\
\hline 4 & Untere Forellenregion \\
\hline 5 & Äschenregion \\
\hline 6 & Barbenregion \\
\hline 7 & Brachsenregion \\
\hline
\end{tabular}

Großräumige Folgewirkungen auf die Fließgewässerbiozönosen lassen sich daher derzeit nicht ableiten. In bestimmten Einzugsgebieten wurde aber in den letzten Jahrzehnten bereits eine signifikante Zunahme der sommerlichen Niederwasserperioden nachgewiesen, was zu verringerter Habitatverfügbarkeit führen kann (Hauer et al., 2012).

Anders als bei der Hydrologie verhält es sich mit der Wassertemperatur, die eng an die Lufttemperatur gekoppelt ist. Bereits in den letzten 100 Jahren ist eine Zunahme der Wassertemperatur in den Fließgewässern zu verzeichnen, wie dies anhand von Langzeitmessungen an der Donau ersichtlich wird (Abbildung 3.15). Die Jahresmitteltemperatur der Donau nahm in den letzten 100 Jahren um ca. $2^{\circ} \mathrm{C}$ zu. Besonders stark war die Zunahme in den letzten 20 Jahren. Als Folge der Wassertemperaturveränderungen ist eine Verschiebung von kaltwasserliebenden hin zu warmwasserliebenden Arten und folglich eine Verschiebung der Fischregionen zu erwarten (siehe Abschnitt 3.2.10).
Die Erwärmung wird für die meisten kälteliebenden Fischarten eine Verschiebung ihrer Lebensräume gegen höhere Breiten und in größere Seehöhen bedeuten (Hari et al., 2006; Schmutz, 2008). Zugleich können kälteliebende durch wärmeliebende Arten verdrängt werden. Das bedeutet auch ein Zurückdrängen der Salmoniden. Einzelne Arten, wie z. B. die Äsche (Thymallus thymallus), sind lokal infolge anthropogener Eingriffe in ihrem Bestand schon derzeit so stark gefährdet, dass zusätzliche, klimabedingte Beeinträchtigungen sie an den Rand des Aussterbens bringen könnten. Es sind jedoch nicht nur einzelne Arten, sondern die gesamte Lebensgemeinschaft betroffen (Melcher et al., 2010; Schmutz und Mielach, 2011).

\section{Stillgewässer}

Die oberflächennahe Wassertemperatur von Seen in Österreich steigt derzeit um etwa $0,4-0,6{ }^{\circ} \mathrm{C}$ pro Dekade an (Dokulil, 2014). Im Tiefenwasser der Seen beträgt die Erwärmung etwa $0,1-0,2^{\circ} \mathrm{C}$ pro Dekade (Dokulil et al. 2006; Abbildung 3.16; vergleiche auch Band 2, Kapitel 2). Diese Änderungen beeinflussen den trophischen Status von Seen ebenso wie deren Nahrungsketten und -netzwerke.

Im Hinblick auf die Biologie ermöglichen die höheren Temperaturen im Frühjahr einen früheren Wachstumsbeginn des Phytoplanktons. Gerten und Adrian (2000) konnten bereits eine Vorverlegung des Maximums im Frühjahr um einen Monat nachweisen. Die wichtigen Zooplankton Arten (Keratella, Bosmin und Daphnia) entwickelten sich ebenfalls zwei Wochen früher, was zu einem früheren Eintritt der sogenannten Klarwasserphase führte.

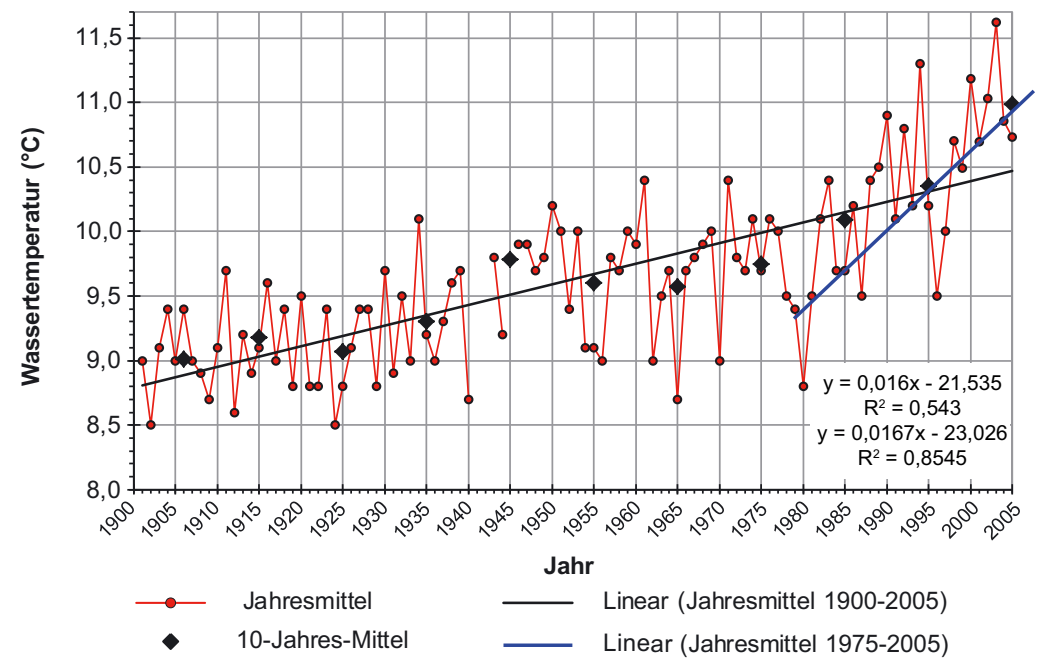

Abbildung 3.15 Langzeitmessung der Wassertemperatur der Donau. Datenquelle: Hydrographisches Zentralbüro

Figure 3.15 Longterm observations of water temperature in the River Danube in Austria. Source: Central Hydrographic Office 


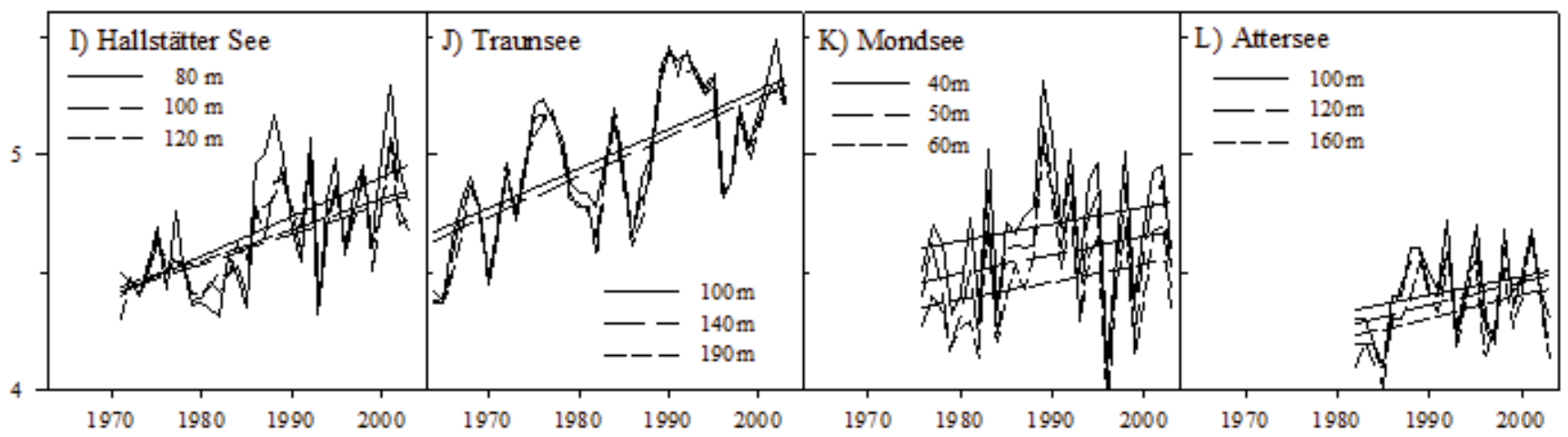

Abbildung 3.16 Langzeitmessung der Wassertemperaturen aus verschiedenen Tiefen ausgewählter Seen in Österreich. Nach Dokulil et al. (2006)

Figure 3.16 Longterm observations of water temperature in different depths of selected lakes in Austria. Adapted from Dokulil et al. (2006)

Als Folge der Temperaturzunahme ist ein Vordringen wärmeliebender aquatischer Vegetationselemente zu erwarten. Die Verbreitung erfolgt dabei vorwiegend entlang der Donau, wobei thermophile Elemente aus dem unteren Donauraum flussaufwärts vordringen und sich aus dem atlantischen Bereich Makrophyten (Wasserpflanzen) über den Rhein-MainDonau-Kanal flussabwärts verbreiten und von dort in die Seen gelangen. Diese Ausbreitung erfolgt aktiv durch Wanderungen bzw. passiv durch Transport mit Schiffen.

Für die heimische Makrophytenvegetation sind Gefährdungen vor allem in stehenden und langsam fließenden Gewässer oder Gewässerabschnitten gegeben (Janauer et al., 2003). Viele der neuen Arten haben starke Auswirkungen auf das befallene Gewässersystem, besonders aber auf die vorher dort wachsenden Wasserpflanzen. Daraus kann eine Gefährdung der heimischen Biodiversität mit Auswirkungen auf die Fisch- und wirbellose Fauna sowie die Sportfischerei entstehen. Von einer Erwärmung der Oberflächengewässer sollten bei den Fischen jene Neozoen profitieren, die höhere Temperaturen bevorzugen, wie etwa der Graskarpfen (Ctenopharyngodon idella) oder der Sonnenbarsch (Lepomis gibbosus; vgl. Rabitsch et al., 2013).

\section{4 Ökosystemleistungen \\ 3.4 Ecosystem services}

\subsubsection{Definition und Abgrenzung}

Die Betrachtung von Leistungen der Natur, die aufgrund ihres Nutzens für die Menschen zur Wohlfahrt beitragen (McVittie et al., 2013) hat in den letzten Jahren einen enormen Aufschwung genommen (Costanza et al., 1997). Die Vereinten Nationen prägten mit dem Millennium Assessment (MEA, 2005) den Begriff der „Ökosystemleistungen“ („,ecosystem services“). Nach dem „Millennium Ecosystem Assessment" lassen sich Ökosystemleistungen in vier Kategorien einteilen, wobei die sogenannten unterstützenden Leistungen (z. B. Erhaltung der genetischen Vielfalt) als Basis für die übrigen Leistungen angesehen werden: (i) Unterstützende Leistungen (Basisleistungen; Ökosystemleistungen, die auf Bodenbildung, Nährstoffkreislauf und Erhaltung der genetischen Vielfalt beruhen), (ii) Bereitstellende Leistungen (Bereitstellung von Nahrung, Wasser, Baumaterial - Holz, Fasern, Rohstoffe für Arzneimittel), (iii) Regulierende Leistungen (Regulierung von Klima, Überflutungen, Erosion, Rutschungen, Steinschlag, Krankheiten, Wasserqualität, Abfallbeseitigung, Bestäubung), und (iv) Kulturelle Leistungen (Ökosystemleistungen, die Erholung, Naturtourismus, ästhetisches Vergnügen und spirituelle Erfüllung fördern).

Der Begriff der Ökosystemleistungen muss von „Ökosystemfunktionen" unterschieden werden. Obwohl es terminologische Überschneidungen gibt, werden als Ökosystemfunktionen in der Regel die hinter den Ökosystemleistungen stehenden ökosystemaren Prozesse, seltener auch dahinterstehende ökosystemare Strukturen und Zustände bezeichnet. Die Unterschiede beruhen z. B. darauf, dass der Begriff der Ökosystemleistungen verschieden weit gefasst wird. Teilweise werden Ökosystemfunktionen und -prozesse als „Ökosystemleistung" gekennzeichnet, wohingegen in anderen Definitionen von einer strikten Trennung in ökosystemare Prozesse, Funktionen und Leistungen sowie in den daraus entstehenden Nutzen ausgegangen wird. 
Derzeit ist mit dem CICES-Prozess (Common International Classification of Ecosystem Goods and Services) ein weiterer Versuch auf EU-Ebene im Gange, aufbauend auf MEA und TEEB (Haines-Young und Potschin, 2010) einen konsistenten Rahmen für die Analyse von Ökosystemleistungen zu schaffen. Letztendlich sollen Klassifikationssysteme die Grundlage für die Erfassung und Bewertung von „Naturleistungen“ bilden. Im CICES werden jedoch, die Basisleistungen (supporting services; z. B. Photosynthese, Nährstoffkreislauf etc.) des MEA nicht angeführt, um Doppelzählungen zu vermeiden.

Im Rahmen des gegenständlichen Kapitels wird die vorhandene Literatur zu potentiellen Auswirkungen eines Klimawandels auf Ökosystemleistungen mit Bezug zu Österreich gesammelt und dargestellt. Im Sinne des MA wird die Erhaltung der Biodiversität als Voraussetzung für die Erbringung der anderen Ökosystemleistungen (bereitstellende, regulierende und kulturelle) betrachtet.

Es wird hier im Rahmen der bereitstellenden Ökosystemleistungen zwischen der Produktion von Holzbiomasse sowohl für materielle Zwecke als auch zur Energiegewinnung und der Produktion von Biomasse zu Ernährungszwecken unterschieden. Im Sinne von regulierenden Ökosystemleistungen werden die Speicherung von Kohlenstoff als Klimaschutzleistung, die Sicherung der Wasserschüttung bzw. der Grundwassernachlieferung und der Schutz vor gravitativen Naturgefahren betrachtet. Es wird darauf verweisen, dass dieses Kapitel keinen Gesamtüberblick zu Ökosystemleistungen in Österreich liefert und viele wichtige Ökosystemleistungen nicht berücksichtigt werden, da keine Information zu deren Beeinflussung durch den Klimawandel vorliegen.

Für Moore, Wälder, Grünland und Ackerflächen werden nachfolgend ausgewählte Ökosystemleistungen, zu denen wissenschaftliche Literatur vorhanden ist, in Bezug auf ihre Anfälligkeit gegenüber Phänomenen des Klimawandels zumeist qualitativ auf Basis von vorliegenden Detailstudien bzw. als Synthese verfügbarer Information beurteilt. Der Begriff der Vulnerabilität wird hier im Sinne von O’Brien et al. (2004) ohne die Miteinbeziehung von möglichen Anpassungsoptionen als summarische qualitative Bewertung der zu erwartenden Klimawandelauswirkungen verwendet (vgl. Abschnitt 3.1 und Band 2, Kapitel 1). Berücksichtigt werden dabei die Erzeugung von Nahrungs- und Futtermitteln, Holzbiomasse für materielle Verwendung sowie für energetische Zwecke (bereitstellend), die Speicherung von Kohlenstoff als Klimaschutzleistung, die Sicherung der Wasserschüttung bzw. der Grundwassernachlieferung und der Schutz vor gravitativen Naturgefahren (regulierend).

\subsubsection{Moore}

Moorgebiete stellen nicht nur spezielle Habitate dar, die eine Anzahl hochgradiger Spezialisten aus der Pflanzen- und Tierwelt beherbergen, sondern sind auch hocheffiziente Kohlenstoffspeicher mit über $150 \mathrm{t}$ gespeichertem Kohlenstoff pro Hektar in dem obersten $50 \mathrm{~cm}$ Bodenhorizont. Waldböden haben im Durchschnitt nach Weiss et al. (2000) in Österreich etwa 119 t/ ha Kohlenstoff gespeichert. Vor allem Hochmoore sind sensitiv auf wärmeres und niederschlagsärmeres Klima. In Österreich handelt es sich ca. um 4000 ha solcher klimasensitiver Hochmoore. Niedermair et al. (2010) sehen $85 \%$ der Hochmoore in Österreich bei Temperaturerhöhungen von $2-3{ }^{\circ} \mathrm{C}$ als gefährdet an. $\mathrm{Zu}$ ähnlichen Ergebnissen kommen auch Essl et al. (2012; vgl. auch Tabelle 3.5).

Absolut gesehen ist die Relevanz dieser ökologisch bedeutsamen Ökosysteme als Kohlenstoffspeicher jedoch als eher gering einzustufen.

\subsubsection{Wälder}

Mit ca. 50 \% der Fläche Österreichs ist die Relevanz von Waldökosystemen für die Erbringung von Ökosystemleistungen offensichtlich. Die Bedeutung einzelner Waldleistungen variiert örtlich stark und kann in einzelnen Regionen in Abhängigkeit von ökologischen Produktionsbedingungen oder der jeweiligen Regionalpolitik generell unterschiedlich sein (EEA, 2010). Tabelle 3.7 zeigt einen Überblick zu Waldleistungen und deren Beeinflussung durch Klimawandeleffekte.

Die Holzproduktion könnte einerseits von höheren $\mathrm{Zu}$ wächsen profitieren, doch wird es vor allem in jetzt schon trockenen inneralpinen Tallagen und auf seichtgründigen Standorten, die wenig Wasser speichern können, zu einem teilweisen Rückgang der Produktivität durch Trockenperioden und Hitzewellen kommen (Seidl et al., 2011b). Die Fichte wird in submontanen Höhenlagen auf großen Flächenanteilen als Hauptbaumart für eine geregelte Forstwirtschaft nicht mehr geeignet sein, da sich durch eine Klimaerwärmung in diesen Höhenlagen regelmäßig 2-3 Generationen Fichtenborkenkäfer pro Jahr entwickeln können (Seidl et al., 2008; Jönsson et al., 2011; siehe auch Box 3.5). Allgemein wird im heute nadelholzdominierten Bergwald durch die zunehmende Konkurrenzkraft von Laubhölzern, wie z. B. Buche und Bergahorn, die Baumartenvielfalt und damit der waldbauliche Entscheidungsspielraum bei der Baumartenwahl vergrößert. Der durchschnittliche Holzvorrat in den Alpenwäldern wird sich wahrscheinlich weiter erhöhen: Denn einerseits wird weniger Holz genutzt als zuwächst, andererseits steigt durch das Älterwerden 
Tabelle 3.7 Qualitative Beurteilung der Vulnerabilität ausgewählter Ökosystemleistungen von Wäldern im Ostalpenraum. (+) nicht vulnerabel, (-) vulnerabel. Vor dem allgemeinen zeitlichen Horizont bis 2050, perspektivisch bis 2100. Die Aussagen basieren auf den gesamten Quellen die in vorangegangenen Kapiteln zu Arten und Ökosystemen verwendet wurden

Table 3.7 Qualitative judgement of vulnerability of selected forest ecosystem services in Austria. (+) not vulnerable, (-) vulnerable. Time horizone 2050. Longterm until 2100. Based on all sources used in previous chapters on species and ecosystems

\begin{tabular}{|lcl|}
\hline Ökosystemleistung & Einschätzung der Vulnerabilität \\
\hline Holzproduktion & $+(-)$ & $\begin{array}{l}\text { auf großen Flächen Zunahme der Produktivität; lokal-regional durch großflächige Störungen } \\
\text { und durch Trockenheit gefährdet; langfristig Erhöhung des Laubholzanteiles }\end{array}$ \\
\hline Kohlenstoffspeicherung & $+(-)$ & $\begin{array}{l}\text { korrespondiert tw. mit Holzproduktion; Kohlenstoffpools im Waldboden könnten bei Erwär- } \\
\text { mung durch intensiveres Störungsregime zur } \mathrm{CO}_{2} \text {-Quelle werden }\end{array}$ \\
\hline Objektschutz & - & $\begin{array}{l}\text { durch höhere Störungsfrequenz, häufigere und intensivere Niederschlagsereignisse vulnera- } \\
\text { bel; wichtig zur Aufrechterhaltung von Infrastruktur und Siedlungsräumen }\end{array}$ \\
\hline Trinkwasserschutz & - & $\begin{array}{l}\text { durch höhere Störungsfrequenz, häufigere und intensivere Niederschlagsereignisse raschere } \\
\text { Humusabbauraten und Nitratauswaschung vulnerabel }\end{array}$ \\
\hline Biodiversität & $+/-$ & $\begin{array}{l}\text { über der Waldgrenze Verdrängung artenreicher Grasvegetation durch das Höherwandern } \\
\text { der Waldgrenze; die Baumartendiversität in der montanen Vegetationsstufe nimmt zu }\end{array}$ \\
\hline
\end{tabular}

der Waldbestände der Holzvorrat. Dieser weitere Anstieg des Holzvorrates hat möglicherweise negative Auswirkungen auf die Schadanfälligkeit durch Stürme, wodurch der Trend zu ansteigenden Vorräten sich in sein Gegenteil verkehren könnte.

Wälder mit Schutzfunktion (d.h. Wälder, welche entweder menschliche Einrichtungen und Bauwerke oder aber den Boden vor negativen Effekten durch gravitative Naturgefahren wie Lawinen, Steinschlag oder Erosion schützen) haben im Alpenraum eine besondere Relevanz. So geht etwa in der Schweiz das Bundesamt für Umwelt davon aus, dass zirka 40 $60 \%$ des Schweizer Waldes eine Schutzfunktion gegen Naturgefahren aufweisen (Wehrli et al., 2007). In den Bayerischen Alpen gelten gemäß Waldgesetz ungefähr $60 \%$ des Waldes als Schutzwald, in Österreich sind etwa $31 \%$ der gesamten Waldfläche prioritär mit einer Schutzfunktion belegt (Niese, 2011). In einzelnen alpinen Regionen liegt der Schutzwaldanteil höher, beispielsweise in Tirol mit mehr als $66 \%$. In den letzten Jahrzehnten hat die Bedeutung der Schutzfunktionalität zugenommen, weil Gebiete, die früher im Winter gemieden wurden, heute ganzjährig besiedelt sind oder eine bedeutende Rolle im Tourismus spielen.

Durch die klimawandelbedingt zu erwartende Intensivierung der Störungsregime wird auch zunehmend der Schutz vor gravitativen Naturgefahren betroffen sein und es werden vermehrt temporäre technische Schutzmaßnahmen wie Steinschlagnetze und Schneewerke erforderlich sein. Insgesamt werden die Anforderungen in Bezug auf stabile, ausreichend zahlreiche Dauerbestockungen gegen Steinschlag und Lawinenanbrüche sowie gutes Wasserrückhaltevermögen durch humusreiche, biologisch aktive Böden zur Vorbeugung und Abschwächung von Hochwasserereignissen in Zukunft noch wichtiger werden (Maroschek et al., 2009). Zusätzlich wird wahrscheinlich auch das Naturgefahrenpotential regionsspezifisch zunehmen. Zum Beispiel wird etwa die Erosionsgefährdung aufgrund der Zunahme von Starkniederschlägen ansteigen. In tieferen Lagen ist zwar allgemein mit geringeren Schneehöhen zu rechnen, jedoch aufgrund von häufigeren Nassschneesituationen auch mit vermehrten Lawinenanbrüchen im Waldbereich (Perzl und Kammerlander, 2010). Ein Beispiel aus den Dolomiten in Italien zeigt, dass es durch den Klimawandel aber auch zu geringerer Gefährdung durch $\mathrm{Na}-$ turgefahren kommen könnte. So wird wegen der geringeren Schmelzwassermengen im Frühjahr mit einer Verminderung von Hangrutschungen gerechnet (Dehn, 1999).

Bisher stellte die Verfügbarkeit von qualitativ hochwertigem Trinkwasser im Alpenraum kein Problem dar. Mit Ausnahme einiger prioritär als Quellschutzwälder bewirtschafteter Flächen wurde die Sicherstellung der Trinkwasserschüttung im „Kielwasser“ anderer Waldfunktionen als gegeben unterstellt. Bei weiter anhaltendem Eintrag von atmosphärischem Stickstoff in Waldökosysteme bei gleichzeitig klimabedingt zunehmenden Störungen und häufigeren Starkniederschlägen könnten die Nitratgehalte im Quellwasser jedoch über die Grenzwerte ansteigen (Herman et al., 2007). Um die Wasserqualität zu sichern, werden daher in Zukunft auf Quellschutz zugeschnittene Waldbaukonzepte notwendig werden, die spezielles Augenmerk auf waldhydrologisch günstige Baumartenzusammensetzung, stabile Bestandesaufbauformen und Humusmanagement legen.

Der österreichische Wald repräsentierte nach Weiss et al. (2000) im Jahr 1990 einen Kohlenstoffvorrat von $783 \pm 190$ Mt C (Waldbiomasse: $320 \pm 42 \mathrm{Mt} \mathrm{C}$; Waldboden: 


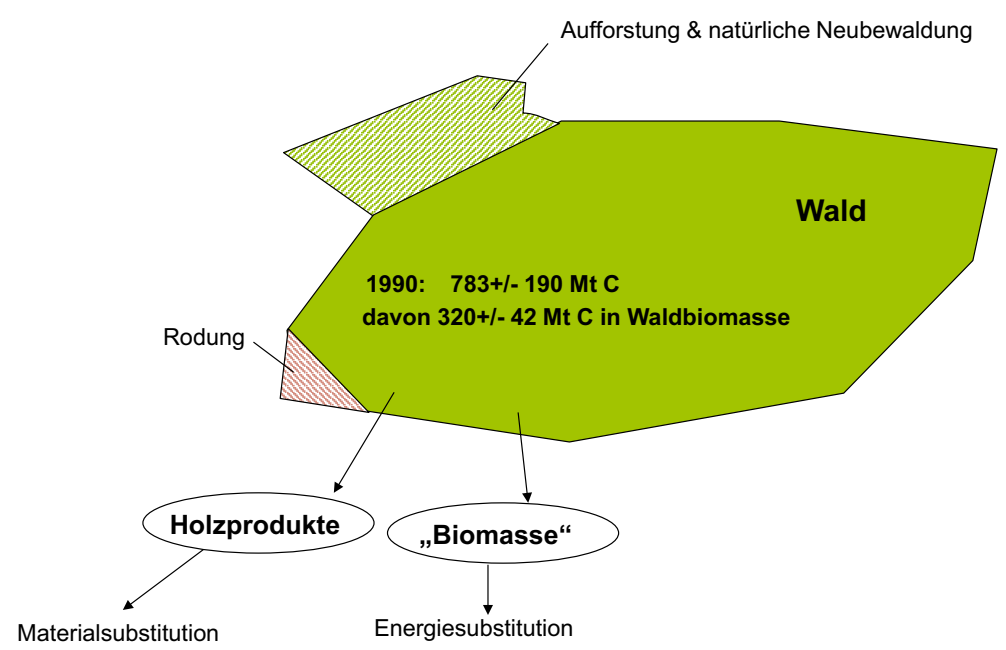

Abbildung 3.17 Klimaschutzfunktion des österreichischen Waldes. In situ waren 1990 nach Weiss et al. (2000) 783 Mt C gespeichert. Die Nutzung von Waldbiomasse wurde ex situ durch Substitution von fossilen Energieträgern sowie energieintensiveren Materialien durch Holzprodukte klimaschutzwirksam. Natürliche Neubewaldung = Zuwachsen von bisherigen Nichtwaldflächen

Figure 3.17 Climate change mitigation effects of the Austrian forests. In situ storage of $783 \mathrm{Mt} \mathrm{C}$ (Weiss et al., 2000), harvested biomass contributed ex situ to climate change mitigation via substitution of fossil fuels and energy intensive materials. Natural afforestation $=$ forest succession on current non-forest land
$463 \pm 185$ Mt C; vgl. Abbildung 3.17) und somit den mit Abstand größten Kohlenstoffspeicher in der österreichischen Landschaft. Dieser Vorrat entspricht in etwa 40 österreichischen $\mathrm{CO}_{2}$ - ̈̈q.-Emissionen der Treibhausgase $\mathrm{CO}_{2}, \mathrm{CH}_{4}$ und $\mathrm{N}_{2} \mathrm{O}$ im Jahr 1990. Nach Weiss et al. (2000) war der österreichische Wald im Zeitraum 1961 bis 1996 eine Nettokohlenstoffsenke. Die mittlere jährliche Nettokohlenstoffbindung der Waldbiomasse betrug in diesem Zeitraum $2527 \mathrm{kt} \mathrm{C}\left(9267 \mathrm{Gg} \mathrm{CO}_{2}\right)$ mit einem Jahresminimum von $1014 \mathrm{kt} \mathrm{C}$ und einem Jahresmaximum von $3689 \mathrm{kt} \mathrm{C}$ (Unsicherheit \pm 748 kt C). Für den Zeitraum 1980 bis 1996 entspricht diese Nettokohlenstoffbindung etwa $14 \%$ der gesamten österreichischen Brutto$\mathrm{CO}_{2}$ - ̈̈q.-Emission der Treibhausgase $\mathrm{CO}_{2}, \mathrm{CH}_{4}$ und $\mathrm{N}_{2} \mathrm{O}$.

Das Temperaturregime hat einen wesentlichen Einfluss auf den Bodenkohlenstoff. Eine Temperaturzunahme führt zu erhöhter mikrobieller Aktivität und damit zu erhöhten $\mathrm{CO}_{2}^{-}$ Freisetzungsraten aus Waldböden. Experimentelle Klimamanipulationen in Achenkirch / Tirol zeigen dass bei einer Bodenerwärmung um $4^{\circ} \mathrm{C}$ kurzfristig bis zu fünfzig Prozent mehr $\mathrm{CO}_{2}$ $\left(-2,5 \mathrm{tha}^{-1}\right)$ freigesetzt werden können (Schindlbacher et al., 2009). Inwieweit dieser Trend langfristig anhält und ob Österreichs Waldböden entsprechend große Mengen an Kohlenstoff verlieren, ist noch unklar und eine der zentralen Fragestellungen der Bodenökologie. Veränderungen im Niederschlag könnten den Bodenkohlenstoff in ähnlichem Umfang beeinflussen. Die Richtung kann allerdings entgegengesetzt sein, sodass vermehrte Trockenheit im Sommer möglicherweise zu einer verminderten Freisetzung von $\mathrm{CO}_{2}$ und zu einer Kompensation des Erwärmungseffekts führt (Schindlbacher et al., 2012).

Dieser Temperatureffekt und ansteigende Nutzungen (z.T. durch Kalamitäten bedingt) haben in den 1990er und 2000er Jahren die Senkenstärke des österreichischen Waldes deutlich verringert (siehe dazu Band 3, Kapitel 2). Diese Entwicklung zeigt auf, dass in Zukunft in Abhängigkeit von Störungsregime und Bewirtschaftung die Kohlenstoffpools im Wald abnehmen könnten. Für eine Gesamtbewertung der waldbasierten Minderungswirkung ist jedoch der Energiesektor, Materialsubstitution und die Speicherung von Kohlenstoff in Holzprodukten zu berücksichtigen (siehe dazu Band 3, Kapitel 2).

Am Standort Poschach (Obergurgl, Ötztal) wurde festgestellt, dass die Verdrängung von Zwergsträuchern an der Waldgrenze nach Hochlagenaufforstung zu Kohlenstoffverlusten im Boden führt. Die Zwergsträucher Calluna und Rhododendron sind für ihre schlecht abbaubare Streu und für den extrem geschlossenen Nährstoffkreislauf bekannt. Die Böden unter Zwergsträuchern erwiesen sich als wesentlich kohlenstoffreicher als jene unter einem 50 Jahre alten Zirbenwald (Jandl, 2011). Dies hat Implikationen für die Kohlenstoffbilanz: Zwar wird in der oberirdischen Biomasse im Wald ein großer Kohlenstoffvorrat aufgebaut, doch wird gleichzeitig der stabilere Kohlenstoffvorrat im Boden abgebaut. Die Implikation für die österreichische Kohlenstoffbilanz ist, dass durch die Vegetationsänderung insgesamt nur ein kleiner Bodenkohlenstoffpool aufgebaut wird, der überdies stark auf Temperaturanstieg reagiert und leicht abbaubar ist.

Biologisch könnten die Wälder in Österreich in den kommenden Dekaden auch weiter zusätzlichen Kohlenstoff speichern (z. B. Zierl und Bugmann, 2007; Seidl et al., 2008, Hagedorn et al., 2010). Allerdings ist die Speicherleistung von Wäldern limitiert, da nicht unbegrenzt große Biomassevorräte und damit Kohlenstoffmengen aufgebaut werden können. Geht man davon aus, dass in Zukunft Störungsintensität und -häufigkeit zunehmen, besteht das Risiko, dass der durchschnittliche Hektarvorrat an Waldbiomasse sinken könnte. Die in situ Senkenwirkung der Waldflächen ist stark von der zukünftigen Nutzungsintensität abhängig. Obwohl Kohlen- 
Tabelle 3.8 Qualitative Beurteilung der Vulnerabilität ausgewählter Ökosystemleistungen von Grünlandflächen im Ostalpenraum. (+) nicht vulnerabel, (-) vulnerabel. Die Aussagen basieren auf den gesamten Quellen die in vorangegangenen Kapiteln zu Arten und Ökosystemen verwendet wurden

Table 3.8 Qualitative judgement of vulnerability of grassland ecosystem services in Austria. (+) not vulnerable, (-) vulnerable. Based on all sources used in previous chapters on species and ecosystems

\begin{tabular}{|lcl|}
\hline Ökosystemleistung & Einschätzung der Vulnerabilität \\
\hline Holzproduktion & $+(-)$ & $\begin{array}{l}\text { auf großen Flächen Zunahme der Produktivität; lokal-regional } \\
\text { durch großflächige Störungen und durch Trockenheit gefährdet; } \\
\text { langfristig Erhöhung des Laubholzanteiles }\end{array}$ \\
\hline Kohlenstoffspeicherung & $+(-)$ & $\begin{array}{l}\text { korrespondiert tw. mit Holzproduktion; Kohlenstoffpools im Wald- } \\
\text { boden könnten bei Erwärmung durch intensiveres Störungsregime } \\
\text { zur } \mathrm{CO}_{2} \text {-Quelle werden }\end{array}$ \\
\hline Objektschutz & - & $\begin{array}{l}\text { durch höhere Störungsfrequenz, häufigere und intensivere Nie- } \\
\text { derschlagsereignisse vulnerabel; wichtig zur Aufrechterhaltung } \\
\text { von Infrastruktur und Siedlungsräumen }\end{array}$ \\
\hline Trinkwasserschutz & - & $\begin{array}{l}\text { durch höhere Störungsfrequenz, häufigere und intensivere Nie- } \\
\text { derschlagsereignisse raschere Humusabbauraten und Nitrataus- } \\
\text { waschung vulnerabel }\end{array}$ \\
\hline Biodiversität & $\begin{array}{l}\text { über der Waldgrenze Verdrängung artenreicher Grasvegetation } \\
\text { durch das Höherwandern der Waldgrenze; die Baumartendiversi- } \\
\text { tät in der montanen Vegetationsstufe nimmt zu }\end{array}$ \\
\hline
\end{tabular}

stoffspeicherung aufgrund der fehlenden Märkte zurzeit noch eine untergeordnete Rolle in der Waldbewirtschaftung in Österreich spielt, konnten erste Abschätzungen auf Basis von Simulationsmodellen zeigen, dass waldbauliche Maßnahmen die Senkenfunktion von Wirtschaftswald deutlich weiter erhöhen können (Seidl et al., 2007, 2008). Es würde allerdings zu kurz greifen, nur die in situ Klimaschutzfunktion der Wälder zu berücksichtigen. Über eine kaskadische Nutzung von Waldbiomasse kann dieser Effekt verstärkt werden (siehe dazu Band 3, Kapitel 2).

Neophyten, wie z. B. der Götterbaum, aber auch heimische Baumarten bilden im Klimawandel neue Nischen auf Standorten, wo sie bisher nicht konkurrenzstark genug waren. Für den Naturschutz ergeben sich daraus neue Herausforderungen (z. B. Maroschek und Lexer, 2010).

\subsubsection{Grünland, Weiden und Wiesen}

Die land- und forstwirtschaftlich genutzte Fläche in Österreich beträgt laut Agrarstrukturerhebung 20107348000 ha, davon werden 1441000 ha als Dauergrünland und 1371000 ha als Ackerland bewirtschaftet (BMLFUW, 2013). Eine Klimaveränderung hat potentiell großen Einfluss auf die landwirtschaftliche Produktion und könnte eine bedeutsame Veränderung der Landnutzung erzwingen (u. a. Schaumberger et al., 2011). An Ökosystemleistungen sind sowohl bei Grünland- als auch Ackerflächen Produktion (Futter, Nahrungsmittel), Kohlenstoffspeicherung in situ, Erosionsschutz, Trinkwasser-, Gewässerschutz und die Erhaltung der Biodiversität bedeutsam.

Das österreichische Grünland nimmt in all seinen sehr unterschiedlichen Ausprägungen eine ganz besondere Rolle in der Bereitstellung multifunktionaler Ökosystemleistungen durch die Landwirtschaft ein (Götzl et al., 2011). Neben der Produktion von hochwertigem Grundfutter erfüllt und unterstützt Grünland zahlreiche ökologische Funktionen wie Artenvielfalt, Erosions-, Boden- und Gewässerschutz und stellt ein markantes sowie unverzichtbares Element der Kultur- und Erholungslandschaft dar (Pötsch, 2012; vgl. auch Tabelle 3.8). Die zunehmenden Ansprüche der menschlichen Gesellschaft durch den steigenden Bedarf an Nahrungsmitteln sowie stofflich und energetisch genutzter Biomasse führen zu stärkeren Flächenkonkurrenzen, die durch die Verknappung fossiler Ressourcen und insbesondere durch den Klimawandel noch verstärkt werden (Exner, 2011).

Es gibt Grünlandflächen, die aufgrund der klimatischen oder topografischen Bedingungen nur eine extensive Nutzung zulassen. Die Analyse von Verschiebungen und Veränderungen zwischen intensivem und extensivem Grünland aufgrund von Klimawandeleffekten ist nur bedingt möglich, da intensives Grünland natürlich in Abhängigkeit von Rahmenbedingungen auch extensiv bewirtschaftet werden kann. Die Statistik zeigt eine Reduzierung der Grünlandflächen insgesamt. Das verbleibende Grünland muss daher intensiver genutzt werden, um die Erträge aufrechterhalten zu können. Eine intensivere Nutzung wirkt sich negativ auf die Biodiver- 
Tabelle 3.9 Qualitative Beurteilung der Vulnerabilität ausgewählter Ökosystemleistungen von Ackerflächen im Ostalpenraum. (+) nicht vulnerabel, (-) vulnerabel. Die Aussagen basieren auf den gesamten Quellen die in vorangegangenen Kapiteln zu Arten und Ökosystemen verwendet wurden

Table 3.9 Qualitative judgement of vulnerability of selected arable ecosystem services in Austria. (+) not vulnerable, $(-)$ vulnerable. Based on all sources used in previous chapters on species and ecosystems.

\begin{tabular}{|c|c|c|}
\hline Ökosystemleistungen & Einschätzun & Vulnerabilität \\
\hline Produktion & $+(-)$ & $\begin{array}{l}\text { Überwiegend Zunahme der Produktivität durch autonome } \\
\text { Anpassungen in der Produktionstechnik; Mögliche Zunahme der } \\
\text { interannualen Ertragsschwankungen insbesondere durch Hitze } \\
\text { und Trockenheit, regional auch durch andere Extremwetterereig- } \\
\text { nisse (Hagel, Starkniederschläge) und Schaderreger }\end{array}$ \\
\hline Kohlenstoffspeicherung & - & $\begin{array}{l}\text { Kohlenstoffpools in Ackerböden könnten bei Erwärmung zur } \\
\mathrm{CO}_{2} \text {-Quelle werden, regional Gefährdung durch Bodenerosion }\end{array}$ \\
\hline Standort-/Objektschutz & - & $\begin{array}{l}\text { Bodenerosions- und Überflutungsgefahren durch häufigere und } \\
\text { intensivere Niederschlagsereignisse }\end{array}$ \\
\hline Trinkwasser-, Gewässerschutz & - & $\begin{array}{l}\text { Durch höhere Störungsfrequenz, häufigere und intensivere Nie- } \\
\text { derschlagsereignisse, Bodenerosionsgefahr, raschere Humusab- } \\
\text { bauraten und höhere Nährstoffauswaschung }\end{array}$ \\
\hline Biodiversität & $+/-$ & $\begin{array}{l}\text { Gefährdung der Biodiversität durch Intensivierung; Steigerung der } \\
\text { Biodiversität bei ökologischen oder naturnahen Landbaumethoden }\end{array}$ \\
\hline
\end{tabular}

sität aus. Der Bedarf an zusätzlicher Grünlandfläche könnte so manche bereits aufgegebene extensive Fläche wieder in die Nutzung zurückholen, falls sie noch nicht zu stark verwaldet ist.

Neben der Produktion von Futtermitteln spielt die Kohlenstoffspeicherung bei Grünland eine wichtige Rolle. So liegt das Verlustpotential an Kohlenstoff unter Grünland bei bis zu $13 \mathrm{t} / \mathrm{ha}$, wenn kein Augenmerk auf adäquates Humusmanagement gelegt werden würde (von Haaren et al., 2010; Kirchner et al., 2012).

\subsubsection{Ackerflächen}

Der Flächennutzungsanteil des Ackerbaues ist vor allem in den Flachlandregionen Österreichs hoch. Bezüglich der Vulnerabilität von Ökosystemleistungen der Ackerflächen (Tabelle 3.9) spielt die Topografie eine bedeutende Rolle, wobei hier vor allem die Bodenerosionsanfälligkeit oder die klimatische Wasserbilanz von Bedeutung ist. Allgemein ist für die Vulnerabilität verschiedener Funktionen die Art der Bewirtschaftung von Bedeutung, wie die Bodenbearbeitung, die Fruchtfolgen und die Intensität der Bewirtschaftung (z. B. ökologisch oder konventionell).

Als Beispiel kann der Maisanbau dienen. Wegen der relativ späten Bestandesschließung sind extremere Niederschläge und höhere Winterniederschläge im Maisanbau hinsichtlich der Bodenerosion eine große Gefahr für das Ertragspotenzial des Bodens. Insbesondere in hügeligem Gelände und in den niederschlagsreicheren Anbaugebieten sind Bodenerosion und Verschlämmungen eine bedeutende Klimawandelfolge in bestimmten Regionen Österreichs, wie etwa im Weinviertel (Klik und Eitzinger, 2010).

\subsubsection{Aquakulturen}

Die wirtschaftliche Bedeutung von Fischzuchtanlagen in Österreich hat in den letzten Jahren zugenommen. Im niederösterreichischen Alpenvorland wurde untersucht, wie sich ein zu erwartender Klimawandel auf die Wassertemperatur bzw. die Durchflussmenge der Alpenvorlandflüsse auf Fischzuchtanlagen sowie das Biomassepotential generell auswirken kann (Heissenberger et al., 2010; Kainz, 2011).

Die derzeitige Wasserführung in diesen Alpenvorlandsflüssen liegt in der Regel um ein Vielfaches über dem Schwellwert der für Fischzuchtanlagen für Kaltwasserfische (Forellen, Saiblinge) erforderlich ist. Grundsätzlich sollten Kaltwasserarten wie Forellen und Saiblinge bei Wassertemperaturen $<18^{\circ} \mathrm{C}$ gezogen werden. Dem Datensatz des Hydrographischen Jahrbuchs (2006) zufolge liegen z. B. die Wassertemperaturen im Flussunterlauf der Ybbs (Messstation Greimpersdorf) sowie der Erlauf (Messstation Niederndorf) in den Sommermonaten Juni und Juli bereits jetzt bei $>18^{\circ} \mathrm{C}$ (Greimpersdorf: 20-21 ${ }^{\circ} \mathrm{C}$; Niederndorf: $18,5-19,5^{\circ} \mathrm{C}$ ). Demzufolge werden bei steigenden Wassertemperaturen Aquakulturanlagen im Alpenvorland in Oberflussregionen gedrängt werden, wobei es jedoch insgesamt Steigerungspotential in Bezug auf produzierte Fischbiomasse gibt. 


\subsection{Forschungsbedarf \\ 3.5 Research needs}

Der Wissensstand zu Klimawandelauswirkungen auf die Biosphäre mit spezieller Berücksichtigung österreichischer Verhältnisse ist derzeit in Bezug auf Sektoren, Ökosysteme und Arten(-gruppen) äußerst heterogen. Intensiv beforscht wurden bisher land- und forstwirtschaftliche Sektoren mit zugehörigen Nutzpflanzen bzw. Baumarten und Waldökosystemen sowie einzelne Schädlinge (bzw. Störungsregime), die Hochgebirgsflora und ausgewählte Aspekte der Fauna (z. B. Fische und Gewässerökosysteme).

Der Forschungsbedarf in Bezug auf die Biosphäre ist daher im Allgemeinen bedeutend, die Relevanz hoch. Biodiversität ist die Grundlage für die Erbringung von Ökosystemleistungen, die für das menschliche Wohlbefinden unabdingbar sind. Die Biosphäre spielt eine Schlüsselrolle im globalen Kohlenstoffkreislauf und damit für den Klimaschutz.

- In bisher weniger beachteten Ökosystemtypen bzw. Artengruppen sollte der Wissensstand zu Klimawandeleffekten dringend verbessert werden. Als vordringlich wird die Identifikation klimasensitiver Arten, Lebensräume, Schutzgebiete und Ökosystemleistungen und der erforderlichen Maßnahmen für deren Schutz erachtet. Dies gilt in besonderem Maße für Teile der Biodiversität mit hoher Verantwortung (geschützte, gefährdete und prioritäre Arten und Lebensräume)

- Vermehrtes Augenmerk sollte auf die Auswirkungen von Extremereignissen (Hitze, Frost, Trockenheit, Stürme) und Störungsregime sowie die interannuelle Schwankung von Klimavariablen gelegt werden

- Der Kenntnisstand zur Sensitivität von Arten, Ökosystemen und Ökosystemleistungen in Bezug auf mögliche zukünftige Klimawandelpfade sollte durch gezielteres und konsistenteres Verwenden von mehreren Klimawandelszenarien in den Analysen verbessert werden

- Allgemein sind Forschungsanstrengungen dahingehend $\mathrm{zu}$ intensivieren, dass in der Klimafolgenforschung ein Methodenmix zur Anwendung gelangt, der Modellbildung und Simulation und empirisch-experimentelle Forschungsansätze kombiniert

- Anzustreben sind integrierte Untersuchungsansätze die verschiedene Artengruppen in Ökosystemen bzw. interagierende Ökosystemtypen in zeitlich-räumlichen Untersuchungsansätzen auf verschiedenen Skalen berücksichtigen, um das holistische Systemverständnis zu verbessern
- Insbesondere die Wechselwirkungen mit anderen Faktoren des Globalen Wandels (z. B. Landnutzung, Globalisierung) und die Anpassungskapazitäten der Arten und Lebensräume sind nicht ausreichend bekannt

- Die Einrichtung von Klimafolgen-Monitoringprogrammen (wie z. B. GLORIA) auf Grundlage wissenschaftlicher Methoden, die verschiedene Artengruppen oder Ökosysteme berücksichtigen, ist erforderlich, um klimawandelbedingte Änderungen der Biodiversität zu erkennen. Aufgrund der großen regionalen Vielfalt Österreichs sind räumlich-explizite, vergleichende Untersuchungen von hoher Relevanz

\subsection{Literaturverzeichnis \\ 3.6 References}

Adrian, R., O’Reilly, C.M., Zagarese, H., Baines, S.B., Hessen, D.O., Keller, W., Livingstone, D.M., Sommaruga, R., Straile, D., Van Donk, E., Weyhenmeyer, G.A., Winder, M., 2009. Lakes as sentinels of climate change. Limnol Oceanogr 54, 2283-2297.

AGES, 2012. Maiswurzelbohrer [WWW Document]. URL http:// www.ages.at/ages/landwirtschaftliche-sachgebiete/pflanzengesundheit/maiswurzelbohrer/ (accessed 6.14.12).

Ainsworth, E.A., Long, S.P., 2005. What have we learned from 15 years of free-air $\mathrm{CO}_{2}$ enrichment (FACE)? A meta-analytic review of the responses of photosynthesis, canopy properties and plant production to rising $\mathrm{CO}_{2}$. New Phytologist 165, 351-372.

Alexandrov, V., Eitzinger, J., Cajic, V., Oberforster, M., 2002. Potential impact of climate change on selected agricultural crops in north-eastern Austria. Global Change Biology 8, 372-389. doi:10.1046/j.1354-1013.2002.00484.x

Ambus, P., Zechmeister-Boltenstern, S., Butterbach-Bahl, K., 2006. Sources of nitrous oxide emitted from European forest soils. Biogeosciences 3, 135-145.

Anonymus, 2009. Der Österreichische Wald. BMLFUW, Bundesministerium für Land- und Forstwirtschaft, Umwelt und Wasserwirtschaft, Abteilung I V/1, Wien.

Araújo, M.B., Thuiller, W., Pearson, R.G., 2006. Climate warming and the decline of amphibians and reptiles in Europe. Journal of Biogeography 33, 1712-1728.

Aspöck, H., 2007. Klimawandel und die Ausbreitung von Krankheiten: Durch Arthropoden übertragene Infektionen in Mitteleuropa. Entomologica Romanica 345-365.

Audsley, E., Pearn, K.R., Simota, C., Cojocaru, G., Koutsidou, E., Rounsevell, M.D.A., Trnka, M., Alexandrov, V., 2006. What can scenario modelling tell us about future European scale agricultural land use, and what not? Environmental Science \& Policy 9, 148-162. doi:10.1016/j.envsci.2005.11.008

Austin, M.P., Smith, T.M., 1990. A new model for the continuum concept, in: Grabherr, G., Mucina, L., Dale, M.B., Ter Braak, C.J.F. (Eds.), Progress in Theoretical Vegetation Science. Advances in Vegetation Science, 11. Springer, Netherlands, pp. 35-47.

Bader, M.K.-F., Leuzinger, S., Keel, S.G., Siegwolf, R.T.W., Hagedorn, F., Schleppi, P., Körner, C., 2013. Central European hardwood trees in a high-CO future: synthesis of an 8-year fo- 
rest canopy $\mathrm{CO}_{2}$ enrichment project. J Ecol 101, 1509-1519. doi:10.1111/1365-2745.12149

Bahn, M., Körner, C., 2003. Recent Increases in Summit Flora Caused by Warming in the Alps, in: Nagy, D.L., Grabherr, G., Körner, C., Thompson, D. (Eds.), Alpine Biodiversity in Europe, Ecological Studies. Springer Berlin Heidelberg, pp. 437-441.

Baier, P., Pennerstorfer, J., Schopf, A., 2007. PHENIPS—A comprehensive phenology model of Ips typographus (L.) (Col., Scolytinae) as a tool for hazard rating of bark beetle infestation. Forest Ecology and Management 249, 171-186. doi:10.1016/j.foreco.2007.05.020

Baker-Austin, C., Trinanes, J.A., Taylor, N.G.H., Hartnell, R., Siitonen, A., Martinez-Urtaza, J., 2012. Emerging Vibrio risk at high latitudes in response to ocean warming. Nature Climate Change 3, 73-77. doi: $10.1038 /$ nclimate1628

Bálint, M., Domisch, S., Engelhardt, C.H.M., Haase, P., Lehrian, S., Sauer, J., Theissinger, K., Pauls, S.U., Nowak, C., 2011. Cryptic biodiversity loss linked to global climate change. Nature Climate Change 1, 313-318. doi:10.1038/nclimate1191

Baltensweiler, W., 1993. Why the larch bud-moth cycle collapsed in the subalpine larch-cembran pine forests in the year 1990 for the first time since 1850. Oecologia 94, 62-66. doi:10.1007/ BF00317302

Bates, J.W., 2009. Mineral nutrition, substratum ecology, and pollution, in: Shaw, J.A. (Ed.), Bryophyte Biology. Cambridge University Press, Cambridge, New York.

Bates, J.W., Ashton, N.W., Duckett, J.G. (Eds.), 1998. Bryology for the Twenty-first Century. Maney Publishing, Leeds.

Battarbee, R.W., Grytnes, J.-A., Thompson, R., Appleby, P.G., Catalan, J., Korhola, A., Birks, H.J.B., Heegaard, E., Lami, A., 2002. Comparing palaeolimnological and instrumental evidence of climate change for remote mountain lakes over the last 200 years. Journal of Paleolimnology 28, 161-179. doi:10.1023/A:1020384204940

Battisti, A., Stastny, M., Netherer, S., Robinet, C., Schopf, A., Roques, A., Larsson, S., 2005. Expansion of geographic range in the pine processionary moth caused by increased winter temperatures. Ecological Applications 15, 2084-2096. doi:10.1890/041903

Bauer, K., Fardossi, A., 2008. Auswirkungen des Klimawandels - Herausforderung der Zukunft (Teil1). Der Winzer.

Beardall, J., Raven, J.A., 2004. The potential effects of global climate change on microalgal photosynthesis, growth and ecology. Phycologia 43, 26-40. doi:10.2216/i0031-8884-43-1-26.1

Beardall, J., Stojkovic, S., 2006. Microalgae under Global Environmental Change: Implications for Growth and Productivity, Populations and Trophic Flow. ScienceAsia 32, 1-10. doi:10.2306/ scienceasia1513-1874.2006.32(s1).001

Beatty, D.T., Barnes, A., Taylor, E., Pethick, D., McCarthy, M., Maloney, S.K., 2006. Physiological responses of Bos taurus and Bos indicus cattle to prolonged, continuous heat and humidity. Journal of Animal Science 84, 972-985.

Beck, W., 2010. Auswirkungen von Trockenheit und Hitze auf den Waldzustand in Deutschland - waldwachstumskundliche Ergebnisse der Studie im Auftrag des BMEL (Jahrestagung 2010). DVFFA - Deutscher Verband Forstlicher Forschungsanstalten. Sektion Ertragskunde.

Beierkuhnlein, C., Jentsch, A., Reineking, B., Schlumprecht, H., Ellwanger, G. Auswirkungen des Klimawandels auf Fauna, Flora und Lebensräume sowie Anpassungsstrategien des Naturschutzes. Natschutz. B.ologische Vielfalt. In Druck.
Bellard, C., Bertelsmeier, C., Leadley, P., Thuiller, W., Courchamp, F., 2012. Impacts of climate change on the future of biodiversity: Biodiversity and climate change. Ecology Letters 15, 365-377. doi:10.1111/j.1461-0248.2011.01736.x

Bentz, B.J., Régnière, J., Fettig, C.J., Hansen, E.M., Hayes, J.L., Hicke, J.A., Kelsey, R.G., Negrón, J.F., Seybold, S.J., 2010. Climate change and bark beetles of the western United States and Canada: direct and indirect effects. BioScience 60, 602-613.

Berg, B., McClaugherty, C., 2008. Plant litter: decomposition, humus formation, carbon sequestration, 2nd. ed. ed. Springer, Berlin.

Bergmann, J., Pompe, S., Ohlemüller, R., Freiberg, M., Klotz, S., Kühn, I., 2010. The Iberian Peninsula as a potential source for the plant species pool in Germany under projected climate change. Plant Ecology 207, 191-201. doi:10.1007/s11258-009-9664-6

Berthold, P., Helbig, A.J., Mohr, G., Querner, U., 1992. Rapid microevolution of migratory behaviour in a wild bird species. Nature 360, 668-670. doi:10.1038/360668a0

Bigler, C., Kulakowski, D., Veblen, T.T., 2005. Multiple disturbance interactions and drought influence fire severity in Rocky Mountain subalpine forests. Ecology 86, 3018-3029.

Blaustein, A.R., Walls, S.C., Bancroft, B.A., Lawler, J.J., Searle, C.L., Gervasi, S.S., 2010. Direct and indirect effects of climate change on amphibian populations. Diversity 2, 281-313. doi:10.3390/ d2020281

Blenckner, T., Adrian, R., Livingstone, D.M., Jennings, E., Weyhenmeyer, G.A., George, D.G., Jankowski, T., Järvinen, M., Aonghusa, C.N., Nóges, T., Straile, D., Teubner, K., 2007. Largescale climatic signatures in lakes across Europe: a meta-analysis. Global Change Biology 13, 1314-1326. doi:10.1111/j.13652486.2007.01364.x

Blennow, K., Sallnäs, O., 2004. WINDA - a system of models for assessing the probability of wind damage to forest stands within a landscape. Ecological Modelling 175, 87-99. doi:10.1016/j.ecolmodel.2003.10.009

Blümel, S., 2007. Klimawandel und die möglichen Auswirkungen auf die Pflanzengesundheit in Österreich. 48. Österreichische Pflanzenschutztage, Mautern a. d. Donau, 28.11.2007.

BMLFUW, 2013. Grüner Bericht 2013. Bericht über die Situation der österreichischen Land- und Forstwirtschaft. (Grüner Bericht gemäß $\$ 9$ des Landwirtschaftsgesetzes BGBl No. 375/1992). Bundesministerium für Land- und Forstwirtschaft, Umwelt und Wasserwirtschaft, Wien [online].

Bogin, E., Avidar, Y., Pech-Waffenschmidt, V., Doron, Y., Israeli, B.-A., Kevkhayev, E., 1996. The relationship between heat stress, survivability and blood composition of the domestic chicken. Clinical Chemistry and Laboratory Medicine 34, 463-470.

Bonada, N., Dolédec, S., Statzner, B., 2007. Taxonomic and biological trait differences of stream macroinvertebrate communities between mediterranean and temperate regions: implications for future climatic scenarios. Global Change Biology 13, 1658-1671. doi:10.1111/j.1365-2486.2007.01375.x

Bosch, J., Carrascal, L.M., Durán, L., Walker, S., Fisher, M.C., 2007. Climate change and outbreaks of amphibian chytridiomycosis in a montane area of Central Spain; is there a link? Proceedings of the Royal Society B: Biological Sciences 274, 253-260. doi:10.1098/ rspb.2006.3713

Bosch, J., Martínez-Solano, I., García-París, M., 2001. Evidence of a chytrid fungus infection involved in the decline of the common midwife toad (Alytes obstetricans) in protected areas of cen- 
tral Spain. Biological Conservation 97, 331-337. doi:10.1016/ S0006-3207(00)00132-4

Bosch, S., Schmidt-Chanasit, J., Fiedler, W., 2012. Das Usutu-Virus als Ursache von Massensterben bei Amseln Turdus merula und anderen Vogelarten in Europa: Erfahrungen aus fünf Ausbrüchen zwischen 2001 und 2011. Vogelwarte 50, 109-122.

Both, C., Visser, M.E., 2001. Adjustment to climate change is constrained by arrival date in a long-distance migrant bird. Nature 411, 296-298. doi:10.1038/35077063

Britton, A.J., Beale, C.M., Towers, W., Hewison, R.L., 2009. Biodiversity gains and losses: Evidence for homogenisation of Scottish alpine vegetation. Biological Conservation 142, 1728-1739. doi:10.1016/j.biocon.2009.03.010

Brook, B., Sodhi, N., Bradshaw, C., 2008. Synergies among extinction drivers under global change. Trends in Ecology \& Evolution 23, 453-460. doi:10.1016/j.tree.2008.03.011

Brown, J.H., Stevens, G.C., Kaufman, D.M., 1996. The geographic range: size, shape, boundaries, and internal structure. Annual Review of Ecology and Systematics 27, 597-623.

Brugger, K., Rubel, F., 2009. Simulation of climate-change scenarios to explain Usutu-virus dynamics in Austria. Preventive Veterinary Medicine 88, 24-31. doi:10.1016/j.prevetmed.2008.06.023

Büntgen, U., Kauserud, H., Egli, S., 2012. Linking climate variability to mushroom productivity and phenology. Frontiers in Ecology and the Environment 10, 14-19. doi:10.1890/110064

Burger, K., Glauninger, J., 2007. Große Fingerhirse (Digitaria sanguinalis) und Wilde Fingerhirse (Eleusine indica): Wachstum und Entwicklung im Jahre 2007 in Niederösterreich. Posterpräsentation bei den Österreichischen Pflanzenschutztagen, 28.29.11.2007, Mautern a.d. Donau.

Butin, H., 2011. Krankheiten der Wald-und Parkbäume. DiagnoseBiologie-Bekämpfung., 4., neubearbeitete Auflage. ed. Thieme, Stuttgart, New York.

Cabela, A., Grillitsch, H., Tiedemann, F., 2001. Atlas zur Verbreitung und Ökologie der Amphibien und Reptilien in Österreich. Auswertung der Herpetofaunistischen Datenbank am Naturhistorischen Museum in Wien (No. 066). Umweltbundesamt, Wien.

Calanca, P., Fuhrer, J., Jasper, K., Torriani, D., Keller, F., Dueri, S., 2005. Klimawandel und landwirtschaftliche Produktion. Agrarforschung 12, 392-397.

Cannell, M.G.R., Thornley, J.H.M., Mobbs, D.C., Friend, A.D., 1998. UK conifer forests may be growing faster in response to increased $\mathrm{N}$ deposition, atmospheric $\mathrm{CO}_{2}$ and temperature. Forestry 71, 277-296.

Carroll, E.A., Sparks, T.H., Collinson, N., Beebee, T.J.C., 2009. Influence of temperature on the spatial distribution of first spawning dates of the common frog (Rana temporaria) in the UK. Global Change Biology 15, 467-473. doi:10.1111/j.13652486.2008.01726.x

Catalan, J., Pla-Rabés, S., Wolfe, A.P., Smol, J.P., Rühland, K.M., Anderson, N.J., Kopáček, J., Stuchlík, E., Schmidt, R., Koinig, K.A., Camarero, L., Flower, R.J., Heiri, O., Kamenik, C., Korhola, A., Leavitt, P.R., Psenner, R., Renberg, I., 2013. Global change revealed by palaeolimnological records from remote lakes: a review. Journal of Paleolimnology 49, 513-535. doi:10.1007/ s10933-013-9681-2

Cate, P., Klapal, H., Kahrer, A., Wurm, O., 2006. Der Maiswurzelbohrer (Diabrotica virgifera virgifera) 2006 in Österreich - Ergebnisse aus Monitoring und Versuchstätigkeit. Österreichische Pflanzenschutztage, 29.-30.11.2006, Schloss Seggau/Leibnitz.
Cech, T., Perny, B., 1998. Kiefernsterben in Tirol. Forstschutz Aktuell 22, 12-15.

Chadwick, E.A., Slater, F.M., Ormerod, S.J., 2006. Inter- and intraspecific differences in climatically mediated phenological change in coexisting Triturus species. Global Change Biology 12, 10691078. doi:10.1111/j.1365-2486.2006.01156.x

Chakraborty, S., Tiedemann, A.V., Teng, P.S., 2000. Climate change: potential impact on plant diseases. Environmental Pollution 108, 317-326. doi:10.1016/S0269-7491(99)00210-9

Chamaillé-Jammes, S., Massot, M., Aragón, P., Clobert, J., 2006. Global warming and positive fitness response in mountain populations of common lizards Lacerta vivipara. Global Change Biology 12, 392-402. doi:10.1111/j.1365-2486.2005.01088.x

Chmielewski, F.M., Blümel, K., Henniges, Y., Müller, A., Görgens, M., Weber, R.W.S., Kemfert, C., Kremers, H., 2007. Klimawandel und Obstbau in Deutschland (KLIO). BMBF-Verbundprojekt unter Koordination der Humboldt-Universität zu Berlin (1. Zwischenbericht, Gesamtbericht). Berlin.

Chmielewski, F.-M., Roetzer, T., 2002. Annual and spatial variability of the beginning of growing season in Europe in relation to air temperature changes. Climate Research 19, 257-264. doi: $10.3354 / \mathrm{cr} 019257$

Ciais, P., Schelhaas, M.J., Zaehle, S., Piao, S.L., Cescatti, A., Liski, J., Luyssaert, S., Le-Maire, G., Schulze, E.-D., Bouriaud, O., Freibauer, A., Valentini, R., Nabuurs, G.J., 2008. Carbon accumulation in European forests. Nature Geoscience 1, 425-429. doi:10.1038/ngeo233

Clements, A.C., Pfeiffer, D.U., Martin, V., Otte, M.J., 2007. A Rift Valley fever atlas for Africa. Preventive Veterinary Medicine 82, 72-82. doi:10.1016/j.prevetmed.2007.05.006

Colombari, F., Battisti, A., Schroeder, L.M., Faccoli, M., 2012. Lifehistory traits promoting outbreaks of the pine bark beetle Ips acuminatus (Coleoptera: Curculionidae, Scolytinae) in the southeastern Alps. European Journal of Forest Research 131, 553-561. doi:10.1007/s10342-011-0528-y

Cook, G.C., 1992. Effect of global warming on the distribution of parasitic and other infectious diseases: a review. Journal of the Royal Society of Medicine 85, 688-691.

Cooper, E.J., 2004. Out of sight, out of mind: Thermal acclimation of root respiration in Arctic Ranunculus. Arctic, Antarctic, and Alpine Research 36, 308-313. doi:10.1657/15230430(2004)036[0308:OOSOOM]2.0.CO;2

Costanza, R., d'Arge, R., de Groot, R., Farber, S., Grasso, M., Hannon, B., Limburg, K., Naeem, S., O’Neill, R.V., Paruelo, J., Raskin, R.G., Sutton, P., van den Belt, M., 1997. The value of the world's ecosystem services and natural capital. Nature 387, 253-260. doi:10.1038/387253a0

Coste, M., Ector, L., 2000. Diatomées invasives exotiques ou rares en France: Principales observations effectuées au cours des dernières décennies. Systematics and Geography of Plants 70, 373-400. doi: $10.2307 / 3668651$

Courbaud, B., Kunstler, G., Morin, X., Cordonnier, T., 2010. What is the future of the ecosystem services of the Alpine forest against a backdrop of climate change? Journal of Alpine Research | Revue de géographie alpine. doi:10.4000/rga.1317

D’Amen, M., Bombi, P., 2009. Global warming and biodiversity: Evidence of climate-linked amphibian declines in Italy. Biological Conservation 142, 3060-3067. doi:10.1016/j. biocon.2009.08.004

Dämon, W., Krisai-Greilhuber, I., 2012. Die Datenbank der Pilze Österreichs. Stapfia 96, 245-330. 
Danby, R.K., Hik, D.S., 2007. Evidence of Recent Treeline Dynamics in Southwest Yukon from Aerial Photographs. Arctic 60, 411-420.

Daszak, P., Cunningham, A.A., Hyatt, A.D., 2003. Infectious disease and amphibian population declines. Diversity and Distributions 9, 141-150. doi:10.1046/j.1472-4642.2003.00016.x

Dawson, T.P., Jackson, S.T., House, J.I., Prentice, I.C., Mace, G.M., 2011. Beyond Predictions: Biodiversity Conservation in a Changing Climate. Science 332, 53-58. doi:10.1126/science. 1200303

De Witte, L.C., Armbruster, G.F.J., Gielly, L., Taberlet, P., Stöcklin, J., 2012. AFLP markers reveal high clonal diversity and extreme longevity in four key arctic-alpine species. Molecular Ecology 21, 1081-1097. doi:10.1111/j.1365-294X.2011.05326.x

Dehn, M., 1999. Application of an analog downscaling technique to the assessment of future landslide activity - a case study in the Italian Alps. Climate Research 13, 103-113. doi:10.3354/cr013103

DeLong, E.F., Pace, N.R., 2001. Environmental diversity of bacteria and archaea. Systematic Biology 50, 470-478. doi:10.1080/10635150118513

Desprez-Loustau, M.-L., Marçais, B., Nageleisen, L.-M., Piou, D., Vannini, A., 2006. Interactive effects of drought and pathogens in forest trees. Annals of Forest Science 63, 597-612. doi:10.1051/ forest: 2006040

Devictor, V., van Swaay, C., Brereton, T., Brotons, L., Chamberlain, D., Heliölä, J., Herrando, S., Julliard, R., Kuussaari, M., Lindström, Å., Reif, J., Roy, D.B., Schweiger, O., Settele, J., Stefanescu, C., Van Strien, A., Van Turnhout, C., Vermouzek, Z., WallisDeVries, M., Wynhoff, I., Jiguet, F., 2012. Differences in the climatic debts of birds and butterflies at a continental scale. Nature Clim. Change 2, 121-124. doi:10.1038/nclimate1347

Diepolder, M., 2007. Auswirkungen und Strategien für die Grünlandwirtschaft unter dem Aspekt gegenwärtiger Rahmenbedingungen und ertragsphysiologischer Parameter, in: Klimaänderung und Landwirtschaft - Bestandsaufnahme und Handlungsstrategien für Bayern. Tagungsband, Schriftenreihe der Bayerischen Landesanstalt für Landwirtschaft (LfL). Presented at the 6. Kulturlandschaftstag, Bayrischen Landesanstalt für Landwirtschaft, Freising-Weihenstephan, pp. 93-104.

Diez, J.M., D'Antonio, C.M., Dukes, J.S., Grosholz, E.D., Olden, J.D., Sorte, C.J., Blumenthal, D.M., Bradley, B.A., Early, R., Ibáńez, I., Jones, S.J., Lawler, J.J., Miller, L.P., 2012. Will extreme climatic events facilitate biological invasions? Frontiers in Ecology and the Environment 10, 249-257. doi:10.1890/110137

Dirnböck, T., Dullinger, S., Grabherr, G., 2003. A regional impact assessment of climate and land-use change on alpine vegetation. Journal of Biogeography 30, 401-417. doi:10.1046/j.13652699.2003.00839.x

Dirnböck, T., Essl, F., Rabitsch, W., 2011. Disproportional risk for habitat loss of high-altitude endemic species under climate change. Global Change Biology 17, 990-996. doi:10.1111/ j.1365-2486.2010.02266.x

Dobbertin, M., Hilker, N., Rebetez, M., Zimmermann, N.E., Wohlgemuth, T., Rigling, A., 2005. The upward shift in altitude of pine mistletoe (Viscum album ssp. austriacum) in Switzerlandthe result of climate warming? Int J Biometeorol 50, 40-47. doi:10.1007/s00484-005-0263-5

Dohm, D.J., O’Guinn, M.L., Turell, M.J., 2002. Effect of environmental temperature on the ability of Culex pipiens (Diptera: Culicidae) to transmit West Nile virus. Journal of Medical Entomology 39, 221-225. doi:10.1603/0022-2585-39.1.221
Dokulil, M.T., 2014. Predicting summer surface water temperatures for large Austrian lakes in 2050 under climate change scenarios. Hydrobiologia 731:19-29, DOI 10.1007/s10750-013-1550-5

Dokulil, M.T., Mayer, J., 1996. Population dynamics and photosynthetic rates of a Cylindrospermopsis - Limnothrix association in a highly eutrophic urban lake, Alte Donau, Vienna, Austria. Algological Studies 83, 179-195.

Dokulil, M.T., Teubner, K., 2005. The global warming versus re-oligotrophication controversy in lakes: Can effects on phytoplankton be disentangled? Phycologia (Suppl.) 44, 28-29.

Dokulil, M.T., Jagsch, A., George, G.D., Anneville, O., Jankowski, T., Wahl, B., Lenhart, B., Blenckner, T., Teubner, K., 2006. Twenty years of spatially coherent deepwater warming in lakes across Europe related to the North Atlantic Oscillation. Limnology and Oceanography 51, 2787-2793. doi:10.4319/lo.2006.51.6.2787

Dokulil, M.T., Teubner, K., 2011. Eutrophication and Climate Change: Present Situation and Future Scenarios, in: Ansari, A.A., Gill, S.S., Lanza, G.R., Rast, W. (Eds.), Eutrophication: Causes, Consequences and Control. Springer Netherlands, pp. 1-16.

Dokulil, M.T., Teubner, K., 2012. Deep living Planktothrix rubescens modulated by environmental constraints and climate forcing. Hydrobiologia 698, 29-46. doi:10.1007/s10750-012-1020-5

Dokulil, M.T., Teubner, K., Jagsch, A., Nickus, U., Adrian, R., Straile, D., Jankowski, T., Herzig, A., Padisák, J., 2010. The Impact of Climate Change on Lakes in Central Europe, in: George, G. (Ed.), The Impact of Climate Change on Lakes in Central Europe, Aquatic Ecology Series. Springer Netherlands, pp. 387-409.

Domisch, S., Jähnig, S.C., Haase, P., 2011. Climate-change winners and losers: stream macroinvertebrates of a submontane region in Central Europe. Freshwater Biology 56, 2009-2020. doi:10.1111/j.1365-2427.2011.02631.x

Doncaster, C.P., Micol, T., 1990. Response by coypus to catastrophic events of cold and flooding. Ecography 13, 98-104. doi:10.1111/j.1600-0587.1990.tb00594.x

Dörfelt, H., Ruske, E., 2008. Die Welt der Pilze, 2nd ed. WeissdornVerlag Jena, Jena.

Dullinger, S., Dirnböck, T., Grabherr, G., 2004. Modelling climate change-driven treeline shifts: relative effects of temperature increase, dispersal and invasibility. Journal of Ecology 92, 241-252. doi:10.1111/j.0022-0477.2004.00872.x

Dullinger, S., Dirnböck, T., Köck, R., Hochbichler, E., Englisch, T., Sauberer, N., Grabherr, G., 2005. Interactions among tree-line conifers: differential effects of pine on spruce and larch. Journal of Ecology 93, 948-957. doi:10.1111/j.1365-2745.2005.01036.x

Dullinger, S., Gattringer, A., Thuiller, W., Moser, D., Zimmermann, N.E., Guisan, A., Willner, W., Plutzar, C., Leitner, M., Mang, T., 2012. Extinction debt of high-mountain plants under 21st century climate change. Nature Climate Change 2, 619-622. doi: $10.1038 /$ nclimate 1514

Dunn, P.O., Winkler, 2010. Effects of climate change on timing of breeding and reproductive success in birds, in: Møller, A.P., Fiedler, W., Berthold, P. (Eds.), Effects of Climate Change on Birds. Oxford University Press, Oxford; New York, pp. 113-128.

EC, 2009. Zusammenfassender Bericht über den Erhaltungszustand von Arten und Lebensraumtypen gemäß Artikel 17 der Habitatrichtlinie (Bericht der Kommission an den Rat und das Europäische Parlament No. KOM(2009) 358 endgültig). Brüssel, 13. Juli 2009.

EEA, 2008. Impacts of Europe's changing climate - 2008 indicatorbased assessment (No. 4). EEA (European Environment Agency), Copenhagen. 
EEA, 2010. Europe's ecological backbone: recognising the true value of our mountains (Report No. 6/2010). European Environment Agency.

Egli, S., 2011. Mycorrhizal mushroom diversity and productivityan indicator of forest health? Annals of Forest Science 68, 81-88. doi:10.1007/s13595-010-0009-3

Egli, S., Brunner, I., 2011. Mykorrhiza. Eine faszinierende Lebensgemeinschaft im Wald. Eidg. Forschungsanstalt WSL, Merkblatt für die Praxis 35, 3. Auflage, Birmensdorf, Schweiz.

Eitzinger, J., 2007. Einfluss des Klimawandels auf die Produktionsrisiken in der österreichischen Landwirtschaft und mögliche Anpassungsstrategien. Ländlicher Raum (www.laendlicher-raum.at) 10.

Eitzinger, J., Kubu, G. (Eds.), 2009. Impact of Climate Change and Adaptation in Agriculture. Extended Abstracts of the International Symosium, Boku-Met Report. University of Natural Ressources and Applied Life Sciences (BOKU), Vienna, Vienna.

Eitzinger, J., Kubu, G., Thaler, S., 2010. Konsequenzen des Klimawandels für das Ertragspotenzial und den Wasserhaushalt landwirtschaftlicher Pflanzenproduktion, in: ÖWAV (Ed.), Auswirkungen des Klimawandels auf Hydrologie und Wasserwirtschaft in Österreich. Präsentation Der Aktuellen Studien. Österreichischer Wasser- und Abfallwirtschaftsverband, Wien, pp. 181-191.

Eitzinger, J., Stastná, M., Zalud, Z., Dubrovskỳ, M., 2003. A simulation study of the effect of soil water balance and water stress on winter wheat production under different climate change scenarios. Agricultural Water Management 61, 195-217.

Eitzinger, J., Kubu, G., Thaler, S., Alexandrov, U., Utset, V., Mihailovic, D.T., Lalic, B., Trnka, M., Zalud, Z., Semeradova, D., Ventrella, D., Anastasiou, D.P., Medany, M., Altaher, S., Olejnik, J., Lesny, J., Nemeshko, N., Simota, C., Cojocaru, G., 2009a. Final report, including recommendations on adaptation measures considering regional aspects. Final scientific report of the ADAGIO Project: „Adaptation of agriculture in European regions at environmental risk under climate change"; Specific Support Action, FP6-2005-SSP-5-A, Proj.No.044210, Sixth Framework Programme (European Commission). (Final Report No. FP6-2005SSP5-A). BOKU, Vienna.

Eitzinger, J., Kubu, G., Thaler, S., Trnka, M., 2009b. Der Klimawandel, seine absehbaren Folgen für die Landwirtschaft in Oberösterreich und Anpassungsstrategien (Sonderbericht), in: Amt der Oö. Landesregierung (Ed.), Grüner Bericht 2008 - 30. Bericht über die wirtschaftliche und soziale Lage der oberösterreichischen Land- und Forstwirtschaft im Jahr 2008. Amt der Oö. Landesregierung, Linz, pp. 97-106.

Eitzinger, J., Kersebaum, K.C., Formayer, H., 2009c. Landwirtschaft im Klimawandel: Auswirkungen und Anpassungsstrategien für die Land- und Forstwirtschaft in Mitteleuropa. Agrimedia, Clenze, Deutschland.

Eitzinger, J., Laube, W., Gerersdorfer, T., Grabenweger, P., Reitner, H., Heinrich, M., Murer, E., Juni 4, 2012b. Naturraumanalyse im Weinbaugebiet Carnuntum - Klima, in: ALVA Arbeitsgemeinschaft für Lebensmittel-, V.A. (Ed.), Ernährung Sichern - Trotz. B. grenzter Ressourcen. Tagungsband 2012. Lehr- und Forschungszentrum für Gartenbau, Schönbrunn, pp. 125-127.

Eitzinger, J., Trnka, M., Semerádová, D., Thaler, S., Svobodová, E., Hlavinka, P., Šiška, B., Takáč, J., Malatinská, L., Nováková, M., Dubrovský, M., Žalud, Z., 2013. Regional climate change impacts on agricultural crop production in Central and Eastern Europe - hotspots, regional differences and common trends. The Journal of Agricultural Science 151, 787-812. doi:10.1017/ S0021859612000767
Elith, J., H. Graham, C., Anderson, R.P., Dudík, M., Ferrier, S., Guisan, A., Hijmans, R.J., Huettmann, F., Leathwick, J.R., Lehmann, A., Li, J., Lohmann, L.G., Loiselle, B.A., Manion, G., Moritz, C., Nakamura, M., Nakazawa, Y., Overton, J.M.M., Townsend Peterson, A., Phillips, S.J., Richardson, K., Scachetti-Pereira, R., Schapire, R.E., Soberón, J., Williams, S., Wisz, M.S., Zimmermann, N.E., 2006. Novel methods improve prediction of species' distributions from occurrence data. Ecography 29, 129-151. doi:10.1111/j.2006.0906-7590.04596.x

Elliott, J.M., 1981. Some aspects of thermal stress on freshwater teleosts, in: Pickering, A.D. (Ed.), Stress and Fish. Academic Press, London; New York, pp. 209-245.

Ellwood, N.T.W., Whitton, B.A., 2007. Importance of organic phosphate hydrolyzed in stalks of the lotic diatom Didymosphenia geminata and the possible impact of atmospheric and climatic changes. Hydrobiologia 592, 121-133. doi:10.1007/s10750-007-0728-0

Elser, J.J., 2011. A World Awash with Nitrogen. Science 334, 15041505. doi:10.1126/science. 1215567

Engelhardt, W. von (Ed.), 2000. Physiologie der Haustiere. Enke Verlag, Stuttgart.

Engesser, R., Forster, B., Meier, F., Wermelinger, B., 2008. Forstliche Schadorganismen im Zeichen des Klimawandels. Schweizerische Zeitschrift für Forstwesen 159, 344-351. doi:10.3188/ szf.2008.0344

Engler, R., Randin, C.F., Vittoz, P., Czáka, T., Beniston, M., Zimmermann, N.E., Guisan, A., 2009. Predicting future distributions of mountain plants under climate change: does dispersal capacity matter? Ecography 32, 34-45.

Engler, R., Randin, C.F., Thuiller, W., Dullinger, S., Zimmermann, N.E., Araújo, M.B., Pearman, P.B., Le Lay, G., Piedallu, C., Albert, C.H., Choler, P., Coldea, G., De LAMO, X., Dirnböck, T., Gégout, J.-C., Gómez-García, D., Grytnes, J.-A., Heegaard, E., Høistad, F., Nogués-Bravo, D., Normand, S., Puşcaş, M., Sebastià, M.-T., Stanisci, A., Theurillat, J.-P., Trivedi, M.R., Vittoz, P., Guisan, A., 2011. 21st century climate change threatens mountain flora unequally across Europe. Global Change Biology 17, 2330-2341. doi:10.1111/j.1365-2486.2010.02393.x

Englisch, T., Niklfeld, H., Schratt-Ehrendorfer, L., 2005. Biologische Vielfalt - Pflanzenreichtum in den Landschaften Österreichs, in: Borsdorf, A. (Ed.), Das neue Bild Österreichs: Strukturen und Entwicklungen im Alpenraum und in den Vorländern. Verlag der Österreichischen Akademie der Wissenschaften, Wien.

Enserink, M., 2006. During a Hot Summer, Bluetongue Virus Invades Northern Europe. Science 313, 1218-1219. doi:10.1126/ science.313.5791.1218a

Erschbamer, B., Grabherr, G., Reisigl, H., 1983. Spatial pattern in dry grassland communities of the Central Alps and its ecophysiological significance. Vegetatio 54, 143-151. doi:10.1007/ BF00047102

Essl, F., Rabitsch, W. (Eds.), 2013. Biodiversität und Klimawandel Auswirkungen und Handlungsoptionen für den Naturschutz in Mitteleuropa. Springer, Berlin.

Essl, F., Staudinger, M., Stöhr, O., Schratt-Ehrendorfer, L., Rabitsch, W., Niklfeld, H., 2009. Distribution patterns, range size and niche breadth of Austrian endemic plants. Biological Conservation 142, 2547-2558. doi:10.1016/j.biocon.2009.05.027

Essl, F., Dullinger, S., Moser, D., Rabitsch, W., Kleinbauer, I., 2012. Vulnerability of mires under climate change: implications for nature conservation and climate change adaptation. Biodivers Conserv 21, 655-669. doi:10.1007/s10531-011-0206-x 
Essl, F., Rabitsch, W., Dullinger, S., Moser, D., Milasowszky, N., 2013. How well do we know species richness in a well-known continent? Temporal patterns of endemic and widespread species descriptions in the European fauna. Global Ecology and Biogeography 22, 29-39. doi:10.1111/j.1466-8238.2012.00787.x

European Environment Agency EEA, 2009. Water resources across Europe - confronting water scarcity and drought (EEA Report No. 2). European Environment Agency (EEA), Office for Official Publications of the European Communities (OPOCE), Copenhagen.

Exner, A., 2011. Save our surface (No. 57/2011), Sustainable Austria.

Falasco, E., Bona, F., 2013. Recent findings regarding non-native or poorly known diatom taxa in north-western Italian rivers. Journal of Limnology 72. doi:10.4081/jlimnol.2013.e4

Falkowski, P., 2012. Ocean Science: The power of plankton. Nature 483, S17-S20. doi:10.1038/483S17a

Fardossi, A., 2007. Physiologische Untersuchungen an Weinkulturen unter besonderer Berücksichtigung von Stressfaktoren als wahrscheinliche Auslöser der Traubenwelke. HBLA/BA Klosterneuburg.

Ficetola, G.F., Thuiller, W., Padoa-Schioppa, E., 2009. From introduction to the establishment of alien species: bioclimatic differences between presence and reproduction localities in the slider turtle. Diversity and Distributions 15, 108-116. doi:10.1111/ j.1472-4642.2008.00516.x

Fierer, N., Leff, J.W., Adams, B.J., Nielsen, U.N., Bates, S.T., Lauber, C.L., Owens, S., Gilbert, J.A., Wall, D. h., Caporaso, J.G., 2012. Cross-biome metagenomic analyses of soil microbial communities and their functional attributes. PNAS 109, 21390-21395. doi: $10.1073 /$ pnas. 1215210110

Fischer, M.A., Oswald, K., Adler, W., 2008. Exkursionsflora für Österreich, Liechtenstein und Südtirol, 3, 3rd ed. Biologiezentrum der Oberösterreichischen Landesmuseen, Linz.

Flaim, G., Rott, E., Frassanito, R., Guella, G., Obertegger, U., 2010. Eco-fingerprinting of the dinoflagellate Borghiella dodgei: experimental evidence of a specific environmental niche. Hydrobiologia 639, 85-98. doi:10.1007/s10750-009-0013-5

Follak, S., 2007. Neue Unkrautprobleme in der Landwirtschaft Welche Rolle spielt der Klimawandel?, in: Österreichische Arbeitsgemeinschaft für integrierten Pflanzenschutz (Ed.), 48. Österreichische Pflanzenschutztage, 28.-29.11.2007, Mautern A.d. Donau. Mautern a.d. Donau.

Follak, S., 2008. Zum Auftreten neuer Unkrautarten in der Steiermark. Österreichische Agentur für Gesundheit und Ernährun gssicherheit, Institut für Pflanzengesundheit, [online].

Follak, S., Dullinger, S., Kleinbauer, I., Moser, D., Essl, F., 2013. Invasion dynamics of three allergenic invasive Asteraceae (Ambrosia trifida, Artemisia annua, Iva xanthiifolia) in central and eastern Europe. Preslia 85, 41-61.

Fragner, H., 2010. Wichtige Unkrautprobleme in steirischen Feldkulturen in den Jahren 2008 und 2009. Masterarbeit. Universität für Bodenkultur, Wien.

Francesca, S., Simona, G., Francesco Nicola, T., Andrea, R., Vittorio, R., Federico, S., Cynthia, R., Maria Lodovica, G., 2006. Downy mildew (Plasmopara viticola) epidemics on grapevine under climate change. Global Change Biology 12, 1299-1307. doi:10.1111/ j.1365-2486.2006.01175.x

Fresner, R., Schulz, L., Mairitsch, M., 1998. Oscillatoria princeps Vauch. (Cyanophycae) im Ossiacher See. Carinthia II 188/108. Jahrgang, 531-534.
Freyer, B., 2003. Fruchtfolgen: [konventionell, integriert, biologisch. Ulmer, Stuttgart (Hohenheim).

Freyer, B., Surböck, A., Friedel, J.K., Heinzinger, M., 2007. Zukunft einer ökologisch genutzten Agrarlandschaft. GAIA-Ökologische Perspektiven für Wissenschaft und Gesellschaft 16, 158-160.

Frommer, U., 2010. Beobachtungen zum Ausbreitungsverhalten der Efeu-Seidenbiene Colletes hederae Schmidt und Westrich, 1993 (Hymenoptera, Apidae) in Hessen und die Bedeutung des blühenden Efeus (Hedera helix L.). Hessische Faunistische Briefe 29, $1-20$.

Fuhrer, J., 2003. Agroecosystem responses to combinations of elevated $\mathrm{CO}_{2}$, ozone, and global climate change. Agriculture, Ecosystems \& Environment 97, 1-20. doi:10.1016/S0167-8809(03)00125-7

Fuhrer, J., 2006. Sustainability of Crop Production Systems under Climate Change, in: Newton, P.C.D., Carran, R.A., Edwards, G.R., Niklaus, P.A. (Eds.), Agroecosystems in a Changing Climate. CRC Press, Florida, pp. 167-185.

Fuhrer, J., 2007. Sustainability of Crop Production Systems under Climate Change., in: Newton, P.C.D., Carran, R.A., Edwards, G.R., Niklaus, P.A. (Eds.), Agroecosystems in a Changing Climate. CRC Press, Florida, USA.

Fuhrer, J., Calanca, P., Defila, C., Forrer, H.-R., Lehmann, B., Luder, W., Müller-Ferch, G., Münger, A., Sonnevelt, M., Uebersax, A., 2007. Landwirtschaft, in: OcCC/ProClim (Ed.), Klimaänderung Und Die Schweiz 2050. Erwartete Auswirkungen Auf Umwelt, Gesellschaft und Wirtschaft. Bern, pp. 41-53.

Galloy, V., Denoël, M., 2010. Detrimental effect of temperature increase on the fitness of an amphibian (Lissotriton helveticus). Acta Oecologica 36, 179-183. doi:10.1016/j.actao.2009.12.002

Gange, A.C., Gange, E.G., Sparks, T.H., Boddy, L., 2007. Rapid and recent changes in fungal fruiting patterns. Science 316, 71-71. doi:10.1126/science.1137489

Garcia, J.-L., Patel, B.K.., Ollivier, B., 2000. Taxonomic, phylogenetic, and ecological diversity of methanogenic archaea. Anaerobe 6, 205-226. doi:10.1006/anae.2000.0345

Garner, T.W.J., Rowcliffe, J.M., Fisher, M.C., 2011. Climate change, chytridiomycosis or condition: an experimental test of amphibian survival. Global Change Biology 17, 667-675. doi:10.1111/ j.1365-2486.2010.02272.x

Garrett, K.A., 2008. Climate change and plant disease risk., in: Relman, D.A., Hamburg, M.A., Choffnes, E.R., Mack, A. (Eds.), Global Climate Change and Extreme Weather Events: Understanding the Contributions to Infectious Disease Emergence: Workshop Summary. National Academies Press (US), Washington (DC), pp. 143-155.

Garrett, K.A., Dendy, S.P., Frank, E.E., Rouse, M.N., Travers, S.E., 2006. Climate change effects on plant disease: genomes to ecosystems. Annu Rev Phytopathol 44, 489-509. doi:10.1146/annurev. phyto.44.070505.143420

Gehrig-Fasel, J., Guisan, A., Zimmermann, N.E., 2007. Tree line shifts in the Swiss Alps: Climate change or land abandonment? Journal of Vegetation Science 18, 571-582. doi:10.1111/j.1654-1103.2007. tb02571.x

Geiser, E., 1998. Wie viele Tierarten leben in Österreich? Erfassung, Hochrechnung und Abschätzung. Verh.zool.-bot.Ges. Österreich 135, 81-93.

Gerersdorfer, T., Brandenburg, C., Bahrs, E., Eitzinger, J., 2010. Der Beitrag von Landschaftsstrukturen (z. B. Windschutzhecken) zur Ertragssituation im Ackerbau in Ostösterreich, in: Matzarakis, A., Mayer, H., Chmielewski, F.M. (Eds.), Proceedings of the 7th Conference on Biometeorology. Berichte des meteorologischen 
Instituts der Albert-Ludwigs-Universität Freiburg. Albert-Ludwigs-University of Freiburg, Freiburg, Germany, pp. 32-38.

Gerten, D., Adrian, R., 2000. Climate-driven changes in spring plankton dynamics and the sensitivity of shallow polymictic lakes to the North Atlantic Oscillation. Limnology and Oceanography 45, 1058-1066. doi:10.4319/lo.2000.45.5.1058

Glauninger, J., 2011. Neue Unkräuter - Wissen fehlt noch. Bio Austria Fachzeitschrift für Landwirtschaft und Ökologie 16-17.

Glauninger, J., Holzner, W., Klug, P., 2006. Neue Unkrautarten auf Ackerland - eine Herausforderung für Wissenschaft und Praxis. Österreichische Pflanzenschutztage, 29.-30.11.2006, Schloss Seggau/Leibnitz.

Glauninger, J., Kersebaum, K.C., 2009. Auswirkungen von Klimaveränderungen auf biogene Schadfaktoren., in: Eitzinger, J., Kersebaum, K.C., Formayer, H. (Eds.), Landwirtschaft Im Klimawandel: Auswirkungen Und Anpassungsstrategien Für Die Land- Und Forstwirtschaft in Mitteleuropa. Agrimedia, Clenze, Deutschland.

Glauninger, J., Holzweber, M., Kronberger, E., 2010. Kartoffeln: Alternaria-Befallssituation 2009 und 2010 im Weinviertel / Ostösterreich. Witterungsbedingt unterschiedliche Ausprägung der Sortenanfälligkeit. Der Pflanzenarzt 63, 16-17.

Glime, J.M., 2007. Bryophyte Ecology. Volume 1. Physiological Ecology. (e-book). Michigan Technological University and the International Association of Bryologists, Houghton, Michigan.

Gollmann, G., 2007. Rote Liste der in Österreich gefährdeten Lurche (Amphibia) und Kriechtiere (Reptilia), in: Zulka, K.P. (Ed.), Rote Listen Gefährdeter Tiere Österreichs: Kriechtiere, Lurche, Fische, Nachtfalter, Weichtiere, Grüne Reihe Des Lebensministeriums. Böhlau Verlag, Wien, pp. 37-60.

Gottfried, M., Pauli, H., Grabherr, G., 1994. Die Alpen im „Treibhaus": Nachweise für das erwärmungsbedingte Höhersteigen der alpinen und nivalen Vegetation. Jahrbuch des Vereins zum Schutz der Bergwelt 59, 13-27.

Gottfried, M., Pauli, H., Reiter, K., Grabherr, G., 1999. A finescaled predictive model for changes in species distribution patterns of high mountain plants induced by climate warming. Diversity and Distributions 5, 241-251. doi:10.1046/j.14724642.1999.00058.x

Gottfried, M., Hantel, M., Maurer, C., Toechterle, R., Pauli, H., Grabherr, G., 2011. Coincidence of the alpine-nival ecotone with the summer snowline. Environmental Research Letters 6 . doi:10.1088/1748-9326/6/1/014013

Gottfried, M., Pauli, H., Futschik, A., Akhalkatsi, M., Barancok, P., Alonso, J.L.B., Coldea, G., Dick, J., Erschbamer, B., Kazakis, G., Krajci, J., Larsson, P., Mallaun, M., Michelsen, O., Moiseev, M., Moiseev, P., Molau, U., Merzouki, A., Nagy, L., Nakhutsrishvili, G., Pedersen, B., Pelino, G., Puscas, M., Rossi, G., Stanisci, J.-P., Theurillat, Tomaselli, Villar, L., Vittoz, P., Vogiatzakis, I., Grabherr, G., 2012. Continent-wide response of mountain vegetation to climate change. Nature Climate Change Letter 2, 111-115. doi:10.1038/nclimate1329

Götzl, M., Schwaiger, E., Sonderegger, G., Süßenbacher, E., 2011. Ökosystemleistungen und Landwirtschaft. Erstellung eines Inventars für Österreich. (No. REP-0355). Umweltbundesamt Wien, Wien, Österreich.

Grabenweger, G., 2007. Ergebnisse des Maiswurzelbohrer- Monitorings 2007, in: Österreichische Arbeitsgemeinschaft für integrierten Pflanzenschutz (Ed.), 48. Österreichische Pflanzenschutztage, 28.-29.11.2007, Mautern a.d. Donau.
Grabherr, G., 1977. Der CO -Gaswechsel des immergrünen Zwergstrauches Loiseleuria procumbens (L.) Desv. in Abhängigkeit von Strahlung, Temperatur, Wasserstreß und phänologischem $\mathrm{Zu}$ stand. Photosynthetica 11, 302-310.

Grabherr, G., 1980. Variability and ecology of the alpine dwarf shrub community Loiseleurio-Cetrarietum. Vegetatio 41, 111-120.

Grabherr, G., 1990. On community structure in high alpine grasslands, in: Grabherr, G., Mucina, L., Dale, M.B., Braak, C.J.F.T. (Eds.), Progress in Theoretical Vegetation Science, Advances in Vegetation Science. Springer Netherlands, pp. 223-227.

Grabherr, G., Mucina, L. (Eds.), 1993. Die Pflanzengesellschaften Österreichs. Teil II: Natürliche waldfreie Vegetation. Gustav Fischer Verlag, Jena.

Grabherr, G., Mähr, E., Reisigl, H., 1979. Nettoprimärproduktion und Reproduktion in einem Krummseggenrasen (Caricetum curvulae) der Ötztaler Alpen, Tirol. Oecol. Plant 13, 227-251.

Grabherr, G., Gottfried, M., Pauli, H., 1994. Climate effects on mountain plants. Nature 369, 448-; 448. doi:10.1038/369448a0

Grabherr, G., Gottfried, M., Pauli, H., 2001. Long-Term Monitoring of Mountain Peaks in The Alps, in: Burga, C.A., Kratochvil, A. (Eds.), Biomonitoring: General and Applied Aspects on Regional and Global Scales, Tasks for Vegetation Science. SpringerScience+Business Media, B.V. / Kluwer Academic Publishers, Dordrecht, pp. 153-177.

Graf, W., Waringer, J., Pauls, S., 2007. The subfamily Drusinae (Insecta: Trichoptrea) in Central Europe. Taxonomy-EcologyPhylogenetics., in: Abstracts: Entomologentagung 2007, Suppl. Universitätsverlag Wagner, Innsbruck, pp. 62-63.

Grafschafter, R., 2007. Experimentelles Wachstum von Moosen auf unterschiedlichem Substrat. Diplomarbeit. Universität Wien.

Grausgruber, H., Sengthaler, K., Kronberger, E., Glauninger, J., 2010. Effects of genotype, environment and crop management on biotic and abiotic stress responses of potato. Poster presented at INRA, 2nd Conference EUCARPIA, 1.-3.12.2010.

Grillitsch, H., Cabela, A., 2001. Reptilien, in: Cabela, A., Grillitsch, H., Tiedemann, F. (Eds.), Atlas zur Verbreitung und Ökologie der Amphibien und Reptilien in Österreich: Auswertung der herpetofaunistischen Datenbank der herpetologischen Sammlung des Naturhistorischen Museums in Wien. Umweltbundesamt, Wien, pp. 442-610.

Groth, W., 1984. Auswirkungen des Stallklimas auf die Gesundheit und die Produktivität von Rindern und Schweinen. Zentralbl Veterinarmed B. 31, 561-584.

Grummer, J., 2009. Einfluß des Klimawandels auf die Tiergesundheit, in: Eitzinger, J., Kersebaum, K.C., Formayer, H. (Eds.), Landwirtschaft Im Klimawandel: Auswirkungen Und Anpassungsstrategien Für Die Land- Und Forstwirtschaft in Mitteleuropa. Agrimedia, Clenze, pp. 219-235.

Grünbacher, E.M., Kromp, B., Formayer, H., Hann, P., 2006. Einflüsse des Klimawandels auf landwirtschaftliche Schädlinge und Nützlinge im Biologischen Landbau Ostösterreichs. (Endbericht zum Projekt StartClim2005. C3-a, Teilprojekt von StartClim2005 „Klimawandel und Gesundheit! No. StartClim2005.C3-a). Wien.

Guisan, A., Thuiller, W., 2005. Predicting species distribution: offering more than simple habitat models. Ecology Letters 8, 9931009. doi:10.1111/j.1461-0248.2005.00792.x

Guisan, A., Zimmermann, N.E., 2000. Predictive habitat distribution models in ecology. Ecological Modelling 135, 147-186. doi:10.1016/S0304-3800(00)00354-9

Habel, J.C., Rödder, D., Schmitt, T., Nève, G., 2010. Global warming will affect the genetic diversity and uniqueness of Lycae- 
na helle populations. Global Change Biology 17, 194-205. doi:10.1111/j.1365-2486.2010.02233.x

Hagedorn, F., Mulder, J., Jandl, R., 2010. Mountain soils under a changing climate and land-use. Biogeochemistry 97, 1-5. doi: 10.1007/s10533-009-9386-9

Haines-Young, R., Potschin, M., 2010. The links between biodiversity, ecosystem services and human well-being, in: Raffaelli, D.G., Frid, C. (Eds.), Ecosystem Ecology: A New Synthesis, Ecological Reviews. Cambridge University Press, British Ecological Society, Cambridge; New York, pp. 110-139.

Hance, T., van Baaren, J., Vernon, P., Boivin, G., 2007. Impact of extreme temperatures on parasitoids in a climate change perspective. Annual Review of Entomology 52, 107-126. doi:10.1146/ annurev.ento.52.110405.091333

Hanewinkel, M., Cullmann, D.A., Schelhaas, M.-J., Nabuurs, G.-J., Zimmermann, N.E., 2012. Climate change may cause severe loss in the economic value of European forest land. Nature Climate Change 3, 203-207.

Hari, R.E., Livingstone, D.M., Siber, R., Burkhardt-Holm, P., Güttinger, H., 2006. Consequences of climatic change for water temperature and brown trout populations in Alpine rivers and streams. Global Change Biology 12, 10-26. doi:10.1111/j.13652486.2005.001051.x

Hasenauer, H., Nemani, R.R., Schadauer, K., Running, S.W., 1999. Forest growth response to changing climate between 1961 and 1990 in Austria. Forest Ecology and Management 122, 209-219. doi:10.1016/S0378-1127(99)00010-9

Hastings, A., Cuddington, K., Davies, K.F., Dugaw, C.J., Elmendorf, S., Freestone, A., Harrison, S., Holland, M., Lambrinos, J., Malvadkar, U., Melbourne, B.A., Moore, K., Taylor, C., Thomson, D., 2005. The spatial spread of invasions: new developments in theory and evidence: Spatial spread of invasions. Ecology Letters 8, 91-101. doi:10.1111/j.1461-0248.2004.00687.x

Hauer, C., Unfer, G., Holzmann, H., Schmutz, S., Habersack, H., 2012. The impact of discharge change on physical instream habitats and its response to river morphology. Climatic Change 116, 827-850. doi:10.1007/s10584-012-0507-4

He, Z., Piceno, Y., Deng, Y., Xu, M., Lu, Z., DeSantis, T., Andersen, G., Hobbie, S.E., Reich, P.B., Zhou, J., 2012. The phylogenetic composition and structure of soil microbial communities shifts in response to elevated carbon dioxide. ISME J 6, 259-272. doi:10.1038/ismej.2011.99

Hegland, S.J., Nielsen, A., Lázaro, A., Bjerknes, A.-L., Totland, Ø., 2009. How does climate warming affect plant-pollinator interactions? Ecology Letters 12, 184-195. doi:10.1111/j.14610248.2008.01269.x

Heilig, M., 2007. Klimadiagnose Niederösterreich (Endbericht Mai 2007. No. Auftrag Kennzeichen WA2-A-512/004-2005 vom 21.10.2005.). Amt der NÖ Landesregierung, Abt. Wasserwirtschaft, Abt. Hydrologie, 2007.

Heissenberger, M., Watzke, J., Kainz, M.J., 2010. Effect of nutrition on fatty acid profiles of riverine, lacustrine, and aquaculture-raised salmonids of pre-alpine habitats. Hydrobiologia 650, 243-254. doi:10.1007/s10750-010-0266-z

Henle, K., Dick, D., Harpke, A., Kühn, I., Schweiger, O., Settele, J., 2008. Climate change impacts on European Amphibians and Reptiles. (Report to the Convention on the Conservation of European Wildlife and natural Habitats No. T-PVS/Inf (2008) 11 rev). Strasbourg.

Hering, D., Schmidt-Kloiber, A., Murphy, J., Lücke, S., ZamoraMuñoz, C., López-Rodríguez, M.J., Huber, T., Graf, W., 2009.
Potential impact of climate change on aquatic insects: A sensitivity analysis for European caddisflies (Trichoptera) based on distribution patterns and ecological preferences. Aquat. Sci. 71, 3-14. doi:10.1007/s00027-009-9159-5

Herman, F., Smidt, S., Butterbach-Bahl, K., Englisch, M., Gebetsroither, E., Jandl, R., Katzensteiner, K., Lexer, M., Strebl, F., Zechmeister-Boltenstern, S., 2007. Modeling of Nitrogen Dynamics in an Austrian Alpine Forest Ecosystem on Calcareous Soils: A Scenario-Based Risk Assessment under Changing Environmental Conditions. The Scientific World Journal 7, 159-165. doi: $10.1100 /$ tsw.2007.9

Heurich, M., Rall, H., 2006. Hochlageninventur 2005 und Luftbildauswertung 2003 bis 2005. Ergebnisse der Untersuchungen zur Waldentwicklung im Nationalpark Bayerischer Wald. Nationalpark Bayerischer Wald., Berichte aus dem Nationalpark 21.

Hilker, N., Rigling, A., Dobbertin, M., 2005. Mehr Misteln wegen der Klimaerwärmung. Wald Holz 86, 39-42.

Hinterholzer, J., 2004. Auswirkungen der Erderwärmung auf die Maisreife. ALVA-Jahrestagung „Klimawandel - Auswirkungen auf Umwelt und Agrarproduktion“. Arbeitsgemeinschaft Landwirtschaftlicher Versuchsanstalten (ALVA), Österr. Agentur für Gesundheit und Ernährungssicherheit (AGES).

Hirata, M., 1975. Inhibitory effects of antihistamines and antiserotonins on the bone marrow reactions produced by Escherichia coli endotoxin in mice. J. Infect. Dis. 132, 611-616.

Hlásny, T., Turčáni, M., 2008. Insect Pests as Climate Change Driven Disturbances in Forest Ecosystems, in: Střelcová, A.P.D.K., Mátyás, P.D.C., Kleidon, D.A., Lapin, P.D.M., Matejka, D.F., Blaženec, D.M., Škvarenina, P.D.J., Holécy, P.D.J. (Eds.), Bioclimatology and Natural Hazards. Springer Netherlands, pp. 165-177.

Hohenwallner, D., Zechmeister, H.G., Moser, D., Pauli, H., Gottfried, M., Reiter, K., Grabherr, G., 2011. Alpine bryophytes as indicators for climate change: a case study from the Austrian Alps., in: Tuba, Z., Slack, N.G., Stark, L.R. (Eds.), Bryophyte Ecology and Climate Change. Cambridge University Press, Cambridge, pp. 237-250.

Holtgrieve, G.W., Schindler, D.E., Hobbs, W.O., Leavitt, P.R., Ward, E.J., Bunting, L., Chen, G., Finney, B.P., Gregory-Eaves, I., Holmgren, S., Lisac, M.J., Lisi, P.J., Nydick, K., Rogers, L.A., Saros, J.E., Selbie, D.T., Shapley, M.D., Walsh, P.B., Wolfe, A.P., 2011. A Coherent Signature of Anthropogenic Nitrogen Deposition to Remote Watersheds of the Northern Hemisphere. Science 334, 1545-1548. doi:10.1126/science. 1212267

Holzinger, B., Hülber, K., Camenisch, M., Grabherr, G., 2008. Changes in plant species richness over the last century in the eastern Swiss Alps: elevational gradient, bedrock effects and migration rates. Plant Ecology 195, 179-196. doi:10.1007/s11258-0079314-9

Holzmann, H., Lehmann, T., Formayer, H., Haas, P., 2010. Auswirkungen möglicher Klimaänderungen auf Hochwasser und Wasserhaushaltskomponenten ausgewählter Einzugsgebiete in Österreich. Österr Wasser- und Abfallw 62, 7-14. doi:10.1007/ s00506-009-0154-9

Horz, H.-P., Barbrook, A., Field, C.B., Bohannan, B.J.M., 2004. Ammonia-oxidizing bacteria respond to multifactorial global change. Proceedings of the National Academy of Sciences of the United States of America 101, 15136-15141. doi:10.1073/ pnas.0406616101

Huemer, M., Glauninger, J., 2010. Der Einfluss unterschiedlicher Temperatur- und Lichtbedingungen auf die Keimfähigkeit der 
Giftbeere (Nicandra physalodes). Österreichische Pflanzenschutztage, 1.-2.12.2010, Schloss Seggau/Leibnitz.

Hulin, V., Delmas, V., Girondot, M., Godfrey, M.H., Guillon, J.M., 2009. Temperature-dependent sex determination and global change: are some species at greater risk? Oecologia 160, 493-506. doi:10.1007/s00442-009-1313-1

Huntley, B., Collingham, Y.C., Willis, S.G., Green, R.E., 2008. Potential Impacts of Climatic Change on European Breeding Birds. PLOS ONE 3. doi:10.1371/journal.pone.0001439

Huss, H., 2012. Pilzkrankheiten im Ackerbau - Historischer Rückblick und aktuelle Entwicklungen. Stapfia 96, 195-209.

IPCC, 2014. Climate Change 2014: Impacts, Adaptation, and Vulnerability. Working Group II Contribution to AR5. Volume I \& II. Cambridge University Press, Cambridge, United Kingdom and New York, NY, USA.

Jackson, S.T., Sax, D.F., 2010. Balancing biodiversity in a changing environment: extinction debt, immigration credit and species turnover. Trends in Ecology \& Evolution 25, 153-160. doi:10.1016/j.tree.2009.10.001

Jacobsen, D., Milner, A.M., Brown, L.E., Dangles, O., 2012. Biodiversity under threat in glacier-fed river systems. Nature Climate Change 2, 361-364. doi:10.1038/nclimate1435

Jägerbrand, A.K., Björk, R.G., Callaghan, T., 2011. Effects of climate change on Tundra bryophytes, in: Tuba, Z., Slack, N.G., Stark, L.R. (Eds.), Bryophyte Ecology and Climate Change. Cambridge University Press, Cambridge, pp. 211-236.

Janauer, G.A., Hale, P., Sweeting, R. (Eds.), 2003. Macrophyte inventory of the river Danube: A pilot study, Large Rivers. Schweizerbart, Stuttgart.

Jandl, R., 2011. Land use form affects the soil carbon pool - Case study Austria. EGU General Assembly 2011. Geophysical Research Abstracts. 13. EGU2011-3384.

Jandl, R., Gschwandtner, T., Zimmermann, N., 2012. Die künftige Verbreitung der Baumarten im Simulationsmodell. BFW Praxisinformation 30, 16-19.

Jasper, K., Calanca, P., Gyalistras, D., Fuhrer, J., 2004. Differential impacts of climate change on the hydrology of two alpine river basins. Climate Research 26, 113-129.

Jenni, L., Kéry, M., 2003. Timing of autumn bird migration under climate change: advances in long-distance migrants, delays in short-distance migrants. Proceedings of the Royal Society of London. Series B: Biological Sciences 270, 1467-1471. doi:10.1098/ rspb.2003.2394

Jentsch, A., Kreyling, J., Beierkuhnlein, C., 2007. A new generation of climate-change experiments: events, not trends. Frontiers in Ecology and the Environment 5, 365-374. doi:10.1890/15409295(2007)5[365:ANGOCE]2.0.CO;2

Jepsen, J.U., Hagen, S.B., Ims, R.A., Yoccoz, N.G., 2008. Climate change and outbreaks of the geometrids Operophtera brumata and Epirrita autumnata in subarctic birch forest: evidence of a recent outbreak range expansion. Journal of Animal Ecology 77, 257264. doi:10.1111/j.1365-2656.2007.01339.x

Jolly, W.M., Dobbertin, M., Zimmermann, N.E., Reichstein, M., 2005. Divergent vegetation growth responses to the 2003 heat wave in the Swiss Alps: VEGETATION RESPONSE TO ALPINE HEAT WAVE. Geophysical Research Letters 32. doi:10.1029/2005GL023252

Jones, G.V., White, M.A., Cooper, O.R., Storchmann, K., 2005. Climate Change and Global Wine Quality. Climatic Change 73, 319-343. doi:10.1007/s10584-005-4704-2
Jones, P.D., Lister, D. h., Jaggard, K.W., Pidgeon, J.D., 2003. Future climate impact on the productivity of sugar beet (Beta vulgaris L.) in Europe. Climatic Change 58, 93-108.

Jönsson, A.M., Bärring, L., 2011. Future climate impact on spruce bark beetle life cycle in relation to uncertainties in regional climate model data ensembles. Tellus A 63, 158-173. doi:10.1111/ j.1600-0870.2010.00479.x

Jönsson, A.M., Harding, S., Krokene, P., Lange, H., Lindelöw, Å., Økland, B., Ravn, H.P., Schroeder, L.M., 2011. Modelling the potential impact of global warming on Ips typographus voltinism and reproductive diapause. Climatic Change 109, 695-718. doi:10.1007/s10584-011-0038-4

Jung, T., Vannini, A., Brasier, C.M., 2009. Progress in understanding Phytophthora diseases of trees in Europe 2004-2007, in: Goheen, E.M., Frankel, S.J. (Eds.), Proceedings of the Fourth Meeting of the International Union of Forest Research Organizations (IUFRO) Working Party S07.02.09: Phytophthoras in Forests and Natural ecosystems.General Technical Report. U.S. Department of Agriculture, Forest Service, Pacific Southwest Research Station, Albany, California, pp. 3-24.

Jungmeier, M., 2010. Untersuchungen über die Viröse Gelbverzwergung (barley yellow dwarf virus) an Wintergerste (Hordeum vulgare L.) in der Vegetationsperiode 2008/2009. Masterarbeit. Universität für Bodenkultur, Wien, Österreich.

Jungmeier, M., Lethmayer, C., Glauninger, J., 2009. Das Auftreten verschiedener Blattlausarten in Wintergerste auf dem Versuchsstandort Raasdorf/NÖ in der Vegetationsperiode 2008/09.

Jungmeier, M., Werner, K., Pettrich, C., 2004. Moore in Österreich unter dem Schutz der Ramsar-Konvention. Umweltbundesamt, Wien.

Kahle, H.-P., v.Oijen, Spiecker, H., Ågren, G.I., Chertow, M., Kellomäki, S., Mellert, K., Perez-Martinez, P.-J., Prietzel, J., Straussberger, R., Rehfuess, K.-E., Unseld, R., 2008. Analysis of the relative importance of nutrients, climatic factors, and $\mathrm{CO}_{2}$ as causes of observed changes in growth, in: Kahle, H.-P., Karjalainen, T., Schuck, A., Ågren, G.I., Kellomäki, S., Mellert, K., Prietzel, J., Rehfuess, K.-E., Spiecker, H. (Eds.), Causes and Consequences of Forest Growth Trends in Europe, European Forest Institute Research Report. Brill, Leiden; Boston.

Kahrer, A., Formayer, H., 2006. Abschätzung des Risikos einer dauerhaften Festsetzung von Gewächshausschädlingen im Freiland als Folge des Klimawandels am Beispiel des Kalifornischen Blütenthripses (Frankliniella occidentalis). (StartClim2005.C3b). AGES, Institut für Pflanzengesundheit, Universität für Bodenkultur, Institut für Meteorologie, Wien, Österreich.

Kahrer, A., Formayer, H., 2007. Risiko einer dauerhaften Festsetzung des Kalifornischen Blütenthripses (Frankliniella occidentalis) im Freiland als Folge des Klimawandels; 48. Österreichische Pflanzenschutztage, Mautern a. d. Donau, 28.11.2007. AGES Österreichische Agentur für Gesundheut und Ernährungssicherheit, BOKU - Universität für Bodenkultur, [online].

Kahrer, A., Pilz, C., Egartner, A., Grabenweger, G., Scheifinger, H., Matulla, C., Zuvela-Aloise, M., 2012. Abschätzung des Überwinterungserfolgs exotischer Insekten unter künftigen Klimabedingungen in Österreich. 13. Klimatag, 14.-15.6. 2012. Universität für Bodenkultur, Wien.

Kainz, M., 2011. Untersuchung der Wasser-, Futter- und Fischqualität in Freigewässern und Aquakulturen des NÖ Alpenvorlandes. WasserCluster Lunz, Lunz am See. 35.

Kajfež-Bogataj, L., Bergant, K., Zupančič, B., Črepinšek, Z., Matajc, I., Leskošek, M., Gomboc, S., Robič, D., Bizjak, A., Rogelj, D., 
Uhan, J., Skoberne, P., Cegnar, T., Hočevar, A., 1999. Ocena ranljivosti in strategija prilagoditve ekosistemov na spremembo podnebja v Sloveniji. Biotehniška fakulteta, Oddelek za agronomijo : Ministrstvo za okolje in prostor: Hidrometeorološki zavod R Slovenije, Ljubljana.

Kammann, C., Grünhage, L., Grüters, U., Janze, S., Jäger, H.-J., 2005. Response of aboveground grassland biomass and soil moisture to moderate long-term $\mathrm{CO}_{2}$ enrichment. Basic and Applied Ecology 6, 351-365. doi:10.1016/j.baae.2005.01.011

Kammer, A., Hagedorn, F., Shevchenko, I., Leifeld, J., Guggenberger, G., Goryacheva, T., Rigling, A., Moiseev, P., 2009. Treeline shifts in the Ural mountains affect soil organic matter dynamics. Global Change Biology 15, 1570-1583. doi:10.1111/j.13652486.2009.01856.x

Karrer, G., Bassler, G., Schume, H., Matthews, B., Willner, W., 2012. Adapting Austrian forestry to climate change: Assessing the drought tolerance of Austria's authochtonous tree species (Final Report No. StartClim2011.D), StartClim2011: Adaption to climate change in Austria: „Forrests“. BMLFUW, BMWF, ÖBf.

Kauserud, H., Heegaard, E., Büntgen, U., Halvorsen, R., Egli, S., Senn-Irlet, B., Krisai-Greilhuber, I., Dämon, W., Sparks, T., Nordén, J., Høiland, K., Kirk, P., Semenov, M., Boddy, L., Stenseth, N.C., 2012. Warming-induced shift in European mushroom fruiting phenology. Proceedings of the National Academy of Sciences 109, 14488-14493. doi:10.1073/pnas.1200789109

Kellomäki, S., Leinonen, S., 2005. Management of European forests under changing climatic conditions: final report of the project „Silvicultural response strategies to climatic change in management of European forests“. University of Joensuu, Joensuu, Finland.

Kersebaum, K.C., Eitzinger, J., 2009. Grundlegende Wirkungsmechanismen im System Boden-Pflanze-Tier-Atmosphäre, in: Eitzinger, J., Kersebaum, K.C., Formayer, H. (Eds.), Landwirtschaft Im Klimawandel: Auswirkungen Und Anpassungsstrategien Für Die Land- Und Forstwirtschaft in Mitteleuropa. Agrimedia, Clenze, Deutschland.

Kersebaum, K.C., Nendel, C., Mirschel, W., Manderscheid, R., H. J. Weigel, Wenkel, K.O., 2009. Testing different $\mathrm{CO}_{2}$ response algorithms against a face crop rotation experiment and application for climate change impact assessment at different sites in Germany. Quarterly Journal of the Hungarian Meteorological Service (Idöjárás) 113, 79-88.

Kettunen, M., Genovesi, P., Gollasch, S., Pagad, S., Starfinger, U., Ten Brink, P., Shine, C., 2009. Technical support to EU strategy on invasive alien species (IAS) - Assessment of the impacts of IAS in Europe and the EU (final module report for the European Commission). (No. Service contract No 070307/2007/483544/ MAR/B2). Institute for European Environmental Policy (IEEP), Brussels.

Kienast, F., Wildi, O., Brzeziecki, B., 1998. Potential impacts of climate change on species richness in mountain forests-An ecological risk assessment. Biological Conservation 83, 291-305. doi:10.1016/S0006-3207(97)00085-2

Kirchner, M., Strauss, F., Heumesser, C., Schmid, E., 2012. Integrative model analysis of adaptation measures to a warmer and drier climate. Jahrbuch der Österreichischen Gesellschaft für Agrarökonomie 21, 177-186.

Kirisits, T., 2010. Eingeschleppte Krankheitserreger an Waldbäumen und Klimawandel, in: Rabitsch, W., Essl, F. (Eds.), Aliens: Neobiota und Klimawandel - eine verhängnisvolle Affäre? Verlag Pu- blication $\mathrm{PN}^{\circ} 1$ - Bibliothek der Provinz, Weitra, Österreich, pp. 59-69.

Kirisits, T., Cech, T.L., 2012. Alien pathogens of forest trees in Austria., in: Diez, J.J., Martinez-Álvarez, P., Romeralo, C. (Eds.), Global Change and Forest Diseases: New Threats, New Strategies. Proceedings of the Meeting of IUFRO Working Party 7.02.02. Journal of Agricultural Extension and Rural Development, Montesclaros, Cantabria, Spain, pp. 227-229.

Klanderud, K., Birks, H.J.B., 2003. Recent increases in species richness and shifts in altitudinal distributions of Norwegian mountain plants. The Holocene 13, 1-6. doi:10.1191/0959683603hl589ft

Klaveness, D., Lindstrøm, E.-A., 2011. Hydrurus foetidus (Chromista, Chrysophyceae): A large freshwater chromophyte alga in laboratory culture. Phycological Research 59, 105-112. doi:10.1111/ j.1440-1835.2010.00606.x

Kleewein, A., Wöss, G., 2010. Niedliche Tierchen als ökologischer Zündstoff: Über faunenfremde Schildkröten in Österreich, in: Rabitsch, W., Essl, F. (Eds.), Aliens: Neobiota und Klimawandel - eine verhängnisvolle Affäre? Bibliothek der Provinz, Weitra, pp. 105-111.

Kliejunas, J.T., Geils, B.W., Glaeser, J.M., Goheen, E.M., Hennon, P., Kim, M.-S., Kope, H., Stone, J., Sturrock, R., Frankel, S.J., 2009. Review of Literature on Climate Change and Forest Diseases of Western North America (General Technical Report No. PSW-GTR-225). U.S. Department of Agriculture, Forest Service, Pacific Southwest Research Station., Albany CA, USA.

Klik, A., Eitzinger, J., 2010. Impact of climate change on soil erosion and the efficiency of soil conservation practices in Austria. The Journal of Agricultural Science 148, 529-541. doi:10.1017/ S0021859610000158

Knudsen, E., Lindén, A., Both, C., Jonzén, N., Pulido, F., Saino, N., Sutherland, W.J., Bach, L.A., Coppack, T., Ergon, T., Gienapp, P., Gill, J.A., Gordo, O., Hedenström, A., Lehikoinen, E., Marra, P.P., Møller, A.P., Nilsson, A.L.K., Péron, G., Ranta, E., Rubolini, D., Sparks, T.H., Spina, F., Studds, C.E., Sæther, S.A., Tryjanowski, P., Stenseth, N.C., 2011. Challenging claims in the study of migratory birds and climate change. Biological Reviews 86, 928-946. doi:10.1111/j.1469-185X.2011.00179.x

Koch, E., 2000. Phenology in Austria. Phenological Mapping, LongTerm Trends. Selected Papers from the Conference ICB - ICUC 2000, Sydney 8 - 12 November 1999. WMO / TD No. 1026, Genf.

Koch, E., 2008. Datenquellen: Burgunder Daten: Chuine, I., Yiou, P., Viovy, N. et al.: Historical phenology: Grape ripening as a climate indicator, Nature, 432, 289-290, 2004. Schweizer Daten: Meier, N., Ruthishauser, T., Pfister, C., Wanner, H., Luterbacher, J.: Grape harvest dates as a proxy for Swiss April to August temperature reconstruction back to A. D. 1480, Geophys. Res. Lett., 34, L20705, doi: 10.1029/2007GL031381, 2007. Moderne Klosterneuburger und Wiener Daten: Sommer, M.: Zusammenfassung der Analysenkenndaten von authentischen Weinen verschiedener Jahrgänge und deren weinbaulich-klimatische Interpretation. Diplomarbeit aus den Fachgegenständen Chemie der Früchte und Fruchtprodukte Mathematik. Lehr- und Forschungszentrum für Wein- und Obstbau Klosterneuburg, 2008. Historische Klosterneuburger und Bürgerspitaldaten: Dr. Hammerl; Quelle: ZAMG.

Köckinger, H., Kučera, J., Hofmann, H., Müller, N., Amann, G., 2012b. Barbula consanguinea Discovered in Switzerland and Austria, with a Revision of Former European Records of $B$. indica. Herzogia 25, 61-70. doi:10.13158/heia.25.1.2010.61 
Köckinger, H., Schröck, C., Krisai, R., Zechmeister, H.G., 2012 a. Checkliste der Moose Österreichs [WWW Document]. URL http://131.130.59.133/projekte/moose/

Kocmánková, E., Trnka, M., Eitzinger, J., Formayer, H., Dubrovsky, M., Semerádová, D., Zalud, Z., Juroch, J., Mozny, M., 2010. Estimating the impact of climate change on the occurrence of selected pests in the Central European region. Climate Research 44, 95-105. doi:10.3354/cr00905

Koinig, K.A., Kamenik, C., Schmidt, R., Agustí-Panareda, A., Appleby, P., Lami, A., Prazakova, M., Rose, N., Schnell, Ø.A., Tessadri, R., Thompson, R., Psenner, R., 2002. Environmental changes in an alpine lake (Gossenköllesee, Austria) over the last two centuries - the influence of air temperature on biological parameters. Journal of Paleolimnology 28, 147-160. doi:10.1023/A:1020332220870

Koinig, K.A., Schmidt, R., Sommaruga-Wögrath, S., Tessadri, R., Psenner, R., 1998. Climate Change as the Primary Cause for $\mathrm{pH}$ Shifts in a High Alpine Lake. Water, Air, \& Soil Pollution 104, 167-180. doi:10.1023/A:1004941013924

Kölling, C., 2007. Klimahüllen für 27 Waldbaumarten. AFZ/DerWald 62, 1242-1245.

Köpke, U., Haas, G., 1995. Vergleich konventioneller und organischer Landbau - Teil II: Klimarelevante Kohlendioxid-Senken von Pflanzen und Boden. Berichte über Landwirtschaft: Zeitschrift für Agrarpolitik und Landwirtschaft. 73, 416-434.

Koranda, M., Kerschbaum, S., Wanek, W., Zechmeister, H., Richter, A., 2007. Physiological Responses of Bryophytes Thuidium tamariscinum and Hylocomium splendens to Increased Nitrogen Deposition. Annals of Botany 99, 161-169. doi:10.1093/aob/mcl239

Körner, C., Ohsawa, M., 2006. Mountain systems, in: Hassan, R., Scholes, R., Ash, N. (Eds.), Ecosystems and Human Well-Being: Current State and Trends, Volume 1, Millennium Ecosystem Assessment. Island Press, Washington, Covelo, London, pp. 681716.

Kosten, S., Huszar, V.L.M., Bécares, E., Costa, L.S., van Donk, E., Hansson, L.-A., Jeppesen, E., Kruk, C., Lacerot, G., Mazzeo, N., De Meester, L., Moss, B., Lürling, M., Nóges, T., Romo, S., Scheffer, M., 2012. Warmer climates boost cyanobacterial dominance in shallow lakes. Global Change Biology 18, 118-126. doi: $10.1111 / j .1365-2486.2011 .02488 . x$

Kovats, R.S., Edwards, S.J., Hajat, S., Armstrong, B.G., Ebi, K.L., Menne, B., 2004. The effect of temperature on food poisoning: a time-series analysis of salmonellosis in ten European countries. Epidemiology and Infection 132, 443-453. doi:10.1017/ S0950268804001992

Kowalchuk, G.A., Stephen, J.R., 2001. AMMONIA-OXIDIZING BACTERIA: A Model for Molecular Microbial Ecology. Annual Review of Microbiology 55, 485-529. doi:10.1146/annurev. micro.55.1.485

Krehan, H., Cech, T.L., 1998. Pine decline in Austria, in: Cech, T.L., Hartmann, G., Tomiczek, C. (Eds.), Disease/environment Interactions in Forest Decline: Proceedings of a Workshop of the Working Party, Disease/Environment Interactions in Forest Decline, IUFRO 7.02.06: Vienna, Austria, March 16-21, 1998. Federal Forest Research Centre, pp. 83-93.

Kreitmayr, J., Mayr, K., 2007. Auswirkungen und Strategien für Landwirtschaft und Umwelt - aus der Sicht der Bodenbearbeitung, in: LfL (Ed.), Klimaänderung und Landwirtschaft: Bestandsaufnahme Und Handlungsstrategien Für Bayern; Tagungsband, Schriftenreihe Der Bayerischen Landesanstalt Für Landwirtschaft. Presented at the 6. Kulturlandschaftstag, Freising-Weihenstephan:
LfL, Freising-Weihenstephan. LfL, Bayerische Landesanstalt für Landwirtschaft, pp. 71-87.

Krenn, S., 2007. Untersuchungen zum Voltinismus und der Entwicklung des Buchdruckers in montanen und subalpinen Fichtenwäldern der Steiermark. Diplomarbeit. Universität für Bodenkultur, Wien, Österreich.

Kreuter, T., 2007. Auswirkungen und Strategien für Landwirtschaft und Umwelt - aus der Sicht der Agrarfauna, in: LfL (Ed.), Klimaänderung Und Landwirtschaft: Bestandsaufnahme und Handlungsstrategien für Bayern; Tagungsband, Schriftenreihe der Bayerischen Landesanstalt für Landwirtschaft. Presented at the 6 . Kulturlandschaftstag, Freising-Weihenstephan: LfL, Freising-Weihenstephan. LfL, Bayerische Landesanstalt für Landwirtschaft, pp. 71-87.

Krisai-Greilhuber, I., Kraus, G.F., 2013. Definition und Abgrenzung der Pilze, in: Hinker, M., Seibert, M. (Eds.), Pilze in Innenräumen und am Arbeitsplatz. Springer Vienna, pp. 1-15.

Kromp-Kolb, H., Gerersdorfer, T., 2003. Auswirkungen von Klimaänderungen auf die Tierwelt - derzeitiger Wissensstand, fokussiert auf den Alpenraum und Österreich (Endbericht. Studie im Auftrag des Bundesministeriums für Land- und Forstwirtschaft, Umwelt und Wasserwirtschaft No. Projekt GZ 54 3895/171V/4/02). Institut für Meteorologie und Physik, Universität für Bodenkultur, Wien.

Kühn, I., Vohland, K., Badeck, F., Hanspach, J., Pompe, S., Klotz, S., 2009. Aktuelle Ansätze zur Modellierung der Auswirkungen von Klimaänderungen auf die biologische Vielfalt. Natur und Landschaft 84, 8-12.

Kullman, L., 2010. Alpine flora dynamics - a critical review of responses to climate change in the Swedish Scandes since the early 1950s. Nordic Journal of Botany 28, 398-408. doi:10.1111/ j.1756-1051.2010.00812.x

Kumschick, S., Fronzek, S., Entling, M.H., Nentwig, W., 2011. Rapid spread of the wasp spider Argiope bruennichi across Europe: a consequence of climate change? Climatic Change 109, 319-329. doi:10.1007/s10584-011-0139-0

Kyek, M., Pintar, M., Formayer, H., 2003. Amphibien, in: KrompKolb, H. (Ed.), Auswirkungen von Klimaänderungen Auf Die Tierwelt - Derzeitiger Wissensstand, Fokussiert Auf Den Alpenraum Und Österreich. Endbericht Projekt GZ 54 3895/171V/4/02. Im Auftrag des Bundesministeriums für Land- und Forstwirtschaft, Umwelt und Wasserwirtschaft, Wien.

La Porta, N., Capretti, P., Thomsen, I.M., Kasanen, R., Hietala, A.M., Von Weissenberg, K., 2008. Forest pathogens with higher damage potential due to climate change in Europe. Canadian Journal of Plant Pathology 30, 177-195. doi:10.1080/0706066 1.2008.10540534

Lange, H., Økland, B., Krokene, P., 2006. Thresholds in the life cycle of the spruce bark beetle under climate change. Interjournal for Complex Systems.

Langford, T.E., 1990. Ecological Effects of Thermal Discharges. Elsevier Applied Science Publishers Ltd, London, New York.

Larcher, W., 1994. Ökophysiologie der Pflanzen: Leben, Leistung und Stressbewältigung der Pflanzen in ihrer Umwelt, 5th ed. Verlag Eugen Ulmer bei UTB, Stuttgart.

Larcher, W., 2003. Physiological Plant Ecology - Ecophysiology and Stress Physiology of Functional Groups, 4th ed. ed. Springer.

Larcher, W., Wagner, J., 2004. Lebensweise der Alpenrosen in ihrer Umwelt: 70 Jahre ökophysiologische Forschung in Innsbruck (No. 91). Ber. nat.-med. Verein Innsbruck, Innsbruck. 
Lehsten, D., Dullinger, S., Hülber, K., Schurgers, G., Cheddadi, R., Laborde, H., Lehsten, V., François, L., Dury, M., Sykes, M.T., in revision. Modelling the Holocene migrational dynamics of Fagus sylvatica L. and Picea abies (L.) H. Karst. Global Ecol Biogeo 23, 658-668. Vgl. http://onlinelibrary.wiley.com/doi/10.1111/ geb.12145/abstract

Leuzinger, S., Luo, Y., Beier, C., Dieleman, W., Vicca, S., Körner, C., 2011. Do global change experiments overestimate impacts on terrestrial ecosystems? Trends in Ecology \& Evolution 26, 236-241. doi:10.1016/j.tree.2011.02.011

Lexer, M.J., 2001. Simulation der potentiellen natürlichen Vegetation für Österreichs Wälder: Vergleich von statischen und dynamischen Modellkonzepten, Forstliche Schriftenreihe. Österreichische Gesellschaft für Waldökosystemforschung und experimentelle Baumforschung-Universität für Bodenkultur, Wien.

Lexer, M.J., Hönninger, K., 2001. A modified 3D-patch model for spatially explicit simulation of vegetation composition in heterogeneous landscapes. Forest ecology and management 144, 43-65.

Lexer, M.J., Hönninger, K., Scheifinger, H., Matulla, C., Groll, N., Kromp-Kolb, H., Schadauer, K., Starlinger, F., Englisch, M., 2002. The sensitivity of Austrian forests to scenarios of climatic change: a large-scale risk assessment based on a modified gap model and forest inventory data. Forest Ecology and Management, National and Regional Climate Change Impact Assessments in the Forestry Sector 162, 53-72. doi:10.1016/S0378-1127(02)00050-6

Lindner, M., Garcia-Gonzalo, J., Kolström, M., Green, T., Reguera, R., Maroschek, M., Seidl, R., Lexer, M.J., Netherer, S., Schopf, A., Kremer, A., Delzon, S., Barbati, A., Marchetti, M., Corona, P., 2008. Impacts of Climate Change on European Forests and Options for Adaptation (Report to the European Commissi on Directorate-General for Agriculture and Rural Development No. AGRI-2007-G4-06).

Lines, J., 1995. The effects of climatic and land-use changes on insect vectors of human disease, in: Harrington, R., Stork, N.E. (Eds.), Insects in a Changing Environment. Academic Press, London, pp. 158-175.

Lips, K.R., Diffendorfer, J., Mendelson, J.R., Sears, M.W., 2008. Riding the Wave: Reconciling the Roles of Disease and Climate Change in Amphibian Declines. PLoS Biology 6. doi:10.1371/ journal.pbio.0060072

MacLeod, A., Pautasso, M., Jeger, M.J., Haines-Young, R., 2010. Evolution of the international regulation of plant pests and challenges for future plant health. Food Security 2, 49-70. doi:10.1007/ s12571-010-0054-7

Mäder, P., Fliessbach, A., Dubois, D., Gunst, L., Fried, P., Niggli, U., 2002. Soil fertility and biodiversity in organic farming. Science 296, 1694-1697. doi:10.1126/science.1071148

Maiorano, L., Falcucci, A., Zimmermann, N.E., Psomas, A., Pottier, J., Baisero, D., Rondinini, C., Guisan, A., Boitani, L., 2011. The future of terrestrial mammals in the Mediterranean basin under climate change. Philosophical Transactions of the Royal Society B: Biological Sciences 366, 2681-2692. doi:10.1098/ rstb.2011.0121

Marini, L., Ayres, M.P., Battisti, A., Faccoli, M., 2012. Climate affects severity and altitudinal distribution of outbreaks in an eruptive bark beetle. Climatic Change 115, 327-341. doi:10.1007/ s10584-012-0463-z

Maroschek, M.G., 2009. How vulnerable is the protective function of Austria's mountain forests under climate change? A qualitative vulnerability assessment for protective forests in three selected regions. (Diplomarbeit). Institut für Waldbau, Universität für Bodenkultur, Wien.

Maroschek, M.G., Lexer, M., 2010. Österreichs Wald im Treibhaus: Nicht heimische Bäume als Lösung?, in: Rabitsch, W., Essl, F. (Eds.), Aliens: Neobiota und Klimawandel - eine verhängnisvolle Affäre? Bibliothek der Provinz, Weitra, Österreich, pp. 105-113.

Masclaux, H., Bec, A., Kainz, M.J., Desvilettes, C., Jouve, L., Bourdier, G., 2009. Combined effects of food quality and temperature on somatic growth and reproduction of two freshwater cladocerans. Limnology and Oceanography 54, 1323.

Matulla, C., Schmutz, S., Melcher, A., Gerersdorfer, T., Haas, P., Dezember 1, 2007. Assessing the impact of a downscaled climate change simulation on the fish fauna in an Inner-Alpine River. Int J Biometeorol 52, 127-137. doi:10.1007/s00484-007-0107-6

McGregor, G., Petts, G.E., Gurnell, A.M., Milner, A.M., 1995. Sensitivity of alpine stream ecosystems to climate change and human impacts. Aquatic Conservation: Marine and Freshwater Ecosystems 5, 233-247. doi:10.1002/aqc.3270050306

McMenamin, S.K., Hadly, E.A., Wright, C.K., 2008. Climatic change and wetland desiccation cause amphibian decline in Yellowstone National Park. Proceedings of the National Academy of Sciences 105, 16988-16993. doi:10.1073/pnas.0809090105

McMenamin, S.K., Hadly, E.A., Wright, C.K., 2008. Climatic change and wetland desiccation cause amphibian decline in Yellowstone National Park. Proceedings of the National Academy of Sciences 105, 16988-16993. doi:10.1073/pnas.0809090105

McVittie, A., Hussain, S.S., 2013. The Economics of Ecosystems and Biodiversity - Valuation Database Manual.

MEA, 2005. Ecosystems and Human Well-being: General Synthesis. Island Press, Washington, DC, USA.

Measey, G.J., Rödder, D., Green, S.L., Kobayashi, R., Lillo, F., Lobos, G., Rebelo, R., Thirion, J.-M., 2012. Ongoing invasions of the African clawed frog, Xenopus laevis: a global review. Biol Invasions 14, 2255-2270. doi:10.1007/s10530-012-0227-8

Meier, E.S., Lischke, H., Schmatz, D.R., Zimmermann, N.E., 2012. Climate, competition and connectivity affect future migration and ranges of European trees: Future migration and ranges of European trees. Global Ecology and Biogeography 21, 164-178. doi:10.1111/j.1466-8238.2011.00669.x

Melcher, A., Pletterbauer, F., Schmutz, S., 2010. Mögliche Auswirkungen der Klimaänderung auf die Fische in Österreichs Flüssen. Welche Anpassungs-erscheinungen zeichnen sich dabei ab?, in: Tagungsband Des 11. Österreichischer Klimatag, „Klima Im Wandel, Auswirkungen Und Strategien“ Am 11. Und 12. März 2010. Klimaforschungsinitiative AustroClim, Universität für Bodenkultur, Wien.

Melis, C., Szafrańska, P.A., Jędrzejewska, B., Bartoń, K., 2006. Biogeographical variation in the population density of wild boar (Sus scrofa) in western Eurasia. Journal of Biogeography 33, 803-811. doi:10.1111/j.1365-2699.2006.01434.x

Menzel, A., Sparks, T.H., Estrella, N., Koch, E., Aasa, A., Ahas, R., Alm-KüBler, K., Bissolli, P., Braslavská, O., Briede, A., Chmielewski, F.M., Crepinsek, Z., Curnel, Y., Dahl, A., Defila, C., Donnelly, A., Filella, Y., Jatczak, K., Måge, F., Mestre, A., Nordli, $ø$ Yvind, Peñuelas, J., Pirinen, P., Remišová, V., Scheifinger, H., Striz, M., Susnik, A., Van Vliet, A.J.H., Wielgolaski, F.-E., Zach, S., Zust, A., 2006. European phenological response to climate change matches the warming pattern. Global Change Biology 12, 1969-1976. doi:10.1111/j.1365-2486.2006.01193.x

Meyer, J.L., Sale, M.J., Mulholland, P.J., Poff, N.L., 1999. Impacts of Climate Change on Aquatic Ecosystem Functioning and Health1. 
JAWRA Journal of the American Water Resources Association 35, 1373-1386. doi:10.1111/j.1752-1688.1999.tb04222.x

Miller-Rushing, A.J., Lloyd-Evans, T.L., Primack, R.B., Satzinger, P., 2008. Bird migration times, climate change, and changing population sizes. Global Change Biology 14, 1959-1972. doi:10.1111/ j.1365-2486.2008.01619.x

Mills, G.C., Alperin, J.B., Trimmer, K.B., 1975. Studies on variant glucose-6-phosphate dehydrogenases: G6PD Fort Worth. Biochem Med 13, 264-275.

Moiseev, P.A., Shiyatov, S.G., 2003. Vegetation Dynamics at the Treeline Ecotone in the Ural Highlands, Russia, in: Nagy, L., Grabherr, G., Körner, C., Thompson, D.B.A. (Eds.), Alpine Biodiversity in Europe, Ecological Studies. Springer, Berlin, pp. 423-435.

Moore, B.A., Allard, G.B., 2008. Climate change impacts on forest health (Forest Health \& Biosecurity Working Papers FBS/34E), Forest Resources Development Service. Forest Management Division, FAO, Rome.

Moser, D., Dullinger, S., Englisch, T., Niklfeld, H., Plutzar, C., Sauberer, N., Zechmeister, H.G., Grabherr, G., 2005. Environmental determinants of vascular plant species richness in the Austrian Alps. Journal of Biogeography 32, 1117-1127. doi:10.1111/ j.1365-2699.2005.01265.x

Mucina, L., Grabherr, G., Ellmauer, T., Wallnöfer (Eds.), 1993. Die Pflanzengesellschaft Österreichs: Teil I: Anthropogene Vegetation. Teil II: Natürliche waldfreie Vegetation.Teil III: Wälder und Gebüsche. Verlag Gustav Fischer, Jena, Stuttgart, New York.

Muster, C., Herrmann, A., Otto, S., Bernhard, D., 2008. Zur Ausbreitung humanmedizinisch bedeutsamer Dornfinger-Arten Cheiracanthium mildei und C. punctorium in Sachsen und Brandenburg (Araneae: Miturgidae). Arachnologische Mitteilungen 35, 13-20. doi:10.5431/aramit3502

Nathan, R., Horvitz, N., He, Y., Kuparinen, A., Schurr, F.M., Katul, G.G., 2011. Spread of North American wind-dispersed trees in future environments: Spread of wind-dispersed trees. Ecology Letters 14, 211-219. doi:10.1111/j.1461-0248.2010.01573.x

Naucke, T.J., Lorentz, S., Rauchenwald, F., Aspöck, H., 2011. Phlebotomus Transphlebotomus mascittii Grassi, 1908, in Carinthia: first record of the occurrence of sandflies in Austria (Diptera: Psychodidae: Phlebotominae). Parasitol Res 109, 1161-1164. doi:10.1007/s00436-011-2361-0

Netherer, S., Schopf, A., 2010. Potential effects of climate change on insect herbivores in European forests - General aspects and the pine processionary moth as specific example. Forest Ecology and Management 259, 831-838. doi:10.1016/j.foreco.2009.07.034

Neveu, A., 2009. Incidence of climate on common frog breeding: Long-term and short-term changes. Acta Oecologica 35, 671678. doi:10.1016/j.actao.2009.06.012

Nicol, G.W., Leininger, S., Schleper, C., Prosser, J.I., 2008. The influence of soil $\mathrm{pH}$ on the diversity, abundance and transcriptional activity of ammonia oxidizing archaea and bacteria. Environmental Microbiology 10, 2966-2978. doi:10.1111/j.14622920.2008.01701.x

Nicolussi, K., Patzelt, G., 2006. Klimawandel und Veränderungen an der alpinen Waldgrenze - aktuelle Entwicklungen im Vergleich zur Nacheiszeit. BFW-Praxisinformation 10, 3-5.

Nieder, R., Benbi, D.K., Isermann, K., 2003. Soil organic matter dynamics, in: Benbi, D.K., Nieder, R. (Eds.), Handbook of Processes and Modeling in the Soil-Plant System. Haworth Reference Press, New York, pp. 345-408.

Niedermair, M., Lexer, M.J., Plattner, G., Formayer, H., Seidl, R., 2007. Klimawandel und Artenvielfalt - Wie klimafit sind Öster- reichs Wälder, Flüsse und Alpenlandschaften? Österreichischen Bundesforste AG, Universität für Bodenkultur Wien, WWF.

Niedermair, M., Platterer, G., Egger, G., Essl, F., Kohler, B., Zika, M., 2011. Moore im Klimawandel. Studie des WWF Österreich, der Österreichischen Bundesforste und des Umweltbundesamtes.

Nienaber, J.A., Hahn, G.L., Eigenberg, R.A., 1999. Quantifying livestock responses for heat stress management: a review. International Journal of Biometeorology 42, 183-188.

Nierhaus-Wunderwald, D., Lawrenz, P., 1997. Zur Biologie der Mistel (Merkblätter zum Thema Forstschutz No. 28), Merkblatt für die Praxis. Eidg. Forschungsanstalt für Wald, Schnee und Landschaft WSL, Birmensdorf, Schweiz.

Niese, G., 2011. Österreichs Schutzwälder sind total überaltert. BFW-Praxisinformation 24, 29-31.

Niggli, U., Earley, J., Ogorzalek, K., 2007. Organic agriculture and food supply stability. Ecological and environmental stability of the food supply, in: Proceedings of the International Conference on Organic Agriculture and Food Security. FAO, Rome.

Niinemets, Ü., 2010. Responses of forest trees to single and multiple environmental stresses from seedlings to mature plants: Past stress history, stress interactions, tolerance and acclimation. Forest Ecology and Management 260, 1623-1639. doi:10.1016/j. foreco.2010.07.054

Niinemets, Ü., Valladares, F., 2006. Tolerance to shade, drought and waterlogging of temperate northern hemisphere trees and shrubs. Ecological Monographs 76, 521-547. doi:10.1890/00129615(2006)076[0521:TTSDAW]2.0.CO;2

Niklfeld, H., Schratt-Ehrendorfer, L., Englisch, T., 2008. Muster der Artenvielfalt der Farn-und Blütenpflanzen in Österreich, in: Sauberer, N., Moser, D., Grabherr, G. (Eds.), Biodiversität in Österreich: Räumliche Muster Und Indikatoren Der Arten- Und Lebensraumvielfalt. Haupt Verlag, Bern, pp. 87-102.

Nóges, P., Adrian, R., Anneville, O., Arvola, L., Blenckner, T., George, G., Jankowski, T., Järvinen, M., Maberly, S., Padisák, J., Straile, D., Teubner, K., Weyhenmeyer, G., 2010. The Impact of Variations in the Climate on Seasonal Dynamics of Phytoplankton, in: George, G. (Ed.), The Impact of Climate Change on European Lakes, Aquatic Ecology Series. Springer Netherlands, pp. 253-274.

Norby, R.J., Wullschleger, S.D., Gunderson, C.A., Johnson, D.W., Ceulemans, R., 1999. Tree responses to rising $\mathrm{CO}_{2}$ in field experiments: implications for the future forest. Plant, Cell \& Environment 22, 683-714. doi:10.1046/j.1365-3040.1999.00391.x

Nösberger, J., Lüscher, A., 1995. $\mathrm{CO}_{2}-$ Die Zukunft gehört dem Klee. Die Grüne 23/95.

Obertegger, U., Camin, F., Guella, G., Flaim, G., 2011. Adaptation of a Psychrophilic Freshwater Dinoflagellate to Ultraviolet Radiation1. Journal of Phycology 47, 811-820. doi:10.1111/j.15298817.2011.01025.x

Olesen, J.E., Bindi, M., 2002. Consequences of climate change for European agricultural productivity, land use and policy. European Journal of Agronomy 16, 239-262. doi:10.1016/S11610301(02)00004-7

Ostermaier, V., Schanz, F., Köster, O., Kurmayer, R., 2012. Stability of toxin gene proportion in red-pigmented populations of the cyanobacterium Planktothrix during 29 years of re-oligotrophication of Lake Zürich. BMC Biology 10. doi:10.1186/1741-7007-10100

Österreichische Mykologische Gesellschaft (ÖMG), 2013. Datenbank der Pilze Österreichs. Bearbeitet von Dämon, W., Hauskne- 
cht, A. und Krisai-Greilhuber, I. [WWW Document]. URL http://austria.mykodata.net/ (accessed 5.8.13).

Ott, J., 2008. Libellen als Indikatoren der Klimaänderung-Ergebnisse aus Deutschland und Konsequenzen für den Naturschutz. Insecta-Zeitschrift für Entomologie und Naturschutz 11, 75-89.

Ott, J., 2010. Dragonflies and climatic change - recent trends in Germany and Europe. BIORISK - Biodiversity and Ecosystem Risk Assessment 5, 253-286. doi:10.3897/biorisk.5.857

Parmesan, C., 2007. Influences of species, latitudes and methodologies on estimates of phenological response to global warming. Global Change Biology 13, 1860-1872. doi:10.1111/j.13652486.2007.01404.x

Parmesan, C., Yohe, G., 2003. A globally coherent fingerprint of climate change impacts across natural systems. Nature 421, 37-42. doi: $10.1038 /$ nature 01286

Paul, V.J., 2008. Global warming and cyanobacterial harmful algal blooms, in: Hudnell, H.K. (Ed.), Cyanobacterial Harmful Algal Blooms: State of the Science and Research Needs, Advances in Experimental Medicine and Biology. Springer, New York, pp. 239-257.

Pauli, H., Gottfried, M., Grabherr, G., 2001. High summits of the Alps in a changing climate, in: Walther, G.-R., Burga, C.A., Edwards, P.J. (Eds.), „Fingerprints“ of Climate Change. Adapted Behaviour and Shifting Species Ranges. Springer, US, pp. 139-149.

Pauli, H., Gottfried, M., Dirnböck, T., Dullinger, S., Grabherr, G., 2003. Assessing the long-term dynamics of endemic plants at summit habitats, in: Nagy, L., Grabherr, G., Körner, C., Thompson, D.B.A. (Eds.), Alpine Biodiversity in Europe, Ecological Studies. Springer, Berlin Heidelberg, pp. 195-207.

Pauli, H., Gottfried, M., Reiter, K., Klettner, C., Grabherr, G., 2007. Signals of range expansions and contractions of vascular plants in the high Alps: observations (1994-2004) at the GLORIA master site Schrankogel, Tyrol, Austria. Global Change Biology 13, 147-156. doi:10.1111/j.1365-2486.2006.01282.x

Pauli, H., Gottfried, M., Dullinger, S., Abdaladze, O., Akhalkatsi, M., Alonso, J.L.B., Coldea, G., Dick, J., Erschbamer, B., Calzado, R.F., Ghosn, D., Holten, J.I., Kanka, R., Kazakis, G., Kollár, J., Larsson, P., Moiseev, P., Moiseev, D., Molau, U., Mesa, J.M., Nagy, L., Pelino, G., Puşcaş, M., Rossi, G., Stanisci, A., Syverhuset, A.O., Theurillat, J.-P., Tomaselli, M., Unterluggauer, P., Villar, L., Vittoz, P., Grabherr, G., 2012. Recent Plant Diversity Changes on Europe's Mountain Summits. Science 336, 353-355. doi:10.1126/science. 1219033

Pearson, R.G., Dawson, T.P., 2003. Predicting the impacts of climate change on the distribution of species: are bioclimate envelope models useful? Global Ecology and Biogeography 12, 361-371. doi:10.1046/j.1466-822X.2003.00042.x

Peltonen-Sainio, P., Jauhiainen, L., Trnka, M., Olesen, J.E., Calanca, P., Eckersten, H., Eitzinger, J., Gobin, A., Kersebaum, K.C., Kozyra, J., Kumar, S., Marta, A.D., Micale, F., Schaap, B., Seguin, B., Skjelvag, A.O., Orlandini, S., 2010. Coincidence of variation in yield and climate in Europe. Agriculture, Ecosystems \& Environment 139, 483-489. doi:http://dx.doi.org/10.1016/j. agee.2010.09.006

Perkins, D.M., Reiss, J., Yvon-Durocher, G., Woodward, G., 2010. Global change and food webs in running waters. Hydrobiologia 657, 181-198. doi:10.1007/s10750-009-0080-7

Perzl, F., Kammerlander, J., 2010. Schneehöhe und Lawinengefahr einst und im Jahre Schnee? BFW Praxisinformation 23, 8-10.
Petersen, H., Luxton, M., 1982. A Comparative Analysis of Soil Fauna Populations and Their Role in Decomposition Processes. Oikos 39, 287-388. doi:10.2307/3544689

Petgen, M., 2007. Reaktion der Reben auf den Klimawandel. Schweizerischen Zeitschrift für Obst-und Weinbau 9, 6-9.

Phillimore, A.B., Hadfield, J.D., Jones, O.R., Smithers, R.J., 2010. Differences in spawning date between populations of common frog reveal local adaptation. Proceedings of the National Academy of Sciences of the United States of America 107, 8292-8297. doi:10.1073/pnas.0913792107

Pilz, C., Kahrer, A., 2012. Maiswurzelbohrer: Bisher keine Ausbreitung, aber deutlich mehr Käfer. Der Pflanzenarzt.

Pimentel, D., Hepperly, P., Hanson, J., Douds, D., Seidel, R., 2005. Environmental, energetic, and economic comparisons of organic and conventional farming systems. BioScience 55, 573-582. doi:http://dx.doi.org/10.1641/0006-3568(2005)055[0573:EEA ECO]2.0.CO;2

Poczopko, P., 1984. The zone of optimal temperature as related to age of domesticated animals. Archiv für experimentelle Veterinärmedizin 38, 411-418.

Pompe, S., Berger, S., Bergmann, J., Badeck, F., Lübbert, J., Klotz, S., Rehse, A.-K., Söhlke, G., Sattler, S., Walther, G.-R., Kühn, I., 2011. Modellierung der Auswirkungen des Klimawandels auf die Flora und Vegetation in Deutschland (No. 304), BfN-Skripten. Bundesamt für Naturschutz (BfN), Bonn.

Pötsch, E.M., 1998. Über den Einfluss der Düngungsintensität auf den N-Kreislauf im alpenländischen Grünland. Die Bodenkultur 49, 19-27.

Pötsch, E.M., 2012. Optimale Grünlandbewirtschaftung in Bergregionen. (Tagungsbericht zur 39. Viehwirtschaftlichen Fachtagung „Milchproduktion - status quo und Anpassung an zukünftige Herausforderungen"). LFZ Raumberg-Gumpenstein.

Pounds, J.A., Bustamante, M.R., Coloma, L.A., Consuegra, J.A., Fogden, M.P.L., Foster, P.N., La Marca, E., Masters, K.L., Merino-Viteri, A., Puschendorf, R., Ron, S.R., Sánchez-Azofeifa, G.A., Still, C.J., Young, B.E., 2006. Widespread amphibian extinctions from epidemic disease driven by global warming. Nature 439, 161-167. doi:10.1038/nature04246

Pöyry, J., Luoto, M., Heikkinen, R.K., Kuussaari, M., Saarinen, K., 2009. Species traits explain recent range shifts of Finnish butterflies. Global Change Biology 15, 732-743. doi:10.1111/j.13652486.2008.01789.x

Pretzsch, U., Utschig, H., 2000. Wachstumstrends der Fichte in Bayern. Mitteilungen aus der Bayerischen Staatsforstverwaltung 49, 170.

Pröll, G., Dullinger, S., Dirnböck, T., Kaiser, C., Richter, A., 2011. Effects of nitrogen on tree recruitment in a temperate montane forest as analysed by measured variables and Ellenberg indicator values. Preslia 83, 111-127.

Psenner, R., 2002. Alpine waters in the interplay of global change. Complex links - simple effects, in: Steininger, K.W., WeckHannemann, H. (Eds.), Global Environmental Change in Alpine Regions: Recognition, Impact, Adaptation and Mitigation. Edward Elgar Publishing, Cheltenham, U.K, pp. 15-40.

Purse, B.V., Mellor, P.S., Rogers, D.J., Samuel, A.R., Mertens, P.P., Baylis, M., 2005. Climate change and the recent emergence of bluetongue in Europe. Nature Reviews Microbiology 3, 171-181. doi:10.1038/nrmicro1090

Queyriaux, B., Armengaud, A., Jeannin, C., Couturier, E., PelouxPetiot, F., 2008. Chikungunya in Europe. The Lancet 371, 723724. 
Rabitsch, W., 2008. The Times They Are A-Changin': Driving forces of recent additions to the Heteroptera fauna of Austria, in: Grozeva, S., Simov, N. (Eds.), Advances in Heteroptera research: Festschrift in honor of 80th anniversary of Michail Josifov, Faunistica. Pensoft Publishers, Sofia; Moscow, pp. 309-326.

Rabitsch, W., 2010. Insekten-Neozoen in Österreich und Auswirkungen des Klimawandels, in: Rabitsch, W., Essl, F. (Eds.), Aliens: Neobiota und Klimawandel - eine verhängnisvolle Affäre? Verlag Bibliothek der Provinz, Weitra, Österreich, pp. 93-103.

Rabitsch, W., Essl, F., 2009. Endemiten: Kostbarkeiten in Österreichs Pflanzen- und Tierwelt. Naturwissenschaftlicher Verein für Kärnten \& Umweltbundesamt, Klagenfurt.

Rabitsch, W., Essl, F. (Eds.), 2010. Aliens: Neobiota und Klimawandel - eine verhängnisvolle Affäre? Bibliothek der Provinz, Weitra.

Rabitsch, W., Winter, M., Kühn, E., Kühn, I., Götzl, M., Essl, F., Gruttke, H., 2010. Auswirkungen des rezenten Klimawandels auf die Fauna in Deutschland., Natschutz und Biologische Vielfalt. Bundesamt für Naturschutz, Bonn-Bad Godesberg.

Rabitsch, W., Milasowszky, N., Nehring, S., Wiesner, C., Wolter, C., Essl, F., 2013. The times are changing: temporal shifts in patterns of fish invasions in central European fresh waters. Journal of Fish Biology 82, 17-33. doi:10.1111/j.1095-8649.2012.03457.x

Randin, C.F., Engler, R., Normand, S., Zappa, M., Zimmermann, N.E., Pearman, P.B., Vittoz, P., Thuiller, W., Guisan, A., 2009. Climate change and plant distribution: local models predict highelevation persistence. Global Change Biology 15, 1557-1569. doi:10.1111/j.1365-2486.2008.01766.x

Raven, P.H., Evert, R.F., Eichhorn, S.E., 2000. Biologie der Pflanzen, 3. ed. Walter de Gruyter, Berlin, Deutschland, New York, USA.

Reading, C.J., 2007. Linking global warming to amphibian declines through its effects on female body condition and survivorship. Oecologia 151, 125-131. doi:10.1007/s00442-006-0558-1

Rebetez, M., Dobbertin, M., 2004. Climate change may already threaten Scots pine stands in the Swiss Alps. Theoretical and applied climatology 79, 1-9. doi:10.1007/s00704-004-0058-3

Reisenzein, H., Berger, N., Suarez, B., Steffek, R., 2010. Grapevine Flavescence dorée - eine Gefahr für den österreichischen Weinbau? Österreichische Pflanzenschutztage, 1.-2.12.2010, Schloss Seggau/Leibnitz. Leibnitz.

Reusch, T.B., Ehlers, A., Hämmerli, A., Worm, B., 2005. Ecosystem recovery after climatic extremes enhanced by genotypic diversity. Proceedings of the National Academy of Sciences of the United States of America 102, 2826-2831. doi:10.1073/ pnas.0500008102

Rigling, A., Dobbertin, M., Gimmi, U., Pannatier, G.E., Gugerli, F., Heininger, U., Polomski, J., Rebetez, M., Rigling, D., Weber, P., Wermelinger, B., Wohlgemuth, T., 2006. Verdrängen Flaumeichen die Walliser Waldföhren? (No. 41), Merkblatt für die Praxis. Eidg. Forschungsanstalt WSL, Birmensdorf, Schweiz.

Rippel, R., 2007. Auswirkungen und Strategien für Landwirtschaft und Umwelt - aus der Sicht des Erosionsschutzes, in: Klimaänderungen und Landwirtschaft - Bestandsaufnahme und Handlungsstrategien für Bayern, Schriftenreihe der Bayrischen Landesanstalt für Landwirtschaft (LfL). 13/2007.

Roberts, S., Potts, S., Biesmeijer, K., Kuhlmann, M., Kunin, W., Ohlemüller, R., 2011. Assessing continental-scale risks for generalist and specialist pollinating bee species under climate change. BioRisk - Biodiversity \& Ecosystem Risk Assessment 6, 1-18. doi:10.3897/biorisk.6.1325

Robinet, C., Baier, P., Pennerstorfer, J., Schopf, A., Roques, A., 2007. Modelling the effects of climate change on the potential feed- ing activity of Thaumetopoea pityocampa (Den. \& Schiff.) (Lep., Notodontidae) in France. Global Ecology and Biogeography 16, 460-471. doi:10.1111/j.1466-8238.2006.00302.x

Rödder, D., Schulte, U., 2010. Amphibien und Reptilien im anthropogenen Klimawandel: Was wissen wir und was erwarten wir? Zeitschrift für Feldherpetologie 17, 1-22.

Root, T.L., Price, J.T., Hall, K.R., Schneider, S.H., Rosenzweig, C., Pounds, J.A., 2003. Fingerprints of global warming on wild animals and plants. Nature 421, 57-60. doi:10.1038/nature01333

Rott, E., Walser, L., Kegele, M., 2000. Ecophysiological aspects of macroalgal seasonality in a gravel stream in the Alps (River Isar, Austria). Internationale Vereinigung fur Theoretische und Angewandte Limnologie Verhandlungen 27, 1622-1625.

Rott, E., Cantonati, M., Füreder, L., Pfister, P., 2006. Benthic Algae in High Altitude Streams of the Alps - a Neglected Component of the Aquatic Biota. Hydrobiologia 562, 195-216. doi:10.1007/ s10750-005-1811-z

Rott, E., Gesierich, D., Binder, N., 2010. Lebensraumtypen und Diversitätsgradienten lotischer Algen in einem Gletschereinzugsgebiet, in: Koch, E.-M., Erschbamer, B. (Eds.), Glaziale Und Periglaziale Lebensräume Im Raum Obergurgl, Series / Alpine Forschungsstelle Obergurgl. Innsbruck University Press, Innsbruck.

Rott, E., Hotzy, R., Cantonati, M., Sanders, D., 2012. Calcification types of Oocardium stratum Nägeli and microhabitat conditions in springs of the Alps. Freshwater Science 31, 610-624. doi: $10.1899 / 11.084 .1$

Rouault, G., Candau, J.-N., Lieutier, F., Nageleisen, L.-M., Martin, J.-C., Warzée, N., 2006. Effects of drought and heat on forest insect populations in relation to the 2003 drought in Western Europe. Annals of Forest Science 63, 613-624. doi:10.1051/forest:2006044

Rubel, F., Kottek, M., 2010. Observed and projected climate shifts 1901-2100 depicted by world maps of the Köppen-Geiger climate classification. Meteorologische Zeitschrift 19, 135-141. doi:10.1127/0941-2948/2010/0430

Russ, W., 2011. Mehr Wald in Österreich. BFW-Praxisinformation 24.

Salak-Johnson, J.L., McGlone, J.J., 2007. Making sense of apparently conflicting data: Stress and immunity in swine and cattle. Journal of Animal Science 85, E81-E88. doi:10.2527/jas.2006-538

Sauberer, N., 1994. Untersuchungen zur Struktur und Dynamik eines Krummseggenrasens (Caricetum curvulae) in den Ötztaler Alpen. Diplomarbeit. Universität Wien.

Schabhüttl, S., Hingsamer, P., Weigelhofer, G., Hein, T., Weigert, A., Striebel, M., 2013. Temperature and species richness effects in phytoplankton communities. Oecologia 171, 527-536. doi:10.1007/s00442-012-2419-4

Schaller, M., Weigel, H.-J., 2007. Analyse des Sachstands zu Auswirkungen von Klimaveränderungen auf die deutsche Landwirtschaft und Maßnahmen zur Anpassung (Sonderheft No. 316). Landbauforschung Völkenrode - FAL Agricultural Research, Braunschweig, Deutschland.

Schaumberger, A., 2012. Räumliche Modelle zur Vegetations- und Ertragsdynamik im Wirtschaftsgrünland (Dissertation). Technische Universität Graz, Institut für Geoinformation, Graz.

Schaumberger, J., Buchgraber, K., Schaumberger, A., 2011. Teilbericht 5b: Landwirtschaftliche Flächennutzungspotenziale in Österreich und Simulation von Produktionsszenarien bis 2050. Arbeitspaket 3: Flächennutzungspotenziale und -szenarien (Studie 
„Save our Surface“ im Auftrag des Österreichischen Klima- und Energiefonds). LFZ Raumberg-Gumpenstein, Irdning.

Schelhaas, M.-J., Nabuurs, G.-J., Schuck, A., 2003. Natural disturbances in the European forests in the 19th and 20th centuries. Global Change Biology 9, 1620-1633. doi:10.1046/j.13652486.2003.00684.x

Scherm, H., 2004. Climate change: can we predict the impacts on plant pathology and pest management? Canadian Journal of Plant Pathology 26, 267-273. doi:10.1080/07060660409507143

Scherrer, D., Koerner, C., 2010. Infra-red thermometry of alpine landscapes challenges climatic warming projections. Global Change Biology 16, 2602-2613. doi:10.1111/j.1365-2486.2009.02122.x

Schindlbacher, A., Zechmeister-Boltenstern, S., Jandl, R., 2009. Carbon losses due to soil warming: Do autotrophic and heterotrophic soil respiration respond equally? Global Change Biology 15, 901913.

Schindlbacher, A., Rodler, A., Kuffner, M., Kitzler, B., Sessitsch, A., Zechmeister-Boltenstern, S., 2011. Experimental warming effects on the microbial community of a temperate mountain forest soil. Soil biology \& biochemistry 43, 1417-1425. doi:10.1016/j.soilbio.2011.03.005

Schindlbacher, A., Wunderlich, S., Borken, W., Kitzler, B., Zechmeister-Boltenstern, S., Jandl, R., 2012. Soil respiration under climate change: Prolonged summer drought offsets soil warming effects. Global Change Biology 18, 2270-2279.

Schleper, C.N., 2010. Ammonia-oxidising archaea-physiology, ecology and evolution, in: Poole, R. (Ed.), Advances in Microbial Physiology. Academic Press, pp. 1-41.

Schmitt, T., 2007. Molecular biogeography of Europe: Pleistocene cycles and postglacial trends. Frontiers in Zoology 4. doi:10.1186/1742-9994-4-11

Schmutz, S., 2008. Auswirkungen von Klimaänderungen auf die Fischfauna, in: Böhm, R., Godina, R., Nachtnebel, H.P., Pirker, O. (Eds.), Auswirkungen des Klimawandels auf die österreichische Wasserwirtschaft. Bundesministerium für Land- und Forstwirtschaft, Umwelt und Wasserwirtschaft BMLFUW, Wien, pp. 177-186.

Schmutz, S., Mielach, C., 2011. Global warming affecting fish in the Danube River Basin. Danube News 23, 12-14.

Schmutz, S., Matulla, C., Melcher, A., Gerersdorfer, T., Haas, P., Formayer, H., 2004. Beurteilung der Auswirkungen möglicher Klimaänderungen auf die Fischfauna anhand ausgewählter Fließgewässer (Endbericht im Auftrag des Bundesministerium für Land- und Forstwirtschaft, Umwelt und Wasserwirtschaft, Abt. V/4, Immissions- und Klimaschutz No. GZ 54 3895/163 $\mathrm{V} / 4 / 03)$. Institut für Hydrobiologie und Gewässermanagement (IHG), Institut für Meteorologie (BOKU Met), Wien.

Schmutz, S., Kaufmann, M., Vogel, B., Jungwirth, M., Muhar, S., 2000. A multi-level concept for fish-based, river-type-specific assessment of ecological integrity. Hydrobiologia 422-423, 279289. doi:10.1023/A:1017038820390

Schopf, A., Blackwell, Wimmer, V., 2012. Untersuchungen zum Einfluss des Klimas auf Voltinismus und Ausbreitung des Buchdruckers, Ips typographus, im alpinen Raum (Endbericht Start Clim 2011. A), StartClim2011: Anpassung an den Klimawandel in Österreich- Themenfeld Wald. Universität für Bodenkultur, Institut für Forstentomologie, Forstpathologie und Forstschutz, Wien, Österreich.

Schröck, C., Köckinger, H., Amann, G., Zechmeister, H., 2013. Rote Liste gefährdeter Moose Vorarlbergs, Rote Listen Vorarlbergs, Band 8. inatura, Dornbirn.
Schultz, H.R., Hoppmann, D., Hofmann, M., 2005. Der Einfluss klimatischer Veränderungen auf die phänologische Entwicklung der Rebe, die Sorteneignung sowie Mostgewicht und Säurestruktur der Trauben. (Beitrag zum Integrierteen Klimaschutzprogramm des Landes Hessen (InKlim 2012) des Fachgebiets Weinbau der Forschungsanstalt Geisenheim).

Schultz, S., Vallant, B., Kainz, M.J., 2012. Preferential feeding on high quality diets decreases methyl mercury of farm-raised common carp (Cyprinus carpio L.). Aquaculture 338-341, 105-110.

Schumacher, S., Bugmann, H., 2006. The relative importance of climatic effects, wildfires and management for future forest landscape dynamics in the Swiss Alps. Global Change Biology 12, 1435-1450. doi:10.1111/j.1365-2486.2006.01188.x

Schweiger, O., Biesmeijer, J.C., Bommarco, R., Hickler, T., Hulme, P.E., Klotz, S., Kühn, I., Moora, M., Nielsen, A., Ohlemüller, R., Petanidou, T., Potts, S.G., Pyšek, P., Stout, J.C., Sykes, M.T., Tscheulin, T., Vilà, M., Walther, G.-R., Westphal, C., Winter, M., Zobel, M., Settele, J., 2010. Multiple stressors on biotic interactions: how climate change and alien species interact to affect pollination. Biological Reviews 85, 777-795. doi:10.1111/j.1469185X.2010.00125.x

Schweiger, O., Settele, J., Kudrna, O., Klotz, S., Kühn, I., 2008. Climate change can cause spatial mismatch of trophically interacting species. Ecology 89, 3472-3479. doi:10.1890/07-1748.1

Schweiger, O., Heikkinen, R.K., Harpke, A., Hickler, T., Klotz, S., Kudrna, O., Kühn, I., Pöyry, J., Settele, J., 2011. Increasing range mismatching of interacting species under global change is related to their ecological characteristics. Global Ecology and Biogeography 21, 88-99. doi:10.1111/j.1466-8238.2010.00607.x

Seidl, R., Rammer, W., Jäger, D., Currie, W.S., Lexer, M.J., 2007. Assessing trade-offs between carbon sequestration and timber production within a framework of multi-purpose forestry in Austria. Forest Ecology and Management, Meeting the challenges of process-oriented management. Outcomes of the e-Conference „ForwardFORESTs“. 248, 64-79. doi:10.1016/j.foreco.2007.02.035

Seidl, R., Schelhaas, M.-J., Lindner, M., Lexer, M.J., 2009. Modelling bark beetle disturbances in a large scale forest scenario model to assess climate change impacts and evaluate adaptive management strategies. Reg Environ Change 9, 101-119. doi:10.1007/ s10113-008-0068-2

Seidl, R., Rammer, W., Jäger, D., Lexer, M.J., 2008. Impact of bark beetle (Ips typographus L.) disturbance on timber production and carbon sequestration in different management strategies under climate change. Forest Ecology and Management 256, 209-220.

Seidl, R., Rammer, W., Lexer, M.J., 2011a. Climate change vulnerability of sustainable forest management in the Eastern Alps. Climatic Change 106, 225-254.

Seidl, R., Schelhaas, M.-J., Lexer, M.J., 2011b. Unraveling the drivers of intensifying forest disturbance regimes in Europe. Global Change Biology 17, 2842-2852. doi:10.1111/j.13652486.2011.02452.x

Seidl, R., Thom, D., Krehan, H., Steyrer, G., 2012. Analyzing Austria’s forest disturbance regime as basis for the development of climate change adaptation strategies. (Endbericht von StartClim2011.B in Start-Clim2011: Anpassung an den Klimawandel in Österreich: Themenfeld Wald.). Auftraggeber: BMLFUW, BMWF, ÖBF.

Senn-Irlet, B., Egli, S., Boujonm, C., Küchler, H., Küffer, N., Neukom, H.-P., Roth, J.-J., 2012. Pilze schützem und fördern. Eidgenössische Forschungsanstalt WSL, Birmensdorf, Schweiz. (No. 49), Merkblatt für die Praxis. Eidg. Forschungsanstalt WSL, Birmensdorf, Schweiz. 
Settele, J., Kudrna, O., Harpke, A., Kuehn, I., van Swaay, C., Verovnik, R., Warren, M., Wiemers, M., Hanspach, J., Hickler, T., Kühn, E., van Halder, I., Veling, K., Vliegenthart, A., Wynhoff, I., Schweiger, O., 2008. Climatic Risk Atlas of European Butterflies. BioRisk - Biodiversity and Ecosystem Risk Assessment 1. doi:10.3897/biorisk.1

Shaw, M.W., 2009. Preparing for changes in plant diseases due to climate change. Plant Protection Science 45, 3-10.

Shugart, H.H., 1998. Terrestrial ecosystems in changing environments, Cambridge Studies in Ecology. Cambridge University Press, Cambridge, United Kingdom and New York, NY, USA.

Šleger, V., Neuberger, P., 2006. Using meteorological data to determine the risk of heat stress. Res. Agr. Eng. 52, 39-47.

Smith, A.J., 1973. Some effects of high environmental temperatures on the productivity of laying hens (a review). Tropical animal health and production 5, 259-271. doi:10.1007/BF02240427

Smith, P., Andrén, O., Brussaard, L., Dangerfield, M., Ekschmitt, K., Lavelle, P., Tate, K., 1998. Soil biota and global change at the ecosystem level: describing soil biota in mathematical models. Global Change Biology 4, 773-784. doi:10.1046/j.13652486.1998.00193.x

Soja, G., Reichenauer, T.G., Eid, M., Soja, A.-M., Schaber, R., Gangl, H., 2004. Long-term ozone exposure and ozone uptake of grapevines in open-top chambers. Atmospheric Environment 38, 2313-2321. doi:10.1016/j.atmosenv.2003.12.038

Soja, G., Eitzinger, J., Schneider, W., Soja, A.M., 2005. Auswirkungen meteorologischer Extreme auf die Pflanzenproduktion in Österreich, in: Kämpf, A., Claupein, W., Graeff, S., Diepenbrock, W. (Eds.), Wasser und Pflanzenbau - Herausforderungen für zukünftige Produktionssysteme, Mitteilungen der Gesellschaft für Pflanzenbauwissenschaften. Presented at the 48. Jahrestagung des Gesellschaft für Pflanzenbauwissenschaften, Verlag Günter Haimbach, Stuttgart, Wien, pp. 229-230.

Sommaruga, R., Psenner, R., Schafferer, E., Koinig, K.A., Sommaruga-Wograth, S., 1999. Dissolved Organic Carbon Concentration and Phytoplankton Biomass in High-Mountain Lakes of the Austrian Alps: Potential Effect of Climatic Warming on UV Underwater Attenuation. Arctic, Antarctic, and Alpine Research 31. doi: $10.2307 / 1552253$

Sommaruga-Wögrath, S., Koinig, K.A., Schmidt, R., Sommaruga, R., Tessadri, R., Psenner, R., 1997. Temperature effects on the acidity of remote alpine lakes. Nature 387, 64-67. doi:10.1038/387064a0

Spiecker, H., 2000. The growth of Norway spruce (Picea abies (L.) Karst.) in Europe within and beyond its natural range, in: Hasenauer, H. (Ed.), Forest Ecosystem Restoration. Proceedings of the Conference Held in Vienna, Austria 10.-12. April 2000.

Spiecker, H., 2003. Silvicultural management in maintaining biodiversity and resistance of forests in Europe-temperate zone. Journal of Environmental Management 67, 55-65.

Steffek, R., Reisenzein, H., Zeisner, N., 2006. Risikoanalyse zur Wahrscheinlichkeit der Einschleppung und Etablierung von Flavescence dorée in die österreichischen Weinbaugebiete. Österreichische Pflanzenschutztage, 29.-30.11.2006, Schloss Seggau/ Leibnitz. Leibnitz.

Steffek, R., Reisenzein, H., Zeisner, N., 2007. Analysis of the pest risk from Grapevine flavescence dorée phytoplasma to Austrian viticulture. EPPO Bulletin 37, 191-203. doi:10.1111/j.13652338.2007.01102.x

Steffek, R., Reisenzein, H., Strauss, G., Leichtfried, T., Hofrichter, J., Kopacka, I., Schwarz, M., Pusterhofer, J., Biedermann, R., Renner, W., Klement, J., Luttenberger, W., Welzl, A., Kleissner, A.,
Alt, R., 2011. VitisCLIM, a project modelling spread and economic impact of Grapevine Flavescence dorée phytoplasma in Austrian viticulture under a climate change scenario. Bulletin of Insectology (Supplement) 64, 191-192.

Steiner, C., Lexer, M.J., 1998. Ein klimasensitives statisches Modell zur Beurteilung der Baumarteneignung. Forstarchiv 69, 92-103.

Stock, M., Badeck, F., Gerstengarbe, F.W., Hopmann, D., Kartschall, T., Österle, H., Werner, P.C., Wodinski, M., 2005. Perspektiven der Klimaveränderung bis 2050 für den Weinbau in Deutschland (Klima 2050). (PIK-Report No. 106).

Stomp, M., Huisman, J., Mittelbach, G.G., Litchman, E., Klausmeier, C.A., 2011. Large-scale biodiversity patterns in freshwater phytoplankton. Ecology 92, 2096-2107. doi:10.1890/10-1023.1

Strauß, F., Schmid, E., Moltchanova, E., Formayer, H., Wang, X., 2012. Modeling climate change and biophysical impacts of crop production in the Austrian Marchfeld Region. Climatic Change 111, 641-664. doi:10.1007/s10584-011-0171-0

Strauss, G., Steffek, R., Reisenzein, H., Schwarz, M., 2012. Modeling the establishment potential of Scaphoideus titanus, vector of Grapevine Flavescence doree phytoplasma, in Europe by using the CLIMEX model., in: NEOBIOTA 2012 Book of Abstracts. 7th European Conference on Invasive Alien Species. Presented at the 7th European Conference on Biological Invasions. Halting Biological Invasions in Europe: from Data to Decisions, GEIB Grupo Especialista en Invasiones Biológicas, Pontevedra, Spain, pp. 105-106.

Sturrock, R., 2012. Climate change and forest diseases: using today's knowledge to address future challenges. Forest Systems 21, 329336. doi:10.5424/fs/2012212-02230

Sveinbjörnsson, B., Oechel, W.C., 1992. Controls on growth and productivity of bryophytes: environmental limitations under current and anticipated conditions, in: Bates, J.W., Farmer, A.M. (Eds.), Bryophytes and Lichens in a Changing Environment, Oxford Science Publications. Oxford University Press, USA, pp. 77-102.

Sztatecsny, M., 2009. Can protected mountain areas serve as refuges for declining amphibians? Potential threats of climate change and amphibian chytridiomycosis in an alpine amphibian population. Journal on Protected Mountain Areas Research 1, 19-24. doi:10.1553/ecomont2s19

Szukics, U., Abell, G.C.J., Hödl, V., Mitter, B., Sessitsch, A., Hackl, E., Zechmeister-Boltenstern, S., 2010. Nitrifiers and denitrifiers respond rapidly to changed moisture and increasing temperature in a pristine forest soil. FEMS Microbiology Ecology 72, 395406. doi:10.1111/j.1574-6941.2010.00853.x

Szukics, U., Hackl, E., Zechmeister-Boltenstern, S., Sessitsch, A., 2012. Rapid and dissimilar response of ammonia oxidizing archaea and bacteria to nitrogen and water amendment in two temperate forest soils. Microbiological Research 167, 103-109. doi:10.1016/j.micres.2011.04.002

Taubmann, J., Theissinger, K., Feldheim, K.A., Laube, I., Graf, W., Haase, P., Johannesen, J., Pauls, S.U., 2011. Modelling range shifts and assessing genetic diversity distribution of the montane aquatic mayfly Ameletus inopinatus in Europe under climate change scenarios. Conserv Genet 12, 503-515. doi:10.1007/ s10592-010-0157-x

Thaler, S., Eitzinger, J., Trnka, M., Dubrovsky, M., 2012. Impacts of climate change and alternative adaptation options on winter wheat yield and water productivity in a dry climate in Central Europe. The Journal of Agricultural Science 150, 537-555. doi:10.1017/ S0021859612000093 
Thenmayer, F.J., Schmiedl, J., Glauninger, J., 2006. Die Kraut- und Knollenfäule der Kartoffel (Phytophthora infestans) in den Jahren 2000 bis 2006 in Niederösterreich. Österreichische Pflanzenschutztage, 29.-30.11.2006, Schloss Seggau/Leibnitz. Leibnitz.

Theurillat, J.-P., Guisan, A., 2001. Potential impact of climate change on vegetation in the European Alps: a review. Climatic change 50, 77-109. doi:10.1023/A:1010632015572

Thibault, K.M., Brown, J.H., 2008. Impact of an extreme climatic event on community assembly. Proceedings of the National Academy of Sciences 105, 3410-3415.

Thies, H., Nickus, U., Mair, V., Tessadri, R., Tait, D., Thaler, B., Psenner, R., 2007. Unexpected Response of High Alpine Lake Waters to Climate Warming. Environmental Science \& Technology 41, 7424-7429. doi:10.1021/es0708060

Thies, H., Tolotti, M., Nickus, U., Lami, A., Musazzi, S., Guilizzoni, P., Rose, N.L., Yang, H., 2012. Interactions of temperature and nutrient changes: effects on phytoplankton in the Piburger See (Tyrol, Austria). Freshwater Biology 57, 2057-2075. doi:10.1111/j.1365-2427.2011.02661.x

Thom, E.C., 1959. The discomfort index. Weatherwise 12, 57-61. doi:10.1080/00431672.1959.9926960

Thuiller, W., Albert, C., Araújo, M.B., Berry, P.M., Cabeza, M., Guisan, A., Hickler, T., Midgley, G.F., Paterson, J., Schurr, F.M., Sykes, M.T., Zimmermann, N.E., 2008. Predicting global change impacts on plant species distributions: Future challenges. Perspectives in Plant Ecology, Evolution and Systematics 9, 137-152. doi:10.1016/j.ppees.2007.09.004

Thuiller, W., Lavergne, S., Roquet, C., Boulangeat, I., Lafourcade, B., Araujo, M.B., 2011. Consequences of climate change on the tree of life in Europe. Nature 470, 531-534. doi:10.1038/ nature 09705

Tolotti, M., Thies, H., Nickus, U., Psenner, R., 2012. Temperature modulated effects of nutrients on phytoplankton changes in a mountain lake. Hydrobiologia 698, 61-75. doi:10.1007/s10750012-1146-5

Tomiczek, C., Cech, T.L., Fürst, A., Hoyer-Tomiczek, U., Krehan, H., Perny, B., Steyrer, G., 2011. Waldschutzsituation 2010 in Österreich. Forstschutz Aktuell 52, 3-9.

Tryjanowski, P., Rybacki, M., Sparks, T.H., 2003. Changes in the first spawning dates of common frogs and common toads in western Poland in 1978-2002. Annales Zoologici Fennici 40, 459-464.

Tuba, Z., 2011. Bryophyte physiological processes in a changing climate: an overview, in: Tuba, Z., Slack, N.G., Stark, L.R. (Eds.), Bryophyte Ecology and Climate Change. Cambridge University Press, Cambridge, pp. 13-34.

Tuba, Z., Slack, N.G., Stark, L.R. (Eds.), 2011. Bryophyte Ecology And Climate Change. Cambridge University Press, Cambridge, UK.

Uehlinger, U., 2000. Resistance and resilience of ecosystem metabolism in a flood-prone river system. Freshwater Biology 45, 319332. doi:10.1111/j.1365-2427.2000.00620.x

Uehlinger, U., Robinson, C.T., Hieber, M., Zah, R., 2011. The physico-chemical habitat template for periphyton in alpine glacial streams under a changing climate. Hydrobiologia 657, 107-121. doi:10.1007/s10750-009-9963-x

Usbeck, T., Wohlgemuth, T., Dobbertin, M., Pfister, C., Bürgi, A., Rebetez, M., 2010. Increasing storm damage to forests in Switzerland from 1858 to 2007. Agricultural and Forest Meteorology $150,47-55$.

Van der Putten, W.H., Macel, M., Visser, M.E., 2010. Predicting species distribution and abundance responses to climate change: why it is essential to include biotic interactions across trophic levels. Philosophical Transactions of the Royal Society B: Biological Sciences 365, 2025-2034. doi:10.1098/rstb.2010.0037

Van der Schrier, G., Briffa, K.R., Jones, P.D., Osborn, T.J., 2006. Summer moisture variability across Europe. Journal of Climate 19, 2818-2834. doi:http://dx.doi.org/10.1175/JCLI3734.1

Van Dijk, A.A., Huismans, H., 1982. The effect of temperature on the in vitro transcriptase reaction of bluetongue virus, epizootic haemorrhagic disease virus and African horsesickness virus. The Onderstepoort Journal of Veterinary Research 49, 227-232.

Vanderpoorten, A., Goffinet, B., 2009. Introduction to Bryophytes. Cambridge University Press, Cambridge.

Vittoz, P., Bodin, J., Ungricht, S., Burga, C.A., Walther, G.-R., 2008. One century of vegetation change on Isla Persa, a nunatak in the Bernina massif in the Swiss Alps. Journal of Vegetation Science 19, 671-680. doi:10.3170/2008-8-18434

Vittoz, P., Camenisch, M., Mayor, R., Miserere, L., Vust, M., Theurillat, J.-P., 2010. Subalpine-nival gradient of species richness for vascular plants, bryophytes and lichens in the Swiss Inner Alps. Botanica Helvetica 120, 139-149.

Vittoz, P., Cherix, D., Gonseth, Y., Lubini, V., Maggini, R., Zbinden, N., Zumbach, S., 2010. Klimawandel, in: Lachat, T., Pauli, D., Gonseth, Y., Gregor, K., Scheidegger, C., Vittoz, P., Walter, T. (Eds.), Wandel der Biodiversität in der Schweiz seit 1900 ist die Talsohle erreicht?, Zürich, Bristolstiftung. Haupt, Bern, Stuttgart, Wien, pp. 350-377.

Von Haaren, C., Saathoff, W., Bodenschatz, T., Lange, M., 2010. Der Einfluss veränderter Landnutzungen auf Klimawandel und Biodiversität, Naturschutz und Biologische Vielfalt. Bundesamt für Naturschatz. B.N, Landeswirtschaftsverlag.

Von Teuffel, K., Baumgarten, M., Hanewinkel, M., Konold, W., Sauter, U.H., Spiecker, H., Wilpert, K. von, 2005. Waldumbau: für eine zukunftsorientierte Waldwirtschaft. Springer.

Walentowski, H., Lotsch, H., Meier-Uhlherr, R., 2008. Moore und Klimawandel. Viele Moore sitzen bereits heute auf dem Trockenen - steigende Temperaturen sind ihr Hauptfeind. Wald-Wissen-Praxis. LWF-aktuell. Bayerische Landesanstalt für Wald und Forstwirtschaft, 15. Jahrgang 67, 44-48.

Walther, G.-R., Beißner, S., Burga, C.A., 2005. Trends in the upward shift of alpine plants. Journal of Vegetation Science 16, 541-548. doi:10.1111/j.1654-1103.2005.tb02394.x

Walther, G.-R., Roques, A., Hulme, P.E., Sykes, M.T., Pyšek, P., Kühn, I., Zobel, M., Bacher, S., Botta-Dukát, Z., Bugmann, H., Czúcz, B., Dauber, J., Hickler, T., Jarošík, V., Kenis, M., Klotz, S., Minchin, D., Moora, M., Nentwig, W., Ott, J., Panov, V.E., Reineking, B., Robinet, C., Semenchenko, V., Solarz, W., Thuiller, W., Vilà, M., Vohland, K., Settele, J., 2009. Alien species in a warmer world: risks and opportunities. Trends in Ecology \& Evolution 24, 686-693. doi:10.1016/j.tree.2009.06.008

Weckström, K., Huber, K., Salvenmoser, W., Schaidreiter, V., Psenner, R., Rieradevall, M., Schmidt R., Kurmayer, R., (in prep.). Decadal detection of biodiversity in alpine lakes in relation to climate change.

Wehrli, A., Brang, P., Maier, B., Duc, P., Binder, F., Lingua, E., Ziegner, K., Kleemayr, K., Dorren, L., 2007. Schutzwaldmanagement in den Alpen-eine Übersicht. Management of protection forests in the Alps-an overview. Schweizerische Zeitschrift fur Forstwesen $158,142-156$.

Weigand, S., Tischner, H., 2007. Auswirkungen und Strategien für Landwirtschaft und Umwelt - aus der Sicht des Pflanzenschutzes, in: Klimaänderung und Landwirtschaft - Bestandsaufnahme und 
Handlungsstrategien Ffür Bayern. Tagungsband, Schriftenreihe der Bayerischen Landesanstalt für Landwirtschaft. Presented at the 6. Kulturlandschaftstag, Bayerische Landesanstalt für Landwirtschaft (LfL), Freising-Weihenstephan, pp. 33-46.

Weilguni, V., 2009. Bemessungsniederschläge in Österreich, in: Blöschl, G. (Ed.), Hochwässer - Bemessung, Risikoanalyse und Vorhersage, Wiener Mitteilungen. Wasser, Abwasser, Gewässer. Inst. für Wasserbau und Ingenieurbiologie, TU Wien, Wien, pp. $71-84$.

Weinberger, K., 2009. Management von Wetterrisiken in Anbetracht des Klimawandels und der GAP-Reform. Online-Fachzeitschrift des Bundesministeriums für Land- und Forstwirtschaft, Umwelt und Wasserwirtschaft.

Weiss, P., Schieler, K., Schadauer, K., Radunsky, K., Englisch, M., 2000. Die Kohlenstoffbilanz des Österreichischen Waldes und Betrachtungen zum Kyoto-Protokol, Monographien. Umweltbundesamt, Wien.

Weissenbock, H., Kolodziejek, J., Url, A., Lussy, H., Rebel-Bauder, B., Nowotny, N., 2002. Emergence of Usutu virus, an African Mosquito-Borne Flavivirus of the Japanese Encephalitis Virus Group, Central Europe. Emerg Infect Dis 8, 652-656. doi:10.3201/eid0807.020094

Whitton, B.A., Neal, C., 2011. Organic phosphate in UK rivers and its relevance to algal and bryophyte surveys. Annales de Limnologie - International Journal of Limnology 47, 3-10. doi:10.1051/ limn/2010102

Wiens, J.A., Stralberg, D., Jongsomjit, D., Howell, C.A., Snyder, M.A., 2009. Niches, models, and climate change: assessing the assumptions and uncertainties. Proceedings of the National Academy of Sciences 106, 19729-19736.

Wiesner, C., Wolter, C., Rabitsch, W., Nehring, S., 2010. Gebietsfremde Fische in Deutschland und Österreich und mögliche Auswirkungen des Klimawandels: Ergebnisse aus dem F+E-Vorhaben FKZ 80682 330, BfN-Skripten. Bundesamt für Naturschutz, Bonn.

Winder, M., Schindler, D.E., 2004. Climate change uncouples trophic interactions in an aquatic ecosystem. Ecology 85, 21002106. doi:10.1890/04-0151

Winder, M., Sommer, U., 2012. Phytoplankton response to a changing climate. Hydrobiologia 698, 5-16. doi:10.1007/s10750-012$1149-2$

Winkler, H., Scheifinger, H., Pollheimer, J., 2004. Auswirkungen des globalen Klimawandels auf Brut- und Zugphänologie von Vögeln in Österreich. (Endbericht zu einem Expertengutachten für das Bundesministerium für Land- und Forstwirtschaft, Umwelt und Wasserwirtschaft). Wien.

Wipf, S., Stöckli, V., Herz, K., Rixen, C., 2012. The oldest monitoring site of the Alps revisited: accelerated increase in plant species richness on Piz Linard summit since 1835. Plant Ecology \& Diversity 6, 447-455. doi:10.1080/17550874.2013.764943

Wittmann, E.J., Baylis, M., 2000. Climate Change: Effects on Culicoides-Transmitted Viruses and Implications for the UK. The Veterinary Journal 160, 107-117. doi:http://dx.doi.org/10.1053/ tvjl.2000.0470

Woese, C.R., Kandler, O., Wheelis, M.L., 1990. Towards a natural system of organisms: proposal for the domains Archaea, Bacteria, and Eucarya. Proceedings of the National Academy of Sciences 87, 4576-4579. doi:10.1073/pnas.87.12.4576

Wohlfahrt, G., Mayr, S., 2012. Auswirkungen von Bodentrockenheit auf die Transpiration österreichischer Baumarten (Endbericht von StartClim2011.C in StartClim2011: Anpassung an den Klimawandel - Themenfeld Wald). Auftraggeber: BMLFUW, BMWF, ÖBF.

Wolfram, G., Mikschi, E., 2007. Rote Liste der Fische (Pisces) Österreichs, in: Zulka, K.P. (Ed.), Rote Listen Gefährdeter Tiere Österreichs: Kriechtiere, Lurche, Fische, Nachtfalter, Weichtiere, Grüne Reihe Des BMLFUW. Böhlau Verlag Wien, pp. 61-198.

Woods, A., Coates, K.A., Hamann, A., 2005. Is an Unprecedented Dothistroma Needle Blight Epidemic Related to Climate Change? BioScience 55, 761-769. doi:10.1641/00063568(2005)055[0761:IAUDNB]2.0.CO;2

Zarzer, K., 2004. Szenarien für die Grünlandwirtschaft und den Futterbau nach Trockenjahren, in: Toifl, C. (Ed.), Klimawandel: Auswirkungen auf Umwelt und Agrarproduktion. Presented at the ALVA Jahrestagung, Österr. Agentur für Gesundheit und Ernährungssicherheit, pp. 162-165.

Zechmeister, H.., Schmitzberger, I., Steurer, B., Peterseil, J., Wrbka, T., 2003. The influence of land-use practices and economics on plant species richness in meadows. Biological Conservation 114, 165-177. doi:10.1016/S0006-3207(03)00020-X

Zechmeister, H.G., Dirnböck, T., Hülber, K., Mirtl, M., 2007a. Assessing airborne pollution effects on bryophytes-lessons learned through long-term integrated monitoring in Austria. Environmental Pollution 147, 696-705. doi:http://dx.doi.org/10.1016/j. envpol.2006.09.008

Zechmeister, H.G., Moser, D., Milasowszky, N., 2007b. Spatial distribution patterns of Rhynchostegium megapolitanum at the landscape scale-an expanding species? Applied Vegetation Science 10, 111-120. doi:10.1111/j.1654-109X.2007.tb00509.x

Zechmeister, H.., Hagel, H., Gendo, A., Osvaldik, V., Schröck, C., Prinz, M., Köckinger, H., 2013. Rote Liste der Moose Niederösterreichs. Wissenschaftliche Mitteilungen aus dem Niederösterreichischen Landesmuseum. in Druck. 24, 7-26.

Zeisner, N., Hausdorf, H., 2006. Die Amerikanische Rebzikade (Scaphoideus titanus) in Österreich - Ergebnisse vom Monitoring 2005. Österreichische Pflanzenschutztage, 29.-30.11.2006, Schloss Seggau/Leibnitz. Leibnitz.

Zeisner, N., Hausdorf, H., 2010. Die Gefährdung des österreichischen Weinbaues durch die Amerikanische Rebzikade (Scaphoideus titanus).Österreichische Pflanzenschutztage, 1.-2.12.2010, Schloss Seggau/Leibnitz. Leibnitz.

Zierl, B., Bugmann, H., 2007. Sensitivity of carbon cycling in the European Alps to changes of climate and land cover. Climatic Change 85, 195-212. doi:10.1007/s10584-006-9201-8

Zimmermann, N.E., Jandl, R., Hanewinkel, M., Kunstler, G., Klling, C., Gasparini, P., Breznikar, A., S., E., Normand, S., Ulmer, U., Gschwandtner, T., Veit, H., Naumann, M., Falk, W., Mellert, K., Rizzo, M., Skudnik, M., Psomas, A., 2013. Potential Future Ranges of Tree Species in the Alps, in: Management Strategies to Adapt Alpine Space Forests to Climate Change Risks. InTech. 